\title{
THE TRANSNATIONAL MIGRATION STRATEGIES OF CHINESE AND INDIAN STUDENTS IN AUSTRALIA
}

\section{Ghim Thye Tan}

BA Hons. (Adelaide)

Discipline of Geography, Environment and Population Faculty of Humanities and Social Sciences The University of Adelaide

Submitted for the degree of Doctor of Philosophy

February 2012 


\section{Table of Contents}

TABLE OF CONTENTS ..................................................................................................ii

LIST OF TABLES .............................................................

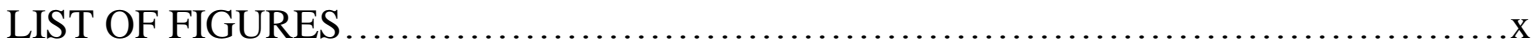

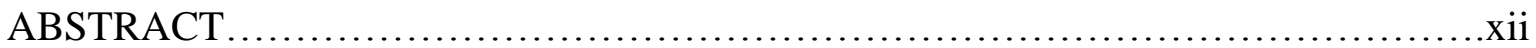

DECLARATION ............................................................

ACKNOWLEDGMENTS......................................................

ABBREVIATIONS AND ACRONYMS .......................................

CHAPTER 1: Introduction ....................................................................................................1

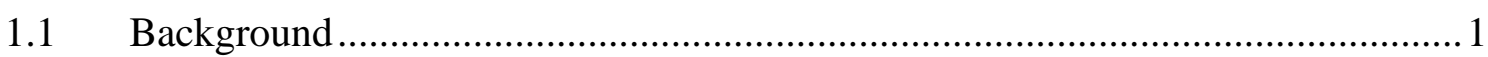

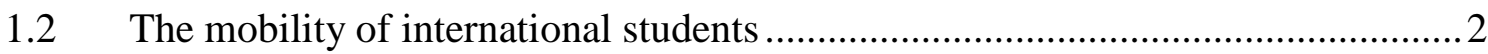

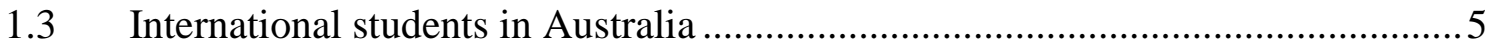

1.3.1 Growth of the international student market in Australia .................................6

1.4 International education as a precursor to permanent settlement................13

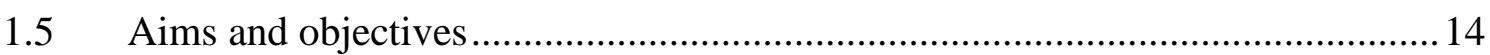

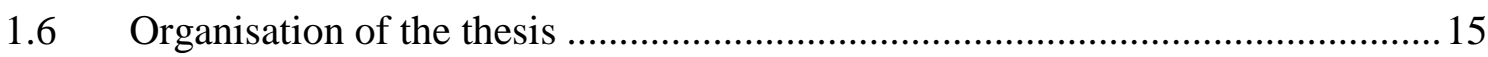

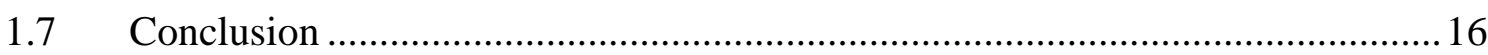

CHAPTER 2: Factors that Influence the Study Abroad decision of Chinese and

Indian Students in Australia ...................................................................................... 18

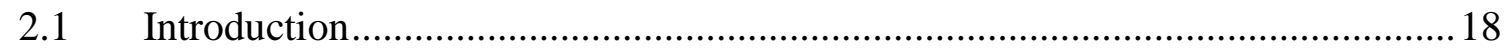

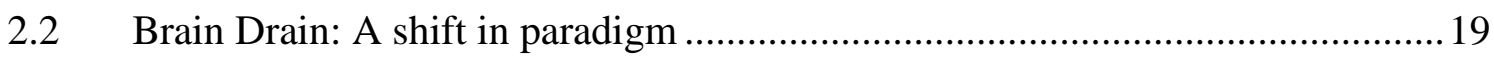

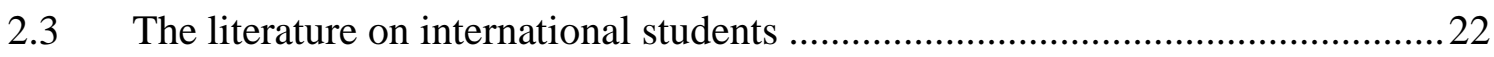

2.4 Push factors that motivate international students .............................................2 24

2.4.1 The outflow of international students from China ..........................................2. 26

2.4.1.1 Higher education in China....................................27

2.4.1.2 Other factors influencing the study abroad decision of Chinese

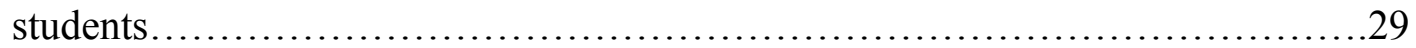

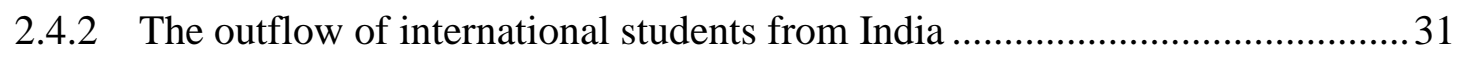

2.4.2.1 Higher education in India................................... 31

2.4.2.2 Other factors influencing the study abroad decision of Indian

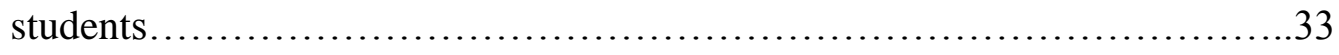


2.5 Pull factors that motivate Chinese and Indian students 35

2.5.1 English as the language medium in the host country 36

2.5.2 Cultural/geographical proximity and historical/economic ties between home and host countries 36

2.5.3 Knowledge and awareness of institution and host country..... 37

2.5.4 Networks of family or friends who live and have lived in the host country.... 38

2.5.5 Reputation and quality of education in the host country ................................. 38

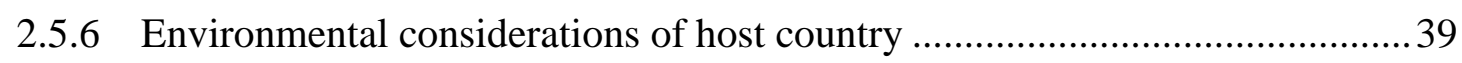

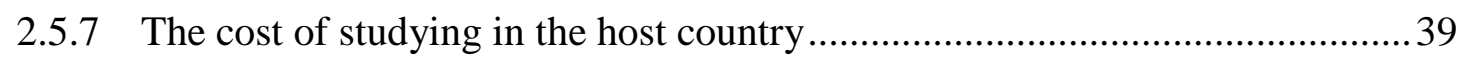

2.5.8 Host country policies related to student immigration .................................... 40

2.5.8.1 The importance of work rights during the course of study ............... 40

2.5.8.2 Ease of obtaining a student visa to enter a host country ................... 41

2.5.8.3 The opportunity for permanent settlement.................................... 43

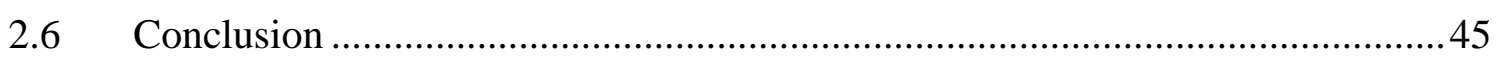

\section{CHAPTER 3: The Role of Government Policy on the Decision Making Process of}

Chinese and Indian Students ..................................................................................................................... 48

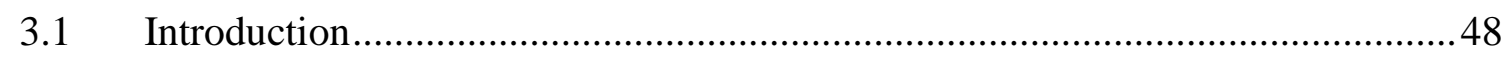

3.2 The retention of international students .......................................................... 49

3.3 International education policy in Australia........................................................ 51

3.4 Evolution of Australia's immigration policy on the permanent settlement of

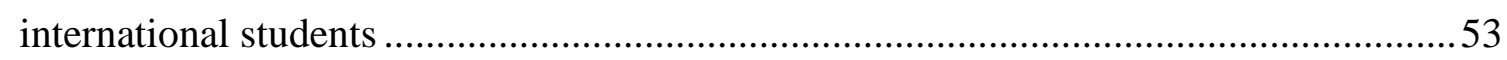

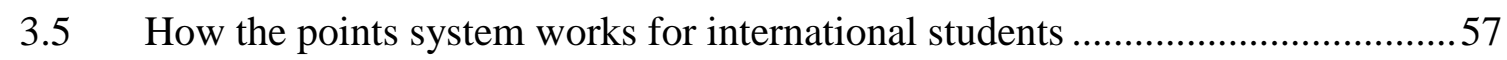

3.6 Examining the link between immigration policy and course selection of

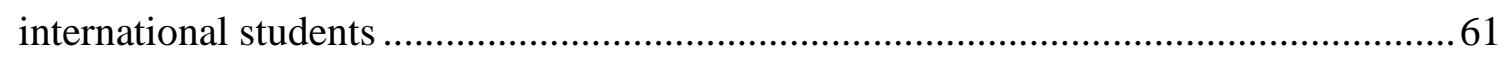

3.7 Examining the spatial aspect presented by regional universities........................65

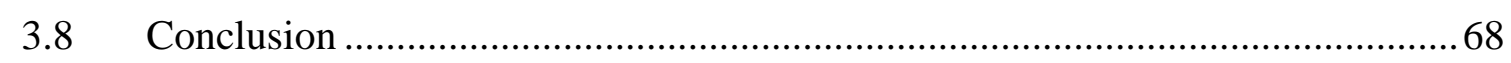

CHAPTER 4: International Students in the context of Migration Theory ..................69

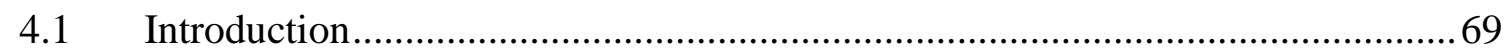

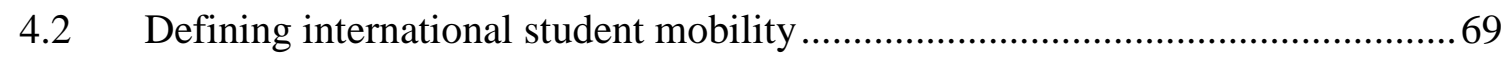

4.3 Migration theories and international student mobility ..................................... 72

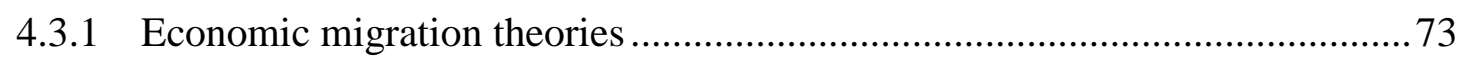




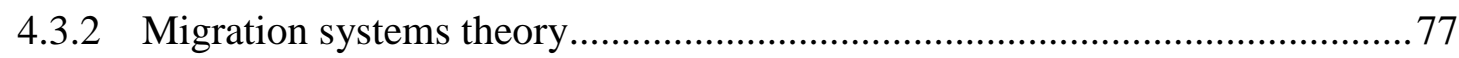

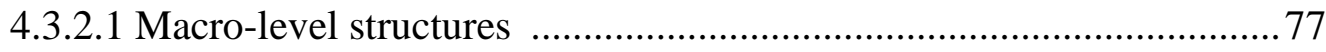

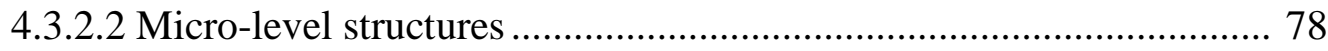

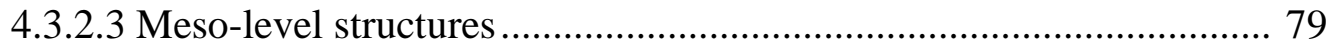

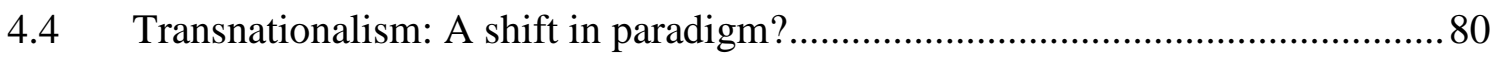

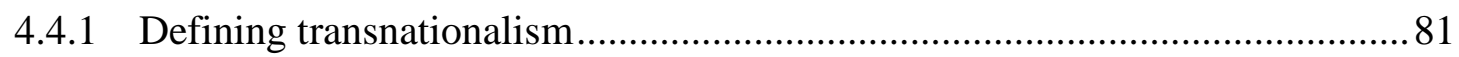

4.4.2 Space, place and international student transnationalism .............................. 83

4.4.3 Physical and social elements in transnational social space............................. 84

4.5 Transnational social spaces within networks in transnational migration strategies

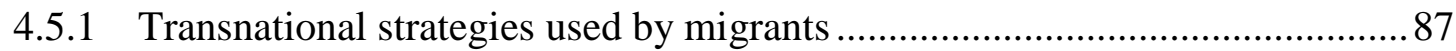

4.5.1.1 The configuration of places in transnational migration strategies ..... 88

4.5.1.2 Modelling the transnational migration strategies of international

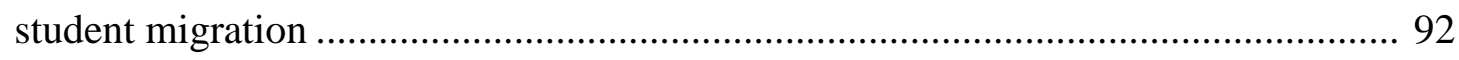

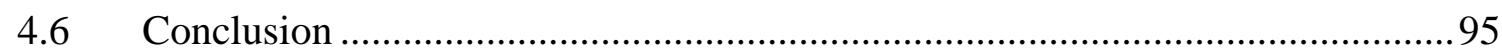

CHAPTER 5: Methodology and case study groups...........................................................97

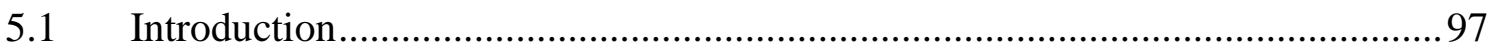

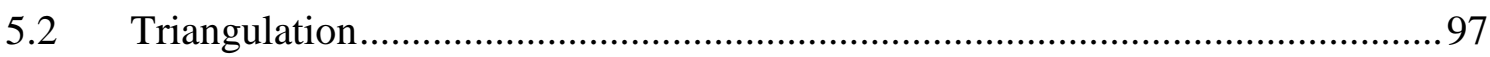

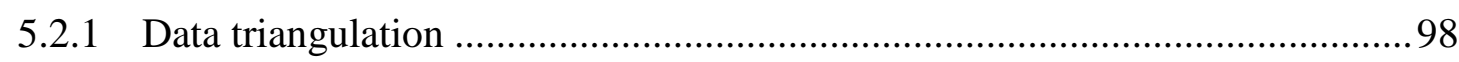

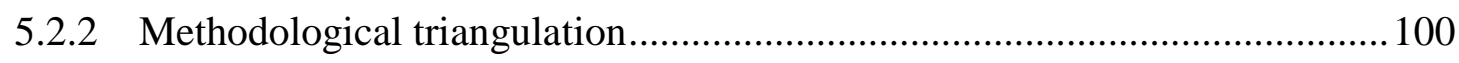

5.3 Survey of Chinese and Indian students questionnaire .................................... 101

5.3.1 Sampling strategy and online data collection ........................................... 103

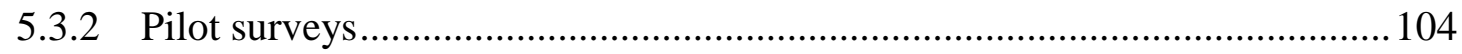

5.3.3 The survey distribution process and response rates .................................... 105

5.3.4 Potential limitations and biases with the online survey and the distribution. 106

$5.4 \quad$ In depth interviews with students and key informants .................................. 108

5.4.1 The recruiting and interviewing process................................................. 109

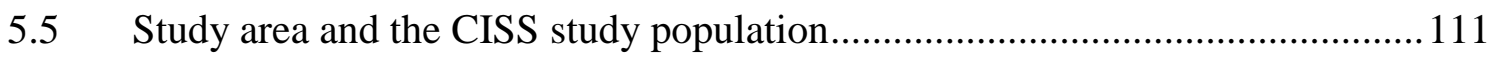

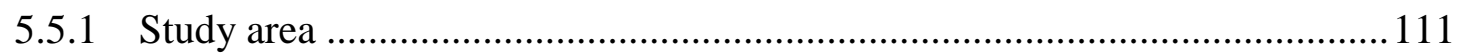

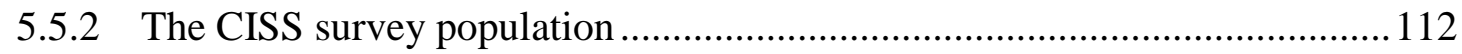

5.5.3 Demographic profile of CISS respondents ............................................... 113

5.6 Educational background of Chinese and Indian respondents .......................... 116

5.7 Financial discussion on Chinese and Indian respondents ............................... 121 
CHAPTER 6: The Decision Making Process of Chinese and Indian Students coming to Australia

6.1 Introduction 127

6.2 The decision to study overseas

6.3 The underlying factors in the decision making process ................................. 130

6.3.1 The consideration of alternative countries as study destinations...................130

6.3.2 The consideration of other Australian States as study destinations 132

6.4 Main factors that influenced the decision to study in Australia and in Adelaide .... 135

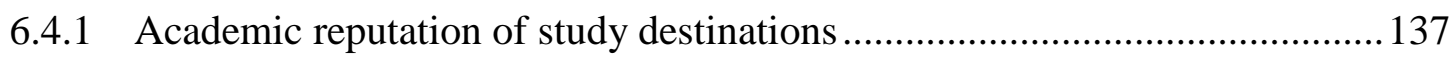

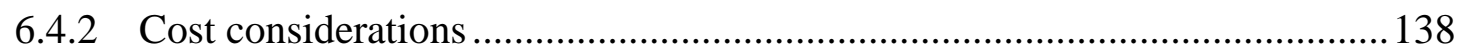

6.4.3 Social amenities, cultural and environmental considerations ....................... 139

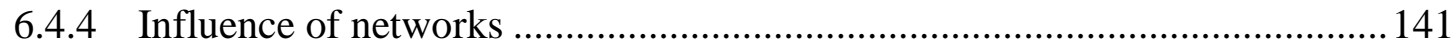

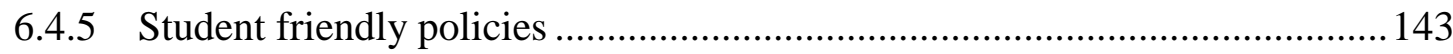

6.5 Additional factors which contributed to the decision to study in Australia and in

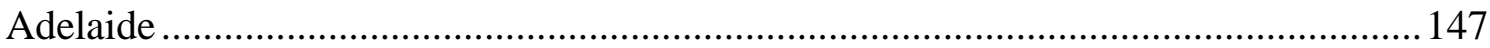

6.5.1 Main sources of information used by respondents .................................... 148

6.5.2 Social networks and its influence on respondents .................................... 150

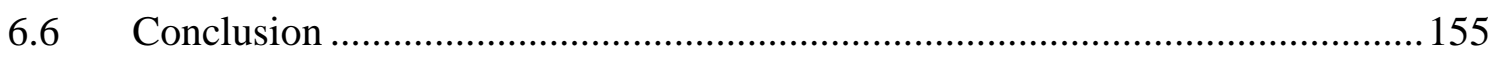

CHAPTER 7: Life after Graduation- Future Intentions of Chinese and Indian

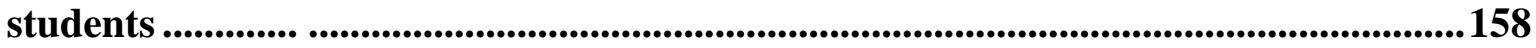

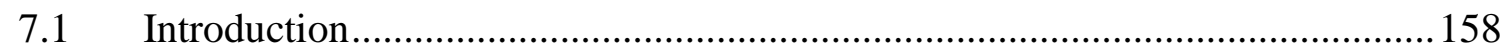

7.2 The permanent migration intentions of Chinese and Indian students................159

7.2.1 Intentions of Chinese and Indian students before coming to Australia ......... 159

7.2.2 Changing future intentions of Chinese and Indian students .........................163

7.3 PR intentions of Chinese and Indian students ................................................ 165

7.3.1 The intention to remain in Australia .......................................................... 168

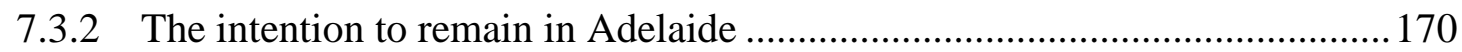

7.4 The onward migration of Chinese and Indian students ................................. 171

7.4.1 The intention to migrate to a third destination.......................................... 171

7.4.2 The intended future destinations of Chinese and Indian respondents ........... 174 
7.5 Main factors that influence the decision to migrate interstate and to a third

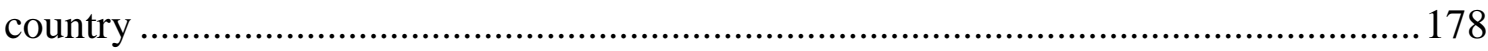

7.5.1 Professional, employment and economic based factors .............................. 180

7.5.2 Lifestyle and cultural considerations ......................................................... 181

7.5.3 A fascination with the West ..................................................................... 182

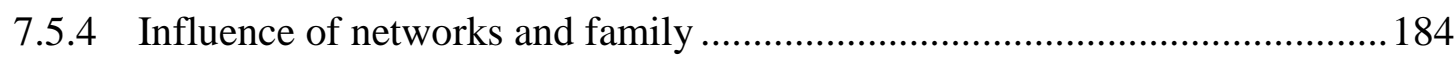

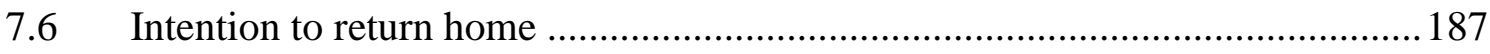

7.6.1 Professional, employment and economic factors in their home countries .... 189

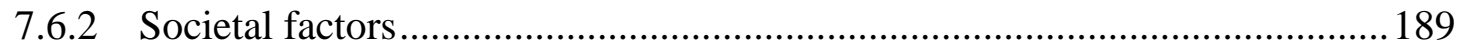

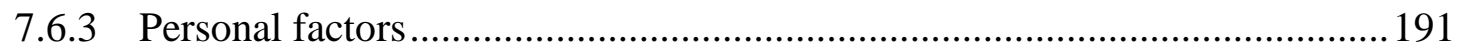

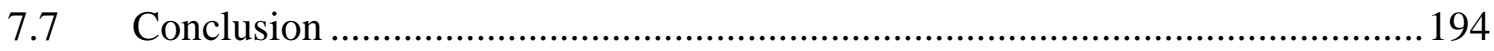

CHAPTER 8: Implications and Conclusion.....................................................................197

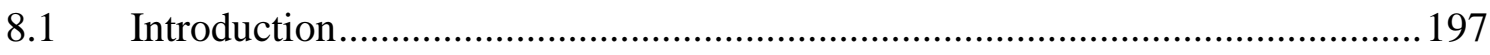

8.2 Summary and discussion of major findings ...................................................... 197

8.2.1 International student mobility in migration literature ................................. 197

8.2.2 Transnational migration strategies of Chinese and Indian students ..............200

8.2.3 Factors influencing the decision making process and mobility of Chinese and

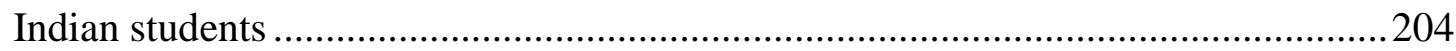

8.2.4 Theoretical and policy implications and recommendations for future research ..

8.2.4.1 Theoretical implications ........................................................... 208

8.2.4.2 Policy implications ................................................................... 211

8.2.4.3 Recommendations for future research ........................................ 217

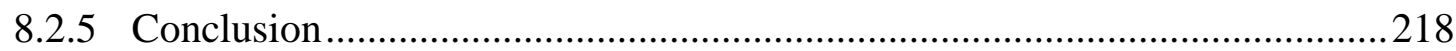

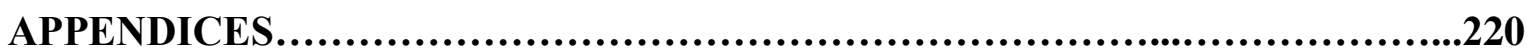

APPENDIX 1: Comparison of retention policies towards international students in

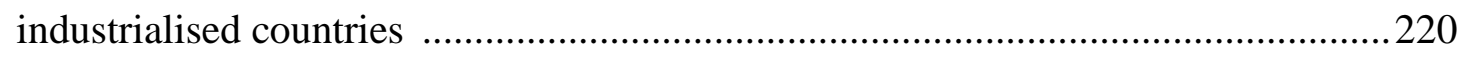

APPENDIX 2: Chronology of Australia's international educational policy shifting

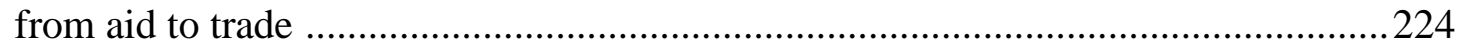

APPENDIX 3: Summary of points test application from July 2005 to September 2007

APPENDIX 4: Chinese and Indian student survey 231 
APPENDIX 5: Sample letter sent to senior University staff requesting for permission to survey students .254

APPENDIX 6: Sample email with participant information sheet sent to Chinese and Indian students 255

APPENDIX 7: Student feedback and the responses to feedback .257 APPENDIX 8: Second email with correct link to the CISS survey sent to students at the University of Adelaide 259

APPENDIX 9: Questions guides used in interviews ..... 260

APPENDIX 10: Sample email and information sheet sent to key informants 265

APPENDIX 11: Sample email sent to student interviewees for their participation in focus groups/interviews . 267

APPENDIX 12: Select information on interviewees; Chinese and Indian students; education agents; migration agents and university staff 268 


\section{List of Tables}

Table 1.1: Successful General Skilled Migration (GSM) visas granted to international

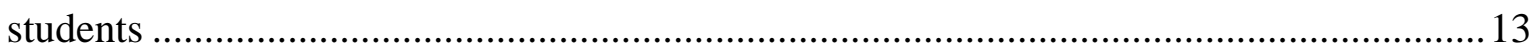

Table 2.1: Push Factors influencing international students ...............................................2 24

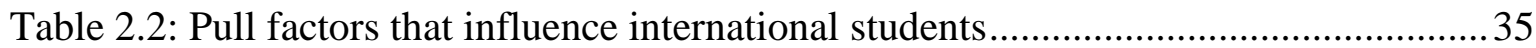

Table 3.1: Key milestones of the evolution of immigration policy for international students (1999-2007)

Table 3.2: Criteria for Skilled Graduate (Temporary) visa (subclass 485) 56

Table 3.3: International student applicants with $120+$ points who gained points on 'non work items' for the 880 subclass visa in 2004-05

Table 5.1: CISS surveys sent to Chinese and Indian students enrolled in the University of Adelaide and UniSA; and the response rate 113

Table 5.2: Average age of Chinese and Indians in the AEI and CISS data..... 115

Table 5.3: Distribution of international enrolments at postgraduate level in Australia in 2007

Table 5.4: Occupation of parents of Chinese and Indian CISS respondents

Table 5.5: Proportion of Chinese and Indian CISS respondents who worked for pay in the last year.

Table 6.1: Main reasons for decision not to study at an institution in their home country 128

Table 6.2: Proportion of respondents who seriously considered other study destinations 130

Table 6.3: The serious consideration of other Australian States as study destinations ..... 133

Table 6.4: States which were seriously considered by Chinese and Indian respondents .. 134

Table 6.5: Factors that discouraged respondents from other seriously considered study destinations 135

Table 6.6: Factors that influenced all respondents' decision to study in Australia 136

Table 6.7: Factors that influenced all respondents' decision to study in Adelaide 137

Table 6.8: The influence of MODL on course enrolment 146

Table 6.9: Respondents who have Family/Relatives and Friends with study experience in Australia and in Adelaide 152

Table 6.10: Respondents who have Family/Relatives and Friends who are Australian citizens or PRs 153

Table 6.11: The influence of Family/Relatives and Friends who are Australian citizens or PRs on PR intentions 154 
Table 7.1: Influence of attractive immigration policy on the original intentions of Chinese and Indian respondents

Table 7.2: Proportion of Chinese and Indian Respondents who changed their original intention

Table 7.3: Future intentions of respondents who have not changed their intentions 164

Table 7.4: Familiarity with PR requirements for respondents who intend to apply for PR or SIR visa. 166

Table 7.5: The intention to remain in Australia of respondents intending to apply for PR and SIR visa 168

Table 7.6: Factors that influenced Chinese and Indian respondents to remain in Australia 168

Table 7.7: Length of time Chinese and Indian respondents intend on remaining in Adelaide

Table 7.8: Intention to migrate interstate

Table 7.9: Intention to migrate to a $3^{\text {rd }}$ country 172

Table 7.10: Proportion of respondents who intend to migrate to the places which they seriously considered studying in 173

Table 7.11: The seriousness of interstate and $3^{\text {rd }}$ country migration 173

Table 7.12: Future interstate destinations of Chinese and Indian respondents 175

Table 7.13: Future $3^{\text {rd }}$ country destinations of Chinese and Indian respondents 175

Table 7.14: Proportion of respondents who intend to return home immediately after their studies 188

Table 7.15: The return home intentions of respondents who remained in Australia and/or in third country after their studies 192 


\section{List of Figures}

Figure 1.1: Distribution of international students in higher education around the world

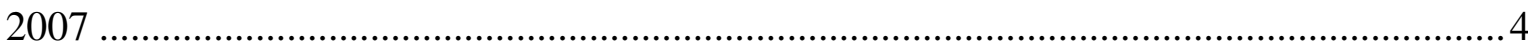

Figure 1.2: Time series of international student enrolment in Australia 1994-2008 _............7

Figure 1.3: International Education Export in Australia 1985-2008/09 ............................. 8

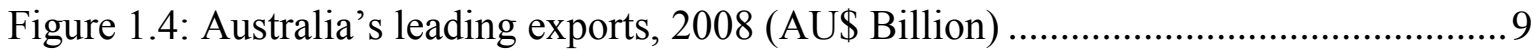

Figure 1.5: Export earnings of International Education to Australia 2008.......................... 10

Figure 1.6: Top 5 source countries for US in the higher education sector 2008 ................. 10

Figure 1.7: Top 5 source countries for UK in the higher education sector 2008................. 11

Figure 1.8: Time series of international students in the higher education sector by top 10

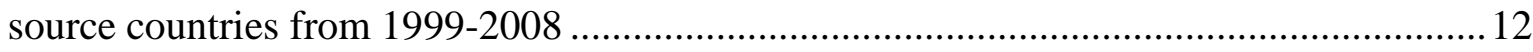

Figure 2.1: Timeline of Chinese students studying abroad from 1999-2008 .....................27

Figure 3.1: Australian Higher Education Funding Trends ...............................................52

Figure 3.2: The proportion of PR visas granted on shore to international students 2002-

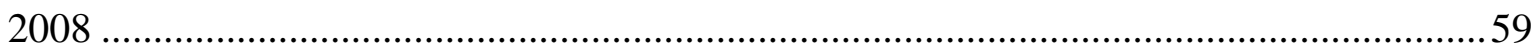

Figure 3.3: Top 5 fields of education for international students 2001-2007 _......................62

Figure 3.4: International enrolment in Masters by coursework in IT and Management \& Commerce 2001-2007. .64

Figure 4.1:Transnational migration strategy of Indian IT professionals 89

Figure 4.2: Conceptual model of the transnational migration strategies of Chinese and Indian students

Figure 5.1: Population distribution of capital cities in Australia 112

Figure 5.2: Breakdown of CISS respondents by nationality 114

Figure 5.3: AEI data on the age distribution of Chinese and Indian students in Australia 2008 114

Figure 5.4: Age distribution of Chinese and Indian CISS respondents 115

Figure 5.5: Marital status of Chinese and Indian CISS respondents 116

Figure 5.6: Highest qualification held by Chinese and Indian CISS respondents 117

Figure 5.7: Level of enrolment for Chinese and Indian CISS respondents 118

Figure 5.8: Postgraduate and undergraduate enrolment of Chinese and Indian students in Australia 2002-2008 118

Figure 5.9: The broad fields education and levels enrolled in by Chinese and Indian CISS respondents 
Figure 5.10: Source of tuition fee for Chinese and Indian CISS respondents 122

Figure 5.11: Source of living expenses for Chinese and Indian CISS respondents 122

Figure 5.12: Weeks worked/year for Chinese and Indian CISS respondents 125

Figure 5.13: Hours worked/week for Chinese and Indian CISS respondents 125

Figure 6.1: Countries seriously considered by Chinese respondents \% 131

Figure 6.2: Countries seriously considered by Indian respondents $\%$ 131

Figure 6.3: Distribution of international student enrolments in Australia by higher education/State 2002-2008 133

Figure 6.4: Main sources of information used by Chinese and Indian respondent 148

Figure 6.5: Top 10 countries with EATC qualified education agents. 150

Figure 7.1: Original intentions of Chinese and Indian students 159

Figure 7.2: Influence of tuition fee sources on the original intentions of Indian respondents

Figure 7.3: Visa categories that Chinese and Indian respondents intend to seek after their studies 165

Figure 7.4: Seriousness of respondents intending to remain in Australia 169

Figure 7.5: Factors influencing the decision to migrate interstate. 179

Figure 7.6: Factors influencing the decision to migrate to a $3^{\text {rd }}$ country 179

Figure 7.7: Intentions to bring family to Australia or to $3^{\text {rd }}$ country destination. 185

Figure 7.8: Factors influencing respondents who intend to return home immediately after their studies 188

Figure 7.9: Factors influencing respondents who, after some time abroad, intend to make an eventual permanent move back home 193 


\section{Abstract}

Migration is increasingly transient, particularly among the highly skilled. In addition, countries engaged in a race for highly skilled labour are prepared to modify immigration regulations to attract those migrants. Australian immigration policy reflects how Australia sees international students as highly skilled migrants. Despite abundant research regarding the mobility of the highly skilled, there is a relative lack of investigation into the mobility of international students and their subsequent migration patterns. This thesis explores the nexus between immigration policy and international education by investigating the determinants of the mobility of Chinese and Indian students in Australia. Chinese and Indian students enrolled in the University of Adelaide and the University of South Australia were surveyed and key informants were interviewed to uncover the underlying factors that motivated the students in going abroad to study and their future intentions when they graduate.

It was found that while decisions were based on myriad factors, Chinese and Indian students were motivated differently. Findings revealed Permanent Residency in Australia as a key objective for many; with Indian students more driven than their Chinese counterparts in seeking this outcome. Skilled migration programmes designed to encourage the permanent settlement of international students influenced the deliberate selection of Australia and Adelaide as study destinations; however, questions of permanency were raised as Chinese and Indian students, particularly the latter, exhibited post study migration intentions to either interstate and/or third country destinations.

The limited effectiveness of policy was highlighted as Australia's skilled migration programme was circumvented through the use of Australia and/or Adelaide as gateways to preferred destinations. In other words, as much as policy can influence the decision of students when deciding on study destinations, students also subvert policy by configuring particular study destinations as gateways en route to a preferred destination. The implications for policy and its role in shaping the migration strategies of the students are thus investigated. International student mobility is conceptualised in this thesis as linkages to permanent settlement and onward migration highlight the inadequate and limited scope of traditional forms of migration research in explaining student migration. 


\section{Declaration}

I, Ghim Tan certify that this work contains no material which has been accepted for the award of any other degree or diploma in any university or other tertiary institution and, to the best of my knowledge and belief, contains no material previously published or written by another person, except where due reference has been made in the text.

I give consent to this copy of my thesis, when deposited in the University Library, being available for loan and photocopying, subject to the provisions of the Copyright Act 1968.

I also give permission for the digital version of my thesis to be made available on the web, via the University's digital research repository, the Library catalogue and also through web search engines, unless permission has been granted by the University to restrict access for a period of time. 


\section{Acknowledgements}

First and foremost, I would like to thank Professor Graeme Hugo for giving me the opportunity to pursue this $\mathrm{PhD}$ by securing funding for my scholarship.

I would also like to thank the Chinese and Indian students who participated in this study. Their contribution has been essential to the completion of this research. Learning about their study experiences has been both eye opening and humbling.

My supervisors Professor Graeme Hugo and Dr Jennifer Bonham, are also acknowledged for their support and assistance. I am grateful to Professor Hugo for his guidance and invaluable advice throughout the course of this study. I particularly thank Dr Bonham for her encouragement and willingness to make time for the endless discussions we've had over the years. Dr Matthew Rofe is also acknowledged for his supervision in the formative years of this research. I would also like to thank Margaret Young, for her technical assistance in setting up the online survey, and Janet Wall and Dr Di Rudd for their help in many different areas.

Further, I need to mention the students and staff of Geography, Environment and Population; past and present. I am fortunate to have met and worked alongside many amazing and hardworking individuals, some of whom I have forged good friendships with. Thanks go out to KTG club for their academic and emotional support - it is very much treasured.

To Damien, Claire, Becky and Miriam, thank you for your constant love and support. It was what I held onto throughout this bumpy postgraduate journey. Lastly, I would like to thank my mother, for her love, patience, understanding and support throughout my candidature. To those mentioned and unmentioned on this page - thank you. 


\section{Abbreviations and Acronyms}
ABC
Australian Broadcasting Corporation
ABS
Australian Bureau of Statistics
$\mathrm{ACE}$
American Council on Education
ACT
Australian Capital Territory
AEI
Australian Education International
AIEF
Australian International Education Foundation
CABE Central Advisory Board of Education
CISS Chinese and Indian Student Survey
CSL Critical Skills List
DEST Department of Education, Science and Training
DFAT Department of Foreign Affairs and Trade
DIAC Department of Immigration and Citizenship
DIMA Department of Immigration and Multicultural Affairs
DIMIA Department of Immigration, Multicultural and Indigenous Affairs
EATC Education Agent Training Course
ELICOS English Language Intensive Course for Overseas Students
ENS Employer Nomination Scheme
ERASMUS European Action Scheme for the Mobility of University Students
EU European Union
GNP Gross National Product
GSM General Skilled Migration
ICT Information and Communications Technology
IIE Institute of International Education
IIT Indian Institute of Technology
IMM Indian Institute of Management
IOM International Organization for Migration
IT Information Technology
MARA Migration Agents Registration Authority
MODL Migrant Occupation in Demand List
MOE Ministry of Education (China)
MPI Migration Policy Institute
NAFSA National Association of Student Advisers 


\begin{tabular}{ll} 
NSW & New South Wales \\
NT & Northern Territory \\
OECD & Organisation for Economic Co-operation and Development \\
OSC & Overseas Student Charge \\
PIER & Professional International Education Resources \\
PR & Permanent Resident/Permanent Residence \\
PRC & People's Republic of China \\
QLD & Queensland \\
SA & South Australia \\
SARS & Severe Acute Respiratory Syndrome \\
SIR & Skilled Independent Regional (visa) \\
SOL & Skilled Occupation List \\
SPSS & Statistical Package for Social Sciences \\
TAS & Tasmania \\
UIS & UNESCO Institute of Statistics \\
UK & United Kingdom \\
UN & United Nations \\
UNESCO & United Nations Educational, Scientific and Cultural Organisation \\
UniSA & University of South Australia \\
US & United States \\
USIEF & United States-India Educational Foundation \\
VET & Vocational Education and Training \\
VIC & Victoria \\
WA & Western Australia \\
\hline
\end{tabular}




\section{CHAPTER 1: Introduction}

\subsection{Background}

International migration has changed significantly in the last decade. Such movement has increased in both scale and complexity as the option of migration becomes available to an increasing proportion of the global population (Hugo 1999, pg 1). The immigrant population of the world has increased at a pace which has surpassed global population growth while the potential for growth in international migration is nothing short of dramatic (Massey \& Taylor 2004 , pg 2). However, "the concepts of migration used as the basis for collecting statistics do not reflect many of the realities of today's movements" (Salt 2005, pg 7), largely due to the changing dynamics and new forms of migration. These emerging forms, according to Salt (2005, pg 7) are difficult to describe as they include non-permanent forms of migration and migrants who change their migratory status in their host countries.

Currently, international migration research in Australia, remains "anchored in a permanent settlement migration paradigm" (Hugo 2003). However, there has been a significant increase in temporary and circular migration between countries in the contemporary world which involves a larger cross-section of groups under a wider variety of forms (Hugo 2003). Although circular migration has been an important aspect of migration, the transformation of global international migration in the last decade saw a shift from migrants who had to live serially in one country or another, to maintaining two homes; largely due to technological advancements in transport and communication allowing them to sustain close links with their home countries (Castles \& Miller 2003, pg 29; Hugo 2003; Martin 2000, pg 41).

A significant group of these temporary migrants are students who move from one country to another for the purpose of education. Such movements as Jones (1986, pg 67) notes, are not new and have existed for generations as scholars have left their homes in the pursuit of added interest, quality and relevance in their learning. Students who cross national borders for education have accelerated from a global figure of approximately 250,000 in the 1960s to one million in the late 1980s (UNESCO statistical yearbook 1960; 1986 cited in Andressen 1991, pg 1) and over three million in 2007 (OECD 2009). Future projections of 
7.2 million by $2025^{1}$ (Bohm et al. 2002, pg ix) underline the growing significance of students in international migration.

While the advent in technology permits migrants to be more mobile and less likely to remain in their destination countries than in the past, there are still some lingering connections to their permanency. This link is currently a topic of debate with international students exemplifying a growing form of temporary migrants becoming permanent settlers in their host countries (Balaz \& Williams 2004, pg 441-443; Balaz et al. 2004; Castles \& Miller 1998, pg 157; Li et al. 1996; Nesdale et al. 1995; Skeldon 1997, pg 110). This trend is not new as it has been argued in the past that part of the overseas student's original strategy for migration was to increase the chances of obtaining permanent residency, in conjunction with some countries preferring international students graduating from their own institutions when selecting permanent residents (Burke 1989, pg 8; Hugo 2003). This raises the role of policy in the debate on the permanent migration intentions of international students.

This thesis will investigate the nexus between international education and immigration policy, with a specific focus on Chinese (People's Republic of China) and Indian students studying in Australia. This study primarily focuses on understanding the underlying factors that motivated the students to study abroad and their intentions after graduation. The implications for policy and its role in shaping the migration of students are examined. Through this analysis, the findings will add to the growing body of knowledge on international students and a deeper understanding of their contemporary migration patterns. Hence, it is important to firstly understand the nature of international student mobility.

\subsection{The mobility patterns of international students ${ }^{2}$}

The character of international migrants is diverse and so is the nature of their movements. It is estimated that approximately 214 million people around the world are living outside the country in which they were born (United Nations 2010). The post-Cold War era

\footnotetext{
${ }^{1}$ A subsequent study by (Banks et al. 2007) has however suggested a less optimistic projection of 3.72 million in 2025 and for the rate of growth to decelerate.

${ }^{2}$ With numerous terms such as 'foreign students' and 'overseas students' used to describe students studying abroad, this study will use the term 'international students' in order to be consistent. Additionally, any use of the term 'student' will be understood as a reference to international students.
} 
witnessed the increasing importance of international migration in all areas of the world with the last half of the twentieth century being an age of migration (Castles \& Miller 1993). International mobility is now considered to be a global phenomenon which has become an important issue to the international community as an increasing number of States act as origin, recipient or transit countries for a diverse range of migrants (IOM 2000, pg vii).

The highly skilled worker from Australia working in Singapore, the refugee from Afghanistan in Iran, the woman from Nigeria trafficked to Italy, and the agricultural worker from Mexico working illegally in the United States are all examples of international migrants.

(IOM 2000, pg vii)

Despite the relatively recent significance of students in the study of migration, commentators (de Ridder-Symoens 1992, pg 302-303) often trace its beginnings to the Middle Ages where figures such as Primas of Orleans "begged and lectured and vilified and versed from Beauvais to Amiens, from Amiens to Orleans, from Orleans to Paris" (Waddell cited in McSwiney 1995, pg 17). Foreign students often concentrated in the Universities of Bologna and Paris which were known as 'studia generalia', a place frequented by scholars. This 'studia generalia' led to suggestions that the expulsion of scholars from the University of Paris culminated into the beginnings of Oxford in the twelfth century (Waddell cited in McSwiney 1995, pg 17), further suggesting that students have always been a highly mobile sub-population. In the modern context, the 1960s saw governments and educational institutions, especially those in the northern hemisphere, favour an increase in international students and the export of educational services (Nesdale et al. 1995, pg 8). The recent growth of international students underlines the need for further research on the various aspects on this group of migrants.

Figure 1.1 shows that there were over three million students who were studying abroad in higher education institutions in 2007, with 83.5 percent of these international students located in OECD countries (Organisation for Economic Co-operation and Development). In addition, five out of ten students studying outside their home countries were geographically concentrated in five countries, namely, the United States (19.7\%), the United Kingdom (11.6\%), Germany (8.6\%), France (8.2\%) followed closely by Australia (7\%) (OECD 2009, pg 313). International students are concentrated in these five OECD 
destinations and these students come from a narrow range of origin countries. In 2007, Asian students formed the majority (48.2\%) of international students enrolled in OECD and partner countries (OECD 2009, pg 320), followed by Europeans (24.\%), EU (16.9\%), Africans (10.5\%), North Americans (3.8\%) and Latin Americans (5.4\%) (OECD 2009, pg $320)$.

Figure 1.1: Distribution of international students in higher education around the world $2007(n=3,021,106)$

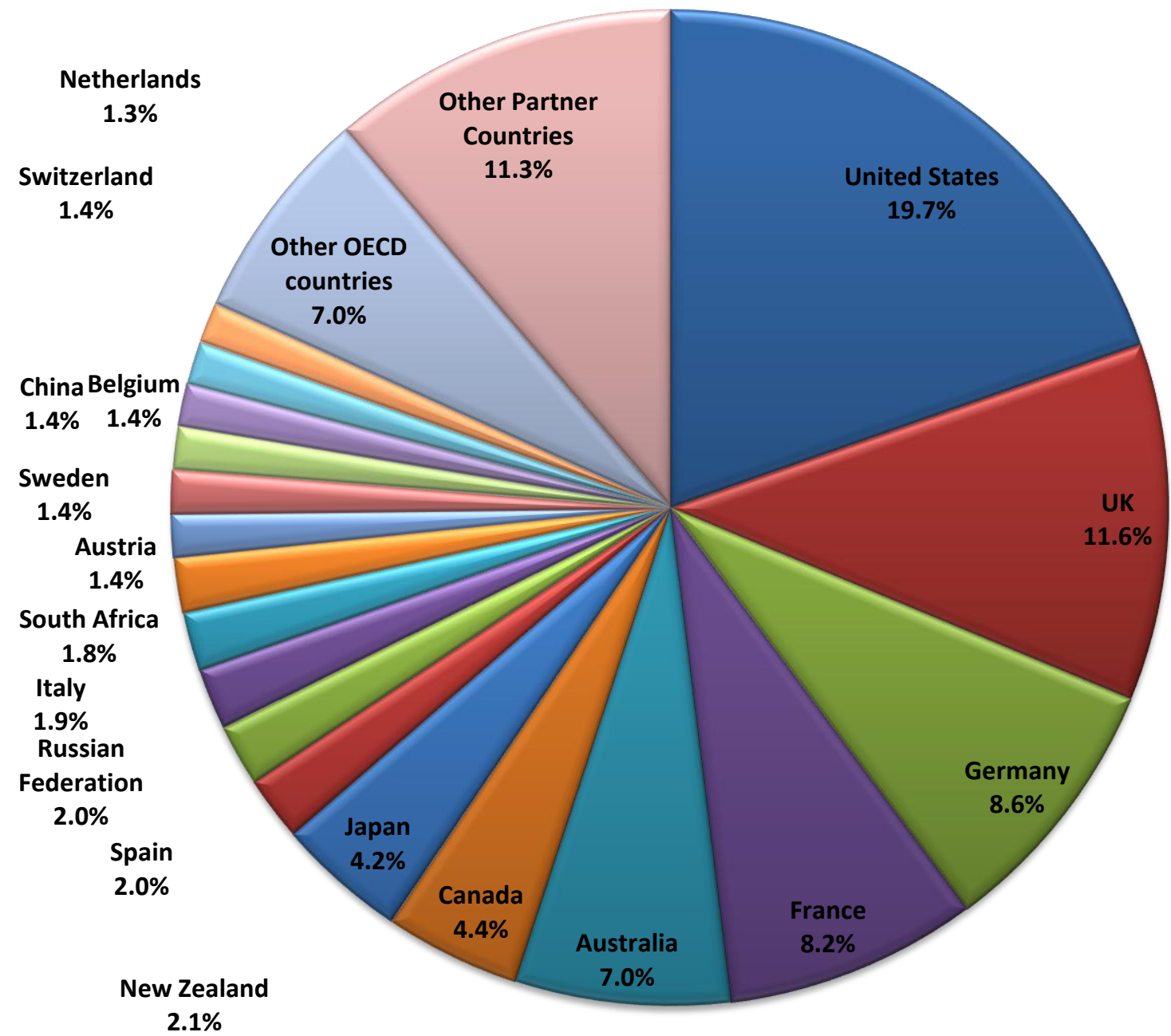

Source: OECD 2009, Chart C2.7

Closer analysis of the data revealed Chinese students as the largest group of international students with 16.3 percent (excluding another 1.4\% which is made up of students from Hong Kong). India was the second largest group as they contributed 6.2 percent of total foreign enrolments, followed by numerous Asian countries (OECD 2009, pg 320). Although Asia and Europe are the main sending regions of international students, China and India are clearly the main contributors. The global demand for international education 
is projected to grow with these two countries forecasted to be the key growth drivers generating half of the global demand in international higher education by 2025 (Bohm et al. 2002, pg 3). The composition of international students entering Australia also paints a similar picture. However, it is important to examine the history of international students studying in Australia in order to gain a comprehensive understanding of this phenomenon.

\subsection{International students in Australia}

Objectives, policies and procedures pertaining to international students in Australia have changed significantly over the past half century (Goldring 1984, pg 368). Beginning in the 1950s, the Colombo Plan was established to provide funds to encourage overseas students to study in Australia. This resulted in an increase in the number of international students from 1,000 to 5,000 between 1950-1965 (Williams 1989, pg 11). Numerous changes took place in 1973 which included the abolition of 'White Australia' policy as the Commonwealth Government assumed responsibility for higher education funding and abolished student fees while also implementing a limit of 10,000 foreign students (Cameron 2002, pg 19; Jones 1986, pg 71; Williams 1989, pg 11).

In the years prior to 1986, the bulk of overseas students in Australia were either sponsored or subsidised by international aid programmes which meant that costs of their education were not covered (Baker et al. 1996a, pg 1). The charging of fees began in 1979 when it was adjudged that part of the international students' agenda was to increase the likelihood of obtaining permanent residency (Burke 1989, pg 8). Although the charging of fees was required in order to ease the financial burden on the Australian Government, it was argued that it should not be at a level which deterred students from coming. Jones (1986, pg 101) argues the concept of using education as a commodity started in 1984 "in the context of attempts to achieve greater overseas access to Australian educational resources". The Federal Government began to adopt a more trade oriented approach due to the increasing recognition of the marketability of Australia's educational resources on an international scale and the promise of export revenue to reduce trade deficit figures (Beazley cited in Baker et al. 1996a, pg 1).

The Jackson and Goldring Committees were appointed in 1983 to review private overseas student policy and their reports varied as the former recommended that international students be charged the full cost of fees whilst the latter felt that the OSC (Overseas 
Student Charge) be set at 30-40 percent of costs as a full-cost recovery system would discourage and disadvantage poor students in particular (Williams 1989, pg 12). The eventual decisions by the Commonwealth supported the Jackson Committee with the establishment of full fee marketing of international education in 1985. However, institutions had to ensure this was not at the expense of depriving qualified Australian applicants or if there was capacity to increase international student enrolment (Williams 1989, pg 13).

In 1988, the Commonwealth announced that the subsidised scheme for private international students would be phased out and a fee based market would be the norm. Ceilings on the number of international students that educational institutions could admit were removed. Furthermore, fees were set at or above cost as the higher education system was encouraged to be more commercially oriented (Bayley et al. 2002, pg 45; Cameron 2002; Williams 1989, pg 13). The changes to the policies pertaining to international students has transformed and led to the creation of the international student market which today is an invaluable export industry. The growth of this market will be discussed in the next section.

\subsubsection{Growth of the international student market in Australia}

International students were not discouraged or deterred from coming to Australia to study despite the gradual shift to a fee based market. This is evident as statistics reveal the total number of international students entering Australia swelled from 7,500 in 1980 to 18,000 in 1988 to 543,898 in 2008, particularly those arriving for the purpose of higher education. In 1993, there were 83 percent full fee paying students compared to 6 percent in 1987 and only 1.6 percent in 2000 were AusAID ${ }^{3}$ students, reflecting the shift in the government's policy on international students (ABS 1995; AEI 2000; AEI 2008d).

A time series illustrating the number of international students arriving into Australia from 1994-2008 by sector is presented in Figure 1.2, further highlighting the considerable increase of international student enrolments. While increases in all education sectors can be described as steady, the growth in the higher education sector has been especially

\footnotetext{
3 AusAID is an Australian government initiative established to deliver aid to governments and people of developing countries. An aspect of AusAID include development awards (in the form of scholarships) which promote knowledge, education links and ties between Australia and the global community, and provide opportunities for study and professional development in Australia.
} 
strong. As Figure 1.2 illustrates, the higher education sector consistently has the most international enrolments. In 2005, it was reported that there was a total of 345, 975 international students enrolled in Australian institutions with nearly half, 47.3 percent or 163, 695 in higher education. Those enrolled in ELICOS (English Language Intensive Course for Overseas Students), vocational education, school education and others made up the remaining $52.7 \%$ (AEI 2008b).

\section{Figure 1.2: Time series of international student enrolment in Australia 1994-2008}

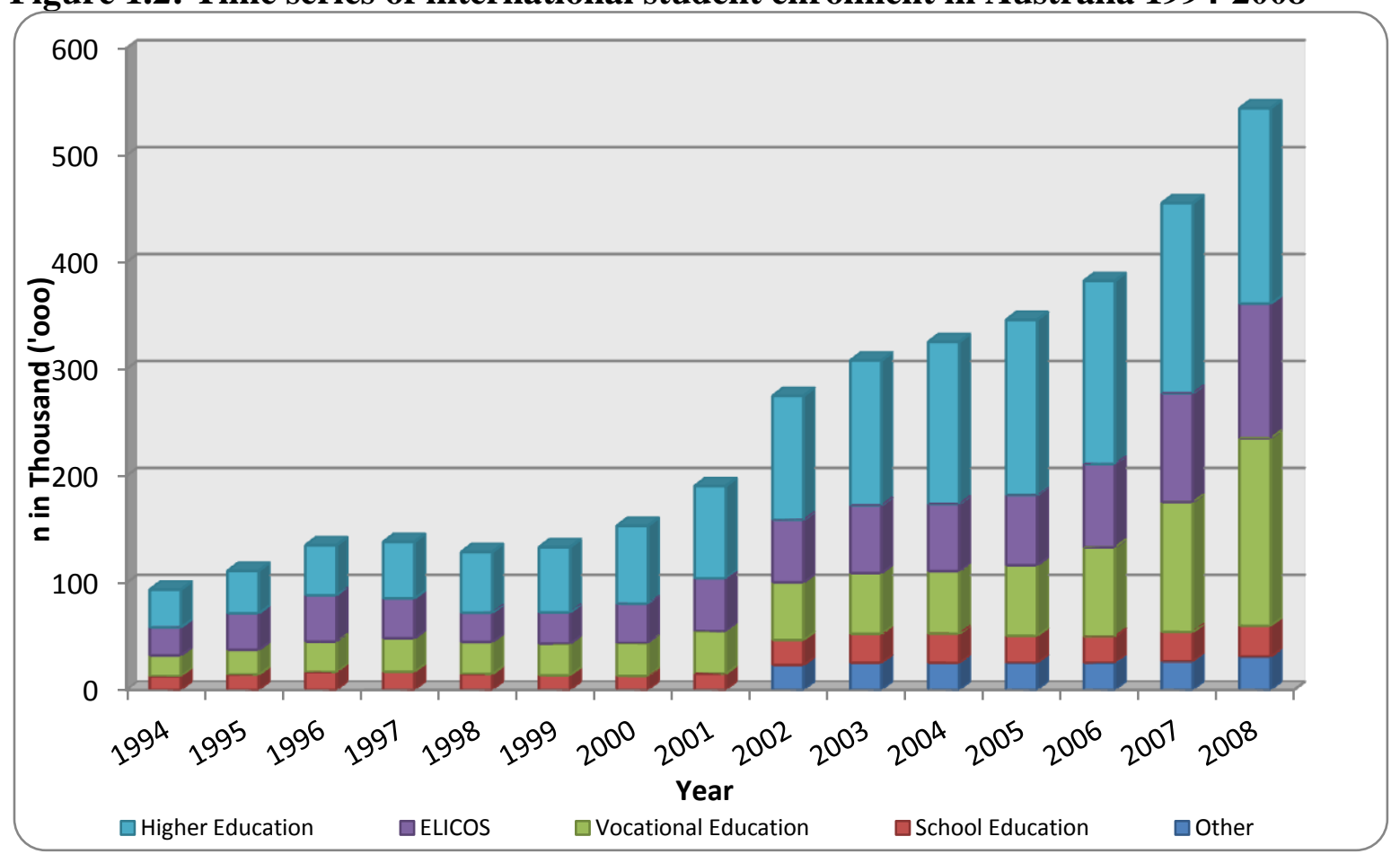

Source: AEI 2008b; AEI 2008d

While the higher education sector saw an increase in proportion from 1994-2008, it has decreased more recently due to the rapid rise of international enrolments in the vocational education sector. For example, in 2008, despite experiencing an increase in enrolments, the higher education sector constituted 33.6 percent of total international enrolments, a decrease of 13.9 percent from 2005. Conversely, the vocational education sector constituted 32.3 percent of total international enrolments, an increase from 19.1 percent in 2005 (AEI 2008d). ${ }^{4}$

\footnotetext{
${ }^{4}$ Although recent trends point towards the increasing popularity of international students studying in the vocational education sector, it must be noted that when commencing the current research project, the higher education sector in Australia was traditionally by far, the largest sector for international education. Hence, this study will solely focus on the higher education sector, although the recent surge by the vocational education sector warrants future research on international students studying in this sector.
} 
The need to focus on international students in the higher education sector is further emphasised by the fact that this sector not only leads by volume but also in terms of its contribution to the Australian economy. The last decade has witnessed a tremendous growth in international trade in education services, especially in the tertiary sector (Sauve 2002, pg 49) and the foremost impact of this would be a direct injection into the Australian economy. This is even more so as full fee paying students bring in foreign exchange, a double injection into the domestic economy due to the need for the payment of their fees as well as to cover their expenditure whilst living in Australia (Harris \& Jarrett 1990, pg 63).

On a global scale, estimates have placed international education to be worth anywhere between US\$100 billion up to US\$2.2 trillion dollars (CBIE n.d); evidently, this is an extremely profitable industry. As Figure 1.3 illustrates, the export income of the international education market in Australia has increased at a phenomenal rate from $\$ 50$ million in 1985 to $\$ 15.5$ billion in 2008 .

\section{Figure 1.3: International Education Export in Australia 1985-2008/09}

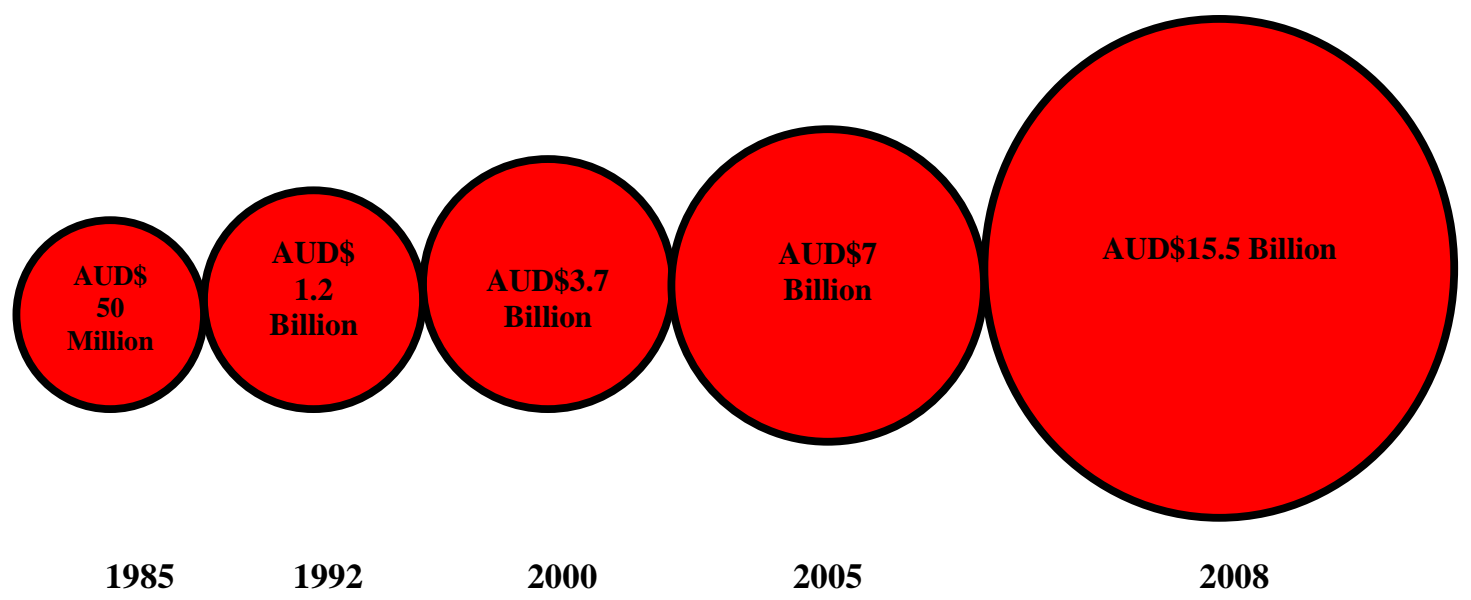

Source: Adapted from AEI 2009b; 2009c; Cameron 2002, pg 91; BIPR cited in Nesdale et al. 1995, pg 20

In addition it appears that the international education sector is fairly resilient. For example, although Australian exports decreased in 2002, which was partly attributed to the drought as well as the global economic slowdown, the education industry on the other hand continued to do well (IDP 2003). As IDP ${ }^{5}$ education's Chief Executive Anthony Pollock

\footnotetext{
${ }^{5}$ IDP played a major role in international education and development since the 1960s when development aid was the main driver behind international education. The mid 1980s saw a shift as they began recruiting
} 
states, analysis of the "performance of international education in Australia in the past three decades shows a steady growth line - it has survived global recessions, the Asian economic crisis, oil and currency shocks, major international security incidents such as 9/11, plus SARS, Avian Flu and other health scares" (IDP 2008). This resilience has seen international education become Australia's third largest exporter, behind coal and iron ore industries as depicted in Figure 1.4. Therefore, with such enormous economic benefits, international students are invaluable to Australia.

Figure 1.4: Australia's leading exports, 2008 (AU\$ Billion)

NOTE:

This figure is included on page 9 of the print copy of the thesis held in the University of Adelaide Library.

Source: DFAT 2009, pg 3

Additionally, as depicted in Figure 1.5, the higher education sector contributed $\$ 8.9$ billion dollars in 2008 more than double the amount of those in the ELICOS and Vocational Education sectors. It is evident that students in this sector are extremely important to the Australian economy as they contributed nearly 60 percent to the overall overseas student expenditure ( $\$ 8.9$ billion out of $\$ 15.5$ billion). Moreover, the majority of international

international students for Australian education institutions. They are currently the world's largest international student placement provider (IDP 2010). 
students originate from Asia with China and India, constituting 22.1 and 15.4 percent of the total export earnings (AEI 2009c).

Figure 1.5: Export earnings of International Education to Australia 2008

\section{NOTE:}

This figure is included on page 10 of the print copy of the thesis held in the University of Adelaide Library.

Source: AEI 2009 c

The significant contribution by Asian students to the Australian economy is not dissimilar with the global demand for international education, as pointed out earlier. Asian countries dominate the international education scene in the United States and United Kingdom, the top two destination countries for international students. As Figures 1.6 and 1.7 illustrate, China and India are particularly dominant in the higher education sector in these two countries.

Figure 1.6: Top 5 source countries for US in the higher education sector 2008

\section{NOTE:}

This figure is included on page 10 of the print copy of the thesis held in the University of Adelaide Library. 
Figure 1.7: Top 5 source countries for UK in the higher education sector 2008

\section{NOTE:}

This figure is included on page 11 of the print copy of the thesis held in the University of Adelaide Library.

Source: IIE $2008 b$

The trend of Asian students coming to Australia can be dated back to the seventies when international students were primarily from neighbouring countries such as Singapore and Indonesia (Rao 1979, pg 29). International student growth has generally been strong and recent times have also seen over 80 percent of students originating from Asia (Baker et al. 1996a, pg 27). Figure 1.8 shows the time series of the top ten source countries that have been contributing to the flow of international students to Australia. China emerged in 2002 as the leading source country for international students enrolled in higher education institutions with Singapore displaced as a top three source country. Chinese enrolments in this sector more than doubled from 6,353 in 2001 to 16,054 in 2002, and continued to rise in subsequent years to 51,500 in 2008 , a 221.4 percent increase.

This was similar with Indian students as figures also began to increase alongside Chinese enrolments. Figure 1.8 shows there were only 3,143 higher education students from India in 1999, making it fifth highest source country. The annual enrolment of Indian students continued to experience significant increases in subsequent years with 2003 seen as a watershed year with numbers swelling from 8,835 to 12,232 in 2003 . This saw India penetrate the top three source countries and become the third highest source country for Australia and the second highest from 2004. This trend continued as Chinese and Indian students were the largest source countries as they constituted 22.2 and 17.3 percent of enrolments respectively in 2008 (AEI 2009d). Hence, it is imperative to examine these two groups of international students as statistics presented in this section have shown that they are a vital source of international students. 
Figure 1.8: Time series of international students in the higher education sector by top 10 source countries from 1999-2008

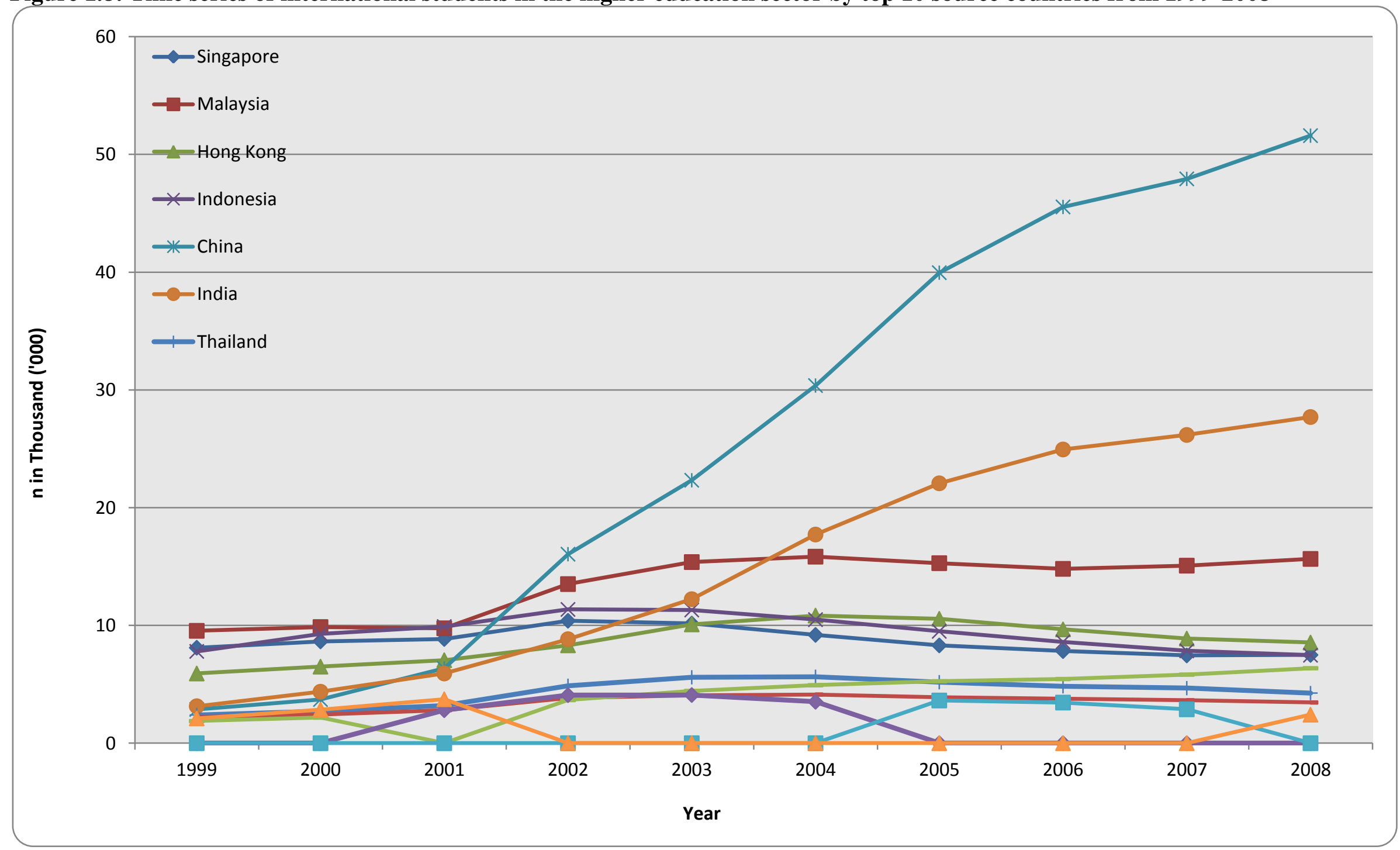

Source: Adapted from AEI 2000; AEI 2008a; 2008d 


\subsection{International education as a precursor to permanent settlement}

Birrell (2005) argues that the growth of international students in Australia was largely attributed to shifts in immigration policy which provided pathways to permanent residency. ${ }^{6}$ As Table 1.1 shows, there has been an increasing participation of international students in Australia's skilled migration programme.

Table 1.1: Successful General Skilled Migration (GSM) visas granted to international students

\begin{tabular}{|cccc|}
\hline & $2003 / 2004$ & $2004 / 2005$ & $2005 / 2006$ \\
\hline $\begin{array}{c}\text { GSM visa grants to } \\
\text { international students }\end{array}$ & 13,144 & 16,485 & 17,896 \\
\hline
\end{tabular}

Source: DIMIA 2005; 2006; DIMA 2007

Chinese and Indian students have a significant presence as they accounted for approximately 40 percent of all international students who obtained permanent residence in Australia (each comprising 20\%) (DIMIA 2005, pg 66). These students continued to lead this trend in 2004/2005 and 2005/2006 with contributions of 36 percent and 47 percent respectively (DIMA 2007, pg 69; DIMIA 2006, pg 67). These figures strengthen the link between international education and permanent settlement, thus substantiating commentators (Hugo 2003; Tremblay 2004) who have suggested this form of temporary migration as a precursor to permanent settlement. The aim of this thesis is to determine when the intention to permanently migrate was formed, and the extent of it as a primary objective in the migration strategies of Chinese and Indian students in Australia.

As this thesis is focused on establishing the link between temporary migration and permanent settlement via education, the motivation and future intentions of international students and the various factors which influence strategies used when going abroad to study will be closely examined. From a theoretical perspective, the approaches in migration studies represent a conundrum for researchers in student migration. Despite the abundance of migration theories, it must be noted that specific theories tend to be more applicable to specific forms of movement (Andressen 1991, pg 28). This study will therefore reveal the aspects of migration theory that have more relevance towards student

\footnotetext{
${ }^{6}$ See Chapters 3.3-3.6 for more detail on key changes in immigration policy.
} 
migration. In recent times, through globalisation, migration is increasingly viewed through a transnational lens (Glick Schiller et al. 1994; Levitt et al. 2003; Vertovec 1999). And while one can surmise that human migration is more ubiquitous than any other form of globalisation (Held et al. 1999, pg 283), Papastrergiadis (2000, pg 4) explains the importance of space when linking migration and globalisation:

The concept of space, which in the 1990s was given theoretical significance by British geographers like Doreen Massey, added a crucial dimension in the rethinking of the relationship between migration and globalization.

The migration of international students primarily involves movement between two separate spaces, namely, their home and host countries. Hence, examining the flows of Chinese and Indian students into Australia will clarify the role of transnational spaces when framing the transnational migration strategies of these students.

\subsection{Aim and objectives}

The overarching aim of the thesis is to explore the link between international education and permanent migration in Australia. The migration patterns of Chinese ${ }^{7}$ and Indian students will be investigated in order to elucidate on how international education enhances their mobility, thus contributing towards the existing literature on international student mobility. Hence, this thesis, through a transnational perspective, will examine the transnational spaces that feature in the migration strategies of Chinese and Indian students in Australia and by doing so determine how international education facilitates permanent settlement. The broad aim of the study will be met by the following objectives.

1) Examine international students in the context of migration theory.

2) Investigate the various migration strategies adopted by students including the transition to permanent settlement, the mechanisms behind the decision to remain in Australia after their studies and future strategies that may go beyond settling permanently in Australia.

\footnotetext{
${ }^{7}$ References to Chinese students in this study include those from PRC and exclude those from Taiwan and Hong Kong.
} 
3) Identify the determinants that feature in the decision making processes of Chinese and Indian students which have a bearing on their mobility.

4) To examine the implications of the findings from the study on policy and migration theory and by doing so, put forward recommendations for future research.

The first objective will conceptualise the mobility of international students and determine the theoretical implications arising from this growing phenomenon. The second objective ascertains the extent to which international education is a precursor to permanent settlement and explores the configuration of study destinations and subsequent post study destinations in the transnational migration strategies of Chinese and Indian students. The third objective provides insight into how different factors influence the motivations of the students before and after coming to Australia, their future intentions and permanent settlement in Australia. Exploring the role of these factors will assist in understanding how the transnational migration strategies of students are formed. The final objective will contribute towards understanding how international students fit into this contemporary form of migration by addressing and putting forth suggestions relating to the theoretical and policy implications that arise. In addition, recommendations for future research will be raised.

\subsection{Organisation of the thesis}

This thesis has been organised into eight chapters. Chapter 2 locates this research in migration literature with a review of the international student migration literature on a global and Australian scale. This chapter will discuss the history and trends of international student mobility with particular reference to Chinese and Indian students and explore the various factors that motivate them to study abroad.

Chapter 3 describes Australia's educational and immigration policies and outlines its evolution over the years. This will demonstrate the role of policy in the decision making process of Chinese and Indian students and further establish the link between international education and permanent migration. This will set the context when conceptualising the migration of these students in Chapter 4.

Chapter 4 thoroughly reviews the literature on migration theory, with the aim of 
conceptualising the migration patterns of these students and to address the gaps in migration theory. Following discussions in Chapters 2 and 3, the major factors driving the migration of Chinese and Indian students will be theorised. The mobility of these students will be applied to a conceptual model illustrating their transnational migration strategies in Australia.

Chapter 5 describes the methodology and the methods utilised in this study. The chapter justifies the use of mixed methods and explains the process of formulating and distributing the survey questionnaire; which was used for primary data collection. Details of the qualitative methods used are also addressed, by describing the interview technique, selection of interviewees and the interview process itself. In addition, a profile of the survey respondents is established so as to ascertain the quality of the sample.

Chapters 6 and 7 presents the empirical findings based on the qualitative and quantitative data obtained from the survey and interviews. Chapter 6 is concerned with the decision making process of Chinese and Indian students, mainly with regards to the factors that influence their decision to study abroad and the selection of their study destination. Chapter 7 explores the post study intentions of the students and the associated factors linked to their plans regarding permanent settlement in Australia, and future migrations to other destinations. Through these chapters, the notion of international education as a precursor to permanent settlement will be argued and main factors influencing the students' mobility will be discussed. These findings will be examined and juxtaposed with the literature and theoretical backdrop set up in earlier chapters. This approach will identify the factors driving the configuration of places and the transnational migration strategies of these students.

Chapter 8 is devoted to summarising the key findings in reference to the aim and objectives set out in section 1.5. The findings will assist in understanding the transnational migration strategies of the students and aid in discussions on the implications for theory, policy and future research.

\subsection{Conclusion}

This chapter has introduced the thesis and its focus on Chinese and Indian students studying in Australia. The rationale for selecting these students was based on their significance in international education worldwide and their considerable presence as 
international students and skilled migrants in Australia. The underlying theme of the thesis is to understand the transnational migration strategies of Chinese and Indian students, and how international education enhances their mobility. 


\section{CHAPTER 2: Factors that Influence the Study Abroad Decision of Chinese and Indian Students in Australia}

\subsection{Introduction}

There is an extensive body of research on international students travelling overseas to pursue their studies. However, there is little research into the reasons students go abroad or their future intentions upon graduation. There appears to be a neglect on student movement in mainstream migration literature and it is not uncommon for the literature to be marketoriented and focused on facts and figures (Andressen 1991, pg 4). Bochner and Wicks' (1972, pg 3) comment from the 1970s that "the principles underlying educational exchange have not gone unexamined, references and debate on this topic are widely scattered...hidden...buried in technical literature" still remains true today.

As Hugo (2006, pg 161) argues:

"One area of concern is the nexus between student migration and brain drain, since ncreasing numbers of the two percent of tertiary students studying outside their home country remain in developed destination countries upon completing their studies".

In order to gain a fuller understanding, this chapter will firstly review the shift in the brain drain paradigm to contemporary international student migration. The emerging link between student mobility and permanent settlement and its significance in the student's decision making process requires further investigation.

The decision making process of Chinese and Indian students will be explored against the backdrop of the higher education scenarios and the range of macro structures in their respective countries that formed a basic set of push factors behind the impetus to study abroad. Examining the considerations involved when deciding on a study destination will complete the myriad push and pull factors behind the decision making process of the students. The factors that influence student migrants will be later juxtaposed with migration theory in Chapter 4, assisting in the conceptualisation of the mobility of Chinese and Indian students studying in Australia and the development of a model to depict their migration. However, it is necessary to firstly examine the brain drain phenomenon and its subsequent shift to contemporary international student mobility. 
Chapter 2: Factors that influence the study abroad decision of Chinese and Indian students in Australia

\subsection{Brain Drain: A shift in paradigm}

Brain drain was first mentioned in the 1950s and 60s by the British Royal Society to depict the accelerated flow of scientists and technologists to the United States and Canada (Cervantes \& Guellec 2002). This subsequently shifted as the focus on the flows which characterised the movements of highly skilled migrants increasingly became a "contentious issue in the North-South debate" (Carrington \& Detragiache 1999). Research on brain drain was mostly concerned with how these flows would result in the detriment of a developing country's economic growth as it struggled to cope with its loss of highly skilled and educated people to developed countries. These migrants were often attracted by the promise of an improved life and work conditions which was to the advantage of more developed countries. Through this example, brain drain feeds into the idea of how poorer economies can provide an indirect subsidy by supplying and contributing highly skilled migrants to the economies of the host countries (Altbach 1991, pg 316; Ammassari \& Black 2001, pg 15; Kwok \& Leland cited in Lien \& Wang 2005; Portes cited in Miller \& Counihan 2005).

International students remaining in their host countries permanently after completing their studies were another aspect of the brain drain debate (Adams cited in Altbach 1991; Rao 1979, pg 18) as "residents of developing countries often see a western degree as a ticket to employment in the more industrialised countries" (Iredale 2001, pg 9). However, the literature focused on the implications for sending and receiving countries as investigation "largely neglected to explore the motivations of individuals" (Alberts \& Hazen 2005, pg 133). Furthermore, research also seemed to adopt a permanent settlement paradigm when examining these migratory flows (Gaillard \& Gaillard 1997; Johnson \& Regets 1998).

Altbach (1991, pg 316) suggests that the migration of highly educated personnel can be quite complicated as:

The issue of the brain drain deserves careful attention since the migration of well educated people has important economic as well as intellectual implications. Foreign students and scholars are among the most important of these migrants, but their sojourns are now in many cases, much more complex (Altbach 1991, pg 317).

The brain drain phenomenon should be re-evaluated in the context of students in international education and the degree of permanency in their migrations. Research on the 
Chapter 2: Factors that influence the study abroad decision of Chinese and Indian students in Australia

brain drain phenomena largely occurred in the 60s and 70s but the debate has been revived recently as the intensification of information and knowledge intensive industries and the adoption of open and aggressive institutional policies in attracting highly skilled migrants has accelerated the flow of skilled labour from less developed countries (Commander 2003, pg 1).

For example, the early stages of contemporary international student mobility in the $1950 \mathrm{~s}$ and 1960s were almost entirely characterised by students originating from low-income, Third World countries, facilitated by exchange and aid programmes such as the Colombo Plan and the Fulbright Programme established by the Australia and the United States respectively. The Fulbright Programme which was set up in 1946 had the official intention to "assist other countries to modernize" (Sidhu 2006, pg 6). Similarly, the Colombo Plan established in 1950, was devised to help countries in South and Southeast Asia by contributing with resources and the benefit of their skills and knowledge, so as to raise the living standards of those in the less developed nations (Bochner \& Wicks 1972, pg 10). Aggressive marketing and recruitment of these students was unheard of in those days as international education was "under the auspices of the 'foreign aid' programmes of advanced industrialised countries to train students from developing countries" (Chadee \& Naidoo 2009, pg 174). Hence, international students led the way in migration between less developed and developed countries with the consequences of their return often important for development and politics in their home countries (Skeldon 1997, pg 109-111). It is thus fair to state that proponents of these programmes would expect these students to return and subsequently contribute to the development of their home countries, as much as they have been argued to be instilled with political and ideological interests inspired by the Cold War (Sidhu 2006, pg 6-13).

However, since the mid 1970s, the reduction of financial support from the State has seen the marketisation and corporatisation of higher education institutions and the transformation of international education into an export commodity (Chadee \& Naidoo 2009; Kwiek 2001, pg 32-35). The global predicament of institutions having to increasingly fund themselves through alternative sources such as tuition fees and alumni donations was also linked with the perspective of higher education as a private good as opposed to being a public good due to its perceived benefits falling more on the individual rather than society (Altbach 1997, pg 17). Slaughter and Leslie (2001) have coined the 
Chapter 2: Factors that influence the study abroad decision of Chinese and Indian students in Australia

term 'academic capitalism' to describe the commodification of tertiary education. Internationalisation has contributed to education operating in fully capitalist markets with private revenue replacing public revenue. This is evidenced by universities in the UK and Australia who have positioned themselves "as sites for commercial investment in foreign study and global mobility" (Marginson 2004, pg 194).

These contemporary flows have led to the re-conceptualisation of brain drain which suggests a marked shift in the paradigm. Khadria (2001, pg 46) lists a wide range of alternatives such as brain exodus, brain bank, brain trust, brain exchange and brain circulation, while other alternatives include 'globalisation of human capital' (Andersson \& Konrad 2001; Khadria 1999) and 'competition for global talent' (Chanda 2005a; b). The underlying commonality of all these terms lies in the fact that they exist "as a result of attempts...to describe the phenomenon of skilled labour migration as close to reality as at a particular point in time" (Khadria 2001, pg 46). Contemporary research has also further contributed to the shift in paradigm with the 'seeming abandonment' of the traditional settler model as migrants are increasingly temporary in nature. This temporary migration is especially important for those with skills that are in demand, demonstrating a higher likelihood to re-migrate to another country (Smith 2002, pg 4). Following from this, it seems logical for researchers and commentators to call for the term brain drain to be replaced by brain circulation (Alberts \& Hazen 2005; Avveduto \& Brandi 2002; Cervantes \& Guellec 2002; Favell et al. 2005; Gaillard \& Gaillard 1997; Johnson \& Regets 1998; Meyer 2003; Zweig \& Chung 2005).

With the shift in the paradigm of the brain drain phenomena and the increasing temporality of highly skilled migratory flows in today's migration climate, it is apt to acknowledge that international students are a significant component of highly skilled migrations. As put forth by some commentators (Li et al. 1996; Tremblay 2005), international students today are essentially "the skilled immigrants of tomorrow" (Migration Policy Institute 2005). Not all international students will become academics or intellectual professionals and some might not even finish their courses (Avveduto \& Brandi 2002, pg 3), however, it is their potential which enhances their mobility. Therefore, in order to be able to conceptualise the flow of international students it is necessary to review the literature and examine the underlying factors that are central in contributing to their decision to study abroad. 
Chapter 2: Factors that influence the study abroad decision of Chinese and Indian students in Australia

\subsection{The literature on international students}

The literature on international students has been largely limited to a few areas such as, the psychological and sociological aspects of studying in a culturally different environment or issues in learning and teaching. The costs and benefits of international students (Ma \& Abbott 2006) have been subject to much discussion (Harris \& Jarrett 1990), particularly the economic benefits which have been of great interest after students were charged full fees (Jolley 1997; Marginson 1997). Other research objectives also looked at helping international students adapt and do well in a foreign environment (Ballard \& Clancy 1984; 1988; 1997; Bochner \& Wicks 1972; Browne \& Dale 1989; Bystydzienski \& Resnik 1994; Ghosh \& Wang 2003; Humfrey 1999; Kinnell 1990; McNamara \& Harris 1997; O' Neill \& Cullingford 2005; Radford et al. 1984) as opposed to investigating and identifying their migratory trends and flows.

There is scant reference to students as migrants or highly skilled migrants, and as King and Ruiz-Gelices (2003, pg 230) noted, recent key literature on the history and theory of migration offered little or insufficient insight into student mobility. The dearth of literature is being addressed with a growing number of studies investigating the factors influencing and motivating the decision making process of international students studying abroad (Alberts \& Hazen 2005; 2006; ACE 2006; ABC 2005; AEI 2000; Baas 2006; 2007a; Bhandari 2006; Finn 2003; Gao \& Liu 1998; Garnaur 2006; Khoo \& Voigt-Graf 2004; Koser \& Salt 1997; Kuptsch 2003; Macnamara 2006; Nesdale et al. 1995; Tan 2003).

The literature appears to take on two different perspectives, namely an aggregate and disaggregate approach. Studies with an aggregate approach homogenise the motivations of students across different student groups (AEI 2005b; AIEF 1997; Rao 1976; 1979; Rao 1995). This can be disadvantageous as an amalgamated approach cannot elucidate what motivates a student to go overseas as it overlooks nuances and variations among specific groups. On the other hand, studies with a disaggregate approach can be limited in their applicability. For example, studies focused on international students situated within the EU (European Union) region (Anonymus 2004; Balaz \& Williams 2004; King \& Ruiz-Gelices 2003) usually includes those participating in the ERASMUS (European Action Scheme for the Mobility of University Students) student exchange, a programme which facilitates the students to study for six months to a year in another European country (Teichler 2004). By contrast, Australia's international students are mainly full fee paying students enrolled in 
Chapter 2: Factors that influence the study abroad decision of Chinese and Indian students in Australia

full degrees (IDP 2005). Other studies also tended to focus on particular kinds of students, such as economics students or those with doctorate degrees (Baker \& Finn 2003), while others revolved around a single nationality, with a wide range of students already surveyed from China (Pang \& Appleton 2004), India (Baas 2006; Khoo \& Voigt-Graf 2004), Singapore (Lewis 1992a; b; Tan 2003), Malaysia (Andressen 1990; 1991; 1993; Sin 2006), Korea (Andressen 2001) and South Africa (Crush et al. 2005; Mattes \& Mniki 2005; Tevera 2005) amongst other countries.

There are international students of differing types, backgrounds and nationalities which makes it difficult to form set motivations and future intentions that factor in their decision making process. To avoid superficiality, it is logical to delimit this study and focus specifically on Chinese and Indian students in order to accurately conceptualise their mobility. Nevertheless, some studies (Mazzarol \& Soutar 2002; Vincent-Lancrin 2004) have attempted to establish a basic set of drivers that influence international students in their decision to study abroad. The following sections will review these generic drivers in comparison with the motivations and future intentions of Chinese and Indian students.

There is also limited research investigating how international education can be a precursor to permanent migration. This link is strengthened by the fact that people with tertiary qualifications display a higher tendency to migrate (Findlay 2001, pg 2) and as Chalamwong notes (2004, pg 24):

Skill mobility stimulates individuals in their home country to pursue higher education. People in the source countries try to study further because they believe that it will give them a better opportunity to emigrate from their poor country to a rich country.

The view that international education is an "investment towards future emigration" (Vincent-Lancrin 2008, pg 105) really strengthens the notion of education as an instrument to enhance one's mobility. While some studies have ascertained that permanent stay is a probable outcome of international education (King \& Ruiz-Gelices 2003; Tan 2003; Tremblay 2002), only a few (Baas 2006; 2007a) have sought to specifically examine permanent settlement as a specific objective of international education. As Mahroum (2000, pg 28) states: 
Chapter 2: Factors that influence the study abroad decision of Chinese and Indian students in Australia

Students are perceived here as passengers who are heading abroad to certain destinations, but it is unknown to most of us the motives or the ultimate destiny of the various passengers at their destinations.

Despite the fact that there are many other factors that influence the study abroad decision, it appears that permanent settlement is a major motivation in this educational process. Hence, the following sections will examine the motivations of international students in the context of Chinese and Indian students and the significance of permanent settlement as a future intention and establish its propensity as an objective in their transnational migration strategies.

\subsection{Push factors that motivate Chinese and Indian students}

Studies of international students conducted in destination countries often include a diversity of nationalities and student types. Following from this, the literature reveals economic, social and political push factors motivating students to study abroad (Agarwal \& Winkler 1985; Altbach 1998; Mazzarol \& Soutar 2002; McMahon 1992; Varghese 2008; Vincent-Lancrin 2004)

Table 2.1: Push Factors influencing international students ${ }^{8}$

\begin{tabular}{|c|}
\hline Inadequate supply of higher education places \\
\hline Poor quality of educational facilities \\
\hline Lack of research facilities \\
\hline Lack of specific course or quotas on specific courses \\
\hline Failure to gain admission to local institutions \\
\hline Discrimination admission policies \\
\hline Politically uncongenial situations \\
\hline Level of economic wealth in home country \\
\hline Intention to migrate \\
\hline
\end{tabular}

Source: Adapted from Mazzarol \& Soutar 2002; Vincent-Lancrin 2004; Varghese 2008

The push factors listed in Table 2.1 above relate to poor access to good quality education. This finding points towards the hypothesis that the "net benefit of studying overseas is

\footnotetext{
${ }^{8}$ The push factors listed in Table 2.1 are not placed in any particular order.
} 
Chapter 2: Factors that influence the study abroad decision of Chinese and Indian students in Australia

expected to be much higher than the net benefit of studying in the home country" (Rao 1979, pg 44). This hypothesis can be explained by neoclassical economic theory which essentially lies in the expectation that any move is based on employment and economic opportunities and that the move will result in financially positive outcomes (Castles \& Miller 2003, pg 22-24; Massey et al. 1998, pg 17-21), a reasoning similarly expressed in more recent studies (Alberts \& Hazen 2006; Altbach 2004; Mazzarol \& Soutar 2002; Rao 1995; Varghese 2008, pg 22-28; Vincent-Lancrin 2004, pg 30-31). As Balaz and Williams (2004, pg 217) state, student migration is the "only form of skilled labour migration where the principal manifest function is human capital acquisition" and individuals regard it "as a further boost to their career both in their home country and on the international job market" (Vincent-Lancrin 2008, pg 105).

The motivation of working and forging a career in their home and host countries along with higher salaries (Alberts \& Hazen 2006, pg 206; Altbach 2004, pg 3-4; Rao 1995, pg 274; Varghese 2008, pg 24-25; Vincent-Lancrin 2004, pg 30) further substantiate how "education and training are the main tools for skill and employment mobility both within regions and between countries" (Bardak 2005, pg 4). Balaz and Williams' (2004) study of Slovakian students in the UK revealed an overwhelming "belief that their experiences of studying in the UK would eventually be economically beneficial" (Balaz \& Williams 2004, pg 233). The study reflected an emphasis placed on enhanced English skills and selfconfidence from their study experience which to an extent dwarfed the values of formal qualifications (Balaz \& Williams 2004, pg 234). This finding suggests these intangible benefits, outcomes of their educational sojourn abroad, can enhance their employment positions and result in significant returns for students who enter the labour market (Salt 2005, pg 31), underlining how international students are not necessarily focused on obtaining specific skill sets or degrees.

There is also some interplay between push factors and government policy. For example, inadequate supply of higher education places are at times linked to poor government policies, as exemplified by the discriminatory admission regulations implemented both in China (Yang 2003, pg 13) and India (Agarwal 2006, pg 95-97). These policies are essentially considered as macro-level structures (Salaff \& Greve 2003) which will be discussed in detail in later sections. In the long run, the factors discussed above would benefit international students as their educational investment would contribute towards 
Chapter 2: Factors that influence the study abroad decision of Chinese and Indian students in Australia

their human capital. Nevertheless, it is in conjunction with macro structures such as the failure of government to provide enough educational places and unpleasant political situations as listed in Table 2.1. The significant macro structures that exist in China and India need to be examined in order to establish their significance in the decision making processes of these students. The following sections will look at the background of Chinese and Indian students firstly by examining the rising trend of international education and secondly, uncovering the determinants that exist in their home countries which encouraged them to choose an overseas education over a local one. This will help shed light on the various push factors (usually at the macro-level) established within the confines of their respective countries that contributed to the outflow of Chinese and Indians studying abroad.

\subsubsection{The outflow of international students from China}

Macro structures in the form of government policy have always had a key role in promoting international education for Chinese students. Study abroad was first noted when approximately a thousand students did so from 1927 to 1937, however, it wasn't until 1943 when China began to expand its number of students going overseas, primarily for the purpose of constructing the country (Yao 2004, pg 4). The year 1978 is often regarded as the turning point (Yang 2004, pg 330, 334; Yao 2004, pg 7) when strong economic growth and the positive stance adopted by the Chinese government opened doors to overseas study and became the main push factor that contributed to the outflow of Chinese students.

Deng Xiaoping recognised that China's development and future was dependent on improving national science and technology, and overseas education was an avenue to which this could be achieved. Higher education was recognised as the key in China's strategy in achieving international competitive standards in economic and social terms by the 21st century (Zhao \& Guo 2002, pg 219). Sending students overseas was part of this strategy with the aim of strengthening China upon their return, armed with the skills and knowledge they have obtained (MOE 2004; Poston Jr \& Luo 2007, pg 325). China's increasing demand for higher education is essentially a function of the shift to a market economy and the need to supply new skills, hence, China's development hinged on the expansion of higher education (DFAT 2005, pg 27). 
Chapter 2: Factors that influence the study abroad decision of Chinese and Indian students in Australia

The expansion of China's economy and its growth since reforms in the late 1970s intensified its demand for higher education, largely characterised by students sponsored either by the China Scholarship Council or other ministerial, provincial governments and organisations. A significant shift in China's total economic and political policy in looking outwards students included the introduction of a policy in 1993 which supported students in their education abroad, and encouraged their return with no restriction on mobility (zichi liuxue, guli hui guo, lai qu ziyou), and contributed to their booming economy in the 90s. This eventually resulted in the significant increase of self funded students studying abroad (Yao 2004, pg 9-10; Zweig 2006a, pg 68). Self funded students constituted one fifth of all overseas Chinese students between 1978 and 1987 (Yao 2004, pg 9-10) and this has risen to 90 percent in 2006 (People Daily 2007). Hence, the role of government policy as a push factor is highlighted with the above outcome attributable to the economic reforms and policies which began with Deng Xiaoping and this is further emphasised with the sharp increase of Chinese students studying abroad in the last decade as depicted in Figure 2.1.

Figure 2.1: Timeline of Chinese students studying abroad from 1999-2008

\section{NOTE:}

This figure is included on page 27 of the print copy of the thesis held in the University of Adelaide Library.

Source: UNESCO Institute of Statistics 2009

\subsubsection{Higher education in China}

Another macro level push factor is the unmet demand for higher education within China due to limited higher education institutions and spaces, particularly for those who wanted to pursue a graduate qualification. In 2001, it was estimated that of the five million 
Chapter 2: Factors that influence the study abroad decision of Chinese and Indian students in Australia

students who passed entry examinations into a university, less than half would be offered a place (Kaufman \& Goodman 2002). Despite rapid social and economic reforms, higher education struggled to keep pace (Yang 2002, pg 138) as China, with only "1\% of the world's educational budget, supports $15 \%$ of the world's population needing education" (Yang 2002, pg 136). Marginson (2006, pg 19) estimated that an average of 8 percent of high school graduates gained entry into local universities in 2000 and projects this to continue as "the growth of middle-class demand for tertiary education will outstrip the rollout of new institutions and places" (Marginson 2006, pg 19). It appears that China's large population and level of economic wealth resulted in the significant demand for higher education which further contributed to the difficulties faced by the Chinese government in providing sufficient higher education places and research facilities, particularly those of adequate quality.

Discriminatory admission policies practised by universities exacerbate the already intense competition for higher education places, underlining the impact of these macro-level push factors in motivating students to study abroad. Yang (2003, pg 13; 2004, pg 359-360) described how quota systems and admission requirements adopted by some universities favoured students from specific regions. For example, Tsinghua University in Beijing would enrol more students from Beijing and significantly less from the Shandong Province and other provinces. Moreover, students from Beijing would require a much lower entrance examination score compared to those from less favoured regions. This practice not only widened the gap between those in less developed and more developed regions of China but it has added further strain on the already very limited spaces available at higher education institutions.

Insufficient places also translated into fierce competition for entry into local universities via passing the national college examination. Hence, going overseas is seen as a way out for those who fail or wish to avoid the intense competition (Yao 2004, pg 10). The booming economy resulted in more affluent families able to afford overseas education for their children (Pope 2008; Yang 2007, pg 3; Yao 2004, pg 10). When coupled with Chinese parents who place great emphasis on the value of being educated, it is not surprising that when faced with such limitations, the other alternative is to explore study options abroad even if it means having to take a loan for the sake of their children's future (Yang 2004, pg 357; Yao 2004, pg 11). With overseas study more accessible than it used 
Chapter 2: Factors that influence the study abroad decision of Chinese and Indian students in Australia

to be, it has become somewhat of a trend in Chinese society (Yang 2007, pg 3; Yao 2004, pg 10).

\subsubsection{Other factors influencing the study abroad decision of Chinese students}

While economic policies and reforms encouraged students to study abroad, the failure to meet the overwhelming demand for places at tertiary level also contributed to Chinese students studying overseas. However, social and political instability in China have been significant factors as well. A 1994 study revealed that a typical Chinese student in the US (Unites States) would not return to China as "he does not trust his government to let him move freely in and out of the country" (Lin 1994). In comparison, Chinese students arriving in Australia as Kendall (2004, pg 27) explains, have the impression that it is a country of relative freedom and little government intervention in their daily lives and dissatisfaction with the Chinese political system was by and large a motivating factor, where instances of corruption, bribery and the abuse of authority were rife (Pang \& Appleton 2004, pg 507-509, 513-515). Historically, the infamous Tian An Men Square incident in 1989 was also seen as a major turning point which led to many losing confidence in the Chinese government. Contemporary observers have argued that this incident has had "a pervasive and profound effect on young, urban, and education Chinese to seek their future outside China" (Man 2005, pg 12) and also motivated those already abroad, not to return until there were significant improvements to the political and economic climate (Chang \& Deng 1992, pg 46-47). Equally, this prompted many Western governments to adopt a humanitarian stance and granted residence to Chinese students and temporary students (Tremblay 2004, pg 11).

The mid to late 90s experienced an average annual increase of 13 percent and although this was estimated to have risen sharply since 2000 (Zweig 2006a, pg 65-66), the proportion of returnees has not increased due to significant outmigration. The reality of this was the loss of many highly educated and skilled Chinese nationals. The Chinese government has since made steps to "limit the costs to China in case of subsequent immigration" (Tremblay 2004, pg 11) Deng Xiaoping's view was that when it came to brain drain, the important thing was not the return of half or even less of emigrating students, but the return of a few which has clearly influenced policy making. The policies implemented essentially acknowledged the need to embrace advanced western science and technologies and 
Chapter 2: Factors that influence the study abroad decision of Chinese and Indian students in Australia

continue opening its doors for the purpose of economic growth (Liu \& Norcliffe 1996, pg 315-317).

Early research has linked the non-return of Chinese students to insufficient incentives which typically referred to the disparity in wages between China and the West (Chang \& Deng 1992). Chinese authorities acknowledged the significance of such flows and established numerous policies with the aim of reversing or decelerating this loss. For example, a policy was introduced in 1992 with the slogan "improving services for returned students" which basically introduced measures to aid students in settling back in and more (Zweig 2006a, pg 69). In addition, Chinese authorities have introduced 10 different programmes since 1996 (Ministry of Education 2004; Zweig 2005a, pg 8-12) to attract returnees and to reverse the brain drain. Incentives include streamlined applications and registration procedures for new business ventures, tax concessions for equipment and construction materials, various fiscal incentives for investments and loans, the set up of High Tech Development Zones or Science Parks specifically for returnees and even the possibility of having a second child without any penalty (Ip 2004, pg 10; Saxenian 2002, pg 196-197; Tremblay 2004, pg 12; Zweig et al. 2005).

However, the successes of these programmes are debatable. Zwieg (2006a, pg 78-80; 2006b, pg 3-4) argued that even though returnees were more talented and of higher quality than those who stayed in China, the prevailing view was that "the truly talented people stay abroad" (Zweig 2006a, pg 79). Although some top academics have opted to return to China, it is another issue when it comes to getting them to stay. Cao's (2008, pg 340-342) research examined the reasons why governmental policies have failed to attract the calibre of returnees it was designed for. Findings revealed that low salaries and the various relocation issues with regards to children and spouses were commonly cited reasons. Furthermore, it was also deemed that on a professional and institutional basis, personal connections and corruption were rife, at the expense of first rate work, meritocracy and ultimately the return of top academics. Although the literature on China's efforts to reverse brain drain is often linked to those in Science and Technology, i.e., the top end of the highly skilled spectrum (Zweig 2005b), the reasons raised above by reluctant returnees are clearly symptomatic of the reasons why Chinese students sought to study abroad in the first instance. 
Chapter 2: Factors that influence the study abroad decision of Chinese and Indian students in Australia

\subsubsection{The outflow of international students from India}

The latest pattern of emigration gaining importance in the Indian diaspora is students studying abroad. Although these dramatic increases are prevalent only in recent times, the international linkages of Indian students have their roots back in colonial times (Chaudhry 2004, pg 4) with international student migration being "a part of the universe of discourse on brain drain for long." (Myer cited in Khadria 2002, pg 5).

One of the major push factors behind the mass exodus of Indian students has been the liberalisation of the Indian economy in 1991, as only the affluent could afford to send their children abroad prior to economic reform. Since then however, a burgeoning middle class estimated at 350 million and the increased wealth of the upper class led to the staggering increase of Indian students able to pursue an education overseas (Agarwal 2006, pg 8; Chaudhry 2004, pg 5). The rapid growth of the Indian middle class coupled with their willingness to invest and put a child through university, often in engineering or medicine, has contributed to the growing demand for international education (Chaudhry 2004, pg 5).

Economic liberalization which led to the export of Indian currency, coincided with the Indian government's decision in April 1993 to free up and ease foreign exchange regulations. This change in policy permitted currency to be taken out for the purpose of tertiary education, thus further contributing to the surge of Indians studying overseas. In addition, the introduction of the Educational Loan Scheme after the announcement of the 2000-2001 budget, allowed Indian commercial banks to administer loans to any student who has secured a placed in a foreign institution which increased the overseas study option for Indian families (Chaudhry 2004, pg 6; Gillan et al. 2003, pg 1401; Louden cited in Voigt-Graf \& Khoo 2004, pg 434; Mazzarol et al. 2001a, pg 24; Rani 2004, pg 13-16). Although there were debates over the disadvantages and the equity of these schemes (Rani 2004), it is clear that these policies set by the Indian government are important as economic reforms and the increasing availability of education loans have been fundamental push factors motivating Indian students to study abroad.

\subsubsection{Higher education in India}

The influence of policy is also extended to the failure of the government in the restructuring of the higher education sector in India. Gillan et al. (2003, pg 1400) note an imbalance in State funding when it comes to education in India. While the Indian 
Chapter 2: Factors that influence the study abroad decision of Chinese and Indian students in Australia

government has over the last 50 years been committed towards creating one of the world's largest systems of higher education, the majority of institutions have on the other hand been unable to maintain standards and keep pace with technological developments around the world. Inevitably, "financial constraints with exploding enrolments, and a very high demand from primary and secondary education has led to the deterioration in the financial support provided by the government" (Kaul 2006, pg 21).

The higher education sector has always been viewed to be excessively developed and subsidised at the expense of the basic educational needs of the majority of the population, particularly those in rural areas. Moreover, brain drain concerns have also led to criticism over State funding for elite institutions ${ }^{9}$ as this indirectly financed the loss of India's best and brightest. Crippling debts of US\$ 12 billion (in 2003) combined with economic reform in 1991 impacted public budgets on the education sector with higher education particularly affected after subsequent structural adjustment policies (Gupta 2005, pg 7-8; Rani 2004, pg 2-3). Diversion of resources reflected the shift in priorities to primary and secondary education (Swar \& Pandey 2008, pg 54) in the attempt to achieve the "long cherished goal of universal elementary education" (Rani 2004, pg 2). However, this has impeded the growth of the higher education sector and ironically, to an extent, the integration of the Indian economy and the world economy (Rani 2004, pg 2-3; Tilak 2004, pg 2163-2164).

Public expenditure on higher education in the last two decades has been estimated to be less than 0.5 percent of the GNP (Gross National Product) (CABE 2005, pg 23-25). This compelled institutions to look for alternate sources for funds and to reduce costs through various means as recommended by policy (Rani 2004, pg 11). One of the recommendations was to shift funding primarily onto the individual with substantial fees hikes primarily viewed as a main source of income (Gillan et al. 2003, pg 1400; Tilak \& Rani 2002, pg 7-8). Tilak and Rani (2002, pg 12-19) noted the negative impact of fee hikes combined with decreasing government grants, particularly on State universities who had a more pronounced increase in fees. Overall, the restructuring of the education sector and the consequent paucity of funds further contributed to resource pressures, resulting in the poor or declining quality of teaching in State universities and the absence of research intensive universities. Thus, the maintenance of academic standards, as Gillan et al. (2003, pg 1401)

\footnotetext{
9 These elite institutions refer to IITs (Indian Institutes of Technology) and IIMs (Indian Institutes of Management., established to identify the brightest and more talented individuals in India.
} 
Chapter 2: Factors that influence the study abroad decision of Chinese and Indian students in Australia

notes, "is only likely to deteriorate over the next decade and this may intensify demand for international education".

The decrease in the quality of higher education is further intertwined with the higher education system's struggle to cope with the growing demand. With India's population standing at over 1.1 billion, it is not surprising that 400 universities struggle to accommodate the overwhelming demand, particularly for professional courses (Altbach \& Jayaram 2009; Arunachalam 2008). Nearly half of Indian student respondents in Mazzarol et al.'s study (2001a, pg 36) also indicated that the failure to secure a place in a domestic institution was a major factor in their study abroad decision. Despite recent expansion in domestic tertiary places from 9 million in 1999 to 11.9 million in 2004 (UIS 2006), demand continues to be unmet (Banks et al. 2007). In addition, India's caste-based quota system further exacerbated the issue of inadequate supply of university places. A set proportion of places which ranged from 7.5 percent up to 50 percent in some institutions, were prioritised for certain castes and classes to ensure their educational opportunities (Agarwal 2006, pg 95). Therefore, middle class Indians, the main consumers of higher education in India, tend to feel disadvantaged when they fail to get a place in the field or institution of their choice (Khoo \& Voigt-Graf 2004, pg 434).

Hence, it is apparent that the situation in India is quite similar to the one in China where macro-level structures in the form of government policy are largely responsible for the lack of quality institutions and facilities, the dire shortage of places and discriminatory admission regulations that further intensify the competition for university places.

\subsubsection{Other factors influencing the study abroad decision of Indian students}

An initial review of the literature on migrants from India, particularly IT (Information Technology) specialists, has revealed that career, money and personal experiences are key motivations which triggered their move abroad (Meijering \& van Hoven 2003, pg 176). Indians going to the United States, according to Mehra (2003, pg 378) were motivated by the essential lack of educational or occupational prospects back home, not dissimilar to the motivations of Chinese students as discussed in the last section. However, it is important to note how these factors are interrelated with individual motivations as well. 
Chapter 2: Factors that influence the study abroad decision of Chinese and Indian students in Australia

A study by USIEF (United States-India Educational Foundation) (cited in Chaudhry 2004, pg 5-6) revealed that Indians viewed an education in the US as a chance to better their career prospects while other studies (Mahmood \& Schomann 2003) revealed that economic reasons as major factors for Indian IT graduates in their decision to leave India. An overseas qualification is commonly perceived to be of higher quality compared to most Indian universities (Arunachalam 2008; Mazzarol et al. 2001a, pg 36). As Gillan et al. (2003, pg 1401) argue, the Indian demand for international education is driven by:

...the perception that a comparative advantage in terms of 'market value' and employment prospects, in relation to employers in India and overseas, can be gained by some degree of international exposure at a historical moment where globalisation is the catch-cry du jour.

These work related motivations have been noted by some commentators as an expected outcome of studying abroad (Gillan et al. 2003, pg 1401; Khadria 2001, pg 52), linked to employment concerns in India. Khadria (2001, pg 56) argues that education functioned as a 'safety valve' against acute unemployment in India's labour market, as most graduates had poor employment outcomes (Altbach \& Jayaram 2009; Maslen 2007). This was reflected by Raj Lokiyan, an Indian living in NewYork:

I came here to do my studies in computers and I got a job the day after the course was over...I am sure in India I would have had to wait for months, maybe years, to find a suitable job (Anbasaran 1998).

Alberts and Hazen (2005, pg 141) also found how some Indian students preferred to remain abroad as the skills learnt while studying in the US for example, were inapplicable back home due to different standards of quality or culture in their respective fields. As Vincent-Lancrin (2008, pg 105) states:

Individuals see it as a further boost to their career both in their home country and on the international job market, or even as an investment towards possible future emigration.

This section has examined how the decision of Indian students to seek an overseas education stems from the expectation of acquiring human capital to increase one's employability abroad and at home. Such work related reasons include, better career advancement prospects, global career opportunities, the chance to work for international organisations and build international networks and of course, higher salaries (Jones 2003; 
Chapter 2: Factors that influence the study abroad decision of Chinese and Indian students in Australia

Mehra 2003, pg 378). However, the study abroad decision is also comprised of certain pull factors. The following section will examine the range of such factors that motivate international students.

\subsection{Pull factors that motivate Chinese and Indian students}

Pull factors are specific to host countries and institutions as they seek to attract international students (Yang 2007, pg 4). Although intrinsic push factors motivate students to seek an education abroad, the literature revealed some interplay with pull factors. As Table 2.2 shows, foreign qualifications were perceived by students to be more prestigious and of higher quality than the ones from their domestic institutions, while the lack of 'world-class' institutions and the poorer quality or lack of specific courses in their home countries (often developing nations) motivated students to seek an education abroad (Varghese 2008, pg 23-24; Vincent-Lancrin 2004,pg 30).

Table 2.2: Pull factors that influence international students

\begin{tabular}{|c|} 
Euglish as the language medium in the host country \\
\hline Cultural/geographical proximity and historical/ties between the host and home \\
countries \\
\hline Knowledge and awareness of institution and host country \\
\hline Networks of family or friends who live or have lived in the host country \\
\hline Reputation and quality of education in the host country \\
\hline The cost of studying in the host country \\
\hline Environmental considerations of host country \\
\hline Host country policies related to student immigration
\end{tabular}

Source: Adapted from Mazzarol \& Soutar 2002; Vincent-Lancrin 2004; Varghese 2008; Bodycott 2009; Rao 1979, Altbach 1998

The rationale behind the selection of a study destination can be broadly classified as pull factors, and based on a few studies (Altbach 1998; Bodycott 2009; Mazzarol \& Soutar 2002; Rao 1979; Tan 2003; Vincent-Lancrin 2004), one can establish a range of factors as listed in Table 2.2. Although the factors listed above are not definitive, a review of the literature does suggest these pull factors are basic considerations that motivate international students. The following sections will explore the extent of how the various 
Chapter 2: Factors that influence the study abroad decision of Chinese and Indian students in Australia

pull factors listed above influence the decision making of Chinese and Indian students when selecting a study destination.

\subsubsection{English as the language medium in the host country}

Although there is a wide spectrum of pull factors influencing Chinese students (Yang 2007, pg 5-8), they can be grouped into fewer categories. For example, the aim of learning or improving English is often cited as a factor for Chinese students (Yao 2004, pg 21) and is actually prevalent among most international students as the "acquisition of linguistic and cultural skills in English is a key objective" (Marginson 2004, pg 220). In addition to linguistic objectives, Bodycott (2009, pg 360) reveals how Chinese students seek to learn more about Western culture and to have a Western experience. Additionally, Marginson (2004, pg 218-224) notes hegemonic views centered around English language universities which can be linked to the wider picture. As Gao and Liu (1998, pg 39) argue, due to the "world dominance of Western cultural values and technology, many students from developing countries value their experiences in a developed Western country". Li and Bray's (2005, pg 807-808) study on Chinese students studying in Macau and Hong Kong substantiate this point. The students felt disadvantaged as a lack of foreign culture and language climate would not help them understand Western culture. Dasgupta (cited in Mehra 2003, pg 378) revealed that Indian students seeking a US education either had the desire to see the world or were 'inspired' by successful Indians educated in the US or other European countries. Although Indian students aren't motivated by learning English, an evident "craze for the West and all things Western" (Khadria 2002, pg 37) is explained by the increased exposure to Western countries and lifestyles (Mazzarol et al. 2001a, pg 23). Mazzarol and Soutar's (2002, pg 84-85) study similarly revealed a large proportion of Indian postgraduate students who wanted to gain a better understanding of Western culture through international education. Hence, one can infer that the objective of learning or improving one's English is also closely associated with the desire to learn Western culture and to have a Western experience.

\subsubsection{Cultural/geographical proximity and historical/economic ties between home and host countries}

Cultural/geographical proximity and historical/economic ties are exemplified by students and the colonial history of their countries. Students from Indonesia for example, displayed 
Chapter 2: Factors that influence the study abroad decision of Chinese and Indian students in Australia

a tendency towards studying in Holland (Altbach 1998, pg xiii). Such linkages also enhanced student flows between Nordic countries and between former republics of the Soviet Union and the Russian Federation (Vincent-Lancrin 2004, pg 30; Vincent-Lancrin 2008, pg 112). Studies identified how studying in a country which was geographically close or had social/cultural ties (Bodycott 2009, pg 360; Li \& Bray 2005, pg 807; Mazzarol et al. 2001a, pg 61; Yao 2004, pg 6) was considered to be a factor or advantage for some students. For example, Indians, both skilled and unskilled, have traditionally gravitated towards the UK (United Kingdom), which is mainly due to the history between the two countries. These linkages are commonly used to explain the early attraction British universities had on Indian students before 1970 (Mazzarol et al. 2001a, pg 25). The use of English as the language of instruction in the Indian education system, particularly at the higher, professional and technical level is associated with colonialism and often seen as a pull factor. The emphasis on the English language is further perpetuated by a degree of familiarity with Anglophone educational traditions or British educational institutions (Gillan et al. 2003, pg 1395; Islam \& Borland 2006, pg 2; Khadria 2002, pg 11). A similar sense of affinity between Indians and Australia as "a result of migration, membership in the Commonwealth and the shared fondness for cricket" (Khoo \& Voigt-Graf 2004, pg 435) further demonstrates the strength of such ties when deciding on a study destination.

\subsubsection{Knowledge and awareness of institution and host country}

The ease of finding or accessing information on the host country and their education programmes is an important variable (Mazzarol et al. 2001a; Mazzarol \& Soutar 2002; Mazzarol et al. 2001b). Middle man agencies as studies have shown (Blight \& Archer 2005; Mazzarol \& Soutar 2002, pg 85; Mazzarol et al. 2001c, pg 52; Tan 2003, pg 59-62), are an important source of information for students, which was similarly reflected by Chinese and Indian students in their decision making (Mazzarol et al. 2001a, pg 42-44; 2002, pg 84-85; Mazzarol et al. 2001b, pg 56-58). As indicated by Chinese students, various sources such as educational fairs (Yao 2004, pg 11), education agents (Biao 2005, pg 13) and various forms of mass media in the form of Internet and print advertising played a big role (Bodycott 2009, pg 375). Likewise, despite Mazzarol's et al. (2001a, pg 50) study focusing only on Indian students in Science and Technology in the postgraduate sector, the influence of similar sources is clear with conventional channels such as education/information centres, education fairs, agents and associated guides sent by 
Chapter 2: Factors that influence the study abroad decision of Chinese and Indian students in Australia

potential institutions. These sources of information improved information access, helping Indian students make intelligent informed decisions (Jones 2003).

\subsubsection{Networks of family or friends who live and have lived in the host country}

Although students have access to an increasing amount of information, it appears that social links or networks comprised of friends/relatives/alumni that have lived or studied in potential countries highly were highly valued. Family or friends who were studying or had studied in host countries were regarded as important networks and invaluable sources of information and in some instances, a strong alumni is regarded by institutions as vital sources of referral (Mazzarol \& Soutar 2002, pg 89; Vincent-Lancrin 2004, pg 30). Blight and Archer (2005) have argued the high regard international students have for friends and family members. For example, studies by Sin (2006, pg 254-255) and Tan (2003, pg 60) on Malaysian students and Singaporean students respectively, reflect the importance of personal or extended networks (immediate family members and relatives) when deciding on a study destination.

These networks were also important information for Chinese (Mazzarol et al. 2001b, pg 56-61; Yang 2007, pg 8) and Indian students (Mazzarol et al. 2001a, pg 50). Such networks were vital as "those who went abroad earlier became familiar with the admission system...they started to help their friends or relatives in China by either directly applying for them or passing information to them" (Zhao 1996, pg 156). The information passed on through these networks is related to the environment which as mentioned, includes factors like climate, attractions, lifestyle and the conducive nature of the study destination for education. Mazzarol and Soutar (2002, pg 86) along with other studies (Andressen 1991, pg 255-266; AIEF 1997; Baker et al. 1996a, pg 72-73; Tan 2003, pg 60) note how the presence of an established network of international students in a host country can act as additional pull factor.

\subsubsection{Reputation and quality of education in the host country}

Receiving reputable and quality education can be particularly important as it is intertwined with international students who were motivated to leave their home countries due to the lack of quality institutions locally. Moreover, 'Knowledge and awareness of a host country or institution' as earlier discussed, is further enhanced with the relative reputation and 
Chapter 2: Factors that influence the study abroad decision of Chinese and Indian students in Australia

profile of the institutions. While the factor of poor quality or insufficient supply of higher education facilities as mentioned often pushed Chinese and Indian students abroad, it is however combined with the pull factor of seeking a more prestigious overseas education. Foreign institutions are often regarded to be superior to domestic institutions as they are usually reputable, of higher quality and provide a wider range of programmes. Additionally, Chinese and Indian students would gravitate towards a potential study destination if the qualification was recognised back home (Bodycott 2009, pg 360, 363; Maslen 2007; Mazzarol \& Soutar 2002, pg 84-85; Yang 2004, pg 6). Possessing an overseas degree has also been acknowledged to give one an advantage in market value and employment prospects (Arunachalam 2008; Gillan et al. 2003, pg 1401; Khoo \& VoigtGraf 2004, pg 434).

\subsubsection{Environmental considerations of host country}

This includes a wide range of factors which usually refers to the quality of life with aspects such as climate, tourist and cultural attractions and activities influencing a student's decision (Mazzarol \& Soutar 2002, pg 86). Australia for example was a preferred destination for students from South-East Asia due to its warmer climate to countries such as the UK or Canada. The conduciveness of a place for study can also be included in this factor with Japanese and American students regarding Australia as a fun destination and not for serious study (Mazzarol \& Soutar 2002, pg 89). This attitude was similarly raised in Tan's (2003, pg 75-76) study on Malaysian and Singaporean students. Additionally, aspects such as safety, racism, and crime rates were considered as relatively important pull factors by Chinese (Mazzarol et al. 2001b, pg 56, 59) and Indian students (Mazzarol et al. 2001a, pg 43-44).

\subsubsection{The cost of studying in the host country}

'The cost of studying in the host country' is a factor which international students can also be quite conscious of as it is by no means inexpensive. One can surmise that the "smaller the cost differential between studying abroad and studying at home, the more mobile students will be" (Vincent-Lancrin 2004, pg 20). Cost is thus an important factor (Ma \& Abbott 2006, pg 4; Mazzarol et al. 2001b, pg 89), and one can assume that a study destination will be more popular if the cost of higher education is comparatively lower. The decline of students to the US and the UK due to their relatively higher costs compared 
Chapter 2: Factors that influence the study abroad decision of Chinese and Indian students in Australia

to New Zealand, Ireland and Australia in Varghese's (2008, pg 22) study substantiates the importance of cost. Despite the emphasis placed on cost considerations by some studies (Sin 2006, pg 254; Tan 2003, pg 53), others have stressed how high tuition fees maybe not always prove to be an obstacle and may vary between students from different regions (Vincent-Lancrin 2004, pg 30-31).

Chinese and Indian students often reflect how cost can be a mitigating factor (Bodycott 2009, pg 360-361; Ma \& Abbott 2006, pg 2; Marginson 2004, pg 228) and studies have shown the former (Yang 2007, pg 8) and the latter (Anbasaran 1998; Jones 2003; Sharda 2005, pg 47; Voigt-Graf 2004, pg 434-435) choosing to study in Australia as it was a cost effective option, even though the US was their preferred study destination. However, while the relative cost of education is a significant factor in the decision making process of Chinese and Indian students, "it is important not to exaggerate the relative estimated cost differentials between countries, or to attribute destination preferences solely to the factor of comparative advantage on the question of cost" (Gillan et al. 2003, pg 1401).

\subsubsection{Host country policies related to student immigration}

The policies established by host countries are important macro-level structures that feature prominently in the decision making process of Chinese and Indian students. Different aspects of immigration policy relating to international students such as being able to work while studying, being able to obtain a student visa and post study options will be examined, demonstrating the interplay between the push factor of intending to migrate as earlier discussed and attractive permanent immigration policies established to retain international students.

\subsubsection{The importance of work rights during the course of study}

Cost considerations as discussed above are also linked to another factor- the importance of working part-time whilst studying (Mazzarol \& Soutar 2002, pg 89). This is increasingly acknowledged by countries such as the UK who eased restrictions on international students and their work rights since 1999 (Kuptsch 2005, pg 13). Germany similarly allowed non EU international students to work for 90 full days or 180 half days under their new immigration law in 2005 (Suter \& Jandl 2006, pg 43) These changes are due to governments acknowledging how "students might also be influenced by the degree to 
Chapter 2: Factors that influence the study abroad decision of Chinese and Indian students in Australia

which international students are allowed to work...when they are on student visas" (Kuptsch 2005, pg 13).

Baker et al.'s (1996b, pg 63-83) study on the labour impacts of international students in Australia strengthens the ability to work as a factor. It revealed that nearly 30 percent of respondents indicated that work rights were 'Very Important' and 63 percent indicated that it was 'Important' or 'Fairly Important' in the decision making process. Unsurprisingly, the majority of respondents $(41 \%)$ in the study were employed in the hospitality industry, with the remainder employed in relatively unskilled occupations; which was also reflected by the ABS (Australian Bureau of Statistics) (2008b). Tan's (2003, pg 47) study similarly revealed nearly a quarter of Malaysian and Singaporean students in Adelaide who often worked in unskilled labour on a regular basis. The availability of such work, particularly in the unskilled sector is clearly important to these students who rely on them to finance their studies, although it must be noted that this factor was valued differently by students from different countries in the decision making process (Baker et al. 1996b, pg 81-82).

For Chinese students, working part-time represented "a means to make the cost of an international education possible" (Mazzarol \& Soutar 2002, pg 89) and similar sentiments were imitated by Indian students in studies by Mazzarol et al. (2001a, pg 40-44) and Baas (2007b). Australia's student visa regulations are therefore attractive pull factors for Indian students with work provisions of 20 hours a week during the semester and fulltime off semester (Khoo \& Voigt-Graf 2004, pg 435). Hence, it is fair to agree that "Work permits under student visas have proven to be a major drawcard when recruiting students from India” (Mazzarol et al. 2001a, pg 25).

\subsubsection{Ease of obtaining a student visa to enter a host country}

Being able to work while studying and the conditions attached are usually determined by 'student friendly' immigration systems. Generally speaking, in addition to employment opportunities, other aspects of the immigration policies set in place by host countries do play an important role in the decision making of international students.

For example, the ease of obtaining a student visa can be an important factor in the decision making process. A NAFSA (National Association of Foreign Student Advisers) (2006, pg 5) report stated, "after $9 / 11$, the United States instituted a series of visa restrictions that 
Chapter 2: Factors that influence the study abroad decision of Chinese and Indian students in Australia

made it exponentially harder to get into the United States and- however unintentionallysent a message to international students that they were not really wanted". Such restrictions consequently resulted in a decline of international students studying in the US, which has been well documented (Bollag 2004; Brumfiel 2003a; Brumfiel 2003b; China Daily 2006; Davie 2004; Dillon 2004; Luce 2007; Mooney et al. 2004; Mueller 2005; NAFSA2006) as post 9/11 visa processing delays "discouraged thousands of students, not only from the Middle East but also from dozens of other nations, from enrolling in the United States" (Dillon 2004). Mueller's (2005) study, which examined the link between Canada's experience in rising student enrolments to America's post 9/11 decrease, supports how the perception of the immense difficulty one has to endure in obtaining a US student visa has consequently resulted in beneficiary countries like the UK, Canada, New Zealand and Australia (Batalova 2007; Bollag 2004; Dillon 2004; Mooney et al. 2004). And as the Dean of international studies and programmes at the University of Nebraska states, "The word is out: It's easier and less demeaning to apply in Canada or the U.K” (Bollag 2004, pg A38).

Barriers to entry or the ease of admission to a host country is often cited as an important factor and Australia has been known to have strict entry requirements for selected Asian countries such as China and India (Gillan et al. 2003, pg 1399). As Ma and Abbott argue (2006, pg 6), "The easier it is to be granted a student visa and the less onerous the condition once granted the easier it will be for universities to attract international students" (Yang 2007, pg 8). Chinese students have had a history of being rejected by universities or visa offices in potential study destinations (Xiao 1989 cited in Zhao 1996, pg 158) while the tightening of visa restrictions by the US and Europe since the early 1990s have also constrained the movements of Indian students (Anbasaran 1998). For example, it appears that Chinese students in the US "reportedly face more scrutiny than applicants from any country outside the Middle East" (Biao 2005, pg 72), which according to Shirley Tilghman, the President of Princeton University, appears to be irrational (Dillon 2004).

Mazzarol's et al.'s (2001b, pg 36-39) study revealed Australia's previously stringent, expensive and lengthy visa process as an obstacle, which encouraged Chinese students to apply to the US, Canada or New Zealand. The need to improve student visa processing times was acknowledged by the Australian government as a shift in policy resulted in quicker turnarounds. Such changes in policy were justified as Chinese students in Yang's 
Chapter 2: Factors that influence the study abroad decision of Chinese and Indian students in Australia

(2007, pg 8) study, chose Australia over the US as a study destination due to the fact that they were granted a visa from the Australian embassy first. Similarly, the decision by the Australian government to reduce visa processing fees by over a third and to relax the conditions for entry in 2003 encouraged Indian students to study in Australia (Sharma \& Kumar 2004). These examples therefore underline the importance of policy in facilitating student visas as such barriers to entry to a country can influence a student's decision in the selection of their study destination. However, post study policies that allow students to remain in the country after finishing their studies also play an important role in the decision making process.

\subsubsection{The opportunity for permanent settlement}

The intention of students to settle permanently after completing their studies is beginning to emerge in the literature as an important consideration in their decision making process. As discussed, with the race to stay ahead in today's knowledge driven economy, international students are increasingly looked upon as a source of human capital. Coupled with how international students can view permanent immigration as an objective, governments around the world (Kuptsch 2003; 2005; Tremblay 2004) adopting the "academic gates approach, which aims at attracting foreign students, training them in local higher educational institutions, and enabling them to later work in the country, through adjustments in student visa and employment regulations" (Chanda 2005a). A comparison of migration policies by Suter and Jandl (2006) (Appendix 1) geared specifically towards international students has revealed how such retention policies are usually a part of labour migration schemes for highly skilled migrants that have pathways to permanent residency for highly skilled migrants.

In brief, it is evident from the report that while not all countries encourage retention of international students, most have, in one way or another, accorded international student graduates some dispensation with policies assisting them in gaining employment after their studies. For example, international students in the UK are granted a student visa with an extra four months for them to seek employment after completing their studies. Similarly, France, New Zealand and Germany allow students to remain between six months to a year for the same purpose while Canada's post-graduation work programme allows students to work up to two years in a field related to their study (Appendix 1). These schemes are also usually connected to labour migration schemes which either directly or indirectly translates 
Chapter 2: Factors that influence the study abroad decision of Chinese and Indian students in Australia

to permanent immigration. New Zealand, Canada and Australia for example, award international students graduating with post-secondary qualifications bonus points in their PR (Permanent Residency) applications. On the whole, New Zealand has one of the quickest and more direct schemes leading to PR compared to other countries such as the UK, Germany or Switzerland, who require applicants to continuously live and work in their host countries for 5 to 10 years before they are eligible for PR (Suter \& Jandl 2006, pg 21-23, 33-35, 78). Moreover, these policies can be effective in student retention. Canada for example, is expected to retain 15-20 percent of all international students after their studies (Suter \& Jandl 2006, pg 8).

Chinese students have been known to study abroad as the possibility to remain overseas was seen as an ideal outcome (Gao \& Liu 1998, pg 30). Indian students, as noted by Khadria (2002, pg 42) also tended to emigrate through the education route by changing their visa status when entering the labour market after their studies. Studies have shown the consideration of this factor for Chinese students (Mazzarol et al. 2001b, pg 85) which is akin to Bodycott's (2009, pg 360-361) study which revealed the potential to migrate as an important pull factor when deciding on a study destination. Yang (2007, pg 8), revealed permanent migration abroad as a key motive for 75 percent Chinese students (75\%) while an overwhelming 97 percent of Chinese students decided to study in Australia due to the its favourable skilled migration policies.

Such migration intentions were also indicated by Indians students as a strong motivator in studying overseas. Research by Mazzarol et al. (2001a, pg 38) revealed 59 percent of Indian student respondents indicated permanent settlement in the host country as a motive for overseas study. The National Science Foundation (cited in Khadria 2001, pg 47) also reported out of the 1,173 Indian doctoral recipients in engineering and science in the US in 1997, significant proportions had 'plans to stay' (83\%) and 'firm plans to stay' (61\%). Finn et al. (2003) also revealed Indian Students who received doctorate degrees in 1996 as the second highest group behind Chinese students who remained in the US. Baas' (2006; 2007a) research which explored the motivations of Indian students in Australia, uncovered similar results with a high propensity indicating PR as their major objective in their study plans. 
Chapter 2: Factors that influence the study abroad decision of Chinese and Indian students in Australia

As Ma and Abbott (2006, pg 6) note, many potential young immigrants are attracted to Australian and New Zealand universities as it is "a first step towards immigration to those countries". Despite their separate concerns, universities and immigration are linked when governments modify immigration regulations to entice international students. Australia and New Zealand for example, give special dispensation to potential immigrants with qualifications from their own countries than those with overseas qualifications (Ma \& Abbott 2006, pg 6). Thus, it evident that permanent migration can be a pull factor for Chinese and Indian students when deciding on a host country, emphasising the role of policies set by governments in host countries.

\subsection{Conclusion}

This chapter has shown that Chinese and Indian students are both motivated by similar macro level push factors and to a large extent, similarly influenced by myriad pull factors when selecting a study destination. It must be said that although the push and pull factors identified in this section are not definitive, they can be regarded as a guide to the general motivations that play a part in the decision making process of Chinese and Indian students.

Macro structures in the form of government policy in China and India were contributing factors for Chinese and Indian students. For many, policies which led to economic reforms allowed the realisation of an overseas education for many Chinese and Indians. The pro study abroad attitude of Chinese and Indian governments were further reflected through other policies as well. However, it is clear that both Chinese and Indian governments struggled to meet the demand of Chinese and Indian students at the higher education level. Moreover, the overall quality of Chinese and Indian institutions was considered poor. Discriminatory policies which favoured particular groups of Chinese and Indian students further contributed to the shortage of places. Economic motivations were also a concern as limited career and employment opportunities and lower salaries in China and India were behind the study abroad decision of some Chinese and Indians students. These factors were also linked to the belief that overseas qualifications were more prestigious and would result in higher salaries and more opportunities.

When examining pull factors, macro structures were significant as students were quite dependent on the policies set by the governments of potential host countries. VincentLancrin (2008, pg 117) states: 
Chapter 2: Factors that influence the study abroad decision of Chinese and Indian students in Australia

Visa policy for students and university personnel and more generally, immigration policy are an important part of the machinery for the internationalisation of higher education. Attracting international students to a country will only make sense only if they are able to pursue their studies and, ideally to do so without undue difficulties.

One significant factor which has emerged in the recent history of international students is the opportunity to remain behind in their host countries after the completion of their students. The non return of international students as part of the brain drain phenomenon is quite well established and as also suggested in Section 2.5, the link between the temporary migration of international students and their permanent settlement in recent times has been increasingly researched. Several studies as mentioned, have posited how international students view education as a backdoor or precursor towards permanent immigration simply "because a student visa buys them a ticket into the country" (Borjas 2002).

Regardless of the seriousness of their intention, and whether the decision to migrate permanently was borne before leaving their home countries or during their studies, the actual realisation of their migration intention is nevertheless very dependent on the policies set by the respective governments of their host countries. Governments in recent times have sought to market themselves as attractive study destinations by increasingly accommodating the work needs of international students. Immigration policies in a similar fashion are also increasingly geared towards the retention of these students (Salt 2005, pg 31-32). Therefore, as much as migration policies are tweaked to retain these potential skilled migrants, they are also to an extent, a response to the migration intentions of these students by attracting them with permanent migration possibilities. This link is indicative of a two way relationship in the nexus between international education and permanent immigration. This relationship essentially boils down to the willingness of countries to "reconfigure the boundaries of political membership" with the potential of citizenship in a host country as a competitive instrument in attracting skilled migrants (Shachar 2006, pg 155). The acquisition of citizenship in a stable and affluent country is regarded as a valued good in itself and "may affect the choices of knowledge emigrants in choosing a destination country" (Shachar 2006, pg 158).

Chapter 3 will therefore examine in detail the post graduation policies available to international students in Australia and ascertain the extent of the role immigration policy has in motivating Chinese and Indian students. Although it is clear that macro structures 
Chapter 2: Factors that influence the study abroad decision of Chinese and Indian students in Australia

are influential in study abroad decisions of Chinese and Indian students, many of the other factors raised are pertinent as well. Hence, to further understand the underlying factors driving the decision making process of the students, Chapter 4 will theorise the push and pull factors discussed in this chapter in the context of migration theory. This approach will shed light on how these factors shape the mobility of Chinese and Indian students when conceptualising their transnational migration strategies. 


\section{CHAPTER 3: The Role of Government Policy on the Decision Making Process of Chinese and Indian Students}

\subsection{Introduction}

The objectives, policies and procedures relating to international education in Australia have gradually shifted from aid to trade. Globalisation or internationalisation has transformed the landscape of international education in Australia which has resulted in the 'Commodification and Internationalisation of Higher Education' (Gillan et al. 2003). The transformation of international education is a global phenomenon which has seen it emerge as a significant export industry. The previous chapter revealed macro-level structures as factors influencing the study abroad decision of Chinese and Indian students. Although macro-level push factors contributed to their desire to pursue an international education, government policies in study destinations also influence decision making.

Educational policies are directly linked towards the creation and growth of the international student market, however, it seems that immigration policies have a less obvious yet significant role in this extremely valuable export industry. As discussed, the notion of international students using education as a backdoor, a pathway or safety valve towards permanent settlement in their host countries has been debated since the brain drain era. As mentioned, statistics in Australia do substantiate the tendency of students remaining in Australia after their studies, thus emphasising the need to investigate the linkages between immigration policy and international education.

Chinese and Indian students are quite responsive to policies as it weighs quite heavily in their decision making process, hence, this chapter will discuss the role of policy and its effectiveness as a pull factor. The relationship between permanent immigration and international education for Chinese and Indian students will be illuminated by exploring the increasing focus of major English speaking study destinations on retaining international students, the shift in international education policy in Australia, its evolution ${ }^{10}$ and influence on the PR intentions of international students in Australia.

\footnotetext{
${ }^{10}$ Due to the continuing changes made to immigration policy and the time frame of this study, discussion in this chapter will not go beyond the changes made to policy in September 2007.
} 
Chapter 3: The role of government policy on the decision making process of Chinese and Indian students

\subsection{The retention of international students}

The connection between international education and the permanent immigration of students should be analysed with reference to the way immigration policy has evolved alongside shifts in educational policies. The principal reasons behind expanding international education in higher education sectors was based on the notion of aid to developing countries with the perspective of trade and revenue generation taking on a bigger role due to dwindling government funding, particularly for Australia. However, policies that encourage the expansion of international education can also be linked to immigration policies as international students are viewed by governments as a viable source of skilled immigrants to address skill shortages and ageing populations (DFAT 2005, pg 11). This section will briefly examine how other countries have adapted their immigration policies to retain more international students before analysing how Australia's immigration policy has evolved.

Increasingly, in today's knowledge economy, the race for global talent is intensifying with governments exploring international education as an avenue in their bids to boost their economies (Kuptsch 2005, pg 4-5; Vincent-Lancrin 2008, pg 10). Recent decades have witnessed industrialised countries and universities implementing regulations that facilitate the transition of 'desirable migrants' from international student to permanent migrant. Immigration laws are often influenced by the general politics and labour market requirements of a particular country (Ma \& Abbott 2006, pg 5) and it is clear that students are increasingly part of "the quest for talented human capital" (Suter \& Jandl 2006, pg 9) as they are potentially "the skilled immigrants of tomorrow" (Migration Policy Institute 2005).

The advantages of international students as future immigrants are obvious. It is perceived that they would have little problems integrating into the local labour markets as they would be accustomed to the social and cultural norms of their host country, as well as mastered the language associated with their degree (Kuptsch 2005, pg 6-8; Ma \& Abbott 2006, pg 6; Salt 2005, pg 31; Solimano \& Pollack 2004, pg 18; Suter \& Jandl 2006, pg 10). The concept of 'designer immigrants' (Simmons 1999) arises as countries would strategically align their immigration policies with other policies in order to gain an edge over other countries in attracting international students. 'Student-switching' or 'category jumping' (use of term varies from country to country) in the context of this study refers to 
Chapter 3: The role of government policy on the decision making process of Chinese and Indian students

international students changing their migration status from education to workforce once they complete their studies, without having to return to their home countries (Salt 2005, pg $31)$.

As Suter and Jandl (2006, pg 15) state:

...students are theoretically obliged to leave the country after completion of their studies... however, countries have realised the potential of hiring graduates. Therefore many countries have put regulations in place to facilitate the integration of foreign graduates in their national labour markets

A brief review of immigration policies around the world (Appendix 1) shows evidence of how major English speaking study destinations such as the USA, UK, New Zealand and Canada have adjusted and are continually refining policies to encourage post-graduation employment. In general, although policies vary between countries, international students upon graduating are able to extend their stay with a temporary visa or permit with the purpose of seeking employment (Suter \& Jandl 2006, pg 16). Although employment restrictions differed between countries for international students, some programmes were specific. Germany for example introduced more flexible immigration policies with the German "Green Card" scheme which targeted international students graduating from German universities with IT degrees. The French government also encouraged international students with IT degrees from French universities to remain behind after their studies, not dissimilar to the Post Study and International Graduates Scheme in the UK (Salt 2005, pg 31-32).

The intentions of governments today are clear as policies are "increasingly factoring in the authorization or facilitation of permanent residence for international students in the host country after their studies" (Vincent-Lancrin 2008, pg 118-119). As mentioned, it is commonplace for countries to have labour migration programmes in place for highly skilled migrants which international students are also eligible to participate in (Appendix 1). Countries like Canada, New Zealand and the UK have point based systems which enhances permanent settlement outcomes for international students with university qualifications. Extra points are allocated to students which counts towards their applications, further indicating how closely immigration policy and internationalisation of higher education are intertwined. 
Chapter 3: The role of government policy on the decision making process of Chinese and Indian students

\subsection{International education policy in Australia}

The value of international students to the Australian economy is hard to ignore as international education and the policies governing it have evolved from the perspective of aid into one dominated by market forces. Appendix 2 shows a chronology of how policy with regards to international education in Australia has evolved, leading to the creation of the international student market which is a substantial export industry today (Section 1.3.1).

International students under the Colombo Plan in the 1950s were seemingly educated through the altruism of the Australian government for the benefit of developing Commonwealth countries (Williams 1989,pg 11). This however changed in 1973 as policy lifted the limitation on the number of international enrolments and oversaw the removal of the development assistance agenda (Cameron 2002, pg 19; Jones 1986, pg 71). Subsequently, the Overseas Student Charge (OSC) was introduced in 1979 where international students had to pay a percentage of their fees (Cameron 2002, pg 19; Jones 1986, pg 71; Williams 1989, pg 11). Furthermore, based on the reports of the Goldring and Jackson committees in 1985, the cap on international enrolments was increased with future increments planned for the percentage that international students had to pay on the OSC (Williams 1989, pg 12). The late 1980s saw international education adopt a more trade oriented stance. Institutions were permitted to enrol as many international students as they liked and were encouraged to be entrepreneurial, setting tuition fees at or above cost (Bayley et al. 2002, pg 45; Cameron 2002, pg 19; Williams 1989, pg 13).

The importance of the international education industry is also intertwined with the increasing reduction in government funding for most Australian universities, which to an extent, resulted in a crisis (King 2001, pg 190). Until the late 1980s, the Commonwealth was relied on for 90 percent of higher education funding, however, this was reduced by both Labour and Liberal governments (Marginson 2001, pg 207). Over the last thirty years student contributions have risen as Commonwealth funding has declined (Bayley et al. 2002, pg 45-46). As seen in Figure 3.1, overall higher education institution revenue in 2006 saw student contributions at their highest level at 38 percent, conversely, Commonwealth contributions were at their lowest at 41 percent. 
Chapter 3: The role of government policy on the decision making process of Chinese and Indian students

Declining public funding has forced institutions to seek alternate sources of income, giving the higher education industry "a powerful incentive to work the new markets that had opened up in international and postgraduate education” (Marginson 2001, pg 207). Therefore, it is understandable and inevitable that universities pursued policies which had "clear and predictable outcomes" resulting in priority being given to "recruiting international students, where numbers were open-ended and each place was fully funded" (Marginson 2001, pg 210).

\section{Figure 3.1: Australian Higher Education Funding Trends}

\section{NOTE:}

This figure is included on page 52 of the print copy of the thesis held in the University of Adelaide Library.

Source: Adapted from Group of Eight 2007, pg 2

The evolution of higher education policies with international students as an important source of income has occurred alongside a shift in immigration policy with growing participation of international students in Australia's skilled migration programme. The nexus between international migration and international education is a "thorny one and study opportunities in Australia may have been seen as a pathway to permanent residence" (Harris \& Jarrett 1990, pg 70). As already discussed, it is a relatively under researched aspect of international students. The prospect of immigration is attractive to international students. In the 1970s, it was estimated that approximately 75 percent of international students were granted permanent residence. However, a shift in immigration policy in the 1980s subsequently led to a drop with only 10 percent settling permanently (Goldring 1984, pg 33), a clear indication of the link between immigration and international education. 


\subsection{Evolution of Australia's immigration policy on the permanent settlement of international students}

Immigration policy towards international students in Australia has changed dramatically over the years. Points testing (see: Appendix 3 for current components of the points test) for skilled migration categories was introduced 1989 (Chiswick and Miller 2006, pg 7). This was deemed to offer a means of "selecting immigrants who will adjust rapidly to the circumstances of the Australian labour market and bring benefit to Australia" (Miller 1999, pg 196). This test is generally based on the age, skill and language proficiency of the applicant where points are awarded to each category.

To pass the test applicants needed to amass a total of 110 points (Miller 1999, pg 193-194). Modifications to the points test coupled with key changes in immigration policy with regards to international students, suggests that international students are regarded as a valuable pool of skilled migrants. Recent years suggest a fine tuning process (Table 3.1) to ensure that Australia's benefit from the permanent migration of international students continues.

Reforms were implemented in 1999 to encourage international students to apply for PR after their studies. Soon after, the Federal Government reversed its policy which required international students to return to their home country for a minimum of two years before applying for permanent residency. Bonus points were also allocated to applicants with an Australian qualification which made it easier for students who favoured a move (Hugo 2002a, pg 31-32). In addition, the requirement for applicants to have 3 years of work experience was waived for students, further easing the application process.

In 2001, 3 new onshore visa categories were created for international students, they include, the onshore independent overseas student visa (visa subclass 880), Australian sponsored overseas student (visa subclass 881) and designated area overseas student category (visa subclass 882 ). The 881 visa provided points concession for applicants who were sponsored by a relative who is an Australian resident while the 882 visa required the sponsoring relative to reside in a 'Designated Area' in Australia. The introduction of these visas permitted international students to apply for PR without needing to leave Australia as long as they applied within 6 months of completing their studies/training, however, the 880 visa was the most popular option (Birrell 2006, pg 54-55). 


\section{Table 3.1: Key milestones of the evolution of immigration policy for international students (1999-2007)}

\begin{tabular}{|c|c|}
\hline Year & Key Milestones \\
\hline 1999 & $\begin{array}{l}\text { - Reforms to immigration policy were introduced to encourage international students to obtain Permanent Residence after their studies. } \\
\text { - Students with a relevant Australian qualification which included a minimum of } 12 \text { months stay in Australia were awarded } 5 \text { extra points in } \\
\text { DIAC's skill selection system. } \\
\text { - The previous requirement of an applicant needing } 3 \text { year works of experience was also waived for international students. } \\
\text { - Pass mark for the Skill Independent Overseas Student visa subclass was } 110 \text {. }\end{array}$ \\
\hline 2001 & $\begin{array}{l}\text { - } 3 \text { new onshore visa categories were created for international students. } \\
\text { International Students no longer had to leave Australia after their studies to apply for Permanent Residence as long as they applied within } 6 \\
\text { months of completing their training/studies. }\end{array}$ \\
\hline 2002 & - $\quad$ Pass mark for the Skill Independent Overseas Student visa subclass was increased to 115. \\
\hline 2003 & $\begin{array}{l}\text { - New visa subclasses were created to encourage migrant settlement to regional or low growth settlement areas. } \\
\text { - International students who studied and resided in defined regions or low population growth metropolitan areas }{ }^{11} \text { for at least two years were } \\
\text { granted an additional } 5 \text { bonus points in their visa applications. } \\
\text { - If students had a degree in an occupation listed on the MODL, they would be granted an additional } 15 \text { points in their application. } \\
\text { - Required minimum period of stay in Australia was increased from } 12 \text { to } 24 \text { months. }\end{array}$ \\
\hline 2004 & $\begin{array}{l}\text { - The two-stage Skilled-Independent Regional (Provisional) visa which offered pathways to PR was introduced to encourage international } \\
\text { students to locate in a regional or low population growth area upon completion of their studies. This was also an alternative for students who } \\
\text { failed to meet the requirements needed for the Skilled Independent Overseas Student visa. } \\
\text { - International students enrolling in Masters by coursework programmes were re-categorised from the Postgraduate student visa subclass to } \\
\text { Higher Education visa subclass which involved stricter requirements for visa approval. }\end{array}$ \\
\hline 2005 & $\begin{array}{l}\text { - Pass mark for the Skill Independent Overseas Student visa subclass }(\mathbf{8 8 0}) \text { was increased to } 120 \text { (increase for visa subclass } 136 \text { occured in } 2004) \text {. } \\
\text { - } \quad \text { Changes to GSM points test allowed SIR visa applicants to be awarded } 10 \text { additional points if they received State/Territory sponsorship. }\end{array}$ \\
\hline 2006 & - A report on the GSM categories was released reviewing the policies and subclasses with recommendations to refine them. \\
\hline 2007 & $\begin{array}{l}\text { - All GSM visas were required to have higher English language threshold to address concerns over inferior early employment outcomes. } \\
\text { - Applicants with good English ability were awarded } 25 \text { points in their application compared to those assessed with 'competent' English who } \\
\text { were awarded } 15 \text { points. } \\
\text { New temporary skilled visa options were introduced emphasising the focus on English ability and work experience. Skilled Graduate visa was } \\
\text { created for International students who fail to meet the criteria for a permanent GSM visa. This visa provided a pathway to PR as it allowed } \\
\text { them to remain in Australia for } 18 \text { months to gain skilled work experience or improve their English skills; they are eligible to apply for a PR } \\
\text { visa any time during the } 18 \text { months once they meet the requirement for lodging a valid application. }\end{array}$ \\
\hline
\end{tabular}

\footnotetext{
${ }^{11}$ See www.immi.gov.au/skilled/general-skilled-migration/regional-growth.htm for list of areas considered regional or low population growth metropolitan areas.
} 
Chapter 3: The role of government policy on the decision making process of Chinese and Indian students

Although the expansion of visa categories available to international students implies greater opportunities for students who wish to immigrate to Australia, the increase of the floating pass mark in 2002 from 110 to 115 indicated the government's commitment to maintain the standards of immigrants. More visa categories were further added to encourage migrant settlement in regional defined areas or low population growth metropolitan areas. As seen in Table 3.1, the regional focus adopted by the Federal Government in 2004 created the SIR (Skilled Independent Regional) visa (subclass 495) which provided PR pathways for students who failed to meet the requirements for the Skilled Independent Overseas Student Visa (subclass 880). The new SIR visa categories however applied only to students who lived and studied in the abovementioned areas for at least two years.

The SIR visa required students to relocate to regional or low population growth cities after the completion of their studies/training. Students were only eligible to apply for PR under a range of State and regional visas after 2 years of living and 1 year of employment in the abovementioned areas (Birrell et al. 2006, pg 58). The focus on filling skill shortages in regional areas intensified as 2005 saw further changes to the points test which granted SIR visa applicants 10 additional points if they received State/Territory sponsorship. Extra points, ranging from 5 to 15 'bonus' points were also granted to eligible students in their PR application and the required minimum period of stay in Australia for applicants was further increased from 12 to 24 months. In 2005, the pass mark for the Skilled Independent Overseas Student visa (subclass 880) was again increased to 120, further tightening the requirements for $\mathrm{PR}$ as the skilled migration programme being seen to be failing to deliver its objectives (Birrell et al. 2006, pg 26-28). These changes served to underline the growing importance of 'non-work assessment items' in PR applications, particularly for those who struggled to amass the required points to be eligible for the Skilled Independent Overseas Student visa. The 'non-work assessment items' include spouse skills, regional study or bonus points in applications for PR (subclass 880) in the success of visa applications (Birrell et al. 2006, pg 35).

An 'Evaluation of the General Skilled Migration Categories' (Birrell et al. 2006) reviewed existing GSM categories in 2006 and eventuated in the implementation of some of the report's recommendations in September 2007. One recommendation suggested that all GSM visas were to have higher English language thresholds in response to studies linking 
Chapter 3: The role of government policy on the decision making process of Chinese and Indian students

poor early employment outcomes for onshore applicants to inadequate English ability (Birrell 2006; Birrell et al. 2006, pg 65-87). This resulted in the increase of the minimum requirement for English competency for GSM visa eligibility, although those with good English ability were awarded more points in their application (Appendix 3).

Other changes relevant to international students included amendments for Australian qualifications (Appendix 3) whereby applicants with Doctorate degree were awarded 25 points in their application (providing all conditions were met), an increase from the previous 15 points. Applicants with a Masters or Honours (at least upper second class level) degree were awarded 15 points, an increase from the previous 10 points. In short, the GSM visa structure was simplified with the reduction of visa subclasses from 15 to 9 , demonstrating the Federal Government's efforts in upholding the standards of GSM applicants.

The most significant change in 2007 with regards to international students was the introduction the Skilled Graduate Temporary visa (subclass 485 for onshore applicants; subclass 476 for offshore applicants). This visa is not points tested and focused on the English language ability and work experience of applicants (Table 3.2). International students who failed to meet the pass mark for the points test for a permanent or provisional GSM visa had the option of applying for this Skilled Graduate Temporary (subclass 485) visa which provided a pathway to PR.

Table 3.2: Criteria for Skilled Graduate (Temporary) visa (subclass 485)

\section{NOTE:}

This table is included on page 56 of the print copy of the thesis held in the University of Adelaide Library. 
Chapter 3: The role of government policy on the decision making process of Chinese and

This visa allowed holders the opportunity to remain in Australia for 18 months and travel, improve their English language skills and/or gain skilled work experience in the Australian labour market. Alternatively, holders could complete a professional year ${ }^{12}$, a structured professional development programme that aims to help participants become accustomed to working in an Australian workplace. Moreover, after having fulfilled relevant Australian employment requirements, holders of the 485 visa are further awarded 10 points in their application for a PR visa (DIAC n.d-a; Jackling 2007, pg 40).

This section has looked at the evolution of immigration policy, particularly with regards to international students. The focus has increased where it is pertinent that the Skilled Migration Programme meets its objectives and delivers skilled migrants to industries that have shortages. The facilitation of international students settling permanently after their studies is apparent through the various changes made to immigration policy. The latest changes (at the time of writing) however demonstrate a growing emphasis on the English language ability and skilled work experience of potential migrants. In addition, there has been increasing focus on regional defined and low growth metropolitan areas with new visa categories designed to deliver skilled migrants to these regions. The question however lies in how these changes exactly affect and impact international students coming to Australia and the extent of influence these changes have on the decision making process and migration strategies of international students.

\subsection{How the points system works for international students}

The most direct and permanent visa subclasses which international student graduates were eligible to apply for were 885,886 , and 887 , while temporary visa subclasses such as 485 and 487 also led into permanent visas, providing the required conditions were fulfilled. ${ }^{13}$ The 885 (Skilled Independent), 886 (Skilled Sponsored) and 887 (Skilled Regional) visa options were permanent visa options which allowed successful applicants to live and work as permanent residents in Australia. The basic requirements which applicants need to meet

12 See http://www.immi.gov.au/skilled/general-skilled-migration/professional-year.htm for details on the Skilled Graduate Temporary visa.

${ }^{13}$ Visa subclasses indicated are as they are at the time of writing. More information is available from http://www.immi.gov.au/skilled/general-skilled-migration/visa-options-inside.htm. It needs to be noted that the numbers assigned to current visa subclasses have been changed to what it currently is at the point of writing. 
Chapter 3: The role of government policy on the decision making process of Chinese and Indian students

are listed in Appendix 3. Additionally, as these visas are points tested, the pass mark which applicants need to accumulate is 120 , less for sponsored applicants.

The changes in 2007 to the GSM visas had a significant impact on international students who wished to obtain PR in Australia. When reforms were introduced in 1999, it was fairly straightforward for students to apply for PR as meeting the 110 pass mark was all that was required (Birrell 2001, pg 26), which in comparison to today's regulations, was quite an easy target to achieve. Applicants needed to nominate an occupation classified into 60, 50 and 40 point categories from the SOL (Skilled Occupations List) ${ }^{14}$. The most skilled occupations (worth 60 points) at that time included engineering, nursing, computing, accounting, teaching and some traditional trade. Those which were considered to be less skilled were categorised as 50 or 40 point occupations (Birrell et al. 2006, pg 17). Hence, an international student graduate would be awarded a minimum of 115 points if they had the relevant 60 point credential, was less than 30 years of age (30 points) and was awarded full points (20 points) for their English ability by virtue of their Australian training or studies. Thus surpassing the required 110 pass mark to be eligible for PR and making the additional bonus points redundant.

If a 50 point occupation was nominated instead, applicants could still meet the 110 pass mark via other means. The shortfall of 10 points in their application could be chalked up with reforms in 1999 (Table 3.1) which awarded 5 points for those with Australian qualifications. The remaining five points would then be gained through a range of bonus points available via six months of relevant work experience in Australia, spouse skills or knowledge of a community language (such as Mandarin or Hindu) at a professional level (Birrell 2001, pg 26). Prospective students desiring PR could therefore enrol in courses that would result in qualifications accrediting 60 points in their PR applications, thus "secure in the knowledge that permanent residence could be obtained once the qualification was obtained (as long as that period of training covered at least 12 months in Australia)" (Birrell 2005, pg 7).

Unsurprisingly, there was an increased participation of international students who were issued PR visas under the onshore visa subclasses as shown in Figure 3.2, which suggested

\footnotetext{
${ }^{14}$ Note that the SOL list is constantly updated by DIAC to reflect the labour market needs (see: Birrell et al 2006, pg 31-32)
} 
Chapter 3: The role of government policy on the decision making process of Chinese and Indian students

a need for the Australian government to have some form of control. In 2002-2003, 11.9\% of visas issued under the GSM programme were to international students who applied onshore. As Figure 3.2 shows, this subsequently increased to $15.6 \%$ and $17.5 \%$ in 2003 2004 and 2004-2005 respectively; linked to the policy change in 2001 when international students were permitted to remain in Australia after their studies and apply for PR. Similarly, fluctuations in 2005-2006 and 2007-2008 were also on the back of significant changes which will be discussed later.

Figure 3.2: The proportion of $P R$ visas granted on shore to international students 2002-2008

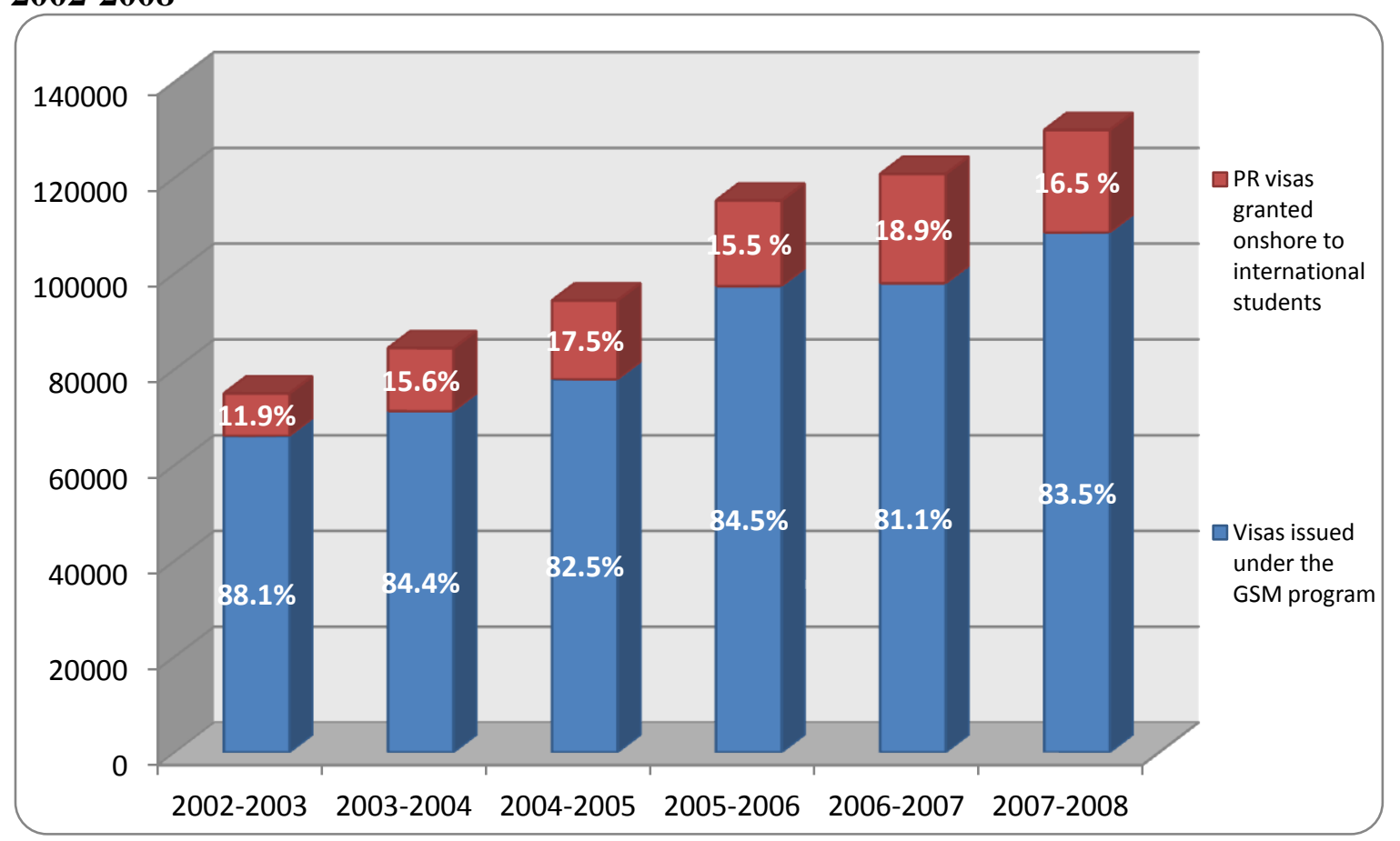

Source:Adapted from DIMIA 2004; 2005; 2006; DIMA 2007; DIAC 2008; 2009

In addition to rapid growth trends, the quality of successful applicants was a concern as the accelerated increase in number of applicants with short duration postgraduate courses (such as accounting or computing courses) exceeded DIAC's ${ }^{15}$ (Department of Immigration Citizenship) expectations. This resulted in the conclusion that these applicants did not meet the objectives set out in the skilled migration reforms as they often had only spent a year to eighteen months in Australia, not have any occupational experience in their

15 Formerly known as DIMIA (Department of Immigration \& Multicultural \& Indigenous Affairs) from 2001-2006. It was renamed DIMA (Department of Immigration and Multicultural Affairs) in 2006 and DIAC in 2007. For consistency, this thesis will use DIAC in discussion. 
Chapter 3: The role of government policy on the decision making process of Chinese and Indian students

field, and had a poor command of colloquial English amongst other reasons (Birrell 2005, pg 11). Hence in 2002, DIAC increased the pass mark to 115 to address the abovementioned concerns. While applicants with 60 point occupations were hardly affected, those with 50 point occupations now had dim prospects of gaining PR (Birrell 2005, pg 1011; Birrell \& Rapson 2005, pg 9-10).

It was progressively harder to become a PR with the increasingly stringent requirements placed in the application process. For example, the minimum period of training/study of applicants was increased from one to two years in 2003 while the pass mark for the Skilled Independent Overseas Student visa (subclass 885) further increased to 120 in 2004. A decrease of 2 percent in the proportion of PR visas granted offshore in 2005-2006 from the previous year can be attributed to the increase in the pass mark in 2004. These changes essentially meant that a 'typical applicant ${ }^{16}$ with a 60 point occupation was no longer 'assured' of PR due to a shortfall of 5 points (Birrell 2005, pg 11; Birrell \& Rapson 2005, pg 10). Although this shortfall could be accrued up through various work or non work assessment items, one of the more significant and popular avenues often utilised was MODL (Migrant Occupation in Demand List) points.

Applicants were given priority if they nominated an occupation which was on the current MODL. Applicants with a nominated MODL occupation without a job offer were awarded 15 points while those with a job offer from a suitable Australian employer were awarded 20 points (Birrell et al. 2006, pg 14). Hence, MODL points were deemed to be a "crucial determinant of which occupations were likely to be selected" (Birrell et al. 2006, pg 24) as the increase in the pass mark to 120 has subsequently "constituted a huge inducement to overseas students to enrol in courses which will give them a qualification in a field which is on the MODL" (Birrell et al. 2006, pg 33). The use of the MODL in this manner hints at an element of strategy necessary if a student intends to apply for PR.

However, significant changes in 2007 reiterated the Australian government's commitment towards the quality of skilled migrants. Although the pass mark for applicants remained the same, there was an increased emphasis on the English language ability and work experience of international student graduates (Table 3.1). A 'typical' applicant would find

\footnotetext{
16 A typical applicant would have a 60 point occupation (60 points), under 30 years of age (30 points), English Language Ability (20 points) and Australian training (5 points), which adds up to 115 points.
} 
Chapter 3: The role of government policy on the decision making process of Chinese and Indian students

it considerably harder to meet the 120 point pass mark under the modifications made in 2007. Moreover, in addition to the abovementioned changes, the decision to remove access to MODL points for applicants without work experience in their nominated occupations was another hurdle (Table $3.1 \&$ Appendix 3). It is hard to determine the impact of the 2007 changes due to its recent nature of its implementation, however, as illustrated in Figure 3.2, a decrease of 2.4 percent in the proportion of international students granted an onshore PR visa in 2007-2008 from the previous year again reflects the influence of policy changes on PR outcomes for international students.

These increasingly stringent measures are directed at improving the credentials of successful applicants to ensure that the reforms meet the objectives set out by the Skilled Migration Programme. The implications of these changes however added to the increasing complexity of the application process to become a $\mathrm{PR}$, requiring students to be quite strategic. Robertson (2009, pg 107) underlines this by explaining how international students are "experts in DIAC's bureaucratic procedures and rhetoric" as they constantly update themselves, especially with changes to the points test and the MODL, illustrating how "their plans are so closely intertwined with the decision of the regulatory body". The proceeding sections will examine some of the different strategies students have been known to adopt when negotiating the various avenues used to enhance their chances of becoming PRs. The link between policy and the decision making of international students with PR intentions and how it is incorporated into their educational strategies will be illuminated.

\subsection{Examining the link between immigration policy and course selection of international students}

There is a very strong suggestion of international students using international education as a pathway towards permanent residency in Australia ever since reforms were made to the skilled selection process in the Skilled Migration Programme. The dot.com boom of the late 1990's demanded an increase in the number of highly skilled IT workers which Australian firms did not have access to, which was seen to be detrimental to Australia's competitiveness in the global economy. With many international students completing IT degrees in Australia, they seemed to be an obvious source of skills to tap into (Birrell 2005, $\operatorname{pg} 6)$. 
Chapter 3: The role of government policy on the decision making process of Chinese and Indian students

International students promptly responded to mid-1999 reforms in the skilled migration selection system with evidence of strong demand as presented by Birrell (2001). As mentioned, applicants were given priority and additional points if they nominated a MODL occupation. In 2000-2001, 53.6 percent of applicants did so under the Skilled-Independent visa category with Accountants and Computing Professionals constituting 89.5 percent of the total who selected MODL occupations (Birrell 2001, pg 23). Additionally, just over half of successful applicants in the Skilled Independent category who nominated accounting and computing (52.8 and 51.1 percent respectively) in the first seven months of 2000-2001 were international student graduates (Birrell 2001, pg 24). These fields are in demand due to their 'global transferability' (Marginson 2002) and the concentration of applicants in these two occupations, particularly for international student graduates, implies a strong correlation between course selection, the MODL list and PR intentions. This connection has been noted by a few studies (Birrell 2005; Birrell et al. 2006; Birrell \& Rapson 2005; Jackling 2007; Robertson 2009) and Figure 3.3 substantiates this link by showing the distribution of international students enrolled across the different fields of education.

Figure 3.3: Top 5 fields of education for international students 2001-2007

\section{NOTE:}

This figure is included on page 62 of the print copy of the thesis held in the University of Adelaide Library. 
Chapter 3: The role of government policy on the decision making process of Chinese and Indian students

The top 5 fields of education for international students in Australia from 2001-2007 have consistently been Management and Commerce; IT; Society and Culture; Engineering and Related Technologies and Health. There was an uneven concentration in Management and Commerce, and IT. It is clear from the chart that the former was the most popular followed by the latter. In 2001, approximately 53.6 and 20.6 percent of international students enrolled in these courses respectively. The popularity of these two fields of education continued in 2007 with 62.7 and 11 percent of international students enrolling Management and Commerce and IT courses respectively.

A causal relationship between the increase or decrease in enrolments in these courses and changes in immigration policy is noted. When accounting was removed from the MODL in September 2002, the enrolments in Management and Commerce had negative rates of increase and started slowing down in 2004. Accounting was eventually reinstated to the MODL in September 2004 (Birrell et al. 2006, pg 25) which directly correlated to the increase in enrolment figures in 2007. This relationship was also validated by Jackling's (2007, pg 35-36) study as the prospect of PR was an important factor for 70.6 percent of international students who decided to major in Accounting. The presence or lack thereof of IT on the MODL presents a stronger link between strategically selecting a course and PR eligibility.

Since late 2003 (Birrell et al. 2006, pg 25), IT was removed from the MODL and this coincided with a decline in enrolments in 2004. Subsequent years witnessed this trend continue as enrolments in IT declined with its market share decreasing from 20.6 percent to 11 percent, an indication that growth in accounting enrolments has been at the expense of IT enrolments. These findings concur with several other studies (Birrell 2006; Birrell \& Rapson 2005; Jackling 2007), which strongly suggests how changes in regulations impacting the PR outcomes of students is reflected in enrolment figures. As Birrell and Rapson (2005, pg 10) argue, the

listing of accounting on the MODL guarantees a permanent residence outcome if desired. By contrast, the outlook for those enrolling in computing courses is not as attractive as it was a few years ago.

The decreasing 'attractiveness' of computing courses can be attributed to the lower probability of gaining PR due to the increase in the pass mark for the Skilled Independent 
Chapter 3: The role of government policy on the decision making process of Chinese and Indian students

Overseas Visa to 120 (Table 3.2), and the removal of IT from the MODL. While some IT skill specialities remained on the MODL, unlike those with an accounting qualification, applicants were required to have a year's work experience before the Australian Computer Society would endorse an applicant for MODL points (Birrell 2006, pg 56). In summary, if PR is the primary objective for an international student, enrolling in IT courses would present itself to be an indirect and less secure route (in terms of guaranteeing PR).

In addition to selecting courses on the MODL list, there is further indication that the route to PR could be sped up. Students with an undergraduate degree from their home countries could enrol in postgraduate diploma or Masters courses that ranged from a year to eighteen months. Figures 3.3 and 3.4 substantiate this view as they reveal the popularity of these courses among international students. Among all the broad fields of education as classified by DEST (Department Education, Science \& Training) Masters by coursework in IT and Management and Commerce consistently have the highest enrolments at postgraduate levels. These statistics lend further weight to the suggestion that these courses were popular because they provided the quickest route towards PR for international students.

Figure 3.4: International enrolment in Masters by coursework in IT and Management \& Commerce 2001-2007

NOTE:

This figure is included on page 64 of the print copy of the thesis held in the University of Adelaide Library.

Source: Adapted from Students: Selected Higher Education Statistics DEST 2002-2008 (this includes international students on offshore campuses) 
Chapter 3: The role of government policy on the decision making process of Chinese and Indian students

These shorter courses fulfilled the professional standards set out by the relevant accrediting agencies to qualify for professional level entry to accounting and IT. The agencies "only require three semesters specialised work in accounting or ICT (Information and Communications Technology), whether at the undergraduate or Masters by coursework level, for the course to be regarded as meeting the requirements for professional level entry to accounting and ICT"' (Birrell et al. 2006, pg 26).

Moreover, international students enrolled in Masters by coursework in IT or accounting need not have prior undergraduate training in their respective fields. Thus, all international students needed to do was complete the necessary three semesters in their field in these short term postgraduate courses as it would technically gain them the required professional accreditation for immigration purposes ( Birrell et al. 2006, pg 26). It would therefore make sense for international students (motivated by PR) to enrol in these courses as they were relatively cheaper in terms of living expenses and tuition fees due to their shorter duration. As Birrell (2005, pg 8) states:

If the option of permanent residence has contributed to overseas-student enrolment levels, it would be expected that prospective students motivated by this outcome would enrol in a course which provided accreditation in a 60 point occupation. Because education in Australia is expensive, as are the costs of making the application, flying to Australia and living expenses while here, it is to be expected that such students would choose courses offered the required accreditation in as short a period as possible. Of all the 60 point occupations, two stood out as preferable on these grounds. They were IT and accounting.

\subsection{Examining the spatial aspect presented by regional universities}

The discussion so far has focused on how international students can be strategic through course selection, however, the interplay between the changes in DIAC (Department of Immigration \& Citizenship) regulations and how universities respond to them further reveal the complexities of international student mobility in Australia. As mentioned, efforts to improve the quality and credentials of international students migrating permanently have influenced the changes made in immigration policy. One of them has been the extension of the required minimum period of stay in Australia from one to two years, which Australian universities have seemingly responded to by extending the duration of some of their 
Chapter 3: The role of government policy on the decision making process of Chinese and Indian students

courses to two years in order to "cater to the needs of overseas students anxious to gain permanent residence" (Birrell et al. 2006, pg 26).

It has been ascertained that regional universities such as Central Queensland University and the University of Ballarat have remained competitive by establishing metropolitan campuses and designing courses with a specific focus on accounting and ICT courses, mainly at the Masters by coursework level. Most other regional universities have followed suit by making similar modifications to their courses to meet DIAC requirements. Outcomes have revealed they have been successful in capturing a significant proportion of international students with their lower cost fee structure being cited as the main attractive factor (Birrell 2005, pg 30; Birrell et al. 2006, pg 25-26).

Hence, the calculated selection of a study locale has a significant role in the decision making process of international students seeking PR. The increase of the pass mark to 120 in 2005 accentuated the spatial element of decision making. Even those who nominated 60 point occupations in their applications for PR were no longer guaranteed of being granted PR and could find themselves short of points. However, in 2003, the allocation of 5 points for applicants who have physically spent time studying at a regional defined university and the creation of the SIR (Provisional) visa gave rise to the spatial element in the decision making process of students with PR intentions. These regional advantages had the sole objective of encouraging migrant settlement in regional defined or low population growth metropolitan areas, an advantage for students who lived and studied in a regional area or low population growth city. Such initiatives were supported by governments like the South Australian government, as migration was seen as a way to counter regional issues such as demographic decline and depopulation linked with a declining economy (Government of South Australia 2004).

In addition, the introduction of the SIR visa which had a lower pass mark of 110 points, allowed international students who failed to amass the required 120 points for the Skilled Independent Overseas Student Visa (subclass 885) the option of applying for the SIR visa. Applicants were eligible to apply for PR upon fulfilling SIR visa requirements (Birrell et al. 2006, pg 58). ${ }^{17}$ The SIR visa clearly brings into play the use of specific regional areas

\footnotetext{
${ }^{17}$ The SIR visa is a two stage visa, the first stage requires the holder to relocate to a regional defined area and upon residing for at least 2 years and working full-time for at least a year, the applicant will then be eligible
} 
Chapter 3: The role of government policy on the decision making process of Chinese and Indian students

and low population growth cities to enhance one's eligibility for PR, although this might be at the expense of metropolitan universities (Birrell 2005, pg 32).

'Non-work assessment items' are especially significant after the increase in the pass mark as international students who fall short may rely on these points to supplement their applications for PR. As Table 3.3 shows, a significant 45 percent of students who applied for the 880 visa in 2004-05 utilised the extra 5 regional campus points in their applications, evidence of the popularity of regional advantages. If one assumes that PR is the main objective of international students, the conscious selection of universities situated in these specific locations by international students who are cognisant of the requirements for PR is indicative that their migration strategy is one which is complex and well thought out.

Table 3.3: International student applicants with $120+$ points who gained points on 'non work items' for the 880 subclass visa in 2004-05 $(n=500)$

\section{NOTE:}

This table is included on page 67 of the print copy of the thesis held in the University of Adelaide Library.

Source: Birrell et al. 2006, pg 35

At this point, it is fair to state that policy is a major factor in the decision making process of international students as the availability of using education as a vehicle towards permanent immigration is an attractive motivating factor. As discussed in some studies (Birrell et al. 2006; Birrell \& Rapson 2005), the strategic manoeuvring through various changes in immigration policy is illustrated by the deliberate selection of a regional over a non-regional study destination, boosting one's eligibility for PR; a hint that the former could be a secondary study destination for international students. If this is the case, it would mean that regional locations have taken on a transitory nature, functioning as a gateway to the preferred or central destination which draws out the spatial element in the student's migration strategies.

to apply for a PR visa through a range of existing permanent State and regionally specific visas (Birrell et al. 2006, pg 58-59) 
Chapter 3: The role of government policy on the decision making process of Chinese and Indian students

\subsection{Conclusion}

This chapter has looked at the evolution of immigration policy in Australia and its influence on the decision making process of international students. It is clear that these macro structures in the form of policy have a pivotal role when shaping the transnational migration strategies of international students. As previously discussed (Sections 2.5.2 \& 2.5.3), the relative ease in obtaining an Australia student visa and opportunities for PR encourages the selection of Australia as a study destination.

The transnational migration strategies of students are also shaped by immigration regulations that motivate them to enrol in courses which enable them to nominate a job on the MODL, particularly in IT and Accounting. Courses at the level of Masters by coursework have also proved to be highly popular as they are relatively cheaper, shorter in duration and quicker in terms of immigration. While the changes in 2007 made it considerably harder for international students to obtain PR, with the emphasis placed on their English language ability and work experience, it is too early (at the time of writing) to ascertain how international students would strategically manoeuvre through these hurdles. Nevertheless, this chapter has demonstrated the influence of policy on the decision making process of international students through the strategic selection of courses for PR purposes.

In addition, the objective of filling skill shortages in regional defined or low population growth metropolitan cities have presented some locations as attractive destinations for immigration purposes. The regional advantages set out by policy which increases one's chances of obtaining PR, introduces the spatial element of the international student's migration strategy which is not dissimilar from other forms of movement presented by other migrant groups which will be discussed in the next chapter. It is clear that the deliberate decision to study in areas with regional advantages for PR is shaped by immigration policy. When framing the student's transnational migration strategy, the emergence of the spatial element highlights the need to conceptualise how locations or regional study destinations are configured in the entire scheme of their mobility. Therefore, the next chapter will focus on theorising the migration of international students and the spatial element in their mobility will be considered as it will aid in constructing a framework towards understanding the migration strategies of Chinese and Indian students. 


\section{CHAPTER 4: International Students in the context of Migration Theory}

\subsection{Introduction}

This chapter reviews migration theory to establish its relevance to international student migration. Although a plethora of theories have been developed since Ravenstein's 'Laws of Migration' (Ravenstein 1885), none of the efforts in erecting a general theory of migration have been successful as no single theory is accepted by social scientists to explain all types of migration (Arango 2004, pg 15; Massey et al., pg 17; Stevens et al. 2006).

Arango (2004, pg 32-33) argues that existing theories are often inflexible and inapplicable as they tend to explain only particular aspects or facets of migration in certain contexts, while failing to do the same for other forms of movement. The increasing diversity "in terms of forms, types, process, actors, motivations, socioeconomic and cultural contexts, and so on" increases the complexity of contemporary migration research, highlighting the flaws in theories that attempt to be generally applicable. While researchers (Massey et al. 1998, pg 17) acknowledge there is no single universal migration theory, a comprehensive understanding of the complex nature of migration can be achieved by adopting a multidimensional approach which "incorporates a variety of perspectives, levels and assumptions" and considers the merits of each individual concept placing greater emphasis on key assumptions and hypotheses. Hence, this chapter will apply a range of migration theories to help explain international student mobility.

It is important to note that the objective of this chapter is neither to critique existing migration theory nor to formulate a new one. The aim is to give an overview by describing the applicability of a range of traditional and contemporary migration theories to international student mobility. This chapter will also explore international student mobility from a transnational perspective. This approach will shed light on the factors that influence student migration and enhance understanding on their transnational migration strategies.

\subsection{Defining international student mobility}

Although a familiar concept, migration remains difficult to define (Boyle et al. 1998, pg 34; Skeldon 1997, pg 1). It is generally understood as the movement of a person from one 
place to another for a certain period of time, however, when examining student mobility, the question is how far and for how long. Migration before the 1980s was considered as an "age of simplicity: patterns were dominated by stereotypical and easily understood migrations" (Boyle et al. 1998, pg 33). An evaluation of international migration theories is however more complex with nineteenth-century concepts focused on the permanent aspect of migration (Massey et al. 1993, pg 432). This focus is similar in Australia as Hugo (1999) argues that the majority of the study towards international migration is anchored in the paradigm of permanent settlement. While some researchers have commented on the shift in the research paradigm towards temporary forms of migration (Hugo 1999; Hugo 2004; King 2002), the extent of how temporary or permanent a migrant is, still pertains, and is the crux of the matter in this study.

The definition of migration is associated with the displacement of a person from one geographic location to another (Demuth 2000, pg 26), carrying a sense of permanence as it involves a "permanent change of residence" (Kosinski \& Mansell Prothero 1975, pg 1) or a "relatively permanent movement...over a significant distance" (Peterson 1968, pg 285). Although this continues to influence international migration research (Kritz 1987, pg 951), there are other migrations that do not result in a permanent dislocation. Temporary mobility is the complement to permanent settlement which Zelinksy (1971) defines as movement with no intention of a permanent change of residence. These moves could be within or across national borders and their frequency could be sporadic, regular or highly variable, ranging from an overnight stop at a single destination to months or years at myriad destinations (Brown \& Martin 2005, pg 2). Despite its complex and diverse nature, "the unifying feature is the absence of any intention to make a lasting change in usual residence" (Brown \& Martin 2005, pg 2), therefore, the term should be used in its widest sense so as to include all the different forms of circulation .

The UN (United Nations) (1998, pg 22) defines international students as "Persons admitted by a country other than their own, usually under special permits or visas, for the specific purpose of following a particular course of study in an accredited institution of the receiving country". At a glance, international student mobility fits into the definition of temporary migration. However, attempts to benefit from the international movement of labour through temporary migration have been proven to be a tricky task as temporary migrant workers used by postwar European countries (Castles \& Miller 2003, pg 69-93; 
Hollifield 2007, pg 62-64; Hugo 2003) have continuously revealed a "permanent presence... of supposedly temporary foreign workers" (Amin \& Mattoo 2005, pg 1).

International students have shown similar tendencies by remaining in their host countries after completing their studies. Johnson and Regets' (1998) research found nearly two thirds of foreign doctoral students in science and engineering remaining in the US after their studies. The sizeable amount of research reinforcing this trend (Alberts \& Hazen 2005; 2006; Baker \& Finn 2003; Finn 2003; Li et al. 1996; Pang \& Appleton 2004; Tremblay 2002; 2004; 2005) emphasises the need for more attention on this particular group of migrants.

Although the temporary nature of student movements is associated with immediate returns to families or home countries after their studies ( $\mathrm{Li}$ et al. 1996, pg 52), there is an increasing transition in the permanency of student migration (Andressen 1993, pg 162; Hawthorne 2005, pg 15-16; Sin 2006, pg 244-246, 256-258; Tan 2003, pg 72-75; Tremblay 2005). Moreover, even though international students are generally categorised as temporary migrants, some commentators have called for them to be classified as highly skilled migrants (Li et al. 1996; Tremblay 2005, pg 204). This is because their time spent studying abroad is regarded as 'brain training' (Balaz \& Williams 2004, pg 218 ), a form of investment or the accumulation of human capital (Balaz et al. 2004b, pg 32 ) which makes them a potential source of skilled labour (Balaz \& Williams 2005, pg 441, 443; Bardak 2005, pg 4 ).

The realities of highly skilled migration is reflected by the term 'brain circulation' (Alberts \& Hazen 2005, pg 133), echoed by migrants educated abroad tending to reside and work outside of their home countries (Findlay 1994; King \& Ruiz-Gelices 2003). This term suggests that there is more to international student mobility than just temporary or permanent settlement, hinting at the complex nature of international student mobility. The nexus between international education and permanent settlement is expanded as questions arise on whether their intentions simply involve obtaining an overseas qualification and returning back to their home countries, or whether it involves migrating to other destinations. While the intricacies of such movement will be discussed later, it is important to note that the shift in the paradigm regarding the permanence of international student mobility leads to transnationalism. 
There is no universally accepted definition of transnationalism however, it will be defined here as the process "by which immigrants forge and sustain multi-stranded social relationships that link together their societies of origin and settlement" (Basch et al. 1994, pg 7). The emergence of 'transnationalism' and 'transnational' communities linking migrants between two societies (Castles \& Miller 2003, pg 29) has led researchers (Levitt 2004) to refer to these migrants as transmigrants. International students fit into this transnational mould due to the connections linking them with their home countries.

The OECD (2001,pg 3 ) states that "a panorama of qualified labour flows cannot ignore international student mobility", further strengthening the call for international students to be "seen as part of the dense and interconnected flows of skilled migrants among more developed economies" (Balaz \& Williams 2004, pg 235 ). It is therefore important to theorise the mobility of international students. The temporary and permanent nature of their mobility will be discussed by investigating the emergence of transnationalism and its suitability as a concept. The following section will review migration literature in the context of international student mobility, with particular reference to the movement of Chinese and Indian students to Australia.

\subsection{Migration theories and international student mobility}

Although approaches to migration "espoused in the literature have changed, with some methods falling out of favour as new techniques and theories have been introduced" (Skeldon 1997, pg 17), it is nevertheless important to examine varying theories and identify the different ways they contribute to conceptualising international student mobility. As Boyle et al. (1998, pg 1) note, the migration events and the experiences of individuals cannot be pigeon holed due to the invariable overlap of the underlying theories.

Rather migration is firmly embedded within the complexity of people's everyday lives and experiences. Indeed, migration decisions are often influenced by factors that are much less obvious than might appear at first sight (Boyle et al. 1998, pg 1).

The theories examined from this perspective can be separated into two categories, the first proposing the initiation of international migration and the second explaining the perpetuation of such movements (Massey et al. 1998). The theories discussed will also be linked to factors influencing the decision making process of students as earlier discussed (Chapter 2). The influence of contemporary theories such as transnationalism will be 
addressed in Section 4.4. Such an eclectic approach which encapsulates older and newer theories will shed light on the gaps in the migration literature with regards to international student mobility. This will assist in constructing a model depicting the flows and mobility of international students and explain the drivers influencing these migratory movements.

\subsubsection{Economic migration theories}

Neoclassical economic theory, which stems from the earliest work produced by nineteenth century geographer Ravenstein (1885), looks at movement being driven by basic supply/push and demand/pull factors. Wage differentials, employment conditions and economic opportunities between countries are some of the factors that contribute towards the individual's decision to move in order to maximise their income (Castles \& Miller 2003, pg 22-24; Massey et al. 1998, pg 17).

This theory has been thoroughly critiqued (Arango 2004, pg 16-19; Boyd 1989, pg 640; Portes \& Borocz 1989; Portes \& Rumbaut 1996, pg 271-272; Skeldon 1997, pg 19-22). Greenwood (1975), for example, considered wage differentials to be an unsuitable determining factor in his review of migration. This theory applies to international students in the context of migration and return decision. International education is a process which invests in an education to acquire human capital (Balaz et al. 2004b, pg 32), and upon graduation, international student graduates are considered as highly skilled migrants (Koser \& Salt 1997, pg 287). As discussed, the pull factor of reputation and quality of education in a potential host country (Chapter 2) is based on the premise of maximising anticipated lifetime earnings when deciding on a study destination. While the concept of human capital and seeking to maximise potential future earnings are important motivational factors, other concepts and theories should be considered as research has shown that the factors behind the student's decision to migrate are multidimensional (Andressen 1991; Tan 2003).

New economics of labour migration is cast in the mould of neo-classical theory with a few tweaks and alterations (Arango 2004, pg 22). While the notion of rational choice still holds true, the decision to migrate is accorded to the family or group, as opposed to the individual. Migration is seen as a household decision made not to primarily maximise income, but to lower risks to family income, to secure employment and the need for risk management over long periods (Massey et al. 1998, pg 17-18; Stark \& Bloom 1985). Risks are controlled by diversifying resources through the allocation of family members working 
in "different geographically discrete labour markets" (Massey et al. 1998, pg 21-22). The factor of wage differentials as a major motivating factor is downplayed as they are not always necessary for migration nor do they always result in migration (Arango 2004, pg 23; Massey et al. 1998, pg 27).

Studying abroad is a risk diversification strategy part of family based migration decisions which is linked to the parents of the students, who are in some cases the main decision makers in going abroad to study (Andressen 1991, pg 263-264; Tan 2003, pg 53-55). Research has highlighted the important role of family in migration decisions in Asia (Hugo 1994). For example, contemporary Chinese diaspora regards education as "a familial (not individual) pursuit and should be understood as part of a wider strategy of household capital accumulation" (Waters 2005, pg 370). The influence of families on Chinese and Indian students and the extent of their role in the decision making process before coming to Australia should therefore be explored.

Another economic theory that has been put forward is dual market theory. Immigration and the structural requirements of modern industrial economies are linked as modern economies generate the demand for immigrant labour (Massey et al. 1993, pg 440-441). This approach is focused on the macro determinants on the receiving end of migration, or the destination as opposed to the micro level determinants at the sending end of neoclassical models. Piore (1979) explains that migrant demand for foreign labour stems from particular intrinsic traits present in the economic structure of developed or advanced industrial societies, namely, ethnic enclaves, structural inflation, economic dualism and hierarchical constraints (Massey et al. 2005, pg 28-34).

Ethnic enclaves are formed when an initial wave of immigrants with sufficient capital (in various forms) settle disproportionately in an urban area. Upon establishment they look towards migrants from their country as a source of low-wage immigrant labour (Massey et al. 2005, pg 31). The aspect of networks and linkages inherent in this concept is a factor for international students as they are highly valued in their decision making process (Section 2.5.4). This connection will be elaborated later (Section 4.3.2.2) to show the importance of social and information networks when explaining international student mobility. 
The remaining traits (structural inflation, economic dualism and hierarchical constraints) basically explains the use of migrants to fill the shortages in low paying, unstable, unskilled labour. Jobs which as locals shun as they are considered to be at the bottom of the hierarchy with no status or prestige attached (Arango 2004, pg 24-25; Massey et al. 2005, pg 29-31). At a glance, it appears these characteristics do not fit international students as they are considered highly skilled migrants (Koser \& Salt 1997), however, as discussed (Section 2.5.8.1), the availability of part time work (often in unskilled labour) is a major drawcard in attracting students. Therefore, employers view international students as a potential and at times even exploitable (Marginson et al. 2010, pg 114-144) source of labour. As Massey et al. (2005, pg 29-30) argue:

immigrants satisfy this need, at least at the beginning of their migratory careers...seeking to earn money for a specific goal that will improve their status or well-being at homebuilding a house, paying for school

The difference in living standards between developing and developed countries would also make low wages seem munificent back in their home communities (Massey et al. 2005, pg 30), particularly for those who have taken out substantial loans to pay for their education abroad. The availability of entry level jobs as a determinant in the overall decision making process of Chinese and Indian students when selecting a study destination will be examined.

Historical structuralist theory ( Portes \& Walton 1981; Sassen 1988) which emerged in the 1970s, postulates the "unequal distribution of economic and political power in the world economy" (Castles \& Miller 2009, pg 26-27). Migration was one of its many manifestations (Massey et al. 1998, pg 36) as cheap labour was mobilised from developing countries for capital in developed countries. This evolved to what became known as dependency theory (Amin 1974; Frank 1969) which subsequently led to the emergence of World systems theory. Acccording to Wallerstein $(1974 ; 1980 ; 1989)$, this theory consisted of three spheres, core, semi-periphery and peripheral countries. Both these theories essentially stand on the same ground as they view migration as a result of core countries interacting with peripheral ones, to the advantage of the former.

'Brain drain' refers to the migration of the talented and educated from peripheral to core countries. It exemplifies the perpetuation of the underdevelopment process, manifesting in 
the former for the benefit the latter (Massey et al. 2005, pg 36). Parallels can be drawn with contemporary flows of international students preferring to study in developed countries. As discussed earlier (Section 1.2), the majority of international students study in OECD countries, 'monopolised' by the US, the UK, Germany, France and Australia. Preferences for an education in English in a Western country (Section 2.5.1) and established links such as colonization, political influence, trade, investment or cultural ties between two countries (Section 2.5.2) are pertinent factors in the migration of international students. The subsequent non return of international students has also been well documented and is often a concern for sending governments (Cao 2005; 2008; Crush et al. 2005; Desai et al. 2001; Johnson \& Regets 1998; Khadria 2002; Lin 1994; Mattes \& Mniki 2005), highlighting the relevance of this theory to contemporary international student mobility.

World systems theory has the similar view that immigration is due to economic globalisation and capitalist market penetration, resulting in the creation of a workforce that is mobile enough to migrate for better job prospects (Massey et al. 1998, pg 34-35). Student migration from this standpoint therefore seems not only to be demand driven but also a response to the forces of supply as Western universities in the modern day context turn to aggressive recruitment campaigns to increase foreign student figures, largely due to decreasing government funding (Li et al. 1996, pg 55 ). Such campaigns are also important sources of information (Section 2.5.3) as they can influence the selection of study destinations.

Although historical-structural and neo-classical theories are older approaches, they continue to contribute towards understanding the drivers and factors that influence the international student's decision making process (mainly economic in nature). However, they are "too one-sided to analyse adequately the great complexity of contemporary migrations" (Castles \& Miller 2003, pg 26). While brain drain is a well documented and researched phenomenon (Carrington \& Detragiache 1999; Chang \& Deng 1992; Crush et al. 2005; Das 1972; Guha 1977; Lowell 2003; Morguerou 2006; Sriskandarajah 2005), the movement of international students has evolved and so has migration theory. Hence contemporary migration theories will be examined in the next section to develop a comprehensive understanding of international student mobility. 


\subsubsection{Migration systems theory}

Migration systems theory is a contemporary approach that has been put forward in the attempt to include an array of disciplines and to cover all aspects of migration. Mabogunje's (1970) seminal work on migration systems was subsequently expanded by Kritz et al. (1992) who attributed migration to linkages connecting sending and receiving countries through the interaction of "colonization, political influence, trade investment or cultural ties" (Castles 2000 ,pg 24) which are present in macro and micro structures.

Macro structures in general consist of 'top down' large scale institutional factors while micro-structures are more 'bottom up' in nature as the individual's networks, practices and beliefs are examined (Castles \& Miller 2009, pg 28-29). Although migration normally revolves around both structures, there is an intermediary level or mechanism called the meso-level which has emerged in theory in recent years (Castles \& Miller 2009, pg 29-30; Faist 1997, pg 187). The drivers behind international student mobility will be examined in the context of macro, micro and meso structures to determine the extent of their influence.

\subsubsection{Macro-level structures}

Macro structures consist of the political economy of the global market, where links between States and the various laws and agreements are implemented to control migration and settlement (Castles 2000 ,pg 24; Salaff \& Greve 2003, pg 6). Parts of international student migration are influenced by macro structures as the integration of world trade has encouraged student mobility. The need for countries to keep pace with technological developments has also sped up internationalisation of education (Tremblay 2002, pg 39). There has also been a considerable increase in the significance of how international relations and States organise and ease the movements between sending and receiving countries (Castles \& Miller 2003, pg 27). As discussed (Section 2.5.8), host country policies pertaining to work rights, obtaining a student visa and PR are examples of important macro structures that influence the migration decisions of international students. Conversely, government led economic reforms combined with the failure to provide sufficient higher education places (Chapter 2) have pushed students to study abroad. Thus, macro-structures in relation to international education and immigration such as educational and governmental institutions will be closely examined to determine their role in both sending and receiving countries when it comes to international student mobility. 


\subsubsection{Micro-level structures}

Micro structures are informal social networks established by migrants to help the migration and settling in process (Castles 2000,pg 24). The concept of networks was introduced by sociologists (Thomas \& Znaniecki 1918-1920) in the 1920's. Migration networks are defined as "sets of interpersonal ties that connect migrants, former migrants, and nonmigrants in origin and destination areas through ties of kinship, friendship, and shared community origin" (Massey et al. 1998, pg 42). Such networks are important to international students in their decision making process (Andressen 1991, pg 61-62). These links are sometimes referred to or regarded as 'social capital' (Bourdieu 1986; Bourdieu \& Wacquant 1992). As Bourdieu (1986) states:

Social capital is an attribute of an individual in a social context. One can acquire social capital through purposeful actions and can transform social capital into conventional economic gains. The ability to do so, however, depends on the nature of social obligations, connections, and networks available to you.

Lin (1999, pg 31) concurs with Bourdieu's view by suggesting that the flow of information within networks, the social connections influencing agents and the reinforcement of identity and recognition are the basic reasons as to why "embedded resources in social networks will enhance the outcomes of actions". However, social capital and networks are only a facet of migration systems theory as they represent an intermediate, relational level that stands between micro and macro level determinants in the migration process, sometimes categorised as the meso-level (Faist 1997; Salaff \& Greve 2003, pg 9-14). But, in order to maintain a consistent train of thought, social capital and networks in this study will be classified under the micro-level category.

Drawing from Portes and Massey, Faist (1997, pg 188) looks at two schools of thought when conceptualising social capital, the first one examines the incorporation of immigrants into receiving societies while the second looks at migrant networks. Social ties are defined by Faist (1997, pg 199) as a series of interpersonal relationships with the strength and weaknesses of these ties dependent on their direct or indirect nature. Similarly, social capital is the "capacity of individuals to command scarce resources by virtue of their memberships in networks or broader social structures" (Portes 1995, pg 12). The resources available do not define social capital, rather, it is the ability to utilise these resources by 
investing in social relations within networks and the norms of reciprocity associated with it (Lin 1999, pg 30; Putnam \& Goss 2002, pg 3). ${ }^{18}$

Therefore, it is essential to examine two aspects of social capital in migration networks and their relation to international students. Firstly, what is the nature of such obligations, networks and connections available to students? And secondly, how are these available channels utilised to achieve their objectives? As discussed (Section 2.5.4), networks used by students consist of friends or contacts who have studied or are currently studying in potential locations are highly valued sources of information. Massey et al. (1993, pg 460) argue that "the greater the barriers to movement, the more important should network ties become in promoting migration" as they decrease the costs and risks of such movements (Massey et al. 1998, pg 42). The applicability of social capital will be approached in the context of migration in order to understand how it operates in the realm of international student mobility.

\subsubsection{Meso-level structures}

Meso structures are increasingly important with the emergence of a migration industry functioning as intermediaries between migrants and economic or political institutions (Castles \& Miller 2003, pg 28). Facilitating migration is a profitable industry with a plethora of informal and commercial recruiters made up of individuals, companies, organisations and agents. These recruiters develop into transnational entrepreneurs over time, as they become familiar to migrants and become stable establishments (Balaz et al. 2004a, pg 20-21; Faist 1997, pg 206; Massey et al. 1998, pg 44 ). There is a lack of attention on meso structures in international student migration as the majority of research is concentrated on internal and international labour migration (Goss \& Lindquist 1995).

Meso structures are a crucial aspect for international students as they engage with 'middleman' agencies who link them with foreign universities (Smart \& Ang 1992, pg 29). These agencies recruit on behalf of overseas educational institutions who pay them a commission

\footnotetext{
18 Although social capital is a concept which has in recent times gained popularity in the different aspects of social sciences (Adler \& Kwon 2002, pg 17), it can however be quite ambiguous as it does not seem to have a clear and universal definition (Dolfsma \& Dannreuther 2003; Foley \& Edwards 1999, pg 142; Robison et al. 2002, pg 1-2). Nevertheless, it has become a salient concept and the focus of researchers in recent years has not only resulted in an exponential growth in the work produced but also led to a wide array of disciplines which have found social capital to be useful (Putnam \& Goss 2002, pg 5).
} 
upon successful recruitment of a student (Biao 2003, pg 31). Agents can represent a number of countries and institutions or specialise in a particular country or institution. Their services which are crucial ingredients in the recruitment of students (Mazzarol et al. 2001c, pg 52) include, providing information to students, assisting them in the application and necessary procedures, arranging travel and accommodation to the study destination and pre-departure briefings among others (Smart \& Ang 1992, pg 29). Although some agents can be corrupt operators (Borjas 2002, pg 39), the information on potential study destinations provided are important factors (Section 2.5.3). The extent of their influence will be examined to determine how much students rely on them in relation to the other factors in their decision making process.

These three structures in migration systems theory are intertwined and connected to international student migration. International student mobility through traditional and contemporary migration theories and their links to a student's motivations and future intentions were discussed, however, further examination is necessary. Chapters 6 and 7 will therefore investigate factors that influence the motivations and future intentions of Chinese and Indian students in Australia. The various macro, micro and meso structures will also be identified in order to form a comprehensive understanding on their mobility in Australia. To recapitulate, individually, migration theories have only been able to address international student mobility to a certain degree. However, such limitations can be overcome by encapsulating different theories, a multidimensional approach as this chapter has attempted to do so far.

\subsection{Transnationalism: A shift in paradigm?}

As discussed, the concept of a move being classified as either temporary or permanent has been prominent in the literature. This approach is however increasingly inadequate in describing modern day migrants, particularly for international students who need to be viewed through a transnational lens. The movement between places invokes images of a physical locale used in the migration pathway or model for the international student. ${ }^{19}$ This section describes the form and movement of international students within the concept of transnationalism. The spatial aspect of migration flows is explored by theorising and

\footnotetext{
19 Countries or cities of study destinations for international students from here forth will be used interchangeably with the terms space and place.
} 
charting the spaces and places that feature in the migration strategies of international students.

Technological advancements in transport and communication have contributed to the transformation of global international migration in the last decade which has shifted from migrants living serially in one country or another, to maintaining close links between two homes (Brettell 2000, pg 104; Castles \& Miller 2003, pg 29; Glick Schiller \& Wimmer 2003, pg 576; Hugo 2003; Levitt et al. 2003, pg 569; Martin 2000, pg 41; Portes 2003, pg 875). International students fit into the mould of temporary migrants as they sojourn overseas for an education, however, this form of non-permanent movement has links to permanency which indicates that the categories used to classify international students according to their status are unsatisfactory and no longer suitable. As Eriksen (2007, pg 94) notes, such contemporary migrants "include people who cannot easily be classified as either this or that: students who have stayed on, getting a boyfriend or girlfriend and a McJob". The concept of temporary migration is inadequate when describing international student mobility and demands further investigation. The next section examines the emergence of transnational migration in the transnationalism literature, and its manifestation in the transnational migration strategies of international students.

\subsubsection{Defining transnationalism}

The concept of transnationalism is ambiguous as theorists, according to Kivisto (2001, pg 549), "fail to specify the temporal and spatial parameters of the term and to adequately locate it vis-à-vis older concepts such as assimilation and cultural pluralism". Vertovec (2004, pg 1-2) argues that critique of transnationalism literature is constantly repeated and focused on the work of a few authors however, we do have the privilege of using the transnational lens to do "the new analytical work of providing a way of seeing what was there that could not be seen before" (Smith 2003, pg 724).

Glick Schiller and Basch (1995, pg 48) describe transnationalism as "the abatement of national boundaries and the development of ideas or political institutions that spanned national boundaries". Despite the fragmented nature of geography limiting the transnational migration approach (Walton-Roberts 2004, pg 362), migration is a perfect example of the deterritorialisation of nation-states (Glick Schiller \& Wimmer 2003). Moreover, as Portes and Dewind (2004, pg 835-836) state, these contemporary flows have "qualitatively transformed the character of immigrant transnationalism, turning it into a far 
more dense and dynamic cross-border exchange than anything that would have been possible in earlier times".

Transnationalism was introduced to migration studies by anthropologists Basch, Glick Schiller and Szanton Blanc (1994) to explain practices developed by migrants which linked origin and destination countries. The debate was that traditional migration theories failed to address the various transnational characteristics that connected home and host countries as they only saw migrants in the light of sending and receiving countries. Basch et al. (1994, pg 7) define transnationalism as:

the processes by which immigrants forge and sustain multi-stranded social relations that link together their societies of origin and settlement...immigrants today build social fields that cross geographic, cultural, and political borders.

The social fields consist of "familial, economic, social, organizational, religious and political" relationships (Glick Schiller et al. 1994, pg 7) embedded in transnational networks. These relationships are configured by the actions and decisions of migrants which link them simultaneously to places of their origin and settlement. Transnationalism according to Vervotec (1999, pg 447), "broadly refers to multiple ties and interactions linking people and institutions across the borders of nation states". This definition resonates with the migration systems theory which further emphasises the significance of how networks facilitate migration. The varying extensions and complexities of transnationalism will need, as Vervotec (1999, pg 448) suggests, "research and theorization on different scales and levels of abstraction", although it is still a "highly fragmented, emergent field which still lacks both a well-defined theoretical framework and analytical rigour" (Portes et al. 1999, pg 218). Nevertheless, the concept of transnationalism in international student mobility is apparent.

Levitt (2004) refers to 'transmigrants' as those that belong to more than one society at the same time and given the rapid increase in educational migration, it is likely that increasing numbers of international students will fit into this category. The simple fact that international students leave their home countries to study and live in a foreign country and the links formed and maintained during the course of their overseas education meets the basic definition of transnationalism, making them transmigrants by virtue of them belonging to more than one society simultaneously. 
The emergence of transnational social space in the transnationalism discourse has received attention in recent times (Faist 2000; Pries 2001) with the introduction of a spatial or geographic element. Hence, the social fields and the resulting migration networks created by students in their educational sojourn will be examined. The following section focuses on the transnational spatial element aspect of international student mobility and will construct a hypothetical model for international students to identity the kind of linkages and flows within such social fields.

\subsubsection{Space, place and international student transnationalism}

The concept of space is important in migration theory since movement involves moving from one place to another. Some commentators have suggested that transnationalism has changed people's relations to space by shifting their social fields (Bhat \& Sahoo 2003). These social fields or transnational spaces connect people across borders and are constructed by transnational networks which in turn are built upon transnational family networks (Bhat \& Sahoo 2003).

There are many ways of conceptualising transnational social space. Basch et al. (1994, pg 29) note the concept of social fields in studies of migrant transnationalism refers to the connection between nation-states which are constructed by personal actors in the "plethora of their daily activities and that are often at odds with the territories of sovereign states" (Kleinschmidt 2006, pg 1). Faist (2000, pg 191) sees transnational social spaces as "combinations of ties, positions in networks and organisations, and networks of organisations that reach across the borders of multiple states". These ties and linkages are by no means static in nature as they serve to create transnational social spaces by connecting positions (nodes and hubs) in networks and organisations that transcend borders of nation-states (Faist 2004). Arising from these connections are "dense, stable, pluri-local and institutionalised frameworks composed of material artifacts, the social practices of everyday life, as well as a system of symbolic representations that are structured by and structure human life" (Pries 2001, pg 8).

However, the deficiency of studies on transnational social spaces in international migration (Faist 2000, pg 190) is reinforced by the dearth of literature on transnationalism in migration studies. This lack of research highlights the neglect in addressing the spatial aspect of transnational spaces. Spatial metaphors are constantly brought up in discussions with only a brief mention of the construction of transnational spaces in the mobility of 
migrants (Voigt-Graf 2004, pg 25-26). The following sections will address this deficiency by examining the relationship between migration flows and transnational social spaces and apply it to international student mobility.

\subsubsection{Physical and social elements in transnational social space}

When conceptualising transnational social space, the varying forms and levels of social space and geographic space need to be considered (Pries 2001, pg 7). Pries (2001,pg 1823) explains that the existence of a social space requires the spatial aspect, at the same time, the traditional view of the nation-state as a container for space is inadequate as a reference for social space. Space in a general physical sense is a "configuration and positional relation of elements" (ibid, pg 21) which exists independently. However it is only constructed in a geographic and spatial sense through the view of social actors. The concept of the social space revolves around "human configuration of interrelationship, actions and mental representations" (ibid, pg 21), made up of "social practices, artifacts and systems of symbols" (ibid, pg 21).

The "mutual embeddedness of geographic space and social space" (Pries 2001, pg 4) is the principle of territorial sovereignty which defines geographic space as nation-states being containers of social spaces. This view has been challenged by the increasing permeability of the sovereign nation-state, accelerated by forces of globalisation such as the advent of transportation and communication technologies (ibid, pg 5). Social relations and social spaces that transcend these national borders further add to the disembedding of geographic and social space. A territory which previously contained a single social space is now seen to be 'stacked' by different social spaces, also linked with other social spaces that span across several other geographic spaces (Pries 2001, pg 5). This suggests a multiplicity of connections and flows which indicates the abatement of a linear migratory flow, reemphasising the transnational shift from the permanent and temporary migration paradigm.

Soja (1989, pg 35) posits the production of space as "a social process rooted in the same problematic as the making of history", where social constructions define its functions, purpose and meaning. Although spatial arrangements are products of "social construction arising within the physical frame of ubiquitous, contextual space" (1980, pg 210), it is a challenge to focus on the social aspect of organised spaces. This is because any reference to the term spatial often results in something physical and external, a container view, 
independent and detached from any social context or action (Soja 1980, pg 210). Thrift (2009, pg 86) concurs as he states that "space is no longer viewed as a fixed and absolute container within which the world proceeds. Rather space is seen as a co-production of those proceedings, as a process in process". However, social relations and processes also have a spatial expression. As Voigt-Graf (2004, pg 27) argues, while actions and processes produce space, the physical notion of space also rebounds back onto the social side of it. Although the concept of space is widely debated (Lake 2010), this thesis views the social and spatial to have a recursive or co-productive relationship.

It is understood that the relationship between social spaces and geographical spaces are changing and no longer viewed within the boundaries of the geographic, however, the focus has shifted to "multi-sited or pluri-local" social spaces (Pries 2001, pg 23). Linkages between multi-sited social spaces focus on the processes that influence them and there have been calls to view these spaces or areas as outcomes of processes rather than just mere physical, objective or cartographic elements (Ford Foundation cited in WaltonRoberts 2004, pg 363). This brings discussion back to migration theories and structures set at macro, micro and meso levels influencing migration. Additionally, a migrant's decision can also influence the very factors or the spaces that play a part in their decision making processes. So, what are these processes that frame these spaces?

With social spaces increasingly viewed as 'not contained', the container view is broken down. Thinking about social spaces in terms of connections between places indicates some form of a network linking multiple sites and the definitions brought forth in this section suggests transnational activities that transcend the borders of nation-states positioned within a network. Without going any further into the discourse on transnational social spaces, it is important firstly to address the phenomenon by defining or specifying the geographical/spatial unit of analysis when it comes to the study of social spaces. The following sections will examine the various transnational migration strategies used by migrants and identify the multiple sites located within their transnational networks. The shapes and forms of the institutionalised frameworks that structure their migration will be explored, along with the artifacts, social practices and symbols which influence and, in return are influenced by, the construction of transnational social spaces. This will put into context a model to describe the transnational migration strategies in international student mobility. 


\subsection{Transnational social spaces within networks in transnational migration strategies}

International student mobility will be approached through the concept of 'space of flows'. First introduced by Castells (1989) in The Informational City, 'space of flows' refers to the ability to interact in real time between places without the need for physical proximity. The issue at hand when it comes to transnationalism and its associated social spaces is that "Place matters: transnational lives are lived that embrace both the sender and receiving countries" (Hardill 2004, pg 378). The concept of networks of organizations and institutions linked by flow exchange (Castells 1996, pg 29) follows and with the increase of global capitalism in recent times, global cities as nodal points are a part of the space of flows (Voigt-Graf 2004, pg 27). The notion of global cities as nodal points in a migration framework is helped by a network approach as surmised by Boyd (1989, pg 641):

Networks connect migrants across time and space. Once begun, migration flows often become self-sustaining, reflecting the establishment of networks of information assistance and obligations which develop between migrants in the host society and friends and relatives in the sending area. These networks link populations in origin and receiving countries and ensure that movements are not necessarily limited in time, unidirectional or permanent.

At the most basic level, space is a "configuration and positional relation of elements" (Pries 2001, pg 21), which at a 'particular, unique, point of their intersection' create meeting places (Massey 1991, pg 28). The concept of space should not be demarcated by boundaries, instead it should be visualised as lucid and conscious of its connections to the world on a grander scale, allowing different scales of connection and integration.

The linkages between temporary and permanent migration are evidenced by studies on international student mobility (Baker \& Finn 2003; Finn 2003; Johnson \& Regets 1998; Li et al. 1996; Pang \& Appleton 2004; Pearson \& Morrell 2002; Tremblay 2002), however, there have been questions raised on the intentions of these non-permanent migrants which essentially drives the outcomes of their mobility. For some temporary entrants in EuroAmerican countries, the temporary migration system is a process towards selecting of permanent settlers. Temporary migrants who have resided in the country for several years are suitable candidates for permanent residency as they have proved their absorption into the labour market and assimilation in other ways (Hugo 2003). Thus, entering a country as 
a temporary migrant might be an easier strategy to obtain permanent residency and such a route could possibly be a "consciously planned initial first stage of an intended relocation" (Hugo 2003).

The possibility of acquiring new citizenship rights or rights of permanent residence using education as a migration instrument has received considerable attention in the recent flurry of research on international student migration (Alberts \& Hazen 2005; 2006; Baker \& Finn 2003; Biao 2001; Pang \& Appleton 2004; Tremblay 2002; 2005). Studies more pertinent to this thesis have underlined the permanent migration of Chinese (Hugo 2005, pg 7-9) and Indian students (Baas 2006, pg 8-23; Khoo \& Voigt-Graf 2004, pg 423-443) in Australia which substantiates the notion of international education as a precursor to immigration. However, current studies assume that international student mobility only takes place between the origin country and the destination country of the international student, resulting in a basic framework that focuses on their movement between two nodes in a migration network.

As raised earlier, whether international students plan to go abroad to obtain a qualification and return back to their home countries adds another dimension to international student mobility and permanent settlement, increasing the complexity of their migration strategies Looking through the transnational lens of Basch et al. (1994) reinforces earlier suggestions of how international students migration pathways can be recursive and not necessarily unidirectional nor permanent. Some commentators (Koser \& Salt 1997; Li et al. 1996) have recognised international students as highly skilled migrants and their tendency for future migratory labour movements is an indication that their migration strategies are not always a singular linear process. With the expansive literature on transnationalism, the following sections will focus on the application of transnational migration strategies of international students and the spaces within the networks these strategies are structured around.

\subsubsection{Transnational strategies used by migrants}

The following section examines transnational migration strategies and how they enhance a migrant's mobility and achieve their objective. These examples will identify the multiple sites (this section will use the terms places, nodes and sites interchangeably) that figure in these transational migration networks. This approach will elucidate how international 
students adopt similar strategies by using international education as a vehicle to achieve their objectives.

\subsubsection{The configuration of places in transnational migration strategies}

Studies looking beyond the paradigm of permanent and temporary settlement (Biao 2004; Guerassimoff 2003; Guo \& Iredale 2002; Huang \& Yeoh 2005; Ley \& Kobayashi 2005; Thuno 2003; Voigt-Graf 2004; Waters 2001; 2003; 2005) have introduced another dimension when charting the mobility of international students. The deliberate configuration of places in the mobility of migrants is not an uncommon strategy. For example, Biao's (2004) 'brain bypass' concept on how different places served a specific purpose in the transnational strategies of Indian IT professionals echoes DeVoretz et al.'s (2002) triangular model on the flows of highly skilled immigrants.

Similarities arise between Biao (2004, pg 164) and DeVoretz \& Ma's (2002) use of the terms 'global gateways' and 'entrepot country' respectively. These terms refer to the use of countries such as Canada or Australia by skilled migrants from the South (eg, China/India) to acquire human capital before moving on to countries such as the US. Biao's (2004) brain bypass concept is depicted in Figure 4.1, and the strategy can be broken down into three parts, the central destination, global gateways and bases for security.

Global gateway and security bases are regarded as temporary destinations en route to the US which was often seen as the central destination for various reasons such as high-income levels and better career advancement prospects. The key to the function of global gateways such as Singapore or Malaysia lie in the fact that these countries are valuable places for Indian IT professionals to gain experience and training while establishing useful contacts, as direct employment in the US is hampered by the lack of contacts. Networks are crucial during this process as connections between workers themselves and agents are utilised when applying for jobs within these countries and abroad (Biao 2004, pg 170).

Australia and Canada are considered bases for security partly due to the relative ease of obtaining PR in these countries. Not only does being a PR improve one's social standing back home in India, but it also is considered a valuable commodity in the Indian marriage market (Biao 2004, pg 172). Other factors include job and financial security through stable employment markets and the social security systems established in these countries. 
Obtaining PR is also seen as an instrument to improve their own mobility as it gives them the freedom to travel in and out of the country. Others may even go to the US upon getting PR in Australia or Canada to gain some valuable work experience or 'a quick buck' (Biao 2002; 2004 pg, 173-174). Clearly, global gateways and security bases provide avenues to seek employment, and to increase one's human capital through gaining highly regarded work experience.

\section{Figure 4.1:Transnational migration strategy of Indian IT professionals}

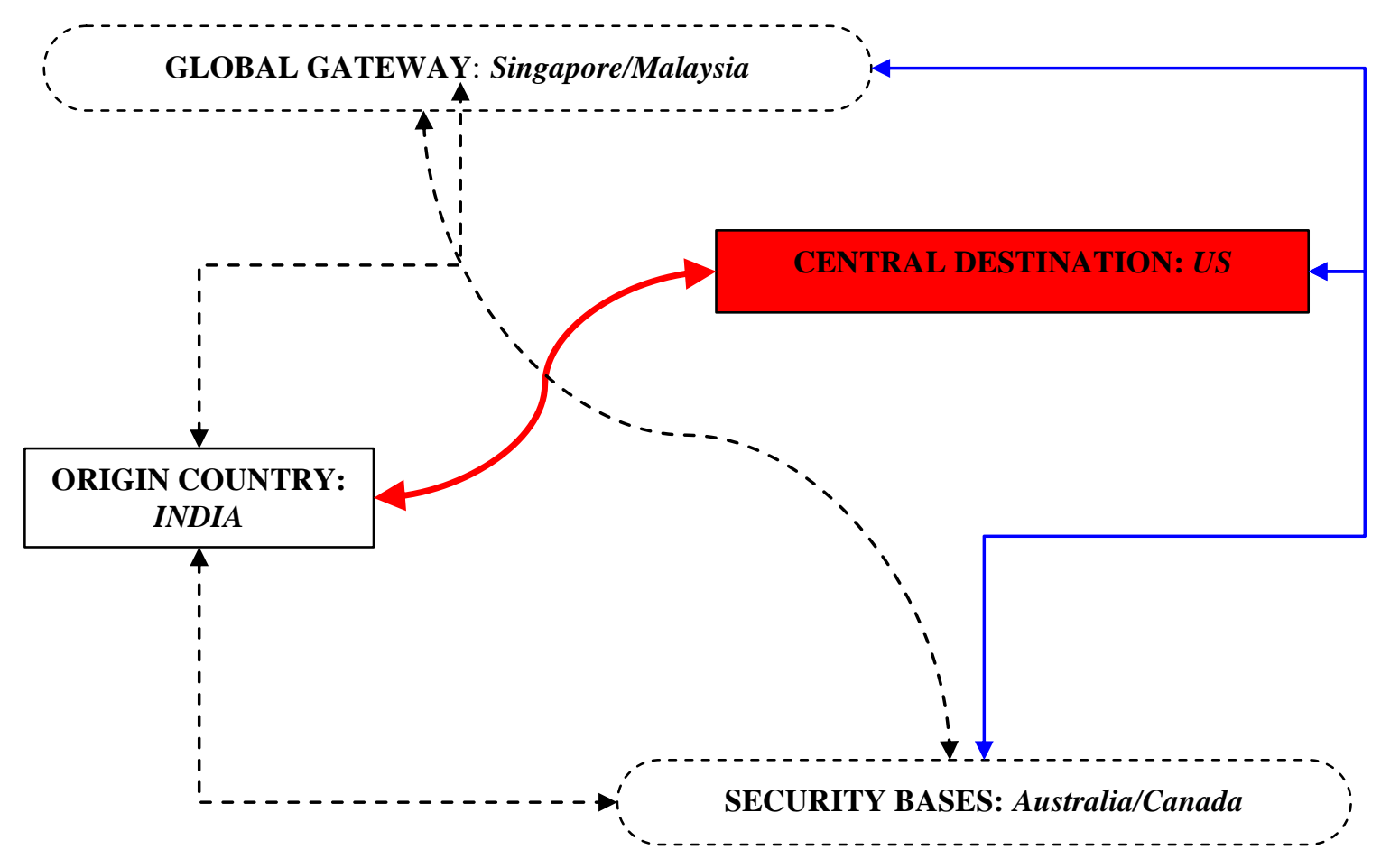

Source: Author's interpretation of Biao's (2004) 'brain bypass' concept.

The nodes in the transnational network of the IITs included more than just two places/countries. The migrations between the nodes were non linear and were instead recursive or circulatory in nature (Biao 2004), epitomising the circular and onward nature of such migrations. The notion of a place in the entire scheme of a migrant's network thus takes on a different tone. Places become strategic as they are configured by motivational factors. These places serve a purpose according to migrant motivations, however, they also structure migrant flows as the realisation of any migration intention rests with macro structures- institutionalised frameworks in the form of immigration regulations established in respective countries. These immigration regulations are exemplified by modifications to migration policies aimed at attracting and retaining highly skilled migrants or international students, as discussed earlier. Nevertheless, migrants to an extent are able to circumvent 
these policies which further highlight the reflexive relationship between social and geographic space.

This relationship is expounded though the transnational strategies of Chinese migrants from the PRC in Europe. Guerassimoff (2003) found Chinese migrants using eastern European countries as springboards for entry into preferred destinations such as France or other EU destinations. The route to Europe is often circuitous in nature for these migrants, especially if they lacked proper travel documents (Guerassimoff 2003, pg 139-140). According to Thuno (2003), some Chinese migrants would use Denmark as an entry point or a gateway into Europe via various channels such as family reunification, political asylum, temporary skilled professional programmes and undocumented entry. The relatively cheaper and easier process of obtaining a student visa to study in Denmark has seen the increasing significance of education as a channel for entry. This strategy shows student migration as another established pathway for entering the EU (Thuno 2003, pg 116-120).

The idea of places as gateways was found in Huang and Yeoh's (2005) study on China's 'study mothers' who uprooted themselves along with their children and moved to Singapore. Singapore served its purpose as place to obtain an education, particularly one in the English medium which would advantage their children as it would "open doors to a cosmopolitan future in which they are able to live and work in almost any city in the world" (Huang \& Yeoh 2005, pg 391). However, it also raised an intricate part of their strategy which deliberates on "whether to return to China or go on to a 'western' country" (Huang \& Yeoh 2005, pg 390).

Similarly, people of Hong Kong have always regarded Hong Kong as a "stepping-stone on their way to some other place or as a place of temporary refuge" (Sweeting 1992, pg 66). The well documented movement of Chinese migrants (Waters 2001; 2003; 2005) from Taiwan or Hong Kong to Canada portrayed similar transnational strategies. Parents sent their children to study in Canada while they themselves shuttled between the two countries, giving rise to the terms 'astronaut family' and 'satellite kid'. Canada was not merely a study destination as it was also a central destination. Reasons such as political instability, economic downturn, academic competition and avoiding military conscription for their children in their home countries, and the promise of job security and gaining a Canadian 
passport as 'insurance' (Waters 2001, pg 18; 2005, pg 367) leads one to surmise that Canada is regarded as a safe haven, a place to relocate to in times of uncertainty.

According to Ley and Kobayashi (2005, pg 111), "migration is undertaken strategically at different stages of the life cycle". In the short term, Hong Kong functions as a place to maximise financial opportunities, to support those left in Canada whose objective is to maximise the accumulation of cultural capital (Waters 2005, pg 370), while 'astronaut parents' periodically visit their 'satellite family' in the medium term (Ley \& Kobayashi 2005, pg 115-120; Waters 2003, pg 220). The long term objective however lies in the retirement plans of the parents who intend to live in Canada due to its higher quality of life compared to Hong Kong (Ley \& Kobayashi 2005, pg 120-123), a trend also observed in Australia (Pe-Pua et al. 1998; Skeldon 1994), New Zealand (Ho et al. 1997a; b) and the US (Ong 1999).

Multiple locations sited within various transnational migration strategies have been identified and it has been illustrated how places are at times regarded as temporary destinations that purely function as stepping stones or springboards to a preferred destination. Each place serves a specific function such as accumulating one's human capital. Some of these migrations fit into the new economics of labour migration theory (Section 4.3.1) with the family unit, not the individual, the focal point of such migratory movements (Waters 2005, pg 370). These examples indicate the "importance of transnationalising the family in order to invest heavily in the children's education as the main route of international social mobility and prestige" (Yeoh et al. 2005, pg 312). Ong (1999, pg 90) argues that the importance attached particularly to Western education was:

for many middle-class Chinese...the ultimate symbolic capital necessary for global mobility...which guarantees that the holder has acquired the cultural knowledge, skills and credentials that enable the transposition of social status from one country to another

To summarise, the underlying reasons for migrating as identified by researchers (Waters 2001; 2005; Yeoh et al. 2005, pg 312-313) revealed the aim of accumulating cultural, social and human capital with education "found to be one of the most important reasons for initial immigration" (Waters 2005, pg 370).

This section demonstrates the use of places in transnational migration strategies and begs the question whether international students in Australia are using a similar strategy. 
Although the migration and transnationalism literature are abound with spatial metaphors, there are gaps in the literature when approaching migration studies from a geographical angle (Voigt-Graf 2004, pg 25). The strategic mobility of the migrants are transnational as the spatial dispersal and movements driven by their underlying objective entails the maintenance of significant social and economic ties with more than one country simultaneously. Transnational migration strategies have seen how places are utilised in a non-permanent fashion to suit the motivations and intentions of migrants, leading to the concept of the configuration of places as bridges or stepping-stones. As Hägerstrand (1982, pg 324) states, "We need to rise up from the flat map with its static patterns and think in terms of a world on the move a world of incessant permutations". The deliberate use of a place by Chinese and Indian students with a view to future migration will be discussed in the following section.

\subsubsection{Modelling the transnational strategies of international student migrants}

This section will construct a model (Figure 4.2) to illustrate the transnational migration strategies of Chinese and Indian students and their transnational flows. The model draws on Voigt-Graf's (2004; 2005) and Biao's (2004) research which examined Indian communities and IT professionals who used places such as Canada or Sydney as stepping stones en route to the US.

The movement of Indian communities in Voigt-Graf's (2004, pg 29) study was illustrated by nodes, flows and transnational space, spatial components of interest to this study. Although there were varying levels of nodes and complex migration and transnational flows between the three Indian communities, the general strategy is centred on the strategic function of places as gateways (Voigt-Graf 2004, pg 30-37).

Figure 4.2 depicts three transnational migration strategies which involves three main nodes, the home country (China or India), a central destination (US/UK) and an intermediate destination (Australia). The colour codes indicate different levels of complexity in their mobility. In line with migration systems theory, these places that frame the transnational strategies are interconnected by macro, micro and meso structures (Section 4.3.2). By incorporating the theories discussed in this chapter, the model will elucidate the underlying factors that influence the transnational migration of Chinese and Indian students. Additionally, with the disembeddment of transnational social spaces 
discussed above, the model will test the suitability of transnationalism as a concept in describing the migration of Chinese and Indian students.

\section{Figure 4.2: Conceptual model of the transnational migration strategies of Chinese and Indian students}

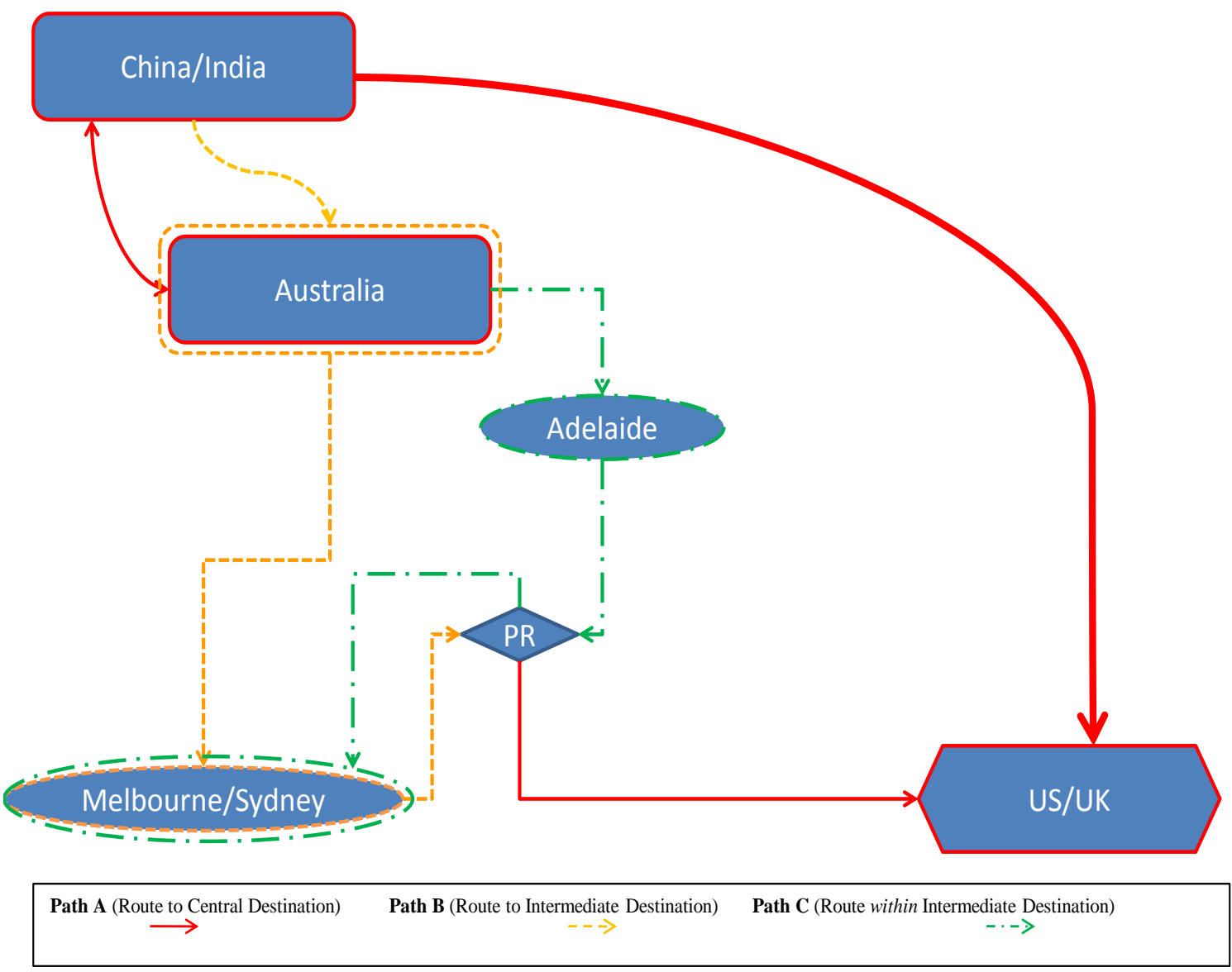

Source: Constructed by author

Borrowing from Biao's research $(2004 ; 2005)$, Path A (indicated in red) refers to the intention to migrate to a student's preferred or central study destination. The hypothesis is that although the US and UK are traditionally popular destinations not just for international students, but also for most migrants in general (Section 1.2 and 4.5.1), factors such as the relatively higher cost of study (Section 2.5.7) and government policies deter students from studying in these countries. It is clear that macro structures have an important role in the students' transnational strategies. As much as government policy enhances the attractiveness of a study destination, it can conversely serve as barriers to entry, leading students to study in other countries instead, therefore constricting the pathway to these central destinations. For example, restrictive immigration policies as a result of the fallout from 9/11 (Section 2.5.8.2) led to many students seeking to study in countries with 
relatively relaxed immigration regulations. Additionally, if one's primary intention is to permanently immigrate, studying in the US or the UK might prove to be a relatively difficult task. Hence, choosing to study in countries with more favourable student retention policies such as Canada, New Zealand or Australia (Appendix 1), subsequently configures these places into central destinations. Conversely, if the main intention of the student is purely educational, their home country would then be regarded as their central destination.

Biao's (2004; 2005) concept of global gateways and security bases provides an insight as to how Australia can be configured as a gateway, functioning as a conduit for onward migration. As Figure 4.2 shows, there are two strategic gateways towards future emigration. Firstly, Australia may be an intermediate destination before migrating to the US, the student's preferred destination. As discussed (Section 2.5.8), Australia's 'student friendly policies' presents an opportunity for Chinese and Indian students to acquire human capital through an Australian qualification and valuable work experience, completing their transition into highly skilled migrants, or a new form of elite (Hawthorne 2005, pg 15; Koser \& Salt 1997, pg 287). It is at this stage where the strategy of leaving the 'intermediary' country for their 'central' destination materialises, a move underpinned by economic motivations or human capital accumulation. The long term objective of migrating to the US would then be achieved with the expectation that the qualifications and work experience acquired, and possibly even the status as an Australian citizen would be enough to circumvent the barriers to entry first encountered.

The intricate complexity of their migration is further elaborated by Path $\mathrm{C}$ in Figure 4.2. Although Victoria and New South Wales are traditionally the most preferred study destinations in Australia, the significant proportion of international students who took advantage regional policies (Table 3.3) suggests the selection of universities in regional defined or low growth metropolitan areas is a precursor for those who plan to eventually relocate to Victoria or New South Wales. It is hypothesised that although places like Adelaide through policy, can influence and shape the migration of Chinese and Indian students, they are also configured as stepping stones en route to other interstate destinations. This strategy emphasises the agency of students and as Robertson (2009) argues, even though policy can at large determine migration, students "still have some agency and can subvert expectations of the state in a number of ways". In this instance, circumventing policy to achieve long term aims of PR and onward migrations to preferred 
cities like Melbourne in Victoria or Sydney in New South Wales sheds light on the recursive influence between geographic and social space and raises further questions on the increasing complexity of the students' transnational migration strategies.

The disembeddment of a transnational space gives rise to multi-sited social spaces (Section 4.4.3). Viewing the model through this lens illuminates the linkages between different places in the strategies of Chinese and Indian students. Discussions so far have shown the importance of macro structures in the form of policy and economic motivations in shaping the transnational strategies of students. The co-productive relationship of geographic and social space is shown via the influence of macro structures such as restrictive immigration policies on the decision making process of Chinese and Indian students. The migration of these students is also influenced by policies that facilitate the relative ease in obtaining a student visa and/or PR. And as mentioned, linking transnational spaces meant regarding study destinations as outcomes of processes or transnational activities. Hence, even though government policy defines national boundaries and structures the migration of students, these geographic spaces are configured by student intentions as indicated by the central and gateway destinations framing their transnational strategies.

This thesis will therefore investigate the factors influencing the motivations and future intentions of Chinese and Indian students in Australia. The linkages that connect places in their transnational strategies are not dissimilar to the role of micro, meso and macro level structures in migration systems theory. These structures will also be identified in order to form a comprehensive understanding on their mobility in Australia. It is necessary to understand the role of these of structures and how they interact with the factors influencing students. This approach will illuminate the co-productive relationship between geographic and social spaces in the transnational strategies of Chinese and Indian students. This will elucidate the extent of influence PR has on their decision making and how education through government policy, is an instrument which enhances their transnational mobility.

\subsection{Conclusion}

This chapter has approached international student mobility with a multi-varied approach. As discussed, traditional migration concepts have accounted for the basic economic drivers that influence the motivations of an international student, and the combination of contemporary migration systems theory has compensated for the associated shortcomings 
of older concepts by incorporating macro, micro and meso level structures to explain the perpetuation of migration flows. Although these migration theories might at a glance seem to be inapplicable to international student mobility, this review has shown otherwise.

In addition, the emergence of transnationalism has shown how conventional permanent and temporary descriptions are less suitable when applied to international student mobility. A review of the transnationalism literature has shown the use of transnational social spaces to describe the networks and the activities that take place in migration flows, the concept of social spaces has however highlighted the lack of discussion on the spatial/physical element when it comes to migration. The co-production of social space and physical space has allowed the physical space to be more lucid in a network, equally, the review of the literature has aided in viewing and applying the notion of how a place/node in a migration network can be strategically configured by a migrant. The various factors, processes and social fields that exist shape how a place can function in a Chinese or Indian student's transnational strategy and conversely, the co-production of space sees a place rebounding back onto social space.

The transnational migration strategies of Chinese and Indian students in Australia will be investigated to shed light on the underlying factors that play a part in their decision to study abroad. Understanding their transnational migration strategies will not only reveal the different extent of influence the factors have on the two groups of students, but also ascertain the value of PR and how education is used as an instrument to enhance their mobility. The findings in Chapters 6 and 7 will be juxtaposed with the conceptual model to identity the places/nodes that exist in the networks of their transnational migration strategies. The gap in the literature will be addressed by showing how their motivations and future intentions (influenced by the interaction of micro, macro and meso structures) can shape and also be shaped by the places/node that are strategically configured in their transnational migration strategies. 


\section{CHAPTER 5: Methodology and Case Study Groups}

\subsection{Introduction}

This chapter describes the methods used in this study in identifying the factors that shape and form the transnational migration strategies of Chinese and Indian students in Australia. The primary source of data is an online survey (Chinese and Indian student survey- hereon referred to as the CISS survey) distributed to students enrolled in South Australian universities (The University of Adelaide and the University of South Australia) and, qualitative research which involved numerous in-depth interviews with key informants and students.

This chapter will contribute to understanding the motivations and future intentions by establishing a profile of the students that were surveyed. The characteristics of international migrants and the nature of their movements are diverse and complex, suffice to say, it is important to make the distinction between international students of different nationalities. Hence, this chapter will examine the attributes of the two groups of international students under study. These include their demographic profile, financial background and the level and type of courses that they enrol in which will provide a context in understanding the findings presented in subsequent chapters.

\subsection{Triangulation}

Researching a subject should have multiple approaches as no one method is ever:

free of rival casual factors...can ever completely satisfy the demands of interaction theory, or can ever completely reveal all relevant features of empirical reality necessary for testing or developing a theory (Denzin 1989, pg 25-26).

Instead triangulation, first introduced by Campbell and Fiske (1959) and Webb et al. (1966) into social science research is a more suitable approach as "it is better to look at something from several angles than to look at it in only one way" (Neuman 2006, pg 149). Triangulation has its origins in navigation and surveying in the military whereby two landmarks are used to determine the exact location of an unknown location (Jick 1983, pg 136; Smith 1975, pg 273). Based on this premise, triangulation allows for greater accuracy through the diversity of data collection on the same phenomenon (Jick 1979, pg 602). Webb et al. (1966, pg 174) argue that a hypothesis that can "survive the confrontation of a 
series of complementary methods of testing" is more valid compared to a hypothesis tested within a single method.

However, "the very concept of validity that is assumed by triangulation" (Hammersley \& Atkinson 2007, pg 185) has been criticised by researchers (Fielding \& Fielding 1996; Flick 1998; Rossman \& Wilson 1994). As Hammersley and Atkinson (2007, pg 185) state, multiple methods involving "discrepant epistemological or ontological assumptions" could produce results that are difficult for comparison and validation. Nonetheless, the value of this technique is to "add breadth or depth to our analysis" (Fielding \& Fielding 1986, pg 33), capturing a more "complete, holistic, and contextual portrayal of the unit(s) under study" (Jick 1979, pg 603) and uncovering an "off-quadrant dimension" (ibid, pg 609) or unique finding otherwise overlooked by a single method. To sum up, the "combination of multiple methodological perspectives, and observers in a single study is best understood, then as a strategy that adds, rigor, breadth, complexity, richness and depth to any inquiry" (Denzin \& Lincoln 2005, pg 5).

Triangulation is distinguished by Denzin (2009, pg 301-303) under four broad categories, methodological, data, theoretical and investigator. In brief, methodological triangulation employs more than one method when investigating the same research objective. Data triangulation pertains to using the same approach to analyse different sets of data to establish the validity of any trends or features surrounding the research problem. Theoretical triangulation approaches an issue with multiple theories and perspectives and investigator triangulation involves using investigators of different backgrounds. This study incorporates data and methodological triangulation methods as a variety of secondary data was utilised and a mixed methods approach was employed to explore the motivations and future intentions of the students.

\subsubsection{Data triangulation}

Denzin (1989, pg 237) defines this approach as the search for a variety of data sources but with regards to the same subject of study. The secondary data used in this study was obtained through various sources from academic, and government organisations. Secondary sources involve analysis of data and information from the websites of governmental organisations such as Australian Education International (AEI), the Australian Bureau of Statistics (ABS) and the Department of Immigration and Citizenship (DIAC). Further information used included series publications such as Overseas Students 
Statistics and various surveys by Australian Education International and Students: Selected Higher Education Statistics published annually by the Department of Education Science and Training. Introductory chapters have discussed and referred to the above data sources. $^{20}$

The broad scale nature of these sources provided a good overview of international students in Australia from a statistical point of view. The AEI has the most extensive collection of statistics on all international students enrolled in all Australian institutions, they include, data on their nationalities, their distribution within Australia, the level of their study and the broad and narrow fields of their courses. On the other hand, data from the ABS and DIAC not only provided a demographic perspective on the flows of international students but also included detailed information on the post study visa options which they took up. These data sets allowed one to chart the trends and one the whole, understand Australia's international student population. This information was valuable when formulating the hypothesis for this study. Additionally, one was able to identify specific information and characteristics of Chinese and Indian students in Australia which helped in the CISS survey design and provided a base for the verification of its findings.

The findings of various surveys published by the AEI $(2002 ; 2005 b ; 1997)$ were extremely useful as the information collected from their studies improved understanding on the underlying factors which influenced international students to study in Australia instead of other countries. One was also able to judge specific patterns such as their level of satisfaction with regards to their education in Australia; their likes and dislikes about studying in Australia; and their future intentions. Although these studies were largely generalised, they nevertheless provided a good overview.

In addition, the usefulness of data sets when combined with surveys, provide the context for primary data (Clark 2005, pg 59) and further enrich information gleaned from surveys (Fawcett \& Arnold 1987, pg 1537). These surveys with specific regard to the motivations and future intentions of students are academic in nature as they help frame the context of the study from a global (Alberts \& Hazen 2005; 2006; Balaz \& Williams 2004; Li et al. 1996; Pang \& Appleton 2004) and Australian perspective (Andressen 1991; 1993; 2001; Bodycott 2009; Gillan et al. 2003; Mazzarol et al. 2001a; Mazzarol \& Soutar 2002;

\footnotetext{
${ }^{20}$ Statistics from AEI and DIAC were mainly discussed in Chapter 1
} 
Mazzarol et al. 2001b; Nesdale et al. 1995; Rao 1976; Rao 1979; Yang 2007) and complements the primary data collected.

The abovementioned studies assisted in forming a framework on the basic factors driving the decision making process of international students, particularly Chinese and Indian students. This further contributed to the design of the CISS survey as questions were refined in order to obtain a close representation of Chinese and Indian students in Adelaide. Despite the incomplete or broad nature of most migration data, the combination of the various data sets and studies as noted in this section will allow greater certainty when verifying their characteristics from this study.

\subsubsection{Methodological triangulation}

This form of triangulation has two forms, 'within-method' and 'between-method'. 'Withinmethod' triangulation essentially uses varieties of the same method to analyse a problem, such as using different scales in a questionnaire to measure the same issue (Blaikie 1991, pg 116). On the other hand, 'between-method' triangulation or multi-method approach (Oppermann 2000, pg 144) refers to using two or more research techniques. Due to the flaws associated with the former, this study utilised the latter technique as it is considered to be the stronger of the two (Denzin 1989, pg 234-244).

Both quantitative and qualitative methods were used in this study for primary data collection. Despite the contrasting or conflicting approach between these methods, they serve as foils for each other (Winchester 2005, pg 10, 12). As Nueman (2006, pg 150) states, "Most researchers develop an expertise in one style, but the styles have complementary strengths". This approach will help overcome any shortcomings that are prone from single method studies by capitalising on the strengths of other methods (Blaikie 1991, pg 115; Jick 1979, pg 604), producing “a more complete and "fuller" picture of the social phenomena under study" (Tashakkori \& Teddlie 2003,pg 462).

Quantitative methods (in this instance, in the form of a survey) seek to generalise a population via inquiry logic where parameters ensuring "rigorous sampling methods and predetermined scales" (Greene 2008, pg 17) allows one to measure the characteristics of a population across particular sites or subgroups and present them in findings that are "statistically valid and accurate for a population" (Secor 2010, pg 196). This method "conceptualizes reality in terms of variables and relationships" (Punch 1998, pg 242). 
Despite the prominence of surveys as a primary data source when studying international migration (Fawcett \& Arnold 1987, pg 1523), they are somewhat limited when it comes to exploring the relationships between variables (Punch 1998, pg 247; Valentine 2005, pg 111).

Conversely, qualitative methods "can play an especially prominent role by eliciting data and suggesting conclusions to which other methods would be blind" (Jick 1979, pg 603). Such outcomes are achieved as samples are typically small scale which allows further exploration on issues that emerge in the process of interpreting phenomena through the individual, resulting in extensive and information rich findings (Denzin \& Lincoln 2000, pg 3; Snape \& Spencer 2003, pgs 3-5). Hence, a multi-method approach is extremely useful approach as qualitative methods "attempt to gather, verify, interpret and understand the general principles and structures that quantitative methods measure and record" (Winchester 2005, pg 17).

The quantitative aspect of primary data collection in this study will therefore involve an online survey designed to establish a profile of Chinese and Indian students and to uncover their motivations and future intentions. There was also a qualitative aspect to the CISS survey as it contained some open ended questions which allowed respondents to include any thoughts or opinions not provided by the survey. However, the main source of qualitative data was through a variety of sources that ranged between in-depth interviews with key informants, namely education agents; migration agents; university staff; and interviews with Chinese and Indian students. This will complement the CISS survey and further elucidate the transnational migration strategies of the students.

\subsection{Survey of Chinese and Indian students questionnaire}

The development of the CISS survey is built up on research by Rao (1976), Andressen (1991), AIEF (1997), Tan (2003) and AEI (2005b). They are a few of the more detailed and comprehensive surveys on the motivations and future intentions of international students in Australia. This approach was also combined with the findings from other studies conducted in an international context as discussed in the literature review in Chapter 2.

Personal work experience at an education agency (which sparked initial interest in this study) also contributed towards the development of the survey. This author spent 
approximately 7 months in 2004, working as a consultant in an education agency in Singapore which represented numerous Australian, US and UK universities and institutions. Daily interactions with students of different nationalities (eg, Singapore, Malaysia, India, China, Bangladesh, Taiwan, Hong Kong, Brunei and Indonesia), their parents, other education agents and representatives from various Australian universities and institutions allowed first hand observation into the psyche of international students. This process is invaluable as it is a form of complementary observation and contextual understanding in qualitative research which sees the researcher as a participant, gaining "additional descriptive information" in the "socio-temporal context of interest" (Kearns 2005, pg 193). That said, although this research was unintended and not formally part of the study, it had immense value when designing the survey.

In a similar vein, a preliminary trip was made to Singapore in November 2005 to conduct in-depth interviews with education agents as Singapore was initially considered as a site for research. However, logistical and funding limitations eventually led to the exclusion of Singapore in this study. Nevertheless, the information gained in the interviews was invaluable and contributed to the survey design. Additionally, in-depth interviews ${ }^{21}$ with migration agents and university marketing staff were also conducted in Adelaide which informed quantitative research as it provided "background information on context and subjects; act as a source of hypotheses; and aid scale construction" (Punch 1998, pg 247). The qualitative approaches assisted in extracting the following themes that framed the overarching objective of the survey:

- To know the general nature of their mobility by understanding the decision making process of the students and the factors involved.

- To ascertain the extent of influence immigration policy on their transnational migration strategies.

- To determine the objective of PR as a primary intention and whether it was formed before or after their arrival into Australia.

- To shed light on their future intentions and transnational migration strategies.

\footnotetext{
${ }^{21}$ Details of the these interviews will be discussed in section 5.4.1
} 
The first section of the CISS survey ${ }^{22}$ had a total of 25 questions which were primarily concerned with the decision making process of the students. The theme of this section was to probe the decision to study overseas and the selection of Australia and Adelaide over alternative places as their eventual study destinations. The questions were mostly close ended or multiple choice questions with open ended options, in order to allow room for respondents to put across any views or thoughts clearly and not be restricted by a ready set of answers.

The second section of the survey had a total of 10 questions which sought to explore the students' experiences in Adelaide. This mainly looked at their participation in the labour market during the course of their study and the transnational links maintained by these students with their friends and family back home.

The third section of the survey had a total of 31 questions which were aimed at discovering the future intentions of the students. Respondents were mainly presented with a series of closed ended questions with open ended extensions which were designed to capture where they intended to relocate to after their studies, the underlying factors driving their migrations and the timing of their migrations.

The final section of the survey had a total of 19 questions with the main focus on capturing the characteristics of the students, i.e. age, sex, country of origin and marital status. Respondents were also asked to reflect the courses they were enrolled in as well as indicate their parents' occupations.

\subsubsection{Sampling strategy and online data collection}

Due to the size of the Chinese and Indian student population in Australia, it was deemed to be logistically and financially unfeasible to survey all the students enrolled in universities throughout Australia. Hence, through stratified purposive sampling (Kemper et al. 2003, pg 282), onshore Chinese and Indian students enrolled in Adelaide based universities were selected for this study. Even though the findings will not be representative of the students throughout Australia, similar regional based policies (Section 3.7) will increase the relevance of the findings to those studying in Adelaide and other regional or low population growth metropolitan areas. Moreover comparing the characteristics of Chinese

\footnotetext{
${ }^{22}$ The CISS survey questionnaire can be viewed at Appendix 4
} 
and Indian students in this survey with other data sources and reports (e.g., Australian Education International) allows the quality and applicability of the survey findings to be assessed.

After some consideration, it was decided that the survey would be best administered online. This decision was essentially based on time and cost as online surveys are fast and inexpensive. Online surveys reach respondents in a very short amount of time and returns are also transmitted instantly (Wright 2005). The reduction in cost was significant with the "nearly complete elimination of paper, postage, mail out and data entry costs" (Dillman 2000, pg 352). The automatic coding of responses to a computer-readable form (Parfitt 2005, pg 101) also greatly reduced the time spent with regards to other methods that required laborious data entry. Moreover, the fact that international students had access to a computer, email and internet at their respective universities meant that dissemination of, and access to the survey was guaranteed.

The CISS survey was developed with the confidentiality of the students in mind as no steps were taken to identify respondents. It was hosted online with the assistance of a computing expert, who also assisted in the layout of the questions by setting them in an uncluttered and easy to view fashion. As mentioned, online surveys allowed the automatic coding of responses and this reduced the need for data entry as every returned survey was collated and downloaded in an Excel spreadsheet. Qualitative responses (from open ended questions) on the other hand were manually entered and coded into appropriate categories. Additionally, numerous trial runs were held to ensure the online survey was functioning properly and to highlight any technical glitches or errors. The collected data was then cleaned and transferred onto the statistical software SPSS (Statistical Package for Social Sciences), where frequencies and cross-tabulations were run for all the variables for analysis.

\subsubsection{Pilot surveys}

Before the online survey was sent out, a pilot test was conducted to note any flaws and to ascertain the effectiveness of the survey. A small number of surveys were distributed to a few Chinese and Indian students who were studying in Adelaide based universities and the feedback obtained was invaluable. For example, the pilot test revealed how some questions were unclear and this resulted in the rewording of a few questions in order to reduce confusion or any misunderstanding for respondents in the final survey. Another suggested 
to reword the variable 'Plan to migrate to Adelaide' to 'Bonus Permanent Residency points on offer after graduation' for the questions which asked the reasons for studying in Adelaide. This demonstrates the need for clarity and straightforwardness when framing the questions.

Students in the pilot test also felt that the survey was fairly lengthy which resulted in the deletion of a few questions. Questions that were deemed to be excessive and unnecessary were removed, particularly those asking about their experiences and living conditions in Adelaide. While the survey was focused on capturing the PR intentions of respondents, the pilot test reflected how it neglected their changing intentions and the decision to return to their home countries. Some students indicated even though attractive immigration policies influenced their decision to study in Australia, the intention to remain permanently waned during the course of their study. Furthermore, it was also revealed that getting PR did not necessarily reflect a desire to settle permanently, and that some also had the long term plan of moving back to their home countries.

Hence, the CISS survey was modified to include questions that investigated the changing intentions of respondents, the intention to return to their home countries, the link of PR and permanent settlement. On the whole, the benefit of the pilot survey provided an insight into these issues and emphasised the importance of being mindful of these factors during analysis of the results.

\subsubsection{The survey distribution process and response rates}

Although the research is set within the time frame of 2005-2007, unforeseen delays led to the continuation of fieldwork into 2008. Permission was required from all three Adelaide based universities and a Melbourne based university before dissemination of the survey. Several meetings were held with the Manager of the International Student Centre at the University of Adelaide over January 2007, and permission was granted with assurances that any privacy or confidentiality issues were not breached. Conversely, attempting to gain permission from the other universities was fraught with difficulty and delay. ${ }^{23}$ Letters were sent out to senior staff members at both UniSA (University of South Australia) and

\footnotetext{
${ }^{23}$ It must noted that the initial plan of including a Melbourne based university was abandoned as the process in obtaining permission from the university in question was slow; it was adjudged that even if permission was granted down the track, it would have significantly delayed the progress of this study.
} 
Flinders University in January 2007, requesting permission to survey their Chinese and Indian students ${ }^{24}$, however, no progress was made as communication appeared to break down. Regardless, repeated attempts to gain permission through emails eventually saw a response from Flinders University in August 2007. They politely declined as they had concerns with 'over-surveying' their international students. A positive response was obtained from UniSA in October 2007, and permission was eventually granted in January 2008, nearly a year since first requesting permission.

The timing of the surveys was also influenced by the university calendar. When permission was granted at the University of Adelaide in January 2007, it was decided that the majority of students would be on holidays until the end of February. In order to maximise response rates, it was decided that emails would only be sent out in April 2007 after international students had returned from their summer break, a similar scenario for UniSA who sent out the emails in March 2008. The credibility and respectability of the study was established as official emails briefly explaining the study were sent to the students through their respective universities ${ }^{25}$, thus preserving the privacy and anonymity of the students as there was no access to their email addresses. Students were invited to participate in the survey by clicking on a link which led them to the survey website. A 'Participant Information Sheet ${ }^{26}$ was attached in the website with further information on the study and assurances that they would not be identified and that their privacy would be maintained. Contact details for the researcher and the supervisor of this study were provided in case students had any issues or queries. Reminder emails were also sent eight weeks after the first emails to further increase response rates.

\subsubsection{Potential limitations and biases with the online survey and the distribution}

A potential bias of the study is linked to poor English skills as students might be discouraged from attempting or completing the survey, particularly for the Chinese who are known for their limited English proficiency (Birrell et al. 2006, pg 29; McGowan \& Potter 2008). This was addressed to an extent, by the pilot test which allowed the survey to

\footnotetext{
${ }^{24}$ A sample of these letters can be viewed in Appendix 5.

${ }^{25}$ A sample of the emails and the participant information sheet can be viewed in Appendix 6. Note that due to the SPAM Act, it was required that the email was addressed to the students from the supervisor of this study and not the researcher.
} 
be refined, shortened and simplified for understanding so as to minimise any ambiguity, misunderstanding and to improve response rates.

Another issue which emerged was the mistrust and suspicion held by several respondents (all of whom were Chinese) towards this study. The emails reflected concerns over why Chinese students were chosen out of all the other nationalities studying in Australia. Some apprehension was detected as some felt that the questions were invasive. Furthermore, there was a fear that survey findings would be handed to Australian authorities and other organisations, with the intention of using the information against the students themselves. These concerns were addressed as emails were sent to these students reassuring their confidentiality and the integrity of the study. ${ }^{27}$ Analysis of results requires taking this into consideration as potential bias might result in poor response rates or less truthful answers. This aspect of bias is similarly reflected in the qualitative aspect of this study in section 5.4.1, where the responses from student interviewees may perhaps impact on the 'full story'.

A technical problem was also encountered in the distribution of the CISS survey for students from the University of Adelaide. Miscommunication and human error was responsible for an incorrect link inserted in the emails. This link led students to a version of the CISS survey which was created for university staff members who wanted to view it before granting permission, moreover, it was not active and did not allow respondents to submit their answers. This incorrect link was sent to the students on Thursday, April 5, 2007, and this mistake was realised on the following Saturday. As it was the weekend, rectification to this problem had to wait until Monday. A second email with the correct link was then sent to the students on April 10, 2007, the following Tuesday. ${ }^{28}$ This technical/human error would have caused some lost responses. It is unknown as to how many surveys were done between April 5 and April 10 and whether respondents redid the survey at the second time of asking.

The above error did not affect respondents from UniSA as their survey was conducted nearly a year later in March 2008 (due to delays as earlier discussed), however, changes in immigration policy (which took effect on September 2007 as discussed in Section 3.4) were deemed to have an impact on the PR intentions of UniSA students. The changes

\footnotetext{
${ }^{27}$ The feedback from these students and the replies to them can be viewed on Appendix 7.

${ }^{28}$ The sample of this email can be viewed on Appendix 8 .
} 
focused on English proficiency and work experience of applicants which made it harder for some to obtain PR. A possible bias thus emerged as data between UniSA and the University of Adelaide were potentially incompatible. However, the changes in policy were not likely to impact on the appreciably on the responses. The introduction of the Skilled Graduate Temporary visa (subclass 485) provided an alternative pathway to PR for those who missed out on the passmark for a permanent GSM visa. This latter pathway which continued to 'keep the doors open for PR', would reduce any bias caused by data incompatibility between UniSA and the University of Adelaide. Nevertheless, this is an important consideration during data analysis.

\subsection{In depth interviews with students and key informants}

The next step in primary data collection consists of in-depth interviews with Chinese and Indian students and several key-informants. In line with Punch (1998, pg 247), quantitative research contributed to the qualitative process by helping select student participants and as mentioned, qualitative research helped facilitate the quantitative aspect of this study. The interviews were on the whole structured on the same themes of the CISS survey.

While the CISS survey was able to provide an insight and answers to factors influencing the students, the decision making process is a dynamic and complex one. The interviews provided an avenue to probe the students for more clarity and detailed information (Johnson \& Turner 2003, pg 305). This approach brought to light and fleshed out the numbers and statistics produced from the surveys, allowing one to gain a comprehensive understanding of the motivations and future intentions of these students which was otherwise unavailable solely through the literature. For example, the influence of parents on the study plans of their children was complex as the literature appeared to contradict survey findings, however, the interviews illustrated and presented a clearer insight into how they factored into the decision making process (Section 7.6.3).

The interviews not only supplemented or clarified preliminary findings, but also offered an opportunity to explore new issues which arose during analysis of survey findings and even during the course of the interviews (Schoenberger 1991, pg 187; Secor 2010, pg 196). A semi-structured technique was adopted and question guides ${ }^{29}$ were created for the

\footnotetext{
${ }^{29}$ A copy of the question guides can be viewed in Appendix 9.
} 
interviews. The sessions were "organised around ordered but flexible questioning" (Dunn 2005, pg 88) and not solely restricted to the pre-determined questions in order to encourage the active engagement of interviewees, and to bring to surface the nuances and complexities of their attitudes and opinions. The interviews involved education agents, migration agents, university marketing staff and of course the students themselves. ${ }^{30}$

Each group of interviewees are important as they not only offer a different perspective but also are involved in various stages of the international student's educational sojourn. Education agents and university marketing staff in general deal with international students before they come to Australia, where students are in the early stages of deciding whether or not to go overseas, and making decisions on which Australian State, university or course to study in. Conversely, migration agents on the whole, actively engage with students during and after the course of their study. A total of 4 education agents ${ }^{31}, 3$ migration agents, 8 university marketing staff and 16 students were interviewed in depth for this study.

\subsubsection{The recruiting and interviewing process}

As earlier mentioned, interviews with key informants in Singapore and Adelaide were held prior to the CISS survey. The education agents in Singapore who represented the University of Adelaide, UniSA and Flinders University were selected from a database that was available on the respective website of each university. The same procedure was followed for migration agents in Adelaide who were selected from the register of migration agents available from the MARA (Migration Agents Registration Authority) website and university marketing staff was selected from their respective university directories.

When recruiting university marketing staff, each interviewee would suggest a fellow colleague whom they thought could add value to this study, a useful method as their colleagues appeared to be more willing and friendly upon the knowledge that their names were put forth by someone they worked with. Emails with an attachment explaining the study was sent to all key informants, requesting for an interview ${ }^{32}$, participant interest was

\footnotetext{
${ }^{30}$ See Appendix 12 for additional information on the characteristics of interviewees.

${ }^{31}$ An IDP student counsellor was interviewed and categorised as an education agent. Although they are not strictly considered as agents, their services are largely comparable to that of an education agent.

${ }^{32}$ A sample of the emails and information sheet sent to key informants can be viewed in Appendix 9.
} 
then measured by their replies. Recruiting Chinese and Indian students for in-depth interviews was done through the CISS survey. Respondents were asked to provide their contact information and email addresses if they were interested in further participation. Emails were then sent out to these potential student interviewees from the University of Adelaide and UniSA in September 2007 and September 2008 respectively. Again, participant interest was measured by replies. ${ }^{33}$

Follow up emails were then sent to all potential interviewees and meetings were arranged at a mutually agreed time and place. All meetings were held in familiar settings, such as the offices of key informants and in meeting rooms at the respective universities of students. Not only was this to reduce the inconvenience caused to them, but also it created a natural and inviting environment, to ensure that they were relaxed and did not resent their involvement in the study.

Straightforward in-depth interviews were used for key informants. Similarly, while it was originally intended to use focus group discussions to interview the students, a lack of sufficient responses resulted in the decision to conduct in-depth interviews and small group interviews (ranging between sizes of 2-4). Notwithstanding, the information gained from the interviews were rich, detailed and of high quality. In hindsight, it was a more suitable technique as students might have felt uncomfortable in discussing their motivations and future intentions (which can be quite private and sensitive) with other students in larger sized focus groups.

A total of 5 in-depth interviews and 4 small group interviews were organised. Students grouped according to their nationalities as this enabled greater discussion. The interviews lasted approximately one and a half to two hours. Taping the interviews was the preferred method as it allowed this researcher to fully concentrate on the interview and to maintain proper conversation without being sidetracked with the need to take notes. The interview could also be played back over and over again which allowed one to clarify or pick up on any issues or ideas which were unclear or missed (Valentine 2005, pg 123-124). A recording device was used with the permission of interviewees, this was reverted to note taking for those who objected to being recorded.

\footnotetext{
${ }^{33}$ A sample of the email sent to students requesting for their participation in focus groups/interviews can be viewed in Appendix 10.
} 
The interviews were largely based on a hybrid of funnel and pyramid structures with conversational, broad and basic questions asked at the beginning, before moving onto "more abstract and reflective aspects, before gradually progressing towards sensitive issues" (Dunn 2005, pg 86-87). Rapport was established as interviewees, particularly students, appeared to be less inhibited upon knowing this researcher's position as a permanent resident and former international student ${ }^{34}$, which Skop (2006, pg 120) posits to be useful in obtaining sensitive information not otherwise divulged.

The sensitive nature of the discussions must not be underestimated. For example, an interview with a Chinese student in his shared office (which was empty apart from us) saw a change in his body language when a fellow student entered and worked in his cubicle from across the room. His answers became guarded and this prompted the researcher to suggest a change in venue which was readily agreed to by the student.

Interviews were generally concluded with an air of continuity in the event of the need for future contact or the need for a second interview. Interviewees were thanked and presented (apart from key informants) with a \$10 gift card in appreciation for their time set apart from their busy schedules. They were also reassured that their identities would remain confidential (as pseudonyms would be used) and that the tapes would be erased after transcription.

\subsection{Study area and the CISS study population}

This section will give an overview and establish some characteristics of the Chinese and Indian students in the CISS survey, namely, their demographic profile, financial situation and educational background.

\subsubsection{Study area}

The fieldwork for this study was conducted mainly in metropolitan Adelaide, the capital city of South Australia. At the 2006 Census, the population of Adelaide was 1,105,839, approximately 73 percent of the South Australian population (ABS 2007b).

As earlier discussed (Section 3.7), the allocation of 5 bonus points for applicants who have physically spent time studying in a university based in a regional or low population growth

\footnotetext{
34 This researcher was an international student from 2000-2003 and has been a Permanent Resident in Australia since 2005 .
} 
metropolitan area, can be a motivating factor for international students. Most capital cities such as Sydney, Brisbane, Melbourne and Perth are excluded from this category (DIAC n.d-b), while Adelaide alongside Hobart and Darwin are afforded this status.

\section{Figure 5.1: Population distribution of capital cities in Australia}

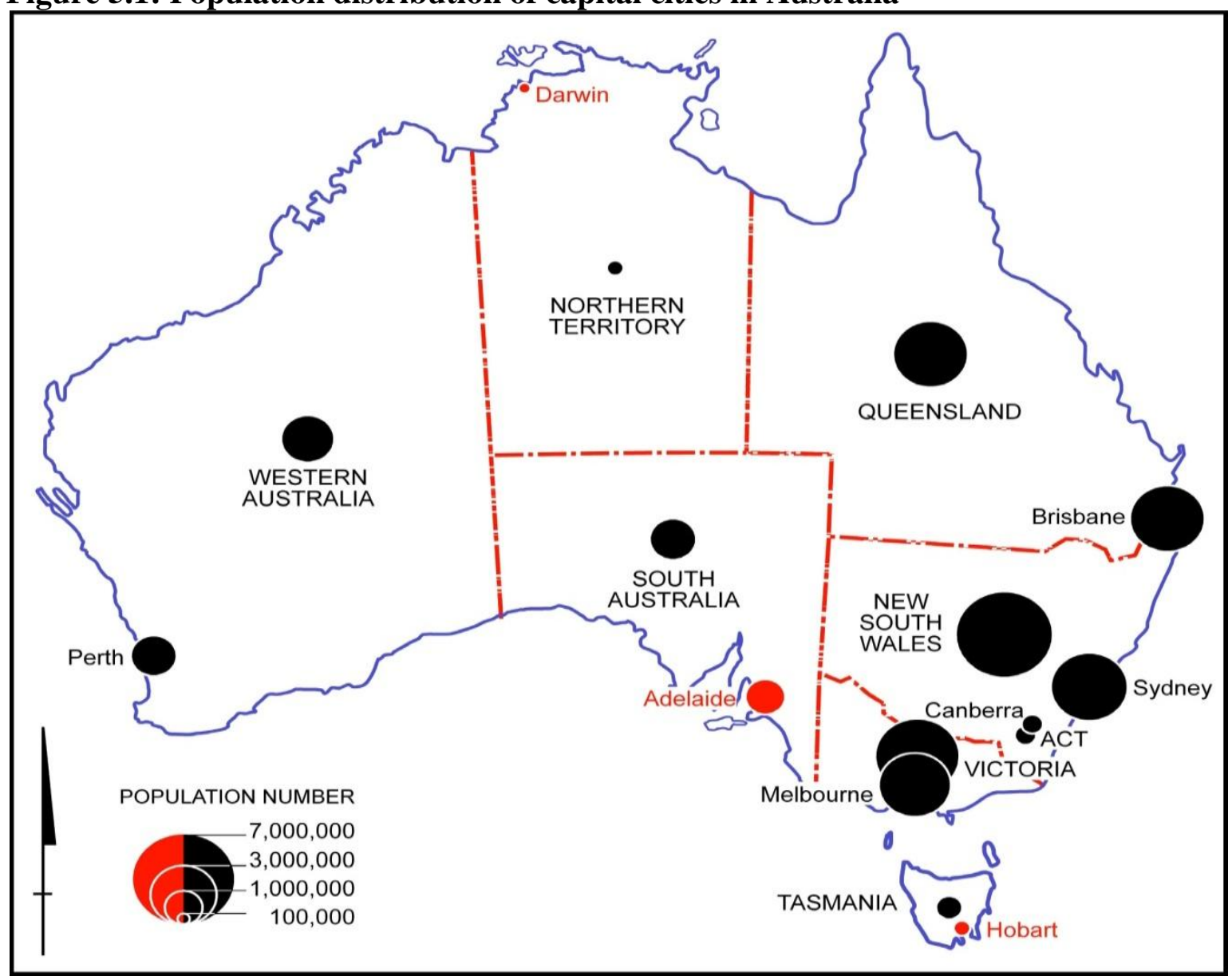

Source: ABS Census 2007b

As Figure 5.1 illustrates, Adelaide possesses a distinct advantage over other capital cities as it is the largest mainland capital city that has regional status. Moreover, that fact that that all three South Australian universities are based in metropolitan Adelaide further enhances its attractiveness as a study destination.

\subsubsection{The CISS survey population}

The quality of the CISS survey sample is determined by making comparisons with datasets from AEI and secondary data from the literature, these comparisons also set the context for discussion in subsequent chapters. As mentioned, the CISS survey was sent to all Chinese and Indian students enrolled onshore at the University of Adelaide and UniSA in 2007 and 2008 respectively. The response rate of the survey is shown in Table 5.1. There is an 
underrepresentation of Indian students as there were only 139 enrolled at the University of Adelaide compared to UniSA who had 1,160 enrolled.

Table 5.1: CISS surveys sent to Chinese and Indian students enrolled in the University of Adelaide and UniSA; and the response rate $(n=4088)$

\begin{tabular}{|c|c|c|c|c|c|c|}
\hline & Chinese & $\begin{array}{c}\% \text { of } \\
\text { Chinese } \\
\text { response }\end{array}$ & Indian & $\begin{array}{c}\% \text { of Indian } \\
\text { response }\end{array}$ & Total & $\begin{array}{c}\text { Total } \\
\text { Percentage } \\
\text { response }\end{array}$ \\
\hline $\begin{array}{c}\text { University of } \\
\text { Adelaide }\end{array}$ & 1673 & $\begin{array}{c}15.8 \\
(n=264)\end{array}$ & 139 & $\begin{array}{c}23.7 \\
(n=33)\end{array}$ & 1812 & $\begin{array}{c}16.4 \\
(n=297)\end{array}$ \\
\hline UniSA & 1116 & $\begin{array}{c}6.6 \\
(n=74)\end{array}$ & 1160 & $\begin{array}{c}7.2 \\
(n=84)\end{array}$ & 2276 & $\begin{array}{c}6.9 \\
(n=158)\end{array}$ \\
\hline Total & 2789 & $\begin{array}{c}12.1 \\
(n=338)\end{array}$ & 1299 & $\begin{array}{c}9 \\
(n=117)\end{array}$ & 4088 & $\begin{array}{c}11.1 \\
(n=455)\end{array}$ \\
\hline
\end{tabular}

Source: CISS Survey 2007; 2008

A UniSA staff member attributes this disparity to the emphasis placed on the Indian student market by UniSA:

It's fair to say first of all that UniSA, the university has been most successful in India. ... Going back about 5 years ago, there was a lot of focus on China, but there was very little focus that I could see on India. And yet when I did the research into India, everything sort of told me this is a market that we..that really should be doing much better in. Because at that stage the evidence showed that very large numbers were going to the US and to the UK. So, the question was whether it was a profile thing about Australian education that we needed to work on and improve. And so we went into the Indian market in quite a heavy way and we've been very successful in attracting them here.

...we've done really well there [in India] but Adelaide hasn't. And that's marketing approaches, they haven't been anywhere near as engaged or active in India as we have.

- Peter, Marketing Staff (UniSA)

Nevertheless, the use of mixed methods in data collection and, comparisons with national data on these students strengthened and lent further weight to the quality of the findings in this study.

\subsubsection{Demographic profile of CISS respondents}

This section will outline the demographic profile of survey respondents by examining both survey data and national statistics. There were a total of 455 valid responses with a larger proportion of Chinese compared to Indians. As Figure 5.2 illustrates, $72.5 \%$ of respondents 
were Chinese, with Indians making up the remaining $25.1 \%$ and $2.4 \%$ failed to complete the survey and/or indicate their nationality.

Figure 5.2: Breakdown of CISS respondents by nationality $(n=455)$

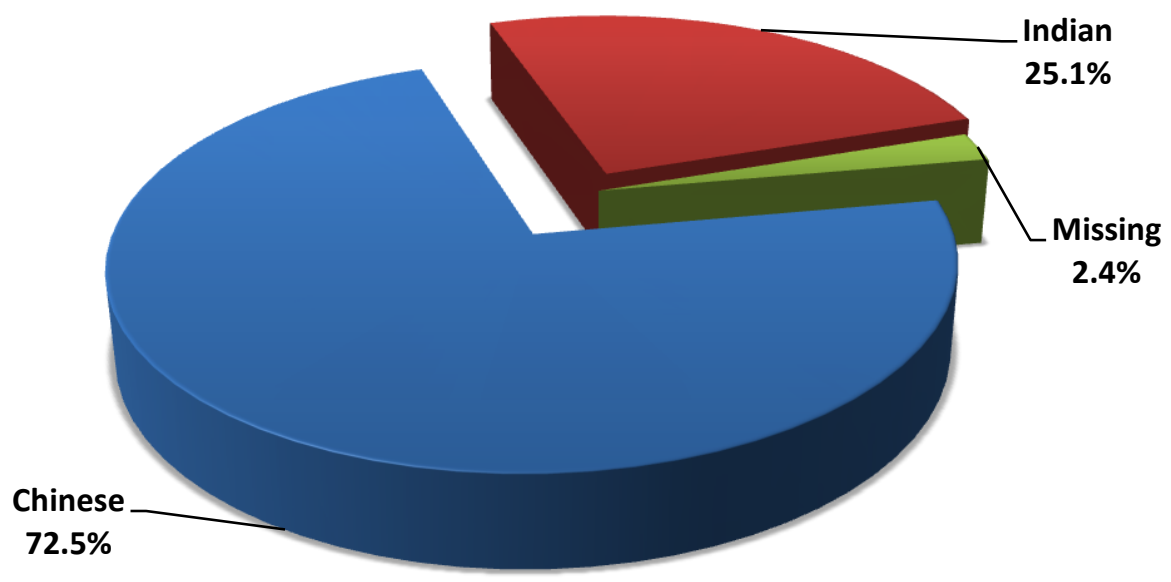

Source: CISS Survey 2007; 2008

Figure 5.3 shows the national data on the age distribution of Chinese and Indian students in Australia in 2008. The majority of the cohorts for both groups were in the 20-24 year age group (54.4\% and 54.6\% respectively) although it appears that Indian students were older with approximately a third in the 24-29 year age group (31.9\%). In contrast, there were 20 percent in this group for Chinese students. The higher proportion of Chinese students in the 15-19 year age group underlines the more youthful nature of this group of students.

Figure 5.3: AEI data on the age distribution of Chinese $(n=96,753)$ and Indian $(n=75390)$ students in Australia 2008

\section{NOTE:}

This figure is included on page 114 of the print copy of the thesis held in the University of Adelaide Library. 
Comparisons with the AEI data and the CISS survey were slightly skewed due to the obvious differences in the size of the sampling frames, however, on the whole, there was some correlation. As Figure 5.4 shows, similarities emerge with a comparable concentration of Chinese respondents in the 20-24 year age group (55.6\%). Indian respondents on the other hand were concentrated in the 25-29 year age group (45.3\%).

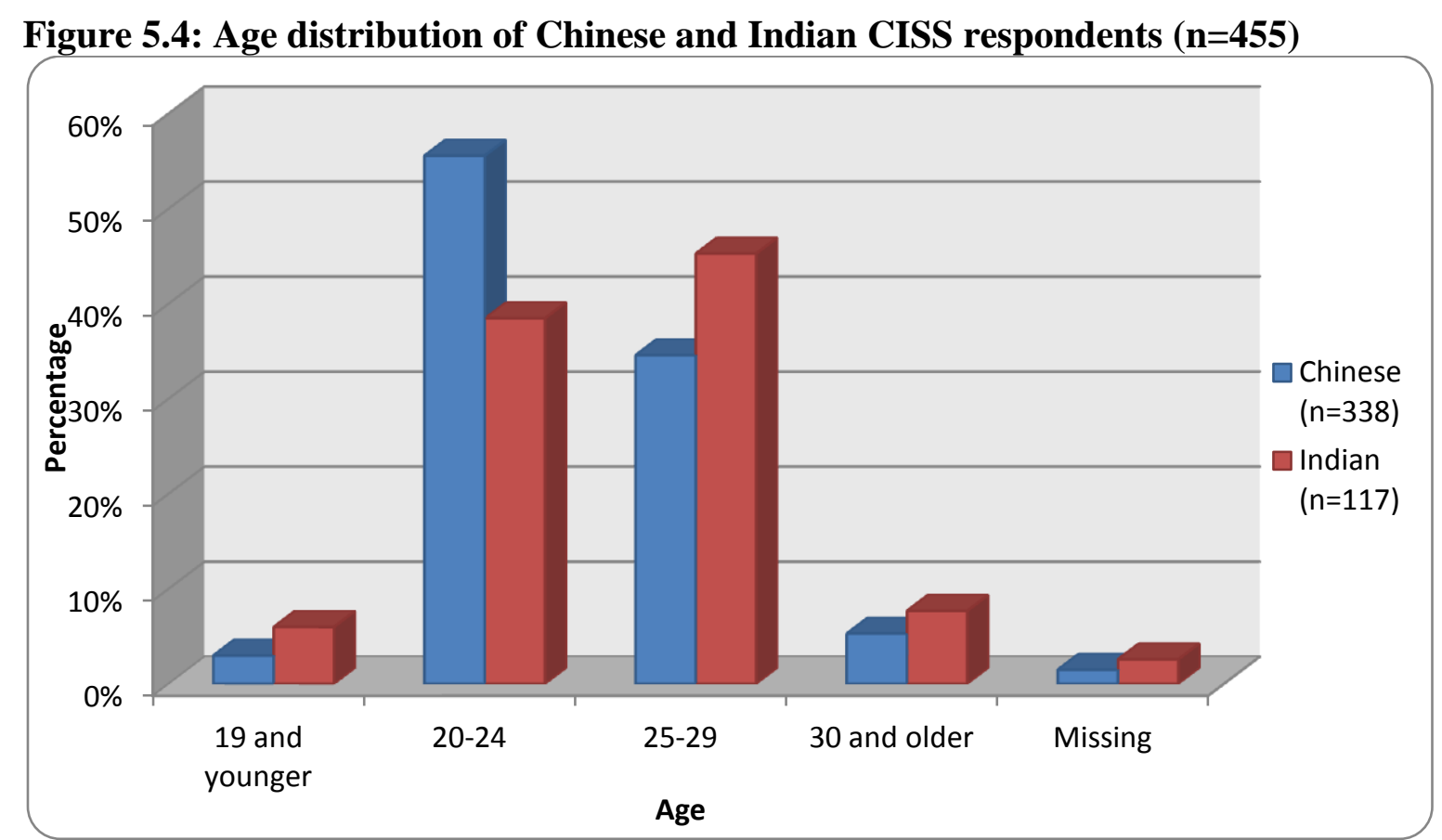

Source: CISS Survey 2007; 2008

Comparing the average age of the CISS respondents reveals Indian students to be slightly older. They had an average age of 25.16 compared to the Chinese who had an average age of 24.17. And as Table 5.2 shows, the average age of the students in the AEI data is not dissimilar from the CISS the survey with Indians in general slightly older than their Chinese counterparts.

Table 5.2: Average age of Chinese and Indians in the AEI and CISS data

\begin{tabular}{|lcc|}
\hline AEI average age (years old) & Chinese & Indian \\
\hline CISS average age (years old) & 22.2 & 24 \\
\hline
\end{tabular}

Source: Adapted from AEI 2009a and CISS Survey 2007; 2008

In addition, the age structure of CISS respondents corresponds with the marital status of these students. As seen in Fig 5.5, while slightly more Indian student respondents (15.4\%) 
were married compared to Chinese student respondents (10.8\%), the vast majority were single as indicated by approximately 84 percent of Chinese and Indian student respondents, a common trait among international students in other studies (Khawaja \& Dempsey 2007; Shanka \& Musca 1998).

Figure 5.5: Marital status of Chinese and Indian CISS respondents $(n=455)$

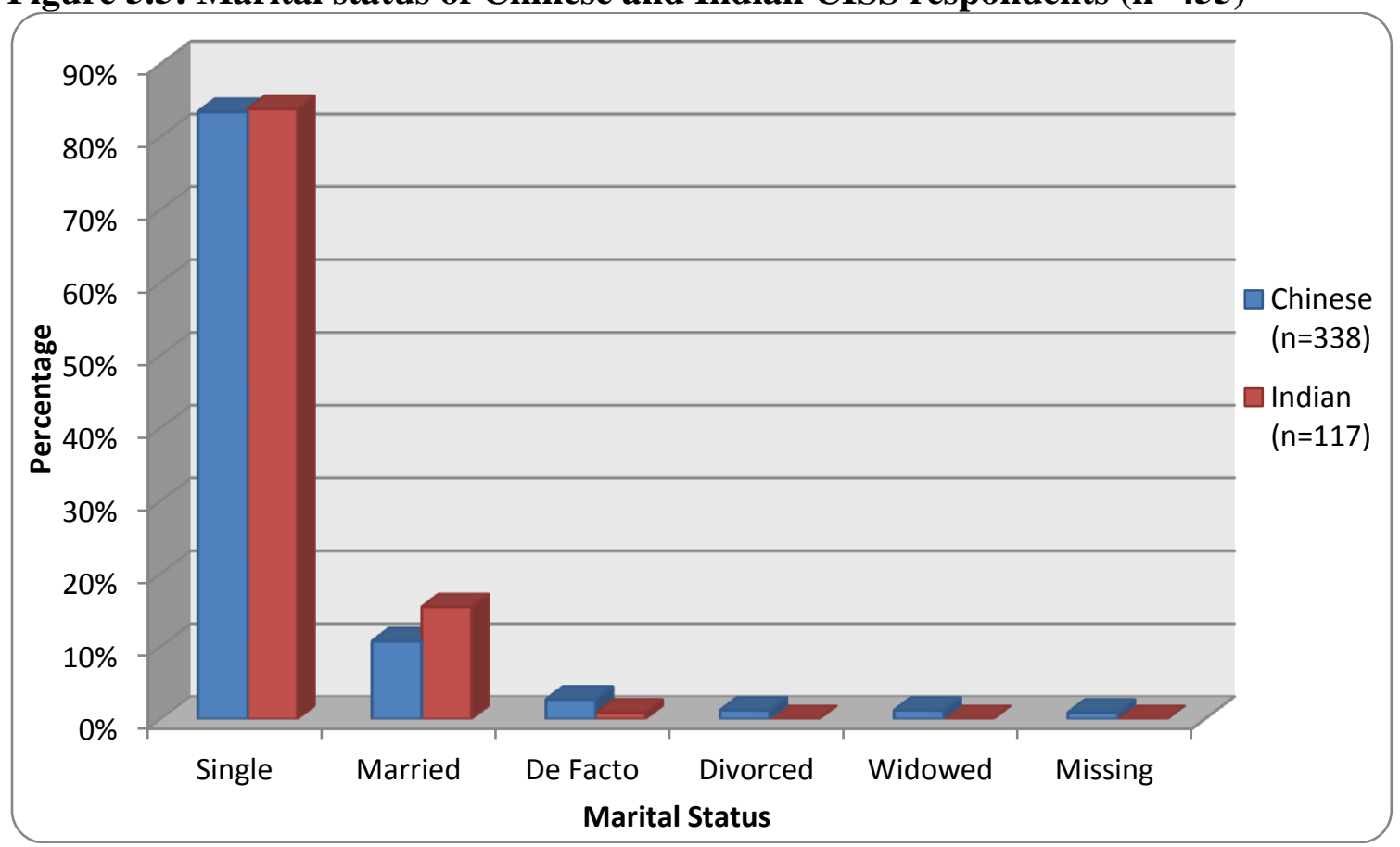

Source: CISS Survey 2007; 2008

Overall, when juxtaposed with AEI data, the CISS has shown itself to be in line with national trends which strengthen the quality of the survey data. The following section will continue profiling other aspects of respondents from the CISS survey.

\subsection{Educational background of Chinese and Indian respondents}

The section will continue 'profiling' Chinese and Indian students by examining their educational backgrounds (Figure 5.6) before their arrival into Australia. It is likely that course selection plays a big role in their migration strategies. Therefore, knowing their highest qualifications held before coming to Australia, will inform the levels and the type of courses they pursue in Australia.

Concerns were raised earlier with regards to misunderstanding questions. In this instance, this appears to be the case when determining the highest qualifications held by respondents before coming to Australia. Some respondents misinterpreted highest qualification to mean their current study. This misinterpretation was identified when answers regarding their 
highest completed qualification, its field of education and country where it was obtained, were similar to their answer on the course they were currently enrolled in Australia. ${ }^{35}$ Nevertheless, the majority of students were ascertained to have understood the question correctly. Figure 5.6 excludes 96 Chinese and 26 Indian respondents who were ascertained to have misinterpreted the question.

\section{Figure 5.6: Highest qualification held by Chinese and Indian CISS respondents} $(\mathbf{n}=333)$

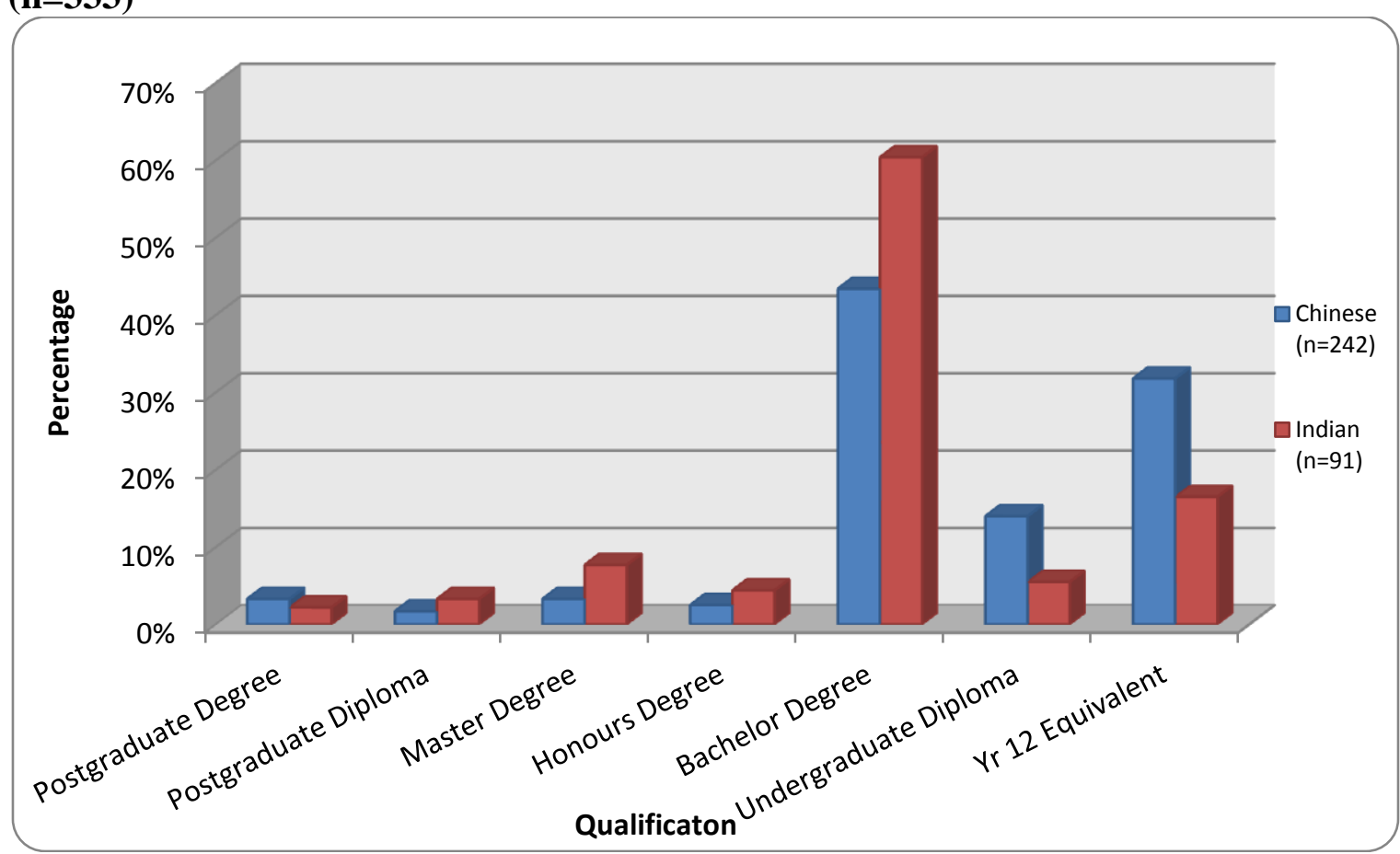

Source: CISS Survey 2007; 2008

Respondents from both countries predominantly possessed a Bachelor degree before coming to Australia which applied to 60.4 percent of Indian to 43.4 percent of Chinese respondents. Conversely, there were a higher proportion of school leavers (Year 12 equivalent) for Chinese (32\%) as opposed to Indian respondents (17\%).

While one can link the considerable proportion of Indian respondents with Bachelor degrees and the higher proportion of Chinese as school leavers to their relative age structures, it is important to consider how these differences might also influence their educational pathways or migration strategies in Australia. This is evidenced in the uneven concentration of the respondents enrolled at undergraduate and postgraduate levels as seen from Figure 5.7.

\footnotetext{
${ }^{35}$ Answers to questions D6 to D7 of the CISS were similar to answers to question D8.
} 
Figure 5.7: Level of enrolment for Chinese and Indian CISS respondents $(n=455)$

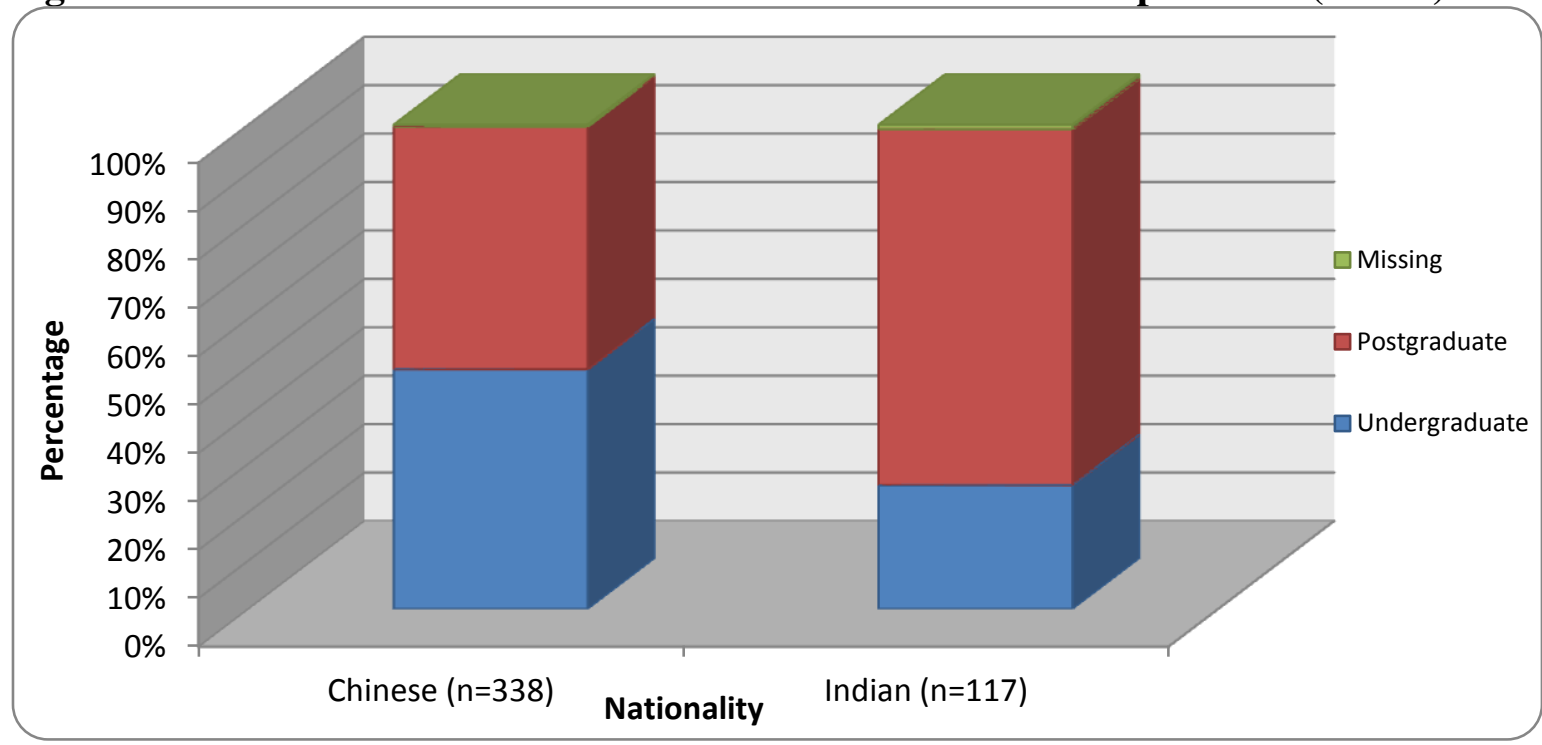

Source: CISS Survey 2007; 2008

The tendency of Indian respondents studying at the postgraduate level is clear with 73.5 percent enrolled at that level. In comparison, Chinese student respondents were balanced at both undergraduate and postgraduate levels. AEI (2009a) data in Figure 5.8 reveals a similar trend from 2002-2008 as the majority of Indian students were enrolled in postgraduate courses, while the Chinese were relatively less disparate at both levels. This further strengthens the quality of the CISS survey.

Figure 5.8: Postgraduate and undergraduate enrolment of Chinese and Indian students in Australia 2002-2008

\section{NOTE:}

This figure is included on page 118 of the print copy of the thesis held in the University of Adelaide Library. 
AEI data (2008c) reflected a similar shift away from the international undergraduate to the international postgraduate market in Australia. Nearly 4 out of 5 postgraduate enrolments in $2007(80.5 \%)$ were concentrated at the Masters by coursework level as shown in Table 5.3 , highlighting the preference by international students for postgraduate coursework degrees.

Table 5.3: Distribution of international enrolments at postgraduate level in Australia in $2007(n=79,635)$

NOTE:

This table is included on page 119 of the print copy of the thesis held in the University of Adelaide Library.

Source: AEI $2008 \mathrm{c}$

Analysis of AEI (2008c) data revealed the rapid growth of Chinese and Indian students at the Masters by Coursework level, increasing at 71 percent and 170 percent respectively from 2002-2007. In 2007, Chinese and Indian students largely constituted (57\%) the Masters by Coursework level ${ }^{36}$. A distinct preference for several particular courses was noted at this level with a majority of all commencements in 'Management and Commerce' $(56 \%)$ and this was largely attributed to 'Accounting' and 'Business and Management' (73\%). Again, Chinese and Indian students had a significant presence as they made up approximately 60 percent of commencements in these particular fields.

Examination of the CISS survey corresponds with national trends with respondents concentrated in similar broad fields of education. 'Management and Commerce' as depicted in Figure 5.9, was the most popular field as reflected by nearly half of Chinese (49.1\%) and nearly a quarter of Indian respondents (23.1\%). This was followed by 'Engineering and Related Technologies', 'Information Technology' and 'Health'.

36 AEI (2008) included Masters by Coursework, graduate certificate and diploma, Masters preliminary, vocational graduate certificate and diploma. 
Figure 5.9: The broad fields education and levels enrolled in by Chinese $(n=338)$ and Indian $(n=117)$ CISS respondents

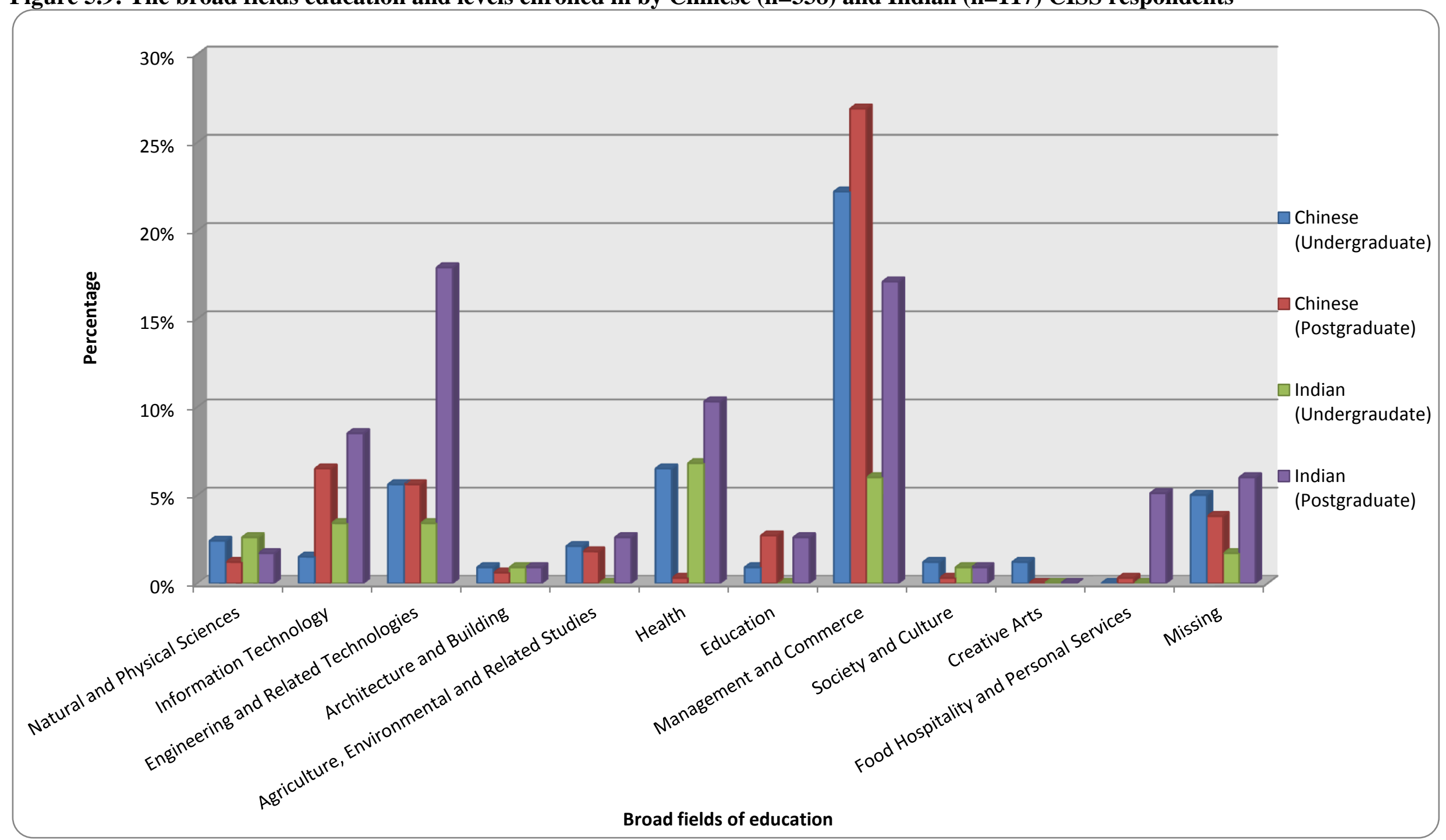

Source: CISS 2007: 2008 
In addition, there were more Chinese and Indian respondents enrolling in postgraduate than undergraduate courses in 'Management and Commerce', 'Engineering and Related Technologies' and 'Information Technology'. AEI data shows a similar preference for these courses particularly at the postgraduate level which continues to verify the strength of the CISS survey. Unfortunately, it is hard to make further comparisons as the survey did not seek responses on the nature of their Masters programmes (Coursework or Research) or the specific field of education. Notwithstanding, the similar trends between AEI and CISS datasets strongly suggests that course selection, especially at the postgraduate level could play a strategic role in the decision making process of Chinese and Indian international students.

As discussed in Chapter $3.6^{37}$, the deliberate selection of courses in the 'appropriate' fields of education can be a part of the transnational migration strategy of students as it enhances the likelihood of obtaining PR. While it is inadvisable to regard the survey data as a representative sample, the comparison between AEI and CISS survey data indicate the CISS student population is in line with the wider Chinese and Indian international student cohort in Australia.

\subsection{Financial discussion on Chinese and Indian respondents}

The aim of this sector is to uncover how Chinese and Indian students fund their courses and their living expenses whilst studying in Australia. The findings will give an insight into how their respective financial situations will influence their motivations, future intentions and subsequently their transnational strategies in Australia.

It is noted that there is a severe lack of empirical information on the financial situation of international students in Australia. A small number of Australian based studies (ForbesMewett et al. 2007; Krause et al. 2005, pg 77) also consistent with other studies in the US (IIE 2009) and New Zealand (Butcher \& McGrath 2004; Ward \& Masgoret 2004), have shown international students in general to rely on their families, particularly their parents. Survey data as presented in Figures 5.10 and 5.11 portray a slightly different picture for Indian students.

\footnotetext{
${ }^{37}$ See Chapter 3.6 for a detailed analysis on the points system and MODL occupations.
} 
Figures 5.10 and 5.11 demonstrate that Chinese respondents are largely reliant on their parents/family for their tuition fees (87.9\%) than Indian respondents (38.5\%). Indian students relied more heavily on bank loans, evidence of the Educational Loan Scheme's role in financing their education abroad (Gillan et al. 2003; Mazzarol et al. 2001a, pg 24). Additionally, 41.9 percent of Indians indicated working in Australia while studying as the main source of funds for their living expenses, quite the opposite for the majority of Chinese respondents who relied on their parents/family for their living expenses (53.2\%).

Figure 5.10: Source of tuition fee for Chinese and Indian CISS respondents $(n=455)$

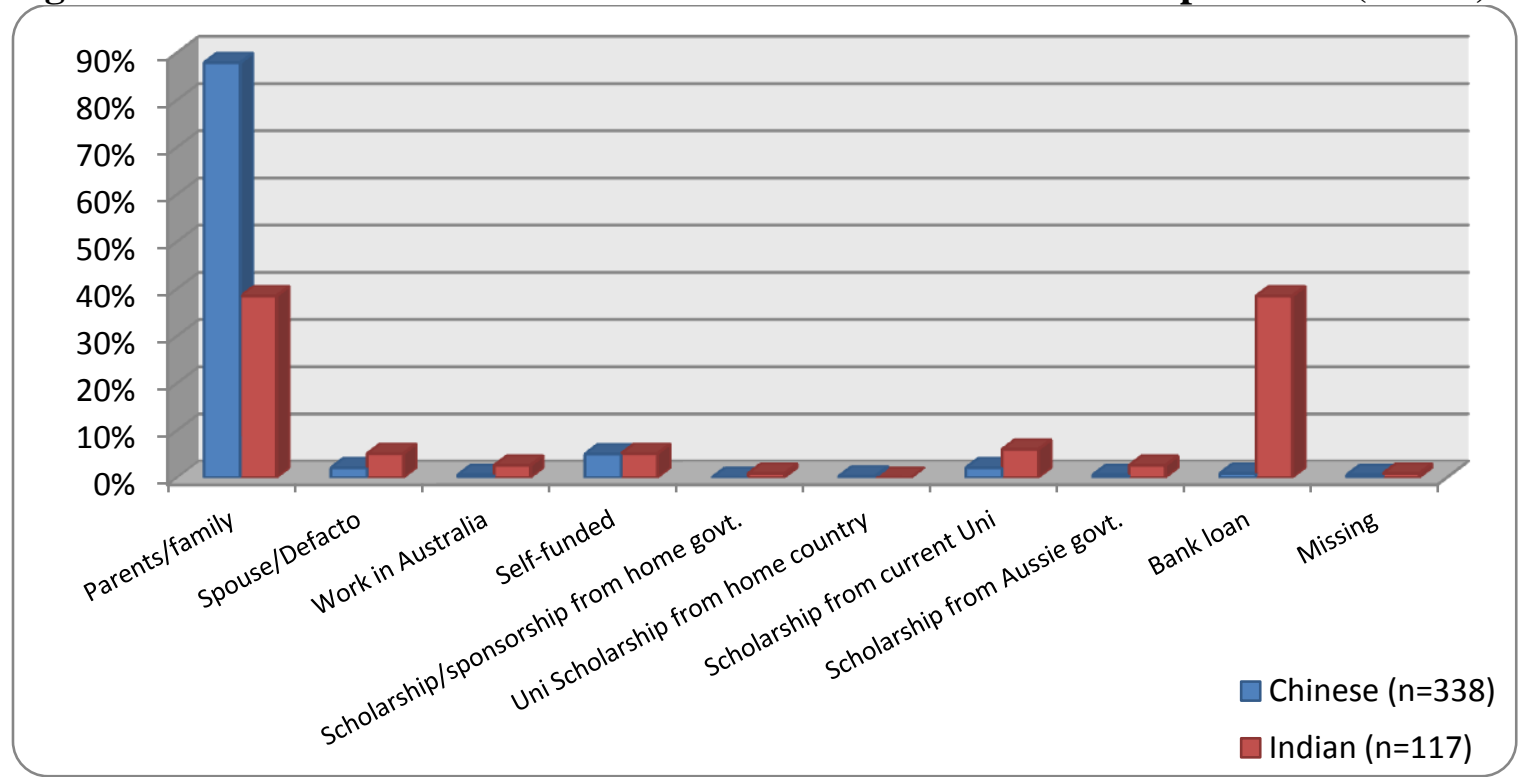

Source: CISS 2007; 2008

Figure 5.11: Source of living expenses for Chinese and Indian CISS respondents $(\mathrm{n}=455)$

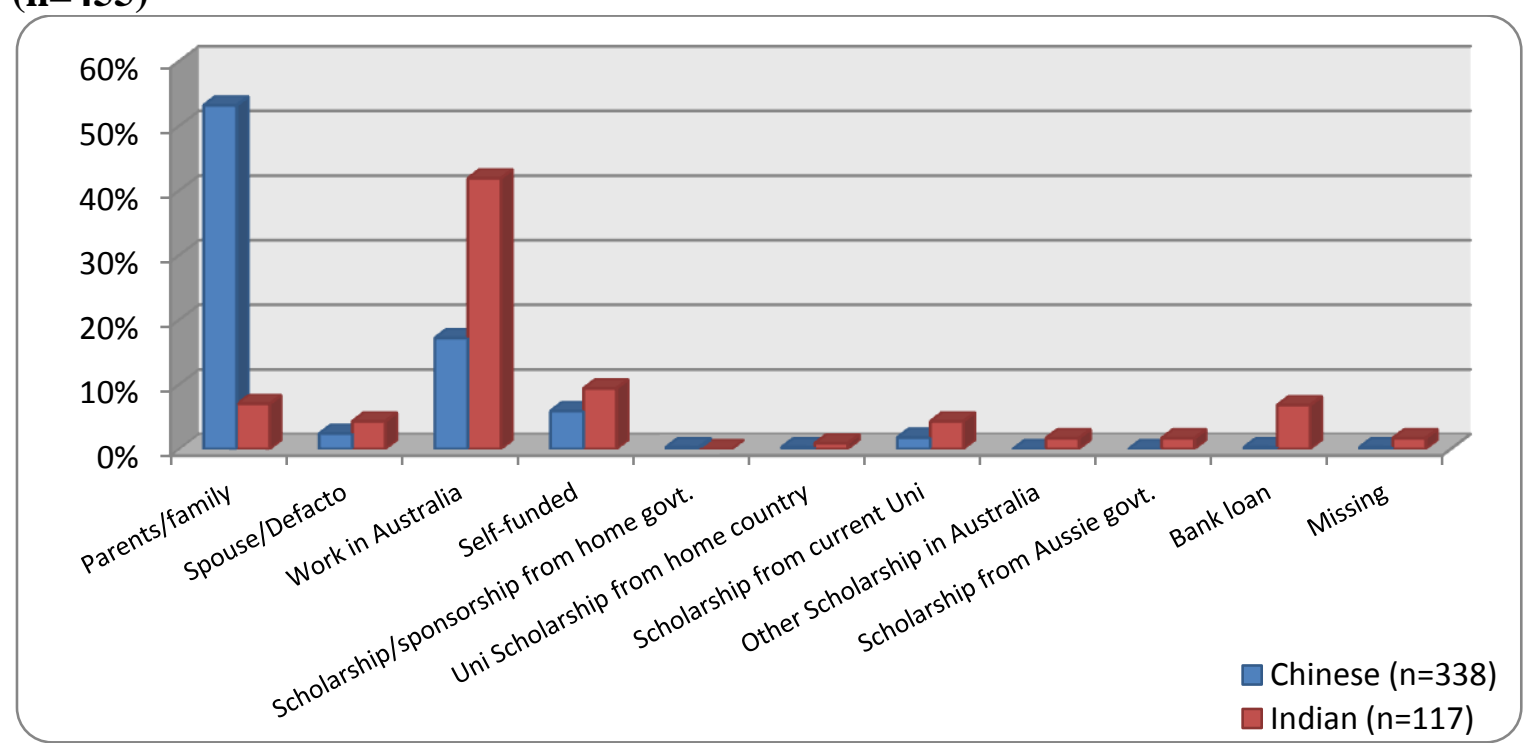


In a sense, the findings suggest Indian students in general to be less well-off than Chinese students. Additional survey indicators, such as the parental occupations of the students (Table 5.4), bear this out and provide further insight into the difference on parental support between the two groups of students.

As Table 5.4 reveals, Chinese parents are predominantly in white collar occupations with nearly half of all Chinese fathers in Managerial/Administrative positions. Chinese mothers are in similar occupations with 28.4 and 24.3 percent in Professional and Managerial/Administrative positions respectively. In comparison, there were fewer Indian parents in these 'high end' occupations with about a quarter of Indian fathers in Managerial/Administrative occupations. Additionally, the composition of Indian mothers was also different with about half as Homemakers/Housewives and 22.2 percent in Professional occupations.

Furthermore, a much higher proportion of Indian fathers were retired as opposed to Chinese fathers. Similarly, about half of all Indian mothers were generally unpaid Homemakers/Housewives. These findings lend weight to the assumption that Chinese students are from relatively wealthier backgrounds due to a higher proportion of Chinese parents in paid employment and in highly skilled occupations.

As illustrated in Table 5.5, the higher proportion of Indian respondents who worked ${ }^{38}$ in the last year continues to lend weight to the suggestion that they are from relatively less wealthy backgrounds than their Chinese counterparts. Working is important for many international students (Mazzarol \& Soutar 2002, pg 89) but it is particularly prevalent amongst Indian students as they worked significantly more weeks per year than Chinese students (Figure 5.12).

A similar trend emerged in Figure 5.13 which shows a higher proportion of Indian respondents working longer hours. Chinese respondents mostly worked around 5-10 hours a week (39.5\%) compared to $18.6 \%$ of Indian students. Conversely, 43.1 percent of Indian students worked more than 20 hours a week compared to 8.9 percent of Chinese respondents working the same hours.

\footnotetext{
${ }^{38}$ Australia's student visa regulations permit international students to work up to 20 hours a week during the semester and fulltime off semester (see: www.immi.gov.au/media/fact-sheets/50student.htm)
} 
Table 5.4: Occupation of parents of Chinese and Indian CISS respondents $(n=455)$

\begin{tabular}{|c|c|c|}
\hline \multicolumn{3}{|c|}{ Father's occupation for CISS respondents } \\
\hline & $\%$ of Chinese $(n=338)$ & $\%$ of Indian $(n=117)$ \\
\hline Managers/Administrators & 46.4 & 27.4 \\
\hline Professional & 18.6 & 17.9 \\
\hline Associate Professional & 11.8 & 12.8 \\
\hline Trades & 7.1 & 6.0 \\
\hline Clerical & 1.2 & 5.1 \\
\hline Sales and Services & 3.3 & 2.6 \\
\hline $\begin{array}{l}\text { Plant and machine } \\
\text { operators and drivers }\end{array}$ & 0.6 & 0.9 \\
\hline $\begin{array}{l}\text { Labourers and related } \\
\text { workers }\end{array}$ & 3.0 & 2.6 \\
\hline Retired & 3.3 & 17.9 \\
\hline Not Applicable & 2.4 & 6.0 \\
\hline Missing & 2.4 & 0.9 \\
\hline \multicolumn{3}{|c|}{ Mother's occupation for CISS respondents } \\
\hline & $\%$ Chinese $(\mathbf{n}=338)$ & $\%$ Indian $(\mathrm{n}=117)$ \\
\hline Managers/Administrators & 24.3 & 2.6 \\
\hline Professional & 28.4 & 22.2 \\
\hline Associate Professional & 7.4 & 4.3 \\
\hline Trades & 5.0 & 0.9 \\
\hline Clerical & 5.6 & 4.3 \\
\hline Sales and Services & 7.1 & 1.7 \\
\hline $\begin{array}{c}\text { Plant and machine } \\
\text { operators and drivers }\end{array}$ & 0.6 & 0.0 \\
\hline $\begin{array}{l}\text { Labourers and related } \\
\text { workers }\end{array}$ & 5.3 & 0.9 \\
\hline Retired & 7.7 & 4.3 \\
\hline Homemaker/Housewife & 5.9 & 50.4 \\
\hline Not Applicable & 1.2 & 5.1 \\
\hline Missing & 1.5 & 3.4 \\
\hline
\end{tabular}


Table 5.5: Proportion of Chinese and Indian CISS respondents who worked for pay in the last year $(n=455)$

\begin{tabular}{|c|cc|}
\hline Yes & \% of Chinese $(\mathrm{n}=338)$ & \% of Indian $(\mathrm{n}=\mathbf{1 1 7})$ \\
\hline No & 46.4 & 61.5 \\
\hline Missing & 53.3 & 37.6 \\
\hline
\end{tabular}

Source: CISS 2007; 2008

Figure 5.12: Weeks worked/year for Chinese and Indian CISS respondents $(n=455)$

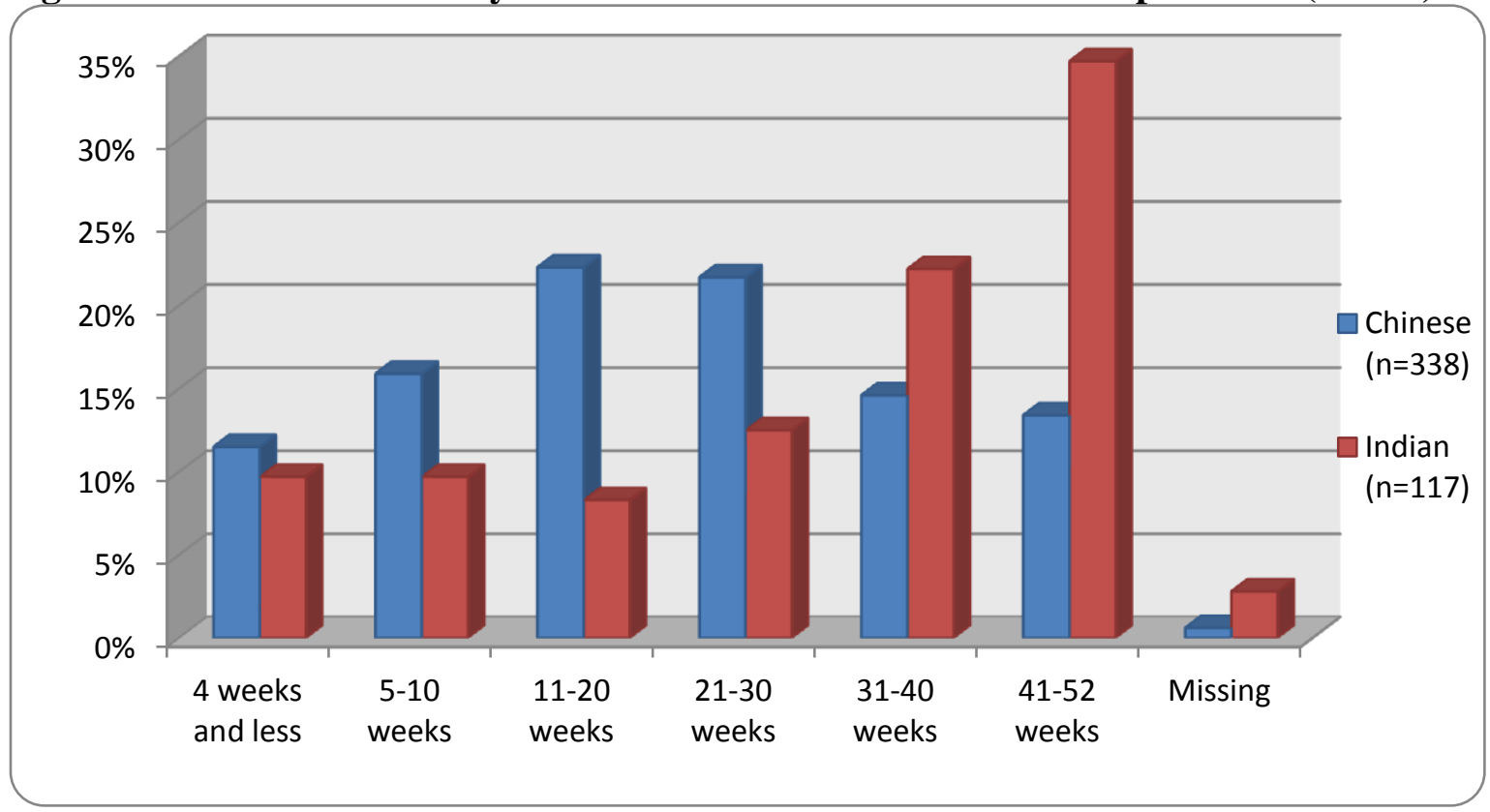

Source: CISS 2007; 2008

Figure 5.13: Hours worked/week for Chinese and Indian CISS respondents $(n=455)$

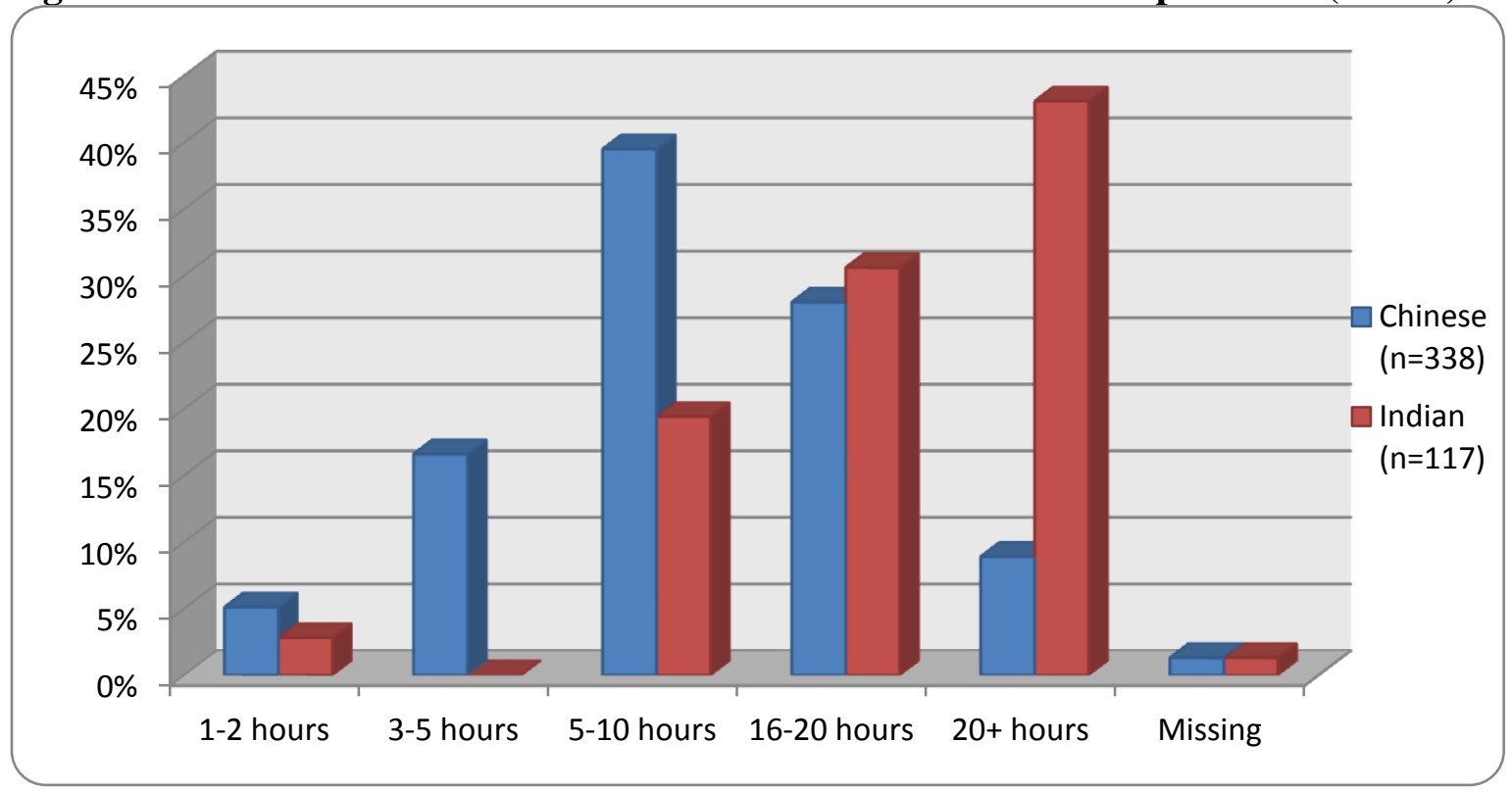

Source: CISS 2007; 2008 
The evidence presented so far suggests how the disparity in wealth between Indian and Chinese parents can influence the differences in part-time and casual work patterns for Chinese and Indian students. Moreover, this evidence continues to support earlier discussion on the importance of having work rights on a student visa for these students (Section 2.5.8.1) and raises the need to investigate the value of part-time employment in the decision making process of Chinese and Indian students studying in Australia.

\subsection{Conclusion}

This chapter has addressed the various triangulation methods used for this study. The design process of the CISS survey and its distribution was explained along with the semistructured interviews held with key informants and students. Findings from CISS survey contributed to understanding the general nature of the students' migration, the factors involved in their decision making process, the objective of PR in their educational sojourn and their future plans. And the qualitative aspect allowed verification and further analysis of issues that cropped up in the survey. Additionally, the quality of the sample was established through comparison with AEI datasets and secondary literature.

Profiling Chinese and Indian respondents revealed differences in age which could be related to courses being pursued. Although, the majority of the respondents were single and youthful, Indians appeared to be slightly older than the Chinese; which was attributed to the higher proportion of Indian students enrolled in postgraduate courses compared to Chinese students. Additionally, the educational background of CISS respondents highlighted 'Management \& Commerce' and 'Information Technology' as the two most popular broad fields of education. While these fields are considered to be popular due to their 'global transferability' as suggested by Marginson (2002), the positive relationship between enrolments in these courses and the MODL is indicative of a migration strategy which requires further investigation. Further, the data analysis shows Indian students are less reliant on their parents/family for financial support while living and studying in Australia. The financial backgrounds between the two groups of students evidently plays a role in their decision making process and their motivations and future intentions. The role of each of these factors in the transnational strategies of Chinese and Indian students will be elaborated in Chapters 6 and 7 . 


\section{CHAPTER 6: The Decision Making Process of Chinese and Indian Students coming to Australia}

\subsection{Introduction}

As discussed in Chapter 2, there are many factors that motivate Chinese and Indian students in pursuing an overseas education. This chapter analyses survey data regarding the decision making process of Chinese and Indian students in Australia. The decision to study abroad and select Australia and Adelaide as study destinations will first be examined. This approach will establish the motivations and the various factors, processes, social fields involved in their decision making process. These findings will be related to migration theory to highlight the interaction of macro, micro and meso structures and how they shape the migration of students. By doing so, this chapter will increase the understanding on how the transnational migration strategies of Chinese and Indian students are formed.

The investigation will not only ascertain how the two groups of students are motivated but also test the conceptual model depicted in Figure 4.2. Furthermore, the findings will elucidate the nexus between international education and permanent migration, particularly in determining the 'pre-planned' nature of permanent migration via international education. Additionally, the recursive relationship in transnational social spaces within transnational strategies of students will be examined, illustrating the strategic configuration of study destinations and their function in the transnational strategies of Chinese and Indian students.

\subsection{The decision to study overseas}

As discussed in Chapter 2, the decision to study abroad often revolved around the perceived poorer quality and standards of Chinese and Indian universities which were largely attributable to macro level structures exacerbated by government policy. While findings shown in Table 6.1 support the literature, the relatively smaller proportion of respondents who indicated that 'Lower Quality of course', 'Limited or no academic freedom in home country', 'Course not available in home country', 'Poor Reputation of Universities' and the failure to gain a place at a domestic university downplays the importance of such macro structures as the literature suggests. 
Table 6.1: Main reasons for decision not to study at an institution in their home country $(n=455)$

\begin{tabular}{|c|c|c|c|}
\hline & $\begin{array}{c}\text { Total } \\
\% \\
\mathrm{n}=(\mathbf{4 5 5})\end{array}$ & $\begin{array}{c}\text { Chinese } \\
\% \\
(n=338)\end{array}$ & $\begin{array}{c}\text { Indian } \\
\% \\
(n=117)\end{array}$ \\
\hline Wanted experience of studying abroad & 80.2 & 83.1 & 71.8 \\
\hline $\begin{array}{l}\text { Wanted to improve my command of English by } \\
\text { studying abroad }\end{array}$ & 60.4 & 73.1 & 23.9 \\
\hline To improve future career prospects & 44.2 & 41.1 & 53 \\
\hline Lower Quality of course & 18 & 20.1 & 12 \\
\hline Limited or no academic freedom at home country & 11.2 & 12.1 & 8.5 \\
\hline Parental Decision & 9.9 & 10.9 & 6.8 \\
\hline Course not available in home country & 9.9 & 5.6 & 22.2 \\
\hline Poor Reputation of Universities & 6.8 & 6.5 & 7.7 \\
\hline Not admitted to home country & 4.6 & 5.3 & 2.6 \\
\hline
\end{tabular}

Source: CISS 2007; 2008

The study abroad decision was indirectly associated with economic motivations. A significant 44.2 percent of respondents reflected that the acquisition of an overseas degree would improve their future career prospects. Having an overseas education is a form of human capital accumulation, with the potential to maximise future earnings as foreign qualifications were highly regarded by employers back home and abroad (Bodycott 2009, pg 359; Gillan et al. 2003, pg 1401; Mazzarol et al. 2001b, pg 36). One would imagine that the opportunity cost of not studying abroad would limit their future careers and earnings, such views were backed up by student interviewees.

Studying overseas is to boost my career. To get into an IMM college is very hard in India although they will make the career for you. Just get in first and then jobs will be waiting for you. So going overseas will boost my career rather than if I remain in India.

-Kunal, Indian student in MBA (UniSA)

Chinese degree may not guarantee a job in China but an overseas degree is more respected. My friends did not attend all the lectures but only focus on the exams and graduating because getting that piece of paper will help get a job back in China

-Wendy, Chinese student in Master of Commerce-Accounting (University of Adelaide) 
Chapter 6: The decision making process of Chinese and Indian students coming to

By and large, Table 6.1 reflects how respondents were driven by the desire to experience an overseas education (80.2\%) and to improve their English (60.4\%). This correlates with studies which emphasise the linguistic objectives of students (Marginson 2004, pg 220; Yao 2004, pg 21) due to the recognition of English as a world language (Stevens et al. 2006). Gaining a better grasp of English would open doors to employment in most parts of the world (Huang \& Yeoh 2005, pg 391), further emphasising the objective of human capital accumulation. Nearly a quarter of Indian respondents had the aim of improving their English, however, it paled in comparison to nearly 75 percent of Chinese respondents who indicated so. This drastic difference is linked to India's colonial history and that education in India is taught in the English medium (Gillan et al. 2003, pg 1395; Islam \& Borland 2006, pg 2; Khadria 2002, pg 11), compared to the Chinese whose education is carried out in their native mother tongue. Linguistic objectives are also closely linked to the desire to have a Western experience which can be explained by the increased exposure and dominance of Western cultures, lifestyles and technology (Gao \& Liu 1998, pg 39; Khadria 2002, pg 37; Mazzarol et al. 2001b, pg 23).

Although parental influence was indicated by a tenth of respondents, their influence should not be underestimated. As mentioned earlier (Section 4.3.1), it is a form of new economics of labour migration with parents often the main decision makers especially among the Chinese diaspora (Andressen 1991; Hugo 1994; Tan 2003; Waters 2005). There appears to be a dearth of literature on the influence of Indian parents. The findings in Table 6.1 in this instance are not dissimilar with more Chinese than Indian respondents (11\% and 6.8\% respectively) indicating parents to be key decision makers in the study abroad decision. Hence, the degree and the nature of influence parents have on their children's transnational migration strategies will be examined later.

The findings in this section suggest that Chinese and Indian students are mainly motivated by economic motivations via human capital accumulation. In addition, it appears that Chinese and Indian respondents are affected by factors differently. For example, although the desire for overseas study experience was the biggest motivating factor for both groups of respondents, it seemed to be more the case for Chinese, than Indian respondents. Additionally, the findings suggest that Indian students might be more career-oriented with a higher proportion indicating that studying abroad was necessary for their future career prospects. Nevertheless, studying abroad is usually driven by a myriad of factors, and with this in mind, the remaining sections will examine the different aspects that factor in 
Chapter 6: The decision making process of Chinese and Indian students coming to Australia

deciding on the study locale. This approach will further illuminate the different motivations and attitudes each group may have towards international education, particularly in Australia.

\subsection{The underlying factors in the decision making process}

The aim here is to ascertain the main reasons that influence these students when it comes to selecting a study destination. Uncovering these reasons will help understand the strategic configuration of a place and its function in the students' transnational migration strategies. With different aspects emerging between Chinese and Indian respondents, this section will also seek to uncover how this process may vary between the two groups. Before doing so, the extent to which other study destinations were considered before respondents decided on Australia will be examined.

\subsubsection{The consideration of alternative countries as study destinations}

Although Australia is one of the leading destinations for international education, countries such as the US, UK, Germany and France have consistently been regarded as more popular destinations for international education. Not surprisingly as Table 6.2 shows, 55.9 percent of Chinese and 57.3 percent of Indian respondents had seriously considered studying in countries other than Australia.

Table 6.2: Proportion of respondents who seriously considered other study destinations $(n=455)$

\begin{tabular}{|ccc|} 
& \% of Chinese $(\mathrm{n}=\mathbf{3 3 8})$ & \% of Indian $(\mathrm{n}=\mathbf{1 1 7})$ \\
\hline Yes & 55.9 & 57.3 \\
\hline No & 43.5 & 41.9 \\
\hline Missing & 0.6 & 0.9 \\
\hline Total & $\mathbf{1 0 0}$ & $\mathbf{1 0 0}$ \\
\hline
\end{tabular}

Source: CISS 2007; 2008

Overall, as illustrated in Figures 6.1 and 6.2, Chinese respondents factored in a wider range of countries compared to Indian students. At a glance, it is evident from the diagrams that 
the US, UK, Canada and New Zealand were the top four countries seriously considered by both groups of respondents. While this finding supports the perception of the US and the UK as the most popular study destinations for international students, it demonstrates that Canada and New Zealand were seriously considered, albeit by lower proportions.

Figure 6.1: Countries seriously considered by Chinese respondents \% (n=189)

US, $\mathbf{4 8 . 7}$

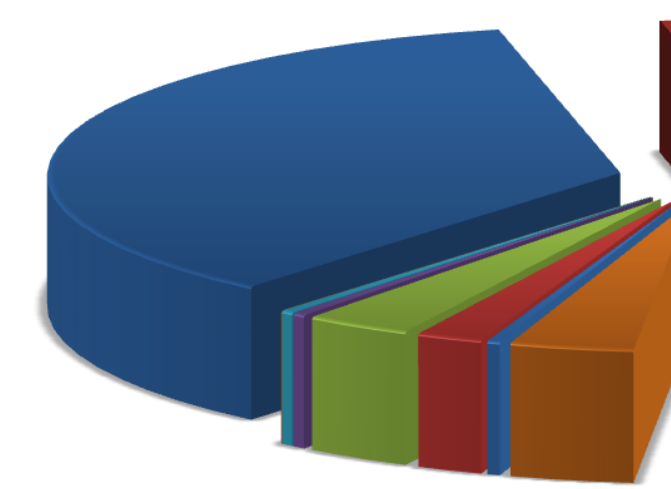

Korea, 0.5
UK, 49.7

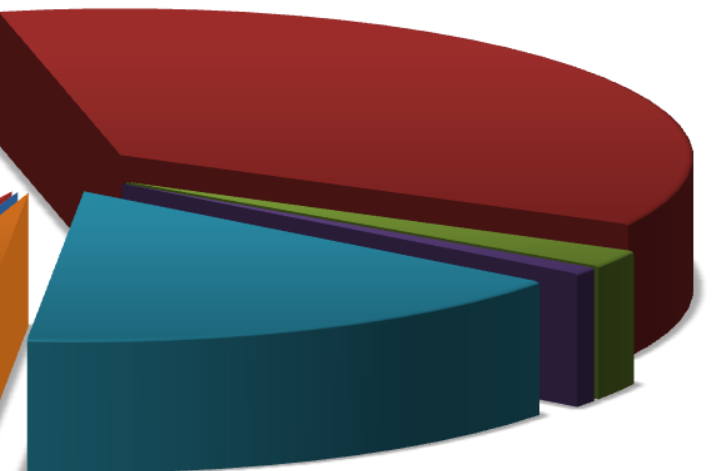

France, 2.6
Switzerland, 0.5
New Zealand, 4.2
Japan, 2.6
Canada, 22.2
Singapore, 1.1
Europe, 4.8
Germany, 0.5

Source: CISS 2007; 2008

Figure 6.2: Countries seriously considered by Indian respondents \% (n=67)

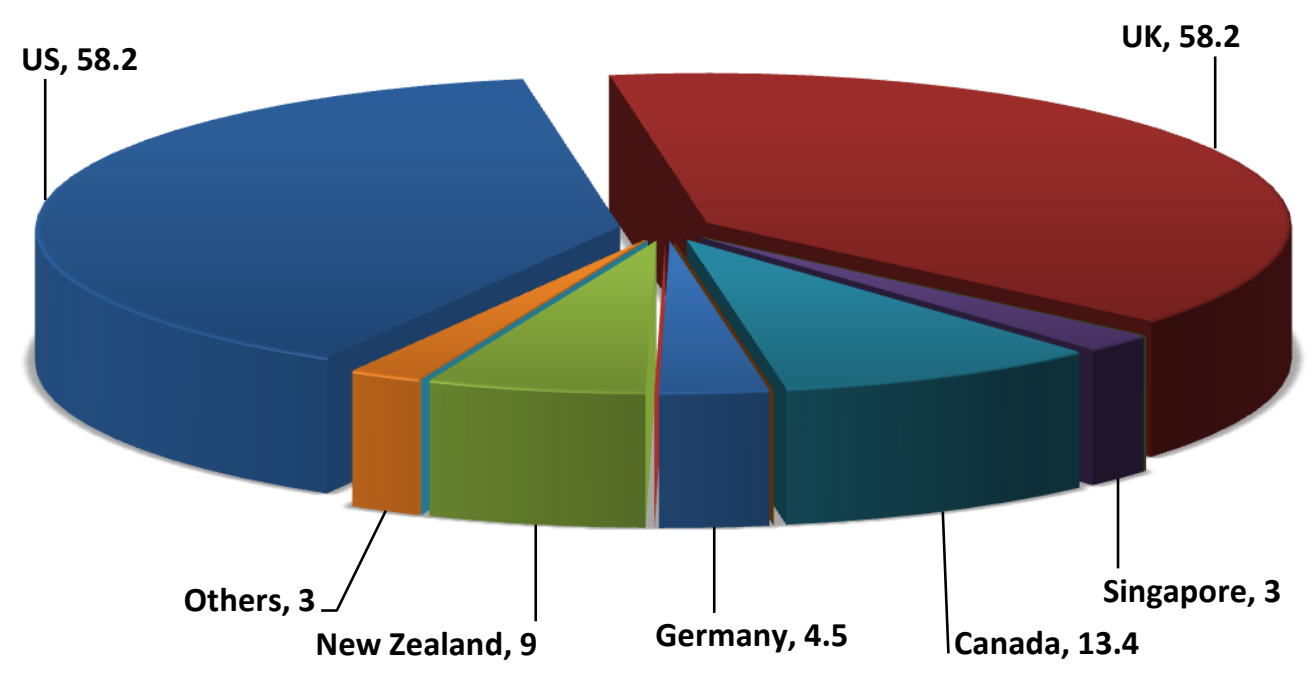

Source: CISS 2007; 2008 
To an extent, the strong preference exhibited by Chinese and Indian students for UK and US is linked to historical structuralist theory. These countries along with Australia are generally regarded as major players, with France and Germany seen as the middle powers (Verbik \& Lasanowski 2007). Although, as mentioned in section 2.3, France and Germany traditionally "tend to attract students from regional European nations or those with sociocultural or historical ties" (Verbik \& Lasanowski 2007, pg 9), with exchange programmes such as ERASMUS perpetuating such flows. Canada and New Zealand on the other hand are increasingly popular and considered as evolving destinations. Additionally, Chinese and Indian students have consistently been amongst the top 5 source countries for major English speaking study destinations (AEI 2005a). This suggests that English speaking countries have an attraction for these students, in line with earlier findings (Table 6.1) which reflected improving English as a major factor, particularly for Chinese respondents.

While some (Verbik \& Lasanowski 2007, pg 13) suggest Canada and New Zealand are becoming "a less significant destination for transnational higher education" due to declining enrolments however, they are still included in the decision making process. As discussed (Section 2.5.8.2), the events of September 11, 2001 made it "more difficult to receive visas in the US", and it appears that Canada's geographical proximity and similarities to the US benefited institutions such as the University of Winnipeg who experienced a 20 percent increase in international student enrolments, mainly comprising Chinese and Indian students (Asian Pacific Post 2005). Although the US and UK are often cited as preferred options, meso and macro structures in the form of recruiting students and government policy, have significant impacts on the decision making process. The Canadian example provides insight into the influence of places on the transnational strategies of students. Nonetheless, after selecting Australia, students are still required to decide on a study destination within the country itself. The following section will explore the configuration of places on a smaller scale.

\subsubsection{The consideration of other Australian States as study destinations}

Respondents were asked to indicate if they had seriously considered studying in parts of Australia other than Adelaide. Table 6.3 shows a significant 44.8 percent of all respondents who seriously considered other Australian States, with a higher proportion of Chinese than Indian respondents (46.7\% and $39.3 \%$ respectively). 
Table 6.3: The serious consideration of other Australian States as study destinations $(\mathbf{n}=\mathbf{4 5 5})$

\begin{tabular}{|cccc|}
\hline $\begin{array}{c}\text { \% of Total } \\
(\mathbf{n = 4 5 5})\end{array}$ & $\begin{array}{c}\% \text { of Chinese } \\
(\mathrm{n}=\mathbf{3 3 8})\end{array}$ & $\begin{array}{c}\text { \% of Indian } \\
(\mathrm{n}=\mathbf{1 1 7})\end{array}$ \\
\hline Yes & 44.8 & 46.7 & 39.3 \\
\hline No & 53.4 & 52.1 & 57.3 \\
\hline Missing & 1.8 & 1.2 & 3.4 \\
\hline
\end{tabular}

Source: CISS 2007; 2008

Similar to preferences to study in the US and the UK, international students prefer Victoria and New South Wales in Australia. Their popularity is reflected in AEI data as shown in Figure 6.3. These States have the lion's share of the international student market in higher education institutions which suggests how Adelaide is not always the first choice destination for international students in Australia.

Figure 6.3: Distribution of international student enrolments in Australia by higher education/State 2002-2008

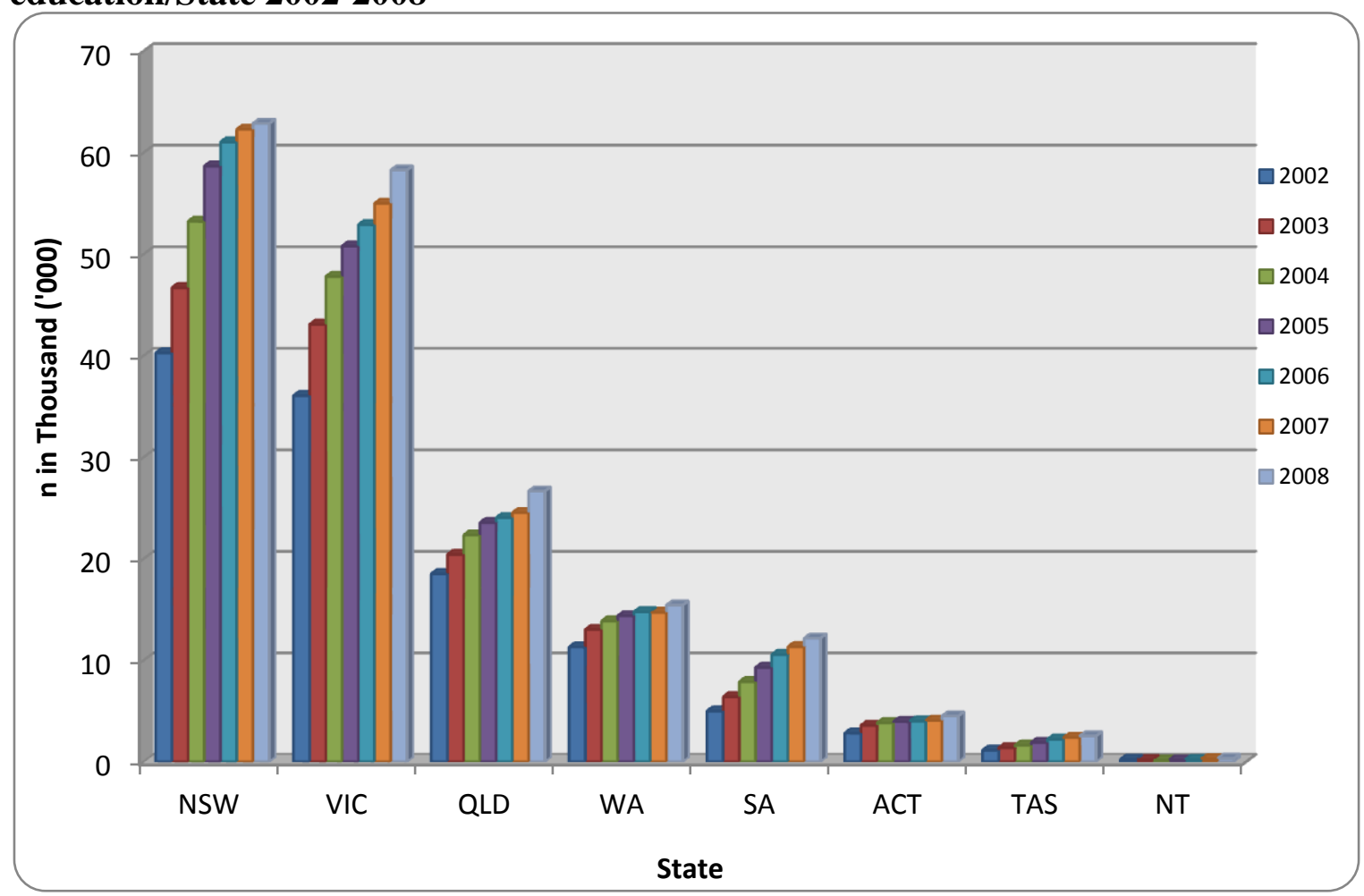

Source: AEI 2008b; $2008 d$

Table 6.4 reflect this tend with significant proportions of respondents who seriously considered Victoria and New South Wales as their study destinations, however, Chinese and Indian students differed slightly in their preferences. 
Chapter 6: The decision making process of Chinese and Indian students coming to

Table 6.4: States which were seriously considered by Chinese and Indian respondents $(n=204)$

\begin{tabular}{|ccc|}
\hline New South Wales & $\begin{array}{c}\text { \% of Chinese } \\
(\mathbf{n}=\mathbf{1 5 8})\end{array}$ & $\begin{array}{c}\text { \% of Indian } \\
(\mathbf{n}=\mathbf{4 6})\end{array}$ \\
\hline Victoria & 54.4 & 41.3 \\
\hline Queensland & 38.6 & 54.3 \\
\hline $\begin{array}{c}\text { Western Australia } \\
\text { Australian Capital } \\
\text { Territory }\end{array}$ & 17.1 & 26.1 \\
\hline Tasmania & 4.4 & 4.3 \\
\hline $\begin{array}{c}\text { Northern Territory } \\
\text { Torn }\end{array}$ & 1.9 & 2.2 \\
\hline
\end{tabular}

Source: CISS 2007; 2008

Victoria $(54.3 \%)$ was the most considered State followed by New South Wales $(41.3 \%)$ for Indian respondents, conversely, more Chinese respondents considered New South Wales (54.4\%) followed by Victoria (38.6\%). The popularity and the partiality expressed for these States by Chinese and Indian students were substantiated in the interviews.

It is very common, about 90 percent of my friends prefer to study in Sydney or Melbourne. People will think of universities in Sydney, Melbourne, Queensland before Adelaide or Tasmania are looked at.

-Wendy, Chinese student in Master of Commerce-Accounting (University of Adelaide)

Sydney is seen as the 'capital' of Australia, the London or New York. Chinese students see it as a place easier to find work. There is also a strong Chinese and Hong Kong community. Sydney is not as popular for Indians due to overall cost. Fees, living expenses, everything. Melbourne is a more feasible option for them.

-Stephen, IDP Staff

Additionally, Indian respondents on the whole seem to consider more States with Western Australia and Queensland considered by significant proportions $(23.9 \%$ and $26.1 \%$ respectively) which again exemplifies the differing attitudes between Chinese and Indian students. It was observed through the interviews that Indian students tended to keep their options open and were more flexible in their decision making process, a point to be 
explored in the next chapter. While Adelaide is not the preferred destination, it may be a gateway to other cities in Australia as described by Path B of the conceptual model in Figure 4.2. Nevertheless, it is necessary to determine the reasons which influenced Chinese and Indian respondents to decide on Australia and Adelaide as their eventual study destinations.

\subsection{Main factors that influenced the decision to study in Australia and in Adelaide}

The serious consideration of alternative study destinations are based on a range of different factors or characteristics pertinent to each location. This section will explore the factors which discouraged respondents from studying in other places (Table 6.5) and the reasons which led to the selection of Australia and Adelaide as their study destination.

Table 6.5: Factors that discouraged respondents from other seriously considered study destinations $(n=256)$

\begin{tabular}{|c|c|c|c|}
\hline & $\begin{array}{l}\% \text { of Total } \\
(n=256)\end{array}$ & $\begin{array}{l}\% \text { of Chinese } \\
(\mathbf{n}=\mathbf{1 8 9})\end{array}$ & $\begin{array}{l}\% \text { of Indian } \\
(n=67)\end{array}$ \\
\hline $\begin{array}{c}\text { More expensive to study in those } \\
\text { countries }\end{array}$ & 53.9 & 50.8 & 62.7 \\
\hline $\begin{array}{l}\text { The possibility of permanently } \\
\text { migrating to those countries after } \\
\text { studies was low }\end{array}$ & 35.5 & 33.3 & 41.8 \\
\hline $\begin{array}{l}\text { Lifestyle and weather in those } \\
\text { countries did not attract me }\end{array}$ & 27 & 27 & 26.9 \\
\hline $\begin{array}{l}\text { Student visa was not granted in } \\
\text { countries considered }\end{array}$ & 23 & 28.6 & 7.5 \\
\hline $\begin{array}{l}\text { Security and safety was an issue in } \\
\text { countries considered }\end{array}$ & 21.9 & 23.3 & 17.9 \\
\hline $\begin{array}{l}\text { Did not have any friends/family in } \\
\text { those countries }\end{array}$ & 12.5 & 12.2 & 13.4 \\
\hline $\begin{array}{c}\text { Course was not available in those } \\
\text { countries }\end{array}$ & 11.3 & 8.5 & 19.4 \\
\hline Parental decision & 9 & 9.5 & 7.5 \\
\hline $\begin{array}{l}\text { Unable to get a scholarship to study in } \\
\text { those countries }\end{array}$ & 7.4 & 6.9 & 9.0 \\
\hline $\begin{array}{l}\text { Unable to obtain credit transfer from } \\
\text { previous course or qualification }\end{array}$ & 7 & 7.9 & 4.5 \\
\hline
\end{tabular}

Source: CISS 2007; 2008 
Due to the structure of the survey, there is a caveat with the findings in Table 6.5. Although respondents indicated the reasons that discouraged them from studying in alternative countries, there was no distinction made between the multiple countries they listed and the reasons given. The dominance of New Zealand, Canada and particularly the US and the UK as shown in Figures 6.1 and 6.2 combined with the information gleaned from focus groups and interviews does however lend weight to the following analysis.

The main reasons which discouraged respondents from studying in other countries essentially revolved around cost, the slim probability of future migration, lifestyle and climate in those countries, student visa complications and security and safety issues. Parallels can be drawn as these factors are by and large the very reasons which led respondents to select Australia as a study destination as seen in Table 6.6.

Table 6.6: Factors that influenced all respondents' decision to study in Australia $(n=455)$

\begin{tabular}{|c|c|c|c|}
\hline & $\begin{array}{l}\text { \% of Total } \\
(n=455)\end{array}$ & $\begin{array}{l}\text { \% of Chinese } \\
(\mathrm{n}=338)\end{array}$ & $\begin{array}{c}\% \text { of Indian } \\
(n=117)\end{array}$ \\
\hline Academic reputation & 52.1 & 52.4 & 51.3 \\
\hline Safe country to study and live in & 45.7 & 46.2 & 44.4 \\
\hline Attractive immigration policies & 41.3 & 42.3 & 38.5 \\
\hline Cheaper to study in Australia & 32.1 & 33.4 & 28.2 \\
\hline Recommended by family/friends & 25.1 & 23.4 & 29.9 \\
\hline $\begin{array}{c}\text { Ease of admission (granted a } \\
\text { student visa) }\end{array}$ & 24.8 & 23.1 & 29.9 \\
\hline $\begin{array}{c}\text { Recommended by education } \\
\text { agent }\end{array}$ & 18.7 & 19.2 & 17.1 \\
\hline Parent's decision & 15.8 & 18 & 9.4 \\
\hline $\begin{array}{c}\text { Was offered a scholarship to } \\
\text { study in Australia }\end{array}$ & 4.8 & 3.3 & 9.4 \\
\hline
\end{tabular}

Source: CISS 2007; 2008

Over half of all respondents indicated Adelaide's cost advantage as a primary factor (Table 6.7). This was followed by the academic reputation of education in the State $(38.5 \%)$ and the availability of courses (34.3\%). In general, there are a few main variables such as cost 
which factored highly when deciding on a host country and the specific study destination within.

Table 6.7: Factors that influenced all respondents' decision to study in Adelaide $(n=455)$

\begin{tabular}{|c|c|c|c|}
\hline & $\begin{array}{c}\% \text { of Total } \\
(n=455)\end{array}$ & $\begin{array}{l}\% \text { of Chinese } \\
(\mathrm{n}=338)\end{array}$ & $\begin{array}{c}\% \text { of Indian } \\
(\mathrm{n}=117)\end{array}$ \\
\hline $\begin{array}{l}\text { Cheaper to study in Adelaide } \\
\text { compared to other States }\end{array}$ & 56.7 & 58 & 53 \\
\hline Academic Reputation & 38.5 & 41.1 & 30.8 \\
\hline Courses available here in Adelaide & 34.3 & 32.5 & 39.3 \\
\hline $\begin{array}{c}\text { Bonus PR points on offer after } \\
\text { graduation }\end{array}$ & 29.9 & 27.8 & 35.9 \\
\hline Recommended by Education Agent & 22.9 & 25.1 & 16.2 \\
\hline Recommended by family/friends & 18 & 18.3 & 17.1 \\
\hline Ease of admission to the University & 13.4 & 13.9 & 12 \\
\hline $\begin{array}{l}\text { Able to obtain credit transfer from } \\
\text { pervious course or qualification }\end{array}$ & 10.3 & 11.2 & 7.7 \\
\hline $\begin{array}{c}\text { Was offered a scholarship to study in } \\
\text { Adelaide }\end{array}$ & 5.9 & 4.4 & 10.3 \\
\hline Parent's Decision & 5.7 & 7.1 & 1.7 \\
\hline
\end{tabular}

Source: CISS 2007; 2008

\subsubsection{Academic reputation of study destinations}

Over half of respondents cited Australia's academic reputation as a factor for studying in Australia. This is linked to earlier discussion (Section 2.5.5) and findings (Table 6.1) which combined the lack of quality and reputation of universities in China and India with the objective of acquiring human capital. Furthermore, the latter reason resonates with studies which revealed that Australian qualifications were recognised at their home countries (Lawrence 2009) and translates into job opportunities (AEI 2005b; Tustin \& Nelson-Field 2006, pg 20). It is safe to say that the consideration of a study destination's academic reputation is inextricably linked to their economic motivations. 
Chapter 6: The decision making process of Chinese and Indian students coming to

Australia

Additionally, a significant proportion of respondents perceived Adelaide's universities to be reputable $(38.5 \%)$ which corresponds with research that revealed this as an important factor (Braham et al. 2007, pg 11; Lawrence 2004; Tustin \& Nelson-Field 2006, pg 20) although it emerged to be more important for the Chinese. A higher proportion of Chinese (41.1\%) than Indian respondents $(30.8 \%)$ indicated academic reputation as a factor which suggests differing attitudes between the two groups of students, an observation which 'seeped' through the interviews.

RESEARCHER: Is the reputation of universities important to these students? For those who want PR that is.

FRANK: They will be, at the start (of the application process). But after that, not so much for Indian students. But reputation is much more important for Chinese students. Indian students will go to Charles Darwin University for example, just to get PR.

-Frank, Education Agent

Chinese students are getting more and more brand conscious, whereby they will go to the top 8 universities and at the same time they would like to get PR.

-Jonathan, Education Agent

While these views suggest the need to expound on the stronger PR intention of Indian students, it also lends weight to the perception of Adelaide as 'PR friendly study destination' which will be discussed in Section 6.4.5. This demonstrates the multidimensional nature of these factors with studies also associating academic reputation with cost considerations (Tan 2003, pg 54-55).

\subsubsection{Cost considerations}

Lawrence's (2009) study revealed cost as the most important factor when choosing the country of study and it was the highest cited reason which discouraged respondents from studying in other countries (53.9\%) (Table 6.5). The issue of cost was significant as $32.1 \%$ of respondents indicated that it was 'Cheaper to Study in Australia' (Table 6.6). Similarly, cost was the chief factor for 56.7 percent of respondents (Table 6.7) when selecting Adelaide as a study destination.

As discussed earlier (Section 2.5.7), foreign exchange rates have often rendered countries like the US and UK unattractive. In a similar vein, Adelaide's relative lower cost of living was established as one of the overriding factors in the decision making process (Braham et al. 2007, pg 20; Lawrence 2004; Radford et al. 1984; Tan 2003, pg 56-57; Tustin \& 
Chapter 6: The decision making process of Chinese and Indian students coming to

Nelson-Field 2006, pg 20). Moreover, as discussed, Chinese and Indian students are cost conscious which was continually emphasised in the interviews.

My first choice is the UK, but I didn't (go) because of the higher cost.

-Dong, Chinese student in Master of Commerce-Accounting

(University of Adelaide)

I had offers from universities in Sydney but I decided on Adelaide because fees were cheaper and living costs were lower as well.

-Dawal, Indian student in Master of Telecommunication (UniSA)

The cost factor is further emphasised by significant proportions of respondents who relied on part-time work while studying (Figure 5.11). However, as Gillan et al. (2003, pg 1401) states 'it is important not to exaggerate the relative estimated cost differentials between countries, or to attribute destination preferences solely to the factor of comparative advantage on the question of cost'.

\subsubsection{Social amenities, cultural and environmental considerations}

Table 6.5 shows lifestyle and weather factors (27\%) discouraged respondents from studying in other countries and this corresponds with Australia's relatively warmer climate and conducive study environment as cited in the literature (Mazzarol \& Soutar 2002, pg 89; Tan 2003, pg 75-76). Participants consistently brought up climate as an attractive factor, which was quite often associated with air quality:

Climate was important when I chose Australia. It has a nice climate, not too cold and it is better for my sinus. Adelaide's not too cold either.

-Ravipraba, Indian student in MBA (UniSA)

I really like the weather and climate. The weather...and it is not polluted compared to China. I'm from Tianjin, close to Beijing where they have a lot of factories. The air quality is very poor and you cannot see the blue sky or white clouds because of pollution. I often have to go to the hospital for treatment, breathing problems.

-Annie, Chinese student in Master of Accounting and Finance (University of Adelaide)

Additionally, the aspect of a good study environment in Adelaide was ironically linked to its tag as a boring city, which consistently emerged in several studies (Braham et al. 2007, 
Chapter 6: The decision making process of Chinese and Indian students coming to

pg 21; Lawrence 2004; Tustin \& Nelson-Field 2006, pg 21) and in interviews. It was also revealed that the view of Adelaide as a small city was associated with fewer Chinese students and the opportunity to learn English:

I like Adelaide because it's small, Melbourne and Sydney were big cities. Because I think this will give me more opportunity to mix with local Australian students and give me more opportunity to learn English.

-Jenny, Chinese student in Master of Accounting and Finance (University of Adelaide)

However, this perception proved to be false with all Chinese interviewees expressing their disappointment:

My agents told me there was low Chinese student population in Adelaide which means I can mix more with the Australian students and improve my spoken English. But this is not true, there are so many Chinese in Adelaide and my chances to learn English are limited. There are a lot of Chinese students in my course and I even asked my Australian classmate if she feels like she is studying in China.

-Carol, Chinese student in Master of Commerce-Accounting (University of Adelaide)

We've had a wave of success precisely for that reason [Adelaide with a low population of Chinese students]. Now Adelaide has more Chinese than Perth so Perth might get that spin-off. So yes, students do say that and now I've had to say, "I'm sorry but that's not true anymore". So that clearly has been a reason for coming to Adelaide because there weren't so many Chinese students. We've lost that advantage, sooner or later you get killed by your own success.

-Rose, Marketing Staff (University of Adelaide)

These perceptions were not evident among Indian respondents which links to and reinforces earlier discussion on the linguistic expectations of the Chinese (Table 6.1). Another environmental consideration as indicated in Table 6.5 revolved around security and safety. This was an issue which discouraged approximately a fifth of respondents from studying in other countries, conversely, this benefited Australia with 45.7 percent of respondents who felt it was a safe country to study and live in (Table 6.6). Moreover, this factor was further reinforced when it came to choosing Adelaide over other Australian cities (Lawrence 2004; Tustin \& Nelson-Field 2006, pg 20). While these concerns are usually associated with low crime rates and little racial discrimination, they also seem to be attributed to heightened political tension and the events of $9 / 11$. However, the perception that Australia was a safer destination than the US was established in pre 9/11 research 
Chapter 6: The decision making process of Chinese and Indian students coming to

(Mazzarol \& Soutar 2002, pg 86, 89). On the other hand, recent reports of violence toward Indian students in Australia (D' Costa 2010; Marginson 2010, pg 3-6) might have impacted Australia's reputation as a safe study destination and this will be discussed further in the next chapter. Overall, there was a general view by interviewees and some education agents that Australia and Adelaide were safe destinations for international education. Environmental considerations have several aspects and as stated by one interviewee:

Education is not just down to the provider but place and environment also play a part. Adelaide is an ideal place to study, it's got a conducive study environment and is economical too.

-Abhay, Indian student in Master of Accounting (UniSA)

The above sentiment therefore sums up how different aspects of the environment in a place can influence the selection of a study destination in the decision making process.

\subsubsection{Influence of networks}

The survey also revealed that the decision to study in Australia was influenced by a range of actors which are examples of a combination of micro and meso structures (Sections 4.3.2.2; 4.3.2.3). Although only 12.5 percent of respondents were affected by the absence of family or friends in other countries (Table 6.5), higher proportions relied heavily on the recommendations of family and friends and education agents when selecting Australia and Adelaide as a study destination (Tables 6.6 and 6.7).

Education agents play a bigger role for Chinese students while Indian students are influenced more by recommendations from family and friends when selecting a study destination. To some extent, the importance of these actors should be carefully considered as some studies have downplayed their importance in the decision making process (Lawrence 2004). Nevertheless, the 'word of mouth' phenomenon is not to be underestimated. Agents and university marketing staff suggest that it is a crucial element for potential students who rely on such existing connections:

We have this terminology which we use often is "because of my friend", that is exactly what is said by students. Let's say somebody comes to our counter and they say, "I want to do a Bachelor of Nursing and I have one year of credit from this institution" and our response back which may actually suit what they're thinking. They will then come to the counter and say, "No no no, this is not what I want because my friends has got this degree" which is what they are after. So the networking phenomenon, even though that is just one example, is something that is ubiquitous in every aspect of the work we do in international student recruitment. Every single decision about 
migration, about course fees, about application, about institution, everything is discussed within networks, with friends and family. It is absolutely critical and hugely important that we certainly don't underestimate.

-Natalie, Marketing Staff (UniSA)

These meso structures are important as they serve to strengthen migration flows from one place to another, hence, not only will the role of such networks be further examined later (Section 6.5), the extent of influence they have on the PR intentions of students will also be investigated as well. Also, parents have been known to be influential in the decision making process for international students albeit the final decision was usually down to the students themselves (Tustin \& Nelson-Field 2006, pg 20).

As mentioned, data from the survey (Tables 6.5-6.7) indicated parental influence was stronger for Chinese than Indian respondents. This is linked to earlier findings (Figures 5.9 $\&$ 5.10) which revealed the financial dependence of the majority of Chinese respondents on their parents/family. In comparison, Indians respondents were reliant on bank loans and part-time work. Interviews back up the importance of parents and reveal the extent of their influence:

RESEARCHER: For students from China, could you maybe talk about parents, do you think they are a major factor?

SIMON: I think definitely it is and this is probably one of the best examples I can give. One of our agents in Nanjing had a student, a young girl who wanted to go into nutrition and dietetics and she had a real passion for that. However, her father was actually an academic at a local uni and he was a science based person as well and he was directing her saying she had to do a business course.

-Simon, Marketing Staff (Flinders University)

RESEARCHER: What are your thoughts on parental influence [Chinese] on their child's decision to study overseas?

ROSE: I wouldn't like to quantify it but it is significant, particularly at the bachelor level. But even at the Masters level. It comes down to parents paying the money...Ultimately for any international students, even if we're not aware of it, I'm pretty certain the most significant interest are the parents. Of course sometime you have parents wanting their child to do business, not music. It's an investment and you want a return on your investment and you look for the best prospects.

-Rose, Marketing Staff (University of Adelaide)

My parents wanted me to study accounting or something like finance although I wanted to study tourism or hospitality. Because they felt that it (being an accountant) would be better, higher pay and more comfortable sitting in an office compared to someone in the tourism industry. 
Chapter 6: The decision making process of Chinese and Indian students coming to

-Annie, Chinese student in Master of Accounting and Finance (University of Adelaide)

I was thinking of (studying in) Canada and Switzerland...but my parents did not want me to go Switzerland because it was too cold. Also they want me to get PR in Australia, that's why I did not go to Canada.

-Carol, Chinese student in Master of Commerce-Accounting (University of Adelaide)

The evidence from the interviews gives a strong sense that parents are a bigger factor in the decision making process than suggested by findings from the CISS survey which resonates with new economics of labour migration theory. Chapter 7 will expand on the role of parents and their influence on the PR intentions and transnational migration strategies of Chinese and Indian students.

\subsubsection{Student friendly policies}

Part time work is linked to work rights for international students and whether one can work legally while studying is an important factor for Chinese and Indian students. In line with Baas' research (2006, pg 50; 2007a, pg 12; 2007b), the price sensitive nature of Indian respondents emerged with their work patterns revealing this as an important source of funds for them (Section 5.7). It also emerged in the interviews how this factor is linked to the popularity of Melbourne and Sydney when selecting a study destination.

DANIEL: Yes, they do prefer Sydney and Melbourne.

RESEARCHER: Is it for both Chinese and Indian students?

DANIEL: Yes.

RESEARCHER: Do you know why?

DANIEL: I think it's easier to get a job. Most of them go there with an idea that they can work 20 hours a week and save some money to offset the cost of their education and their living expenses. That's why Sydney and Melbourne are the most popular cities.

-Daniel, Education Agent

Work rights for international students are regulated by government policy which highlights the role of such macro structures. Other issues stemming from the role of governmental policy include difficulties in obtaining student visas (23\%) in other countries (Table 6.5). This factor correlates with 24.8 percent of respondents who were influenced by the ease of getting one in Australia (Table 6.6). Lawrence (2009, pg 16) argues that the unwanted reputation of some countries for having lengthy, difficult and expensive visa application 
processes combined with perception that student visas were easily accessible in Australia benefited Australia.

Students visas are harder to get for US, we have to travel to the American embassy which is only in some parts of China, and we have to go through an interview. And if the interviewer sense that the main reason for going to the US is to settle down, the visa will be rejected.

-Linda, Chinese student in Master of Commerce- Accounting (University of Adelaide)

The US is known and seen as a hard country to gain entry into. It is hard to get a student visa and the process of getting and applying for one is extremely lengthy as well. Australia on the other hand is a lot easier to get a visa.

-Ranjiv, Indian student in Master of Occupational Therapy (UniSA)

I have noticed when processing PR applications for my students (Indians), they often have rejection stamps on their passports from applications to go to the USA. This in way suggests and reinforces the fact that Australia is a secondary choice.

\section{-Gavin, Migration Agent}

Not only does this demonstrate how such policies can influence the selection of study destinations but it also continues to hint at the configuration of Australia as an alternative or fall back study destination when placed in the transnational strategies of students. In a similar fashion, respondents who were deterred by slim chances of future migration $(35.5 \%)$ in potential study destinations (Table 6.5) was reinforced by 41.3 percent of respondents who were influenced by attractive immigration policies in Australia (Table 6.6). This analysis suggests the inclination of respondents in basing their study destination around favourable immigration policies, which is in line with studies emphasising the importance of permanent migration (Section 2.5.8.3), a sentiment also reflected in the interviews:

Canada and US are hard places to remain behind after studying compared to Australia. Not like you are going for it but the mere fact that you could get PR makes you comfortable.

-Abhay, Indian student in Master of Accounting (UniSA)

I had a chat with a staff member of DIAC who said that although the student visa is a pathway for PR, the student visa has never been marketed as a pathway to PR and needs to be seen in isolation in the PR visa. Although HE KNOWS and I KNOW that it is blatantly a pathway to PR.

-Gavin, Migration Agent 
This factor was supported by approximately 30 percent of respondents (Table 6.7) who indicated that the provision of bonus points upon their graduation as an influencing factor. A study by Tustin \& Nelson-Field (2006, pg 12) shows that the introduction of awarding international student applicants bonus points in areas defined as regional or low population growth metropolitan was quite effective. Statistics (Table 3.3) highlight its popularity among applicants and this was indicated by many student interviewees who revealed this as a main reason which led them to choose Adelaide over other States. Migration agents and university staff also acknowledged the advantage of this factor:

The bonus points have been good in general for agents. It has been easier to promote South Australia and Adelaide overseas as a place which is easier to migrate and has lower living costs. Especially to those who have never heard about Adelaide before. This has definitely generated more interest in Adelaide.

-Shaun, Migration Agent

Sydney and Melbourne are primary destinations but the regional bonus points are the reason why they come to Adelaide.

-Gavin, Migration Agent

It's been easier to sell Adelaide, to put it that way. It's been easier to put it as a destination.

-Natalie, Marketing Staff (UniSA)

Further analysis also reveals this as a bigger motivating factor for Indian respondents (35.9\%) than their Chinese counterparts $(27.8 \%)$, suggesting the former to be more PR oriented than the latter. The availability of courses as indicated by 34.3 percent of respondents was a constant theme (Tables 6.5 and 6.7) and corresponds with the lack of suitable courses in their home countries. Without getting into the exact nature of these courses, this finding underlines their basic objective of human capital accumulation.

To an extent, perhaps in the broader sense of international education and migration, the specific nature of such courses as discussed earlier (Section 3.6) is linked to another aspect of government policy, the MODL list (Section 3.5). The findings in Table 6.8 reveal the significance of the MODL on the selection of courses and this was more significant for Chinese than Indian respondents. 
Chapter 6: The decision making process of Chinese and Indian students coming to

Table 6.8: The influence of MODL on course enrolment $(n=455)$

\begin{tabular}{|cccc|}
\hline Yes & $\begin{array}{c}\text { \% of Total } \\
(\mathbf{n}=\mathbf{4 5 5})\end{array}$ & $\begin{array}{c}\text { \% of Chinese } \\
(\mathbf{n}=\mathbf{3 3 8})\end{array}$ & $\begin{array}{c}\text { \% of Indian } \\
(\mathbf{n}=\mathbf{1 1 7})\end{array}$ \\
\hline No & 37.1 & 40.8 & 26.5 \\
\hline Missing & 61.5 & 58 & 71.8 \\
\hline Total & 1.3 & 1.2 & 1.7 \\
\hline
\end{tabular}

Source: CISS 2007; 2008

On the whole, the interviews revealed that both groups of students were aware of the benefits of the MODL for PR purposes and many reflected it to be a factor behind the course which they were enrolled in, which were mostly in Accounting:

When I listed out the subjects I was interested in, my agent mentioned that Accounting would help me to work and migrate to Australia. This really enforced the idea that it was the course I should enrol in.

-Anuj, Indian student in Bachelor of Commerce-Accounting (UniSA)

Similarly, education agents, migration agents and university staff agreed that the MODL played a significant role in their decision making process:

RESEARCHER: What are the popular courses that Chinese students are after?

NATALIE: Commerce, Accounting, anything that is on the MODL list.

RESEARCHER: So would you agree that the MODL is a big factor?

NATALIE: Absolutely, absolutely, and you would have to be deluding yourself to think they don't have a huge role.

-Natalie, Marketing Staff (UniSA)

The Indian student is very very knowledgeable of the situation in Australia with regards to employment and residency... The Indian student knows what programmes will stand them in the best stead in getting points in applying for PR. They know that the various strands of engineering, IT, business and health sciences are going to get them more points on a future application for PR... They also know they are going to have to study in Australia for at least 2 years before they can apply for some form of residency which is why they would prefer to select 2 years of the programme rather than the 18 month version. 
Chapter 6: The decision making process of Chinese and Indian students coming to Australia

RESEARCHER: What are the courses which these students are after?

ROSE: Accounting, accounting and accounting... On occasion you have someone who wants to do something else. Still the primary demand is for accounting. Maybe finance and most at the Masters by coursework level.

-Rose, Marketing Staff (University of Adelaide)

Despite the availability to complete the same course in eighteen months, some would deliberately enrol in courses that ran for two years in order to be eligible for PR. In addition, the interviews revealed further intricacies involved with regards to selecting courses on the MODL. Some strategies involved changing their course whilst in Australia, and to an extent, even down skilling their qualifications:

Accounting has been on the list for a long time and every Indian student wanted to do accounting. And when IT was on the list, almost every student whether he was a doctor or engineer wanted to do it. So it does make a difference.

-Mary, Marketing Staff (University of Adelaide)

What we were seeing were qualified doctors coming to a 2 year nursing programme. They still wanted to be doctors but they saw the nursing programme as a pathway to Australia. Once here, they would then upgrade their skills and be registered and recognised as a doctor.

-Simon, Marketing Staff (Flinders University)

This was similar to Liu Farrer's (2009, pg 195) study which revealed a similar practice by Chinese students in Japan who favoured arts over sciences as it was linked to promising careers in Japan and provided a pathway to remain in Japan after their studies. This section has illustrated the decisive role of macro structures and underline how education can be a precursor for migration (Tremblay 2004). Moreover, it illuminated the influence of macro structures on the deliberate selection of Adelaide and courses. This strategy continues to add to the recursive relationship in transnational social spaces and strengthens Australia's and Adelaide's role as alternate study destinations in Paths B and C, offering the best route to PR as shown in Figure 4.2.

\subsection{Additional factors which contributed to the decision to study in Australia and in Adelaide}

This section examines the information sources respondents used before coming to Australia. It considers the role of micro and meso structures in the students' decision making process and elaborates on the strength of transnational links connecting different 
places in their migration strategies. This approach will elucidate on the transnational social spaces in the transnational strategies of Chinese and Indian students and explore the influence of micro and meso structures on PR motivations.

\subsubsection{Main sources of information used by respondents}

Respondents were asked to identify the sources they consulted before coming to Adelaide. They were provided a list of sources and these are presented in Figure 6.4 arranged from the most used sources to the least.

Figure 6.4: Main sources of information used by Chinese and Indian respondents $(\mathrm{n}=\mathbf{4 5 5})$

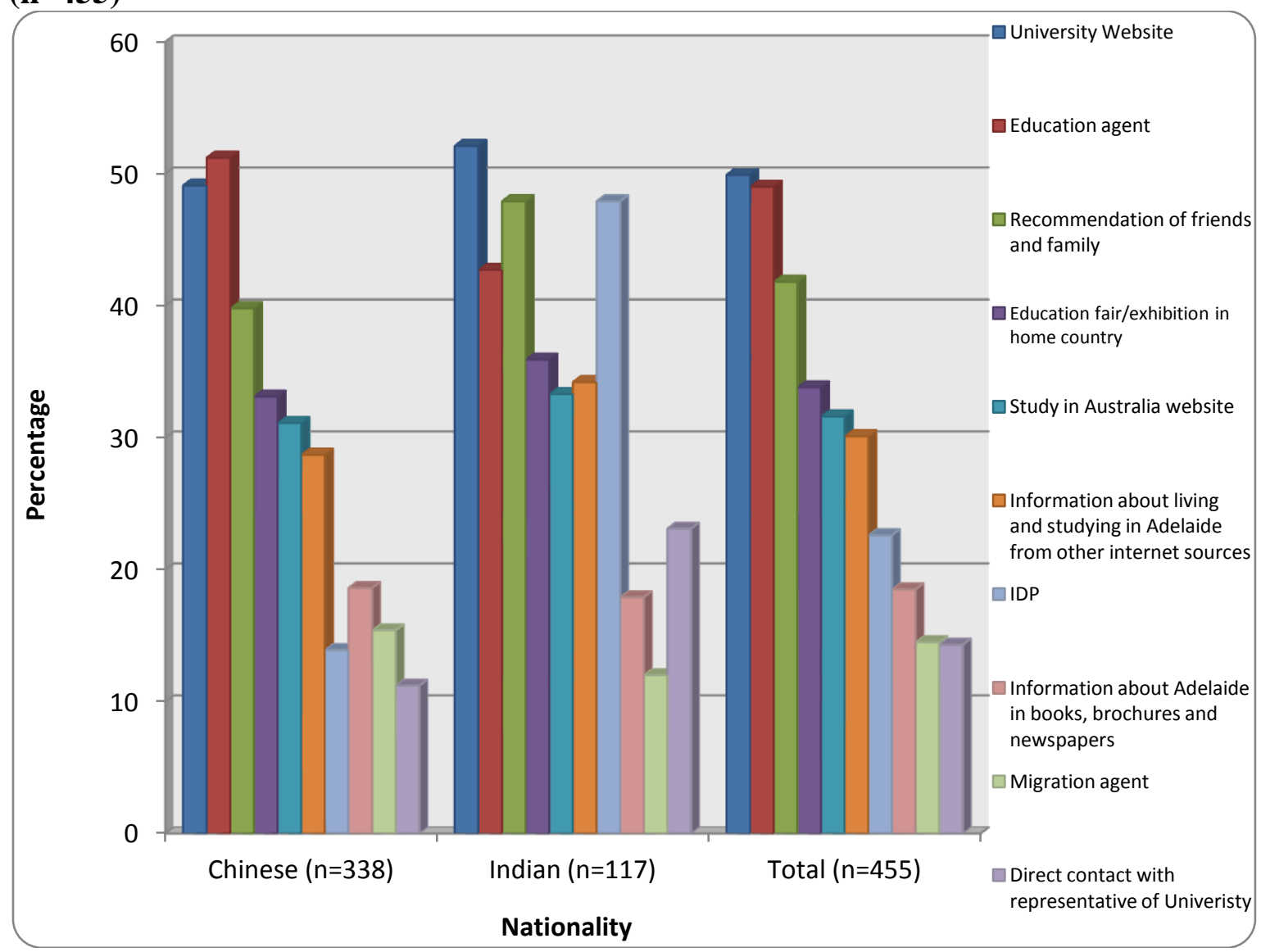

Source: CISS 2007; 2008

Respondents rely on a number of sources with approximately half of all respondents consulting the website of their current university. Almost a third of all respondents also used online sources such as the 'Study in Australia website' (31.6\%) and other internet sources (30.1\%) to obtain information about living and studying in Adelaide. Respondents also cited the use of other websites, which were comparatively less used. While the use of print media such as books, brochures and newspapers were used by 18.5 percent of respondents, it is clear that the Internet is the preferred and most effective medium in the 
decision making process. But overall, in comparison to earlier Australian based studies, the Internet as a form of information flow was either not mentioned or used by an insignificant proportion of international students (AIEF 1997; Nesdale et al. 1995) which demonstrates the prevalence of the Internet in today's globalised society and is indicative of how it is an invaluable tool in reaching out to potential students.

Nearly half of all respondents mentioned the importance of education agents followed by recommendations from friends and family, education fairs or exhibitions held in their home countries. Respondents also consulted IDP and migration agents $(22.6 \%$ and $14.5 \%$ respectively). Education or commercial agents play increasingly important roles in international education by representing a range of countries and institutions with studies revealing international students often using the services of such commercial agents (AIEF 1997; Smart \& Ang 1992; Tan 2003). It is not unusual for these agents to also assist them with a range of other services including: travel, accommodation, applications and other necessary procedures (Smart \& Ang 1992, pg 92).

As Figure 6.4 shows, Chinese respondents were more likely to consult education agents, a tendency consistent with earlier findings reflecting similar patterns when deciding on Australia and Adelaide as a study destination. The explanation behind this distinct preference displayed by Chinese respondents can be seen in Figure 6.5. The chart illustrates the top 10 countries with education agents that have taken the EATC (Education Agent Training Course) and been assessed as competent. Although this is not representative of the exact number of education agents that are actually based in each country, the chart does show that China has nearly twice as many education agents compared to India.

Migration agents were relatively less important as indicated by 14.5 percent of respondents. While this could be due to the fact that the PR process only takes places towards the end of their studies, interviews have revealed how education agents are increasingly doubling up as migration agents as well.

Other sources such as seeking 'Information about living and studying in Adelaide from other internet sources', consulting IDP or having direct contact with a representative from the university and visiting websites of the Australian and South Australian governments had a significantly higher proportion of Indian respondents. With 75 branches in 29 countries, it is therefore unsurprising that IDP is considered to be an important source of 
information. Further research also revealed that India has double the number of branches established in China (IDP 2009) which may explain Indian respondents' greater use of IDP. On the whole, it is clear that Indian respondents consulted a wider range of sources for information and visited more internet sources compared to their Chinese counterparts.

\section{Figure 6.5: Top 10 countries with EATC qualified education agents.}

\section{NOTE:}

This figure is included on page 150 of the print copy of the thesis held in the University of Adelaide Library.

Source: Professional International Educational Resources 2009

Studies (AIEF 1997; Tan 2003) have also pointed out the important role of friends and family as 'trusted' sources, "sometimes able to provide information not easily found in common literature" (Tan 2003, pg 61). A higher proportion of Indian than Chinese respondents ( $47.9 \%$ to $39.8 \%$ respectively) suggest these micro structures to be stronger for Indian, in comparison to the higher reliance on meso structures or agents, by Chinese students. With family and friends being the third highest consulted source of information (41.8\%), the following section will further examine the function of informal networks. It will investigate the influence of these networks on the students' decision on study destinations and the linkages between their social connections and transnational migration strategies.

\subsubsection{Social networks and its influence on respondents}

As stated above, family and friends are extremely influential in students' decision making process. These connections are located in micro structures sometimes referred to as 'social capital'. According to the literature (Mazzarol \& Soutar 2002, pg 89), these connections are comprised of people who are studying or have studied a potential location, thus 
rendering them as valuable sources of information. This section will determine the role of these networks by looking at the presence of family and friends and the extent of influence they have with regards to the selection of Australia and Adelaide as study destinations and how this translates to motivations for PR.

As presented in Table 6.9, approximately a quarter of all respondents (23.8\%) had family/relatives who studied in Australia and 10.3 percent had family/relatives who studied in Adelaide. In general, it is most common for respondents to only have 1 family/relative with study experience in Australia (13.6\%) and Adelaide (5.3\%). Lower percentages were found for those who had 2 or more family/relatives with such study experiences. Comparisons with respondents who had friends with study experience in Australia or Adelaide revealed a much higher proportion with 68.1 percent and 44.2 percent respectively.

Across the board, respondents had significantly more friends than family/relatives with such study experience. Furthermore, a relatively significant proportion of respondents had more than 5 friends who studied in Australia and in Adelaide (26.4\% and $11.6 \%)$ than family/relatives. The availability of first hand advice and information is evident and stronger from this particular subset of social networks. Additionally, between Chinese and Indian respondents, it appears that the latter has in percentage terms, a stronger network with such study experiences. This demonstrates the larger role of friends in the decision making process for Indian students and correlates with earlier suggestions that informal connections were key for Indian respondents when deciding on where to study and as main sources of information.

The significant role of friends are underlined by the fact nearly half of all respondents (46.4\%) had friends who were Australian citizens or PRs compared to an approximate fifth (19.6\%) of family/relatives under the same category as shown in Table 6.10. These statistics continue to reflect a stronger reliance on friends as they constitute a more important aspect of micro structures. Additionally, the higher proportion of Indian respondents (33.3\%) who had family/relatives with such 'permanent' connections compared to Chinese respondents (14.8\%) also suggests that overall, the former has a stronger social network. 
Chapter 6: The decision making process of Chinese and Indian students coming to Australia

Table 6.9: Respondents who have Family/Relatives and Friends with study experience in Australia and in Adelaide (n=455)

\begin{tabular}{|c|c|c|c|c|c|c|c|c|c|c|c|c|}
\hline & \multicolumn{3}{|c|}{$\begin{array}{c}\text { \% of Family/Relatives who } \\
\text { studied in Australia }\end{array}$} & \multicolumn{3}{|c|}{$\begin{array}{l}\text { \% of Family/Relatives who } \\
\text { studied in Adelaide }\end{array}$} & \multicolumn{3}{|c|}{$\begin{array}{l}\% \text { of Friends who studied in } \\
\text { Australia }\end{array}$} & \multicolumn{3}{|c|}{$\begin{array}{l}\text { \% of Friends who studied in } \\
\text { Adelaide }\end{array}$} \\
\hline & $\begin{array}{l}\text { Chinese } \\
(\mathrm{n}=338)\end{array}$ & $\begin{array}{c}\text { Indian } \\
(n=117)\end{array}$ & $\begin{array}{c}\text { Total } \\
(n=455)\end{array}$ & $\begin{array}{l}\text { Chinese } \\
(n=338)\end{array}$ & $\begin{array}{c}\text { Indian } \\
(n=117)\end{array}$ & $\begin{array}{c}\text { Total } \\
(n=455)\end{array}$ & $\begin{array}{l}\text { Chinese } \\
(n=338)\end{array}$ & $\begin{array}{c}\text { Indian } \\
(\mathrm{n}=117)\end{array}$ & $\begin{array}{c}\text { Total } \\
(n=455)\end{array}$ & $\begin{array}{c}\text { Chinese } \\
(\mathrm{n}=338)\end{array}$ & $\begin{array}{c}\text { Indian } \\
(\mathrm{n}=117)\end{array}$ & $\begin{array}{c}\text { Total } \\
(n=455)\end{array}$ \\
\hline 1 & 12.4 & 17.1 & 13.6 & 4.3 & 11.3 & 5.3 & 14.8 & 20.5 & 16.3 & 17.2 & 19.7 & 17.8 \\
\hline 2 & 3.6 & 7.7 & 4.6 & 1.3 & 3.3 & 2.3 & 15.4 & 11.1 & 14.3 & 6.8 & 12 & 8.1 \\
\hline 3 & 2.1 & 1.7 & 2.0 & 0.3 & 2.3 & 1.3 & 7.4 & 8.5 & 7.7 & 3.6 & 1.7 & 3.1 \\
\hline 4 & 0.3 & 1.7 & 0.7 & - & - & - & 2.7 & 4.3 & 3.1 & 0.3 & 1.7 & 0.7 \\
\hline $\begin{array}{c}\text { More than } \\
\quad 5\end{array}$ & 1.5 & 6.8 & 2.9 & 0.3 & 1.3 & 1.3 & 28.1 & 21.4 & 26.4 & 12.4 & 9.4 & 11.6 \\
\hline Missing & 0.6 & 0.9 & 0.7 & 2.4 & 0.9 & 2.0 & 0.9 & 0 & 0.7 & 2.7 & 3.4 & 2.9 \\
\hline $\begin{array}{l}\text { Total } \\
\text { (excluding } \\
\text { missing) }\end{array}$ & 19.9 & 35 & 24.5 & 7.3 & 18.3 & 10.3 & 69.3 & 65.8 & 68.1 & 43 & 47.9 & 44.2 \\
\hline
\end{tabular}


Table 6.10: Respondents who have Family/Relatives and Friends who are Australian citizens or PRs $(n=455)$

\begin{tabular}{|c|c|c|c|c|c|c|}
\hline & \multicolumn{3}{|c|}{$\begin{array}{l}\text { \% of Family/Relatives who are } \\
\text { Australian citizens or PRs }\end{array}$} & \multicolumn{3}{|c|}{$\begin{array}{c}\text { \% of Friends who are Australian } \\
\text { citizens or PRs }\end{array}$} \\
\hline & $\begin{array}{l}\text { Chinese } \\
(\mathrm{n}=338)\end{array}$ & $\begin{array}{l}\text { Indian } \\
(\mathrm{n}=117)\end{array}$ & $\underset{(n=455)}{\text { Total }}$ & $\begin{array}{l}\text { Chinese } \\
(\mathbf{n}=338)\end{array}$ & $\begin{array}{l}\text { Indian } \\
(\mathrm{n}=117)\end{array}$ & $\begin{array}{c}\text { Total } \\
(\mathrm{n}=\mathbf{4 5 5})\end{array}$ \\
\hline 1 & 6.2 & 12 & 7.7 & 11.2 & 14.5 & 12.1 \\
\hline 2 & 4.4 & 8.5 & 5.5 & 8.3 & 5.1 & 7.5 \\
\hline 3 & 0.6 & 5.1 & 1.8 & 5.9 & 5.1 & 5.7 \\
\hline 4 & 0.6 & 3.4 & 1.3 & 2.4 & 1.7 & 2.2 \\
\hline More than 5 & 3.0 & 4.3 & 3.3 & 18.3 & 20.5 & 18.9 \\
\hline Missing & 0.9 & 1.7 & 1.1 & 2.1 & 0.9 & 1.8 \\
\hline $\begin{array}{l}\text { Total } \\
\text { (excluding } \\
\text { missing) }\end{array}$ & 14.8 & 33.3 & 19.6 & 46.1 & 46.9 & 46.4 \\
\hline
\end{tabular}

Source: CISS 2007; 2008

These 'permanent' connections not only lend further weight to how they can influence respondents in deciding where to study, but also suggest how they could also influence the permanent migration strategies of respondents. Iredale (1999, pg 94) argues that information transferred through networks can influence future skilled immigrants when choosing a destination as "moves are mediated by the perceptions of potential migrants of migration destinations in terms of their identities and often changes in social status after migration" (Li et al. 1995, pg 345).

Table 6.11 presents data from a cross-tabulation between respondents with family/relatives and friends who were either Australian citizens or PRs and those with permanent migration intentions, i.e., those who selected 'Attractive Immigration Policies' and the availability of 'Bonus PR points on offer after graduation' when deciding on Australia and Adelaide as their study locales (Tables $6.6 \& 6.7$ respectively). The role of social networks is 
significant. As Table 6.11 shows, 31.5 percent and 46.4 percent of all respondents with family/relatives and friends respectively, who were Australian citizens or PRs, indicated that they decided on Australia as a study destination due to its 'Attractive Immigration Policies'.

Table 6.11: The influence of Family/Relatives $(n=89)$ and Friends $(n=211)$ who are Australian citizens or PRs on PR intentions

\begin{tabular}{|c|c|c|c|c|c|c|}
\hline & \multicolumn{3}{|c|}{$\begin{array}{l}\text { \% of Family/Relatives who are } \\
\text { Australian citizens or PRs }\end{array}$} & \multicolumn{3}{|c|}{$\begin{array}{c}\% \text { of Friends who are Australian } \\
\text { citizens or PRs }\end{array}$} \\
\hline & $\begin{array}{l}\text { Chinese } \\
(n=50)\end{array}$ & $\begin{array}{l}\text { Indian } \\
(\mathrm{n}=39)\end{array}$ & $\begin{array}{c}\text { Total } \\
(\mathbf{n}=89)\end{array}$ & $\begin{array}{l}\text { Chinese } \\
(n=156)\end{array}$ & $\begin{array}{l}\text { Indian } \\
(\mathrm{n}=55)\end{array}$ & $\begin{array}{c}\text { Total } \\
(n=211)\end{array}$ \\
\hline $\begin{array}{c}\text { Attractive } \\
\text { Immigration Policies }\end{array}$ & 28.0 & 35.9 & 31.5 & 47.4 & 43.6 & 46.4 \\
\hline $\begin{array}{c}\text { Bonus PR points on } \\
\text { offer after } \\
\text { graduation }\end{array}$ & 20.0 & 30.8 & 24.7 & 30.8 & 34.5 & 31.8 \\
\hline
\end{tabular}

Source: CISS 2007; 2008

In addition, 24.7 percent (friends/relatives) and 31.8 percent (friends) of all respondents intend to take advantage of the 'Bonus PR points on offer after graduation'. This analysis shows a strong correlation between the PR intentions of the respondents and having contacts who were permanent migrants in Australia. The role of these contacts as valuable sources of information for permanent migration purposes or even serve as examples making the successful transition from international student to permanent migrant is thus highlighted. To quote a student:

The benchmark of influence is often set at what friends or family members have done overseas. And then they try to suggest that that is the path to take as well.

-Kunal, Indian student in MBA (UniSA)

The strength of micro structures found in this study lends further weight to earlier findings (Section 6.4.4). In general, when it comes to consulting these social connections, the survey data consistently reflects a higher proportion of Indian respondents who have more family/relatives and friends with study experience in Australia and Adelaide compared to 
Chinese students. The influence of social networks essentially boils down to the strength of the networks available. As Bourdieu (as translated in John G. Richardson (ed.) 1986) states, the transformation of social capital into a conventional economic gain is dependent "on the nature of social obligations, connections and networks available to you". And as this section has shown, the relatively stronger presence of commercial agents in China explains the reliance on these formal networks by Chinese respondents while Indian respondents are evidently influenced by the strength of informal networks available them.

When breaking down these social connections into two separate categories of family/relatives and friends, analysis demonstrates an extremely strong network of friends, making it reasonable to link the eventual decision made on study locales by Chinese and Indian students to the flow of information provided by their friends. Moreover, crosstabulating these networks with respondents who were motivated by Australia's 'Attractive Immigration Policies' and the provision of bonus points for PR in Adelaide revealed a strong connection between these informal networks, particularly from friends, and their influence on respondents with PR in mind. As much as attractive PR policies can influence students in selecting Australia and Adelaide as study destinations, the role of networks are not to be ignored in strengthening the flows of students to these places.

\subsection{Conclusion}

This chapter has uncovered the main motivations that take place in the decision making process for Chinese and Indian students. It is noted that decisions were often based on myriad factors, also, the extent of influence each factor had was different between Chinese and Indian respondents. In brief, factors that influenced respondents in selecting Australia as a study destination corresponded with the reasons that discouraged them from studying in other countries.

Main analysis revealed economic motivations/human capital accumulation as the reason which played a part in encouraging Chinese and Indian students in seeking an international education. The selection of study destinations was influenced by a range of factors, many which were important, such as cost. However, it was established that macro structures in the form of government policy are significant, with immigration policies playing a substantial role in the decision making process. The emphasis of macro structures underlined the nexus between international education and permanent migration and shows how the intention to migrate can be developed before students leave their home countries. 
In addition, Indian students appear to be are more driven by the prospect of settling permanently in Australia compared to Chinese students.

The influence on policy on the permanent migration intentions of respondents indicates Chinese and Indian students can strategic in choosing their study destination. It was revealed that other countries such as the US or other Australian cities such as Melbourne were often seriously considered by respondents as study destinations. This preference shows how Australia and Adelaide are not necessarily first choice or preferred study destinations, pointing to the fact that Australia and Adelaide can be regarded as fallback or secondary destinations. The transformation of these fallback destinations into gateways (Section 4.5.1.2) draws out the recursive relationship within transnational spaces.

This chapter has shown the strategic selection of study destinations that are favourable for students with permanent immigration intentions. This strategy demonstrates the use of international education as an instrument for permanent migration and strongly suggests the formulation of this intention even before one leaves their home country, exemplifying Hugo's (2003) observation of studying abroad as a "consciously planned initial first stage of an intended relocation". Hence, the conscious selection of Australia and Adelaide are part of the transnational migration strategies of Chinese and Indian students as these places, through policy, influence the decision making process of students. However, their configuration into gateways shows that they are also subject to the future intentions of the students through the circumvention of immigration policy. This strategy illustrates the coproductive relationship between the geographic and social space within transnational spaces.

The selection of study locales was also enhanced by micro structures. A strong presence of informal networks constituting family/relatives and friends, particularly friends, strengthened the flow of Chinese and Indian students to Adelaide and Australia. In addition, these networks were suggested to also have an influence on the PR intentions of the students. On the whole, Indian students had a stronger social network and displayed a higher reliance on informal connections. More Chinese students on the other hand valued formal connections such as education agents, The next chapter will continue to explore these networks in the students' transnational strategies to further understand their role in the decision making process. 
Chapter 6: The decision making process of Chinese and Indian students coming to

In order to elucidate the students' transnational migration strategies, their future intentions will be investigated. This gateway function will be discussed further in Chapter 7, to provide a fuller picture of the students' migration strategies. The plans Chinese and Indian respondents have for their future upon the completion of their studies will also be examined in detail. As mentioned, these two groups of students are motivated differently. Therefore, it is important to further understand their differences and how it translates to their respective future intentions. It is expected that their respective transnational migration strategies will be structured differently. 


\section{CHAPTER 7: Life after Graduation- Future Intentions of Chinese and Indian students}

\subsection{Introduction}

When it comes to selecting a study destination, Chinese and Indian students are largely influenced by economic motivations and cost. Macro structures concerning 'student friendly policies' were also significant drivers in their selection process. The formulation of PR intentions before students leave their home countries further strengthens the link between immigration and the selection of specific study destinations. Through their transnational migration strategies, it was suggested that Australia and Adelaide are not necessarily preferred destinations, and that they might be regarded as 'fall back' or intermediate options that could also function as gateways to their preferred central destinations (Figure 4.2).

This chapter continues to explore the transnational migration strategies of Chinese and Indian students by focusing on their future intentions. The PR intentions of the students will be examined to determine whether the intention to gain PR was formed before or after the students' arrival into Australia. This finding will establish the notion of international education as a precursor to permanent settlement and how it serves to enhance international student mobility. Establishing their future intentions will also emphasise the strategic nature of their future plans. The future destinations and onward migration patterns of the students will be identified, thus illuminating the gateway function of Australia and Adelaide.

The above approaches will help understand the underlying factors that shape these movements. The various factors, processes and social fields and the macro, micro and meso structures involved in the students' decision making process will be established. The findings will help understand the reasons behind their future intentions, and determine whether they intend to remain in Adelaide or migrate elsewhere after their studies. In addition, the co-productive relationship in transnational social spaces within their transnational strategies will be better understood by examining the interaction between their future intentions and the destinations that form their migration strategies. 


\subsection{The future intentions of Chinese and Indian students}

The literature notes (Section 2.5.8.3) the role of government policy on the permanent migration of Chinese and Indian students however, there is a lack of research on whether the intention to migrate was formed before or after arriving in the student's host country. This section will therefore examine the link between the PR intentions of students and the influence of Australia's policies, and also determine when the intention to migrate was formed.

\subsubsection{Intentions of Chinese and Indian students before coming to Australia}

The original intentions of respondents, i.e., the post study plans they had before coming to Australia, are illustrated in Figure 7.1. As shown below, a significant proportion of respondents intend to remain in Australia after their studies for an extended period, with 22.2 percent preferring to stay for a short period of 1-2 years. This was followed by 20 percent who intend to permanently migrate to Australia and 18.5 percent who had no specific plans with regards to their length of stay.

Figure 7.1: Original intentions of Chinese and Indian students $(n=455)$

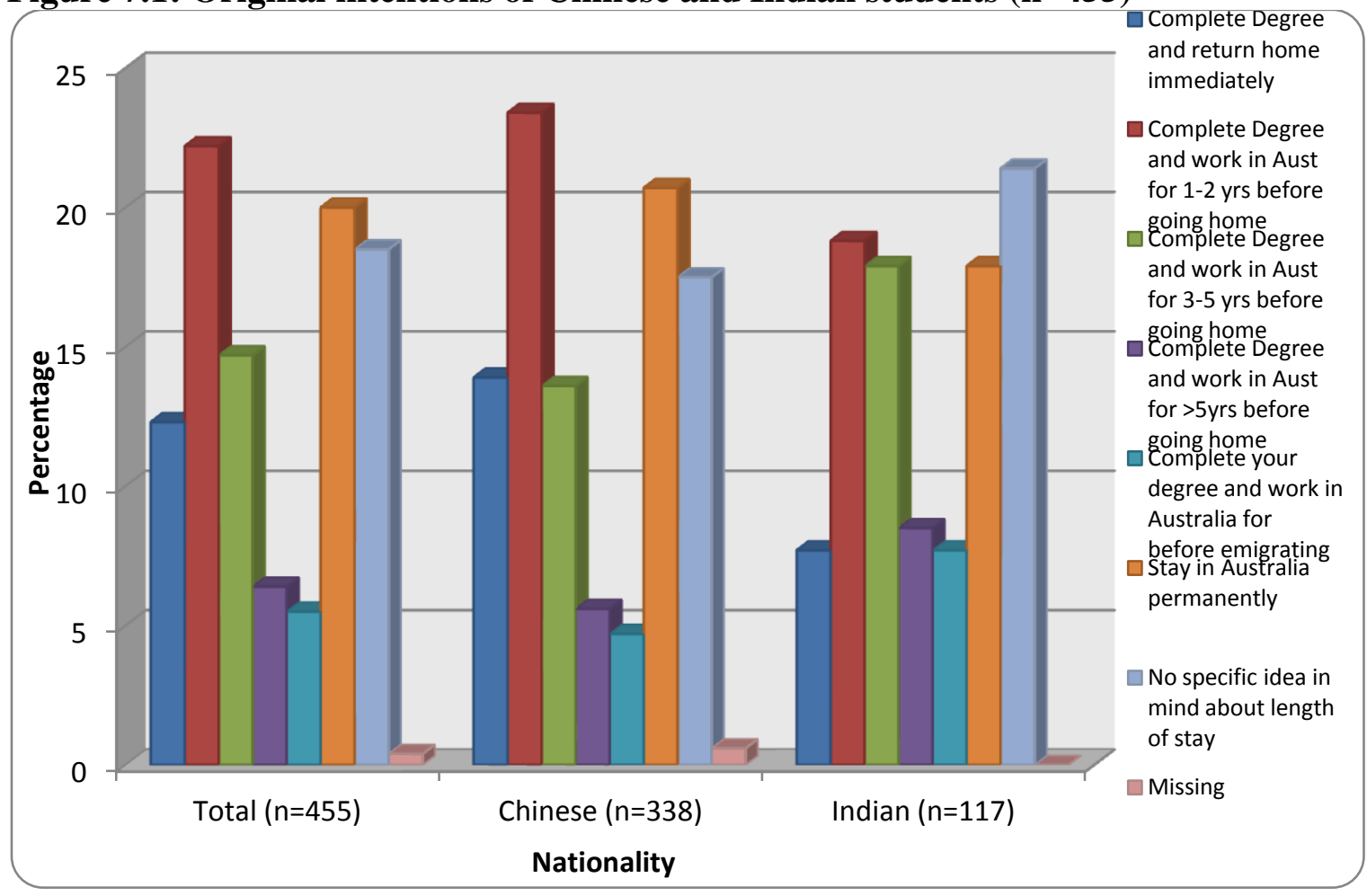

Source: CISS 2007; 2008

These findings correspond with the literature on Chinese and Indian students aiming to remain abroad after their studies (Bodycott 2009, pg 360-361; Gao \& Liu 1998, pg 30; Khadria 2002, pg 42; Mazzarol et al. 2001a, pg 38). This intention indicates the use of 
Chapter 7: Life after graduation- Future intentions of Chinese and Indian students

international education as a migration instrument and lends weight to the notion of how PR intentions are formed right at the beginning of their journey. This notion draws parallels with Figure 6.6 which showed Australia's 'Attractive immigration policies' as a motivating factor when choosing a study destination. The influence of policy on the original intention of the students is further highlighted in Table 7.1.

Table 7.1: Influence of attractive immigration policy on the original intentions of Chinese and Indian respondents $(n=455)$

\begin{tabular}{|c|c|c|c|}
\hline & $\begin{array}{l}\% \text { of Total } \\
(n=455)\end{array}$ & $\begin{array}{l}\text { \% of Chinese } \\
(\mathrm{n}=338)\end{array}$ & $\begin{array}{l}\% \text { of Indian } \\
(n=117)\end{array}$ \\
\hline $\begin{array}{l}\text { Complete Degree and return home } \\
\text { immediately }\end{array}$ & 3.2 & 4.2 & 0 \\
\hline $\begin{array}{c}\text { Complete Degree and work in } \\
\text { Australia for 1-2 yrs before going } \\
\text { home }\end{array}$ & 18.1 & 16.1 & 24.4 \\
\hline $\begin{array}{c}\text { Complete Degree and work in } \\
\text { Australia for 3-5 yrs before going } \\
\text { home }\end{array}$ & 17.6 & 16.1 & 22.2 \\
\hline $\begin{array}{c}\text { Complete Degree and work in } \\
\text { Australia for }>\text { 5yrs before going } \\
\text { home }\end{array}$ & 9 & 8.4 & 11.1 \\
\hline $\begin{array}{l}\text { Complete your degree and work in } \\
\text { Australia for before emigrating }\end{array}$ & 5.3 & 5.6 & 4.4 \\
\hline Stay in Australia permanently & 31.4 & 34.3 & 22.2 \\
\hline $\begin{array}{l}\text { No specific idea in mind about } \\
\text { length of stay }\end{array}$ & 15.4 & 15.4 & 15.6 \\
\hline
\end{tabular}

Source: CISS 2007; 2008

Table 7.1 presents a strong link between the influence of policy and the intention to permanently migrate. Approximately one third (31.4\%) of respondents motivated by Australia's attractive immigration policy also had the intention of permanently migrating. Although the intention to eventually return to their home countries appears to conflict with the fact that they chose Australia due to its immigration policy, it could be attributed to the perception of PR as a by-product of their education, a return for the large amount of money invested into their education (Baas 2006, pg 12). The complexities of such perceptions will be discussed later in this chapter. 
Although both groups of respondents planned to work in Australia before returning to their home countries, Indian respondents across the board were inclined to work for longer periods. For example, a slightly higher proportion of Chinese compared to Indian respondents planned to work in Australia for 1-2 years before returning home (23.5\% and $18.8 \%$ respectively). On the other hand, more Indian respondents intended to work for 3-5 years or more than 5 years after their studies. Although the differences between the two groups of respondents were relatively small, the results do provide an insight into a possible trend or attitude between Chinese and Indian students. According to Baas (2006, pg 12) many Indian students took substantial loans and being able to remain and work after graduation was important in paying off these loans. Figure 7.2 reaffirms this point by illustrating a link between the dependence of Indian respondents on bank loans for their tuition fees and their intention to remain in Australia for extended periods.

\section{Figure 7.2: Influence of tuition fee sources on the original intentions of Indian respondents $(n=117)$}

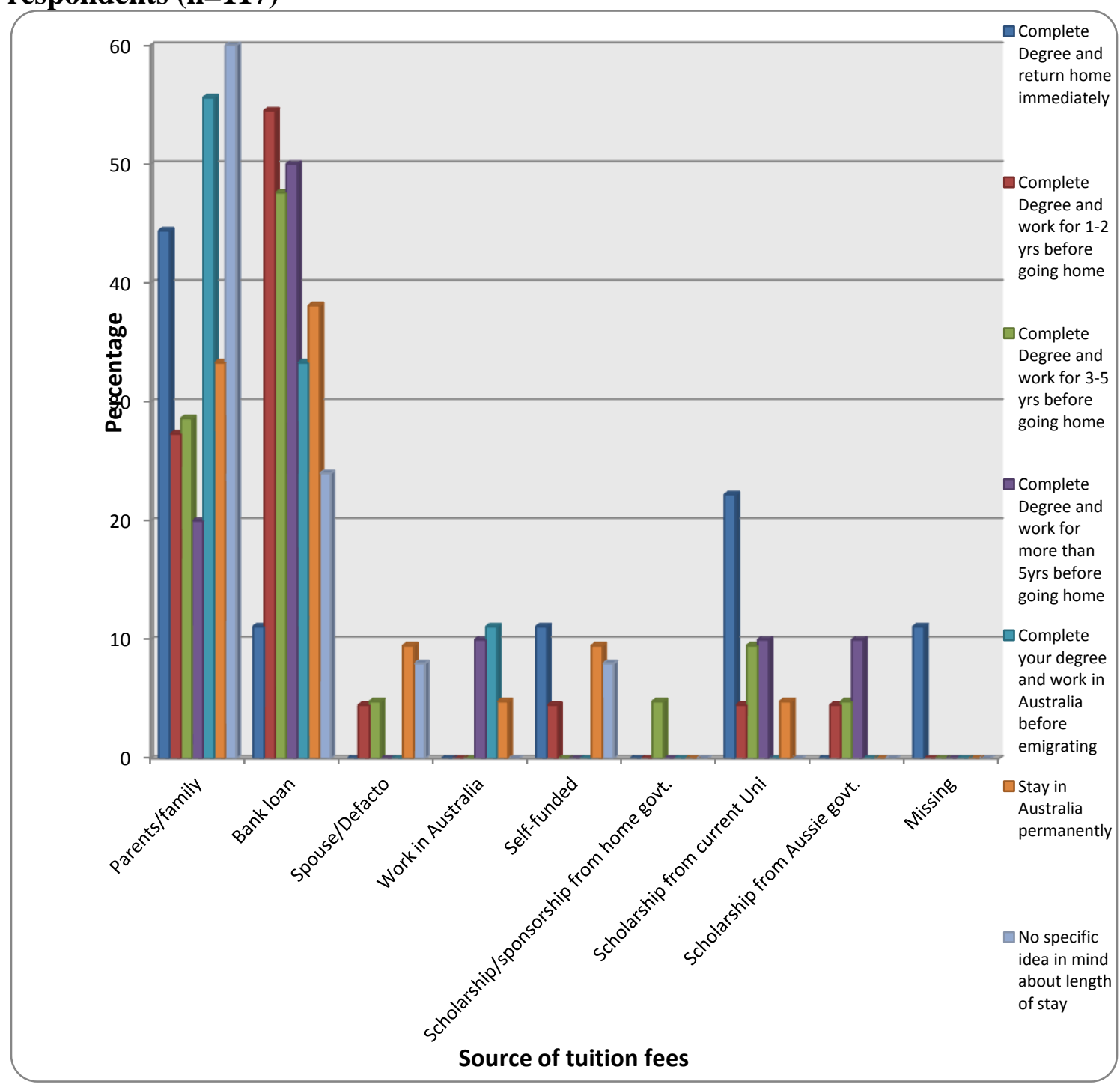


Chapter 7: Life after graduation- Future intentions of Chinese and Indian students

To some extent, those with intentions to return home immediately, emigrate to another country or not having a specific time frame appeared to be influenced by parents as a source of funds. One can thus infer firstly, that the former intention can be attributed to parental influence and secondly, the latter two intentions are possible mainly due to the financial support of their parents- an indication of relatively wealthier backgrounds. The role of parental influence will be further investigated later in this chapter.

Although a minority of respondents (more Indian than Chinese respondents) indicated plans to emigrate to another country at some point after working in Australia (Table 7.1), it nevertheless exemplifies Hugo's (2003) observation of studying abroad as the first stage of migration. This form of migration suggests Australia functions as a gateway to a third country (as discussed in Section 4.5.1.1 and illustrated in Figure 4.2), thus, this aspect of their strategies will be further explored later.

Nearly a-fifth of respondents $(18.5 \%)$ were unsure if, or how long they would remain in Australia after their studies, resonating with migrants in other studies, such as Australians living and working in the US (Parker 2009, pg 150-154). This uncertainty suggests that the duration of time spent or even permanent stay after their studies is not necessarily pre planned and their eventual decision could be influenced by cumulative causation, facilitated by a variety of factors (Szelényi 2003, pg 11-14) experienced during their time in Australia. For example, Massey (1987) found an increase in the probability of Mexican migrants settling in US cities over time as the formation of social and economic ties and the experience gained in handling the associated risks of settling helped facilitate their eventual settlement. Moreover, as Rivero-Fuentes (2006, pg 203) suggests, permanent settlement can be due to "the development of a culture of migration" which refers to the change in the cultural values in a community as migration becomes an idealised lifestyle due to the rise in the rate of migration. Similarly, Bass (2006, pg 12) argues that "one should take into account that many international students end up in a culture of migration when they come to Australia, and this has a strong impact on their behaviour". Such sentiments were reflected in the interviews:

I didn't plan to get PR when I first came but a lot of my friends talk about it. And this partly influenced me.

-Yang, Chinese student in Bachelor of Commerce- Marketing (University of Adelaide) 
Chapter 7: Life after graduation- Future intentions of Chinese and Indian students Bass (2010, pg 25) similarly found Indian students gradually wanting PR as they were constantly exposed to friends who were obsessed with it.

\subsubsection{Changing future intentions of Chinese and Indian students}

Table 7.2 below shows nearly a quarter of all respondents changed their intention after having spent some time in Australia. This continues to reflect a degree of uncertainty surrounding their future intentions underlining how cumulative causation can change their original intentions and shape their future intentions.

Table 7.2: Proportion of Chinese and Indian Respondents who changed their original intention $(n=455)$

\begin{tabular}{|cccc|}
\hline Yes & $\begin{array}{c}\text { \% of Total } \\
(\mathbf{n}=\mathbf{4 5 5})\end{array}$ & $\begin{array}{c}\text { \% of Chinese } \\
(\mathbf{n}=\mathbf{3 3 8})\end{array}$ & $\begin{array}{c}\text { \% of Indian } \\
(\mathbf{n}=\mathbf{1 1 7})\end{array}$ \\
\hline No & 24.8 & 25.4 & 23.1 \\
\hline Missing & 74.7 & 74.3 & 76.1 \\
\hline Total & 0.4 & 0.3 & 0.9 \\
\hline
\end{tabular}

Source: CISS 2007; 2008

Although respondents were asked to elaborate on any changes in their intentions, only 19 percent $(n=21)$ did so. For example, four respondents who initially planned to work in Australia for extended periods before returning home had changed their minds and indicated plans to permanently settle instead. Conversely, three respondents with initial plans to permanently settle in Australia now intended to either return home or emigrate to another country after working in Australia for a few years.

Despite the small number of respondents answering this question, the findings nevertheless provide an insight into their changing intentions which was substantiated by the literature (Alberts \& Hazen 2005, pg 138-139; 2006, pg 208) and interviews with students :

I wanted to go back to China when I finish my study but I have fallen in love with Adelaide, which is why I want to stay here.

-Shu, Chinese student in Bachelor of Media (University of Adelaide)

CAROL: My intention was to get PR, but also because as I said, my parents want me to. But I don't want to apply for PR anymore.

RESEARCHER: Why don't you want to apply for PR? 
Chapter 7: Life after graduation- Future intentions of Chinese and Indian students

CAROL: Because after spending time here I realise this is not what I want and I don't like Accounting, and I wish to change to a Law degree.

-Carol, Chinese student in Master of Commerce-Accounting (University of Adelaide)

More importantly, Table 7.2 demonstrates that the majority of Chinese and Indian students do not change their intentions and this is listed in Table 7.3. At a glance, the intention to permanently remain in Australia was the highest cited motivation, followed by working in Australia for 1-2 years before returning home and not having a specific time frame.

Table 7.3: Future intentions of respondents who have not changed their intentions $(\mathbf{n}=340)$

\begin{tabular}{|cccc|}
\hline $\begin{array}{c}\text { Intentions of respondents } \\
\text { Complete Degree and return home immediately }\end{array}$ & $\begin{array}{c}\text { \% Total } \\
(\mathbf{n = 3 4 0})\end{array}$ & $\begin{array}{c}\text { \% Chinese } \\
(\mathbf{n = 2 5 1})\end{array}$ & $\begin{array}{c}\text { \% Indian } \\
(\mathbf{n = 8 9})\end{array}$ \\
\hline $\begin{array}{c}\text { Complete Degree and work in Australia for 1-2 } \\
\text { years before going home }\end{array}$ & 20.9 & 21.5 & 19.1 \\
\hline $\begin{array}{c}\text { Complete Degree and work in Australia for 3-5 } \\
\text { years before going home }\end{array}$ & 15.9 & 14.3 & 20.2 \\
\hline $\begin{array}{c}\text { Complete Degree and work in Australia for } \\
\text { more than 5 years before going home }\end{array}$ & 5.9 & 5.2 & 7.9 \\
\hline $\begin{array}{c}\text { Complete your degree and work in Australia } \\
\text { before emigrating }\end{array}$ & 5.9 & 4.8 & 9.0 \\
\hline $\begin{array}{c}\text { Stay in Australia permanently } \\
\text { Missing }\end{array}$ & 22.4 & 23.9 & 18.0 \\
\hline No specific idea in mind about length of stay & 17.4 & 16.7 & 19.1 \\
\hline
\end{tabular}

Source: CISS 2007; 2008

It is clear that PR is an important objective when comparing the original intentions of respondents in Figure 7.1, with the intentions that did not change or had not changed at the time of the survey in Table 7.3. Working in Australia for 1-2 years before going home (22.2\% in Fig 7.1 to $20.9 \%$ in Table 7.3 ) and permanent settlement (20\% in Fig. 7.1 to $22.4 \%$ in Table 7.3) were the top two intentions in both tables. These intentions not only emphasise permanent settlement as a primary objective, but also shows how it remains the strongest objective even after spending some time in Australia, further underlining international education as a migration instrument for these students.

In summary, the findings in this section show a number of important findings. The intention to get PR being formed before the student arrives in Australia outlines the strategic nature of Chinese and Indian students. Additionally, the influence of attractive immigration policy on their PR intentions is clear, underlining the key role of macro 
structures. Respondents' intentions to remain in Australia to live and work for varying periods and their plans to emigrate to another country further highlights the strategic nature of their planning. However, a higher proportion of Chinese compared to Indian respondents indicated their intention to stay permanently. Indian respondents on the other hand reflected a higher tendency to live and work for longer periods before leaving Australia, substantiating earlier findings that attributed this trend to the need to repay bank loans. It also suggests Indian students as a more mobile group of students who are less inclined to permanently settle. The following sections will continue to investigate the future intentions of these respondents in order to ascertain their permanency in Australia and elucidate the function of Adelaide and Australia as gateways to other destinations in their transnational migration strategies.

\subsection{PR intentions of Chinese and Indian students}

Although findings in the previous sections have shown permanent settlement as a key objective for Chinese and Indian respondents, the intention to leave after working and living in Australia for extended periods (Figure 7.1 \& Table 7.3) hints at onwards migration to other destinations. However, it is important first to determine their permanency in Australia after their studies.

Figure 7.3: Visa categories that Chinese and Indian respondents intend to seek after their studies $(\mathbf{n}=455)$

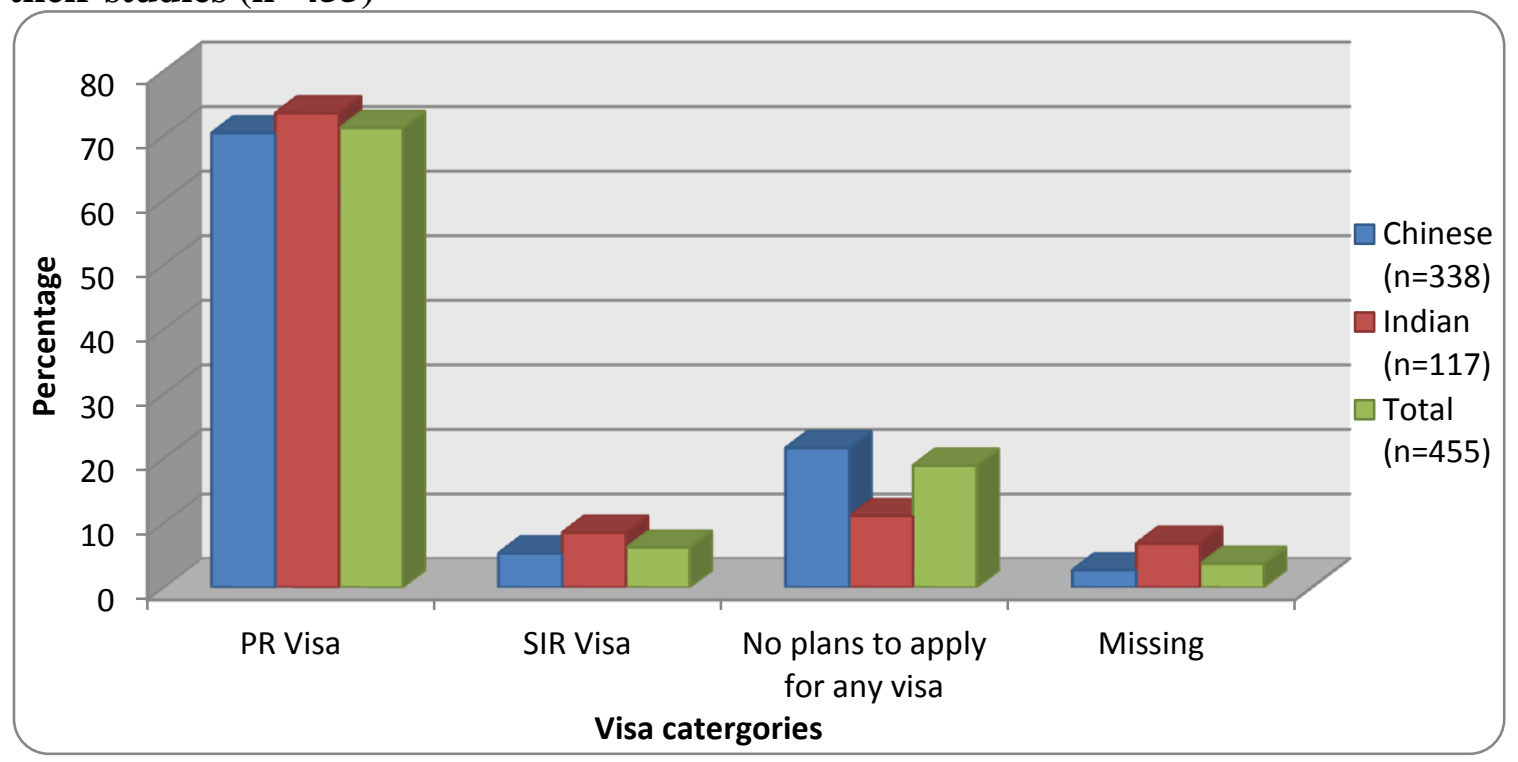

Source: CISS 2007; 2008

As described in Section 3.5, international students have a range of post study visas which they can apply for. The length of time they plan to remain in Australia is roughly determined by the visa they intended to apply for. As illustrated in Figure 7.3, the intention 
Chapter 7: Life after graduation- Future intentions of Chinese and Indian students

to remain in Australia after their studies is apparent with an overwhelming 71.2 percent intending to apply for a PR visa. The SIR visa option (visa subclass 487) was a less popular option $(6.2 \%)$.

On the whole, Indian respondents (73.5\%) displayed a slightly higher propensity in seeking PR visas compared to their Chinese counterparts (70.4\%) also similar for those who intend to apply for the SIR visa. This trend is further backed up in Table 7.4 which shows a higher proportion of Indian respondents to be 'Very familiar' and 'Familiar' with the requirements necessary for PR.

Table 7.4: Familiarity with PR requirements for respondents who intend to apply for PR or SIR visa $(\mathbf{n}=352)$

\begin{tabular}{|c|ccc|}
\hline $\begin{array}{c}\text { Familiarity with PR } \\
\text { requirements }\end{array}$ & $\begin{array}{c}\text { \% of Total } \\
(\mathbf{n}=352)\end{array}$ & $\begin{array}{c}\text { \% of Chinese } \\
(\mathbf{n}=256)\end{array}$ & $\begin{array}{c}\text { \% of Indian } \\
(\mathbf{n}=96)\end{array}$ \\
\hline Very familiar & 14.5 & 9.8 & 27.1 \\
\hline Familiar & 46.6 & 48 & 42.7 \\
\hline Unfamiliar & 28.7 & 32.8 & 17.7 \\
\hline No knowledge & 5.4 & 5.9 & 4.2 \\
\hline Missing & 4.8 & 3.5 & 8.3 \\
\hline Total & $\mathbf{1 0 0}$ & $\mathbf{1 0 0}$ & $\mathbf{1 0 0}$ \\
\hline
\end{tabular}

Source: CISS 2007; 2008

This shows that PR is a key objective particularly for Indian students. While findings suggest the greater tendency of Indian students in settling in Australia after their studies, it is contradicted by earlier findings that showed Chinese students having the stronger intention to settle permanently (Table 7.3 and Figure 7.1). Evidence from Hugo's (2008, pg 93-95) study also revealed a high rate of return migration among China-born settlers from Australia which points to the need to question the extent of their permanency. Subsequent sections will thus explore the onward migration intentions of students.

Additionally, interviews revealed that while PR visas might be desired, they do not equate to permanent settlement per se as it is crucial for post study employment in Australia:

DAWAL: I'll be applying for PR six months before I finish my studies but it is more for convenience sake.

RESEARCHER: Why?

DAWAL: Getting PR will increase the scope of jobs available and it is easier to find jobs that way, especially for jobs in Defence. It is hard finding jobs in my industry 
Chapter 7: Life after graduation- Future intentions of Chinese and Indian students

-Dawal, Indian student in Master of Telecommunication (UniSA)

Getting PR is important to get a job or to get work experience. Not all Chinese students want to be a PR. They only want to work or to get some work experience in Australia but PR is required.

-Xing, Chinese student in Bachelor of Engineering (University of Adelaide)

This perception is supported by other researchers (Baas 2006, pg 16; Jackling 2007, pg 38) and a report from the National Liaison Committee ${ }^{39}$ (2009, pg 28) noted that most employers were "not willing to hire international student graduate on Temporary visas, with Permanent Residency being the minimum requirement for job applications". Moreover, as mentioned, PR can be viewed as a by-product and for some Indian students it is "a form of compensation for something they feel they have not received (a sound education) but for which they have paid a lot of money" (Baas 2006, pg 12).

If you are spending so much money [on studying in Australia], you should get PR!

-Anuj, Indian student in Bachelor of Commerce-Accounting (UniSA)

We should get PR! We deserve it because we spend 3 years in Australia and so much money on our education in Australia!

-Yang, Chinese student in Bachelor of Commerce- Marketing (University of Adelaide)

These sentiments explain the inconsistencies present in their intentions to apply for a PR visa and to permanently settle. Furthermore, it also hints at the onward migration intentions of students after working for extended periods in Australia (Table 7.3 and Figure 7.1), as a migration agent states:

Having PR gives them the flexibility of being able to come back to Australia whenever they want to in future.

-Shaun, Migration Agent

It is however clear that the majority of Chinese and Indian respondents have, at least in the immediate future, plans to live and work in Australia after their studies.

\footnotetext{
${ }^{39}$ The National Liaison Committee is the national peak body for all international students in Australia
} 


\subsubsection{The intention to remain in Australia}

According to Table 7.5, a significant 87.8 percent of respondents who planned on applying for PR or SIR visas, intend to remain in Australia after their studies. By and large as shown in Table 7.6, living conditions were significant factors with Australia's higher quality of life and standard of living (61.5\% and 57\% respectively) influencing the decision to stay.

Table 7.5: The intention to remain in Australia of respondents intending to apply for PR and SIR visa $(n=352)$

\begin{tabular}{|cccc|}
\hline $\begin{array}{c}\text { Intentions to remain } \\
\text { in Australia }\end{array}$ & $\begin{array}{c}\text { \% of Total } \\
(\mathbf{n}=352)\end{array}$ & $\begin{array}{c}\text { \% of Chinese } \\
(\mathbf{n}=256)\end{array}$ & $\begin{array}{c}\% \text { of Indian } \\
(\mathbf{n}=96)\end{array}$ \\
\hline Yes & 87.8 & 87.5 & 88.5 \\
\hline No & 11.6 & 11.7 & 11.5 \\
\hline Missing & 0.6 & 0.8 & 0 \\
\hline
\end{tabular}

Source: CISS 2007; 2008

Table 7.6: Factors that influenced Chinese and Indian respondents to remain in Australia (n=309)

\begin{tabular}{|c|c|c|c|}
\hline & $\begin{array}{c}\% \text { of Total } \\
(n=309)\end{array}$ & $\begin{array}{l}\% \text { of Chinese } \\
(\mathrm{n}=224)\end{array}$ & $\begin{array}{l}\% \text { of Indian } \\
(n=85)\end{array}$ \\
\hline $\begin{array}{l}\text { Higher "quality of life" in Australia } \\
\text { (non-economic factors, eg, weather, } \\
\text { lifestyle) }\end{array}$ & 61.5 & 65.2 & 51.8 \\
\hline Higher standard of living in Australia & 57 & 54 & 64.7 \\
\hline Higher Salary here in Australia & 46.3 & 48.7 & 40 \\
\hline $\begin{array}{l}\text { Employment opportunities are better in } \\
\text { Australia }\end{array}$ & 42.4 & 37.5 & 55.3 \\
\hline To gain work experience & 20.4 & 12.9 & 40 \\
\hline $\begin{array}{l}\text { Better job/career advancement } \\
\text { prospects in Australia }\end{array}$ & 19.4 & 14.7 & 31.8 \\
\hline Marriage/Partnership reasons & 9.1 & 9.8 & 7.1 \\
\hline Parental Influence & 8.7 & 10.7 & 3.5 \\
\hline Ties to friends or family in Australia & 8.1 & 7.6 & 9.4 \\
\hline $\begin{array}{l}\text { Unstable Political Situation in home } \\
\text { country }\end{array}$ & 4.9 & 4.5 & 5.9 \\
\hline $\begin{array}{l}\text { Restrictive Cultural practices (eg, } \\
\text { strong gender roles) in home country }\end{array}$ & 4.2 & 3.1 & 7.1 \\
\hline
\end{tabular}

Source: CISS 2007; 2008

Financial and professional reasons were also important as 46.3 and 42.4 percent of respondents were influenced by higher salaries and better employment opportunities respectively in Australia. To a lesser extent, the opportunity to gain work experience and better job/career advancement prospects in Australia were also cited by 20.4 and 19.4 
Chapter 7: Life after graduation- Future intentions of Chinese and Indian students

percent respectively. Factors such as parental decision (8.7\%), marriage/partnership reasons $(9.1 \%)$, ties to friends or family in Australia (8.1\%), unstable political situation in home country $(4.9 \%)$ and restrictive cultural practices such as discriminative gender roles in their home countries $(4.2 \%)$ make up the remaining reasons.

Australia's quality of life and higher standard of living were the most important factors, and it was striking to note that this was especially so for Chinese respondents. This draws parallels with research (Beal \& Sos 2001, pg 138; Wu 2003, pg 365-366) which revealed Asian (Chinese and Taiwanese) migrants who valued Australia's lifestyle, environment and physical attributes over economic factors. Nevertheless, economic motivations were also strong reasons for remaining in Australia.

Aside from 'Higher salary in Australia', professional and career related factors such as 'Employment opportunities are better in Australia', 'To gain work experience' and 'Better job/career advancement prospects in Australia' had significantly higher proportions of Indian than Chinese respondents. Indian students and migrants in the US also held similar attitudes (George \& Shyamsundar 2007, pg 114-115) which is unsurprising as this is reinforced with acute and poor employment outcomes in India (Khadria 2001, pg 56; Maslen 2007). Overall, these factors, particularly the liking for Australia's lifestyle were also raised by temporary skilled migrants (holders of visa subclass 457) in Khoo et al.'s (2005, pg 25-26) study. Hence, these findings are not to be taken lightly as Figure 7.4 underlines the seriousness of respondents in their intention to remain in Australia.

Figure 7.4: Seriousness of respondents intending to remain in Australia $(n=308)^{40}$

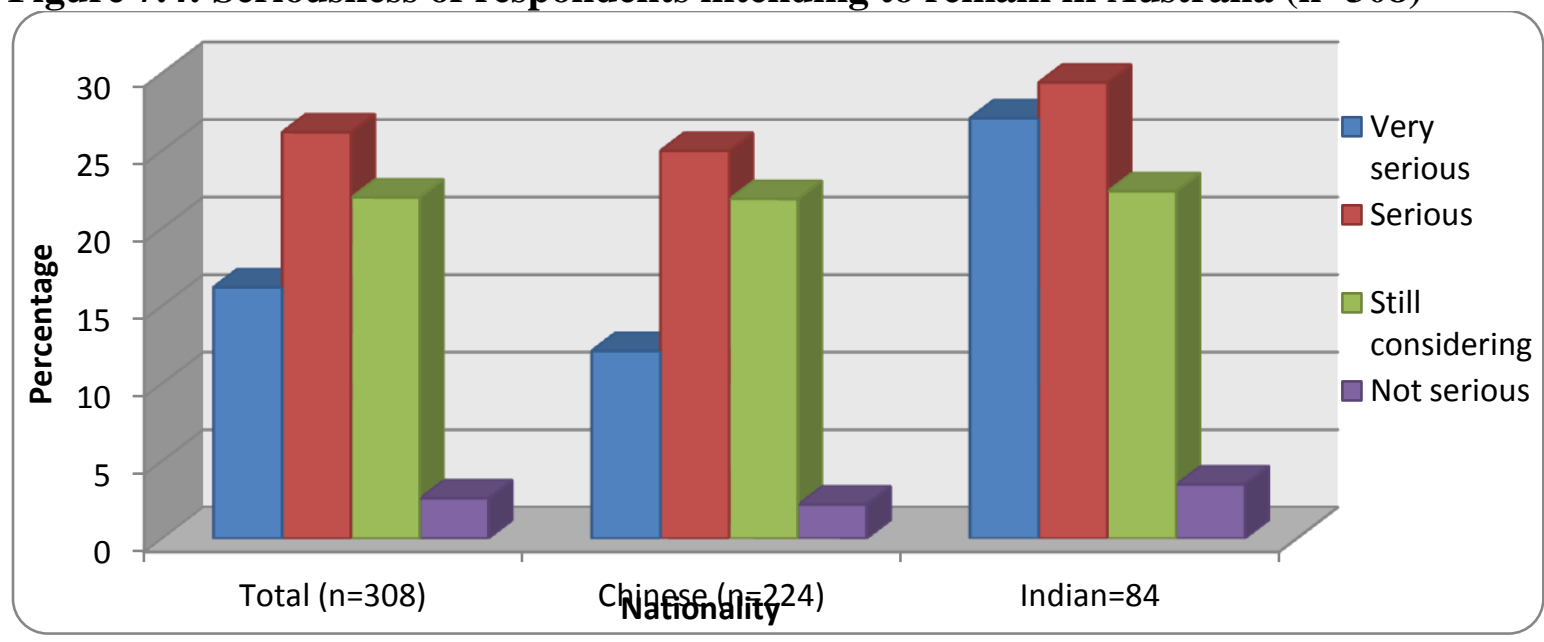

Source: CISS 2007; 2008

\footnotetext{
${ }^{40}$ There were an unusually large proportion of respondents (from the University of Adelaide only) who did not answer this question (33.1\%). The reason for this is unknown but is likely due to an online technical fault with the survey sent out to respondents from the University of Adelaide.
} 
As illustrated above, a significant proportion (42.4\%) were either 'Serious' or 'Very serious', although higher proportions of Indian than Chinese respondents in both categories displayed stronger intentions on their part which backs up earlier suggestions of the stronger PR intention of Indian students (Sections 6.4 \& 6.4.1). More importantly, the fact that 22 percent of respondents were 'Still considering' continues to raise further questions on the extent of their permanency. Their immediate plans upon graduation will be explored following sections to ascertain whether their transnational migration strategies include other destinations.

\subsubsection{The intention to remain in Adelaide}

Respondents who planned on applying for a PR or SIR visa were asked to indicate how long they intended to remain in Adelaide after their studies (Table 7.7). Chinese and Indian respondents generally planned to remain in Adelaide for a year and longer. However, with only 15.6 percent of respondents intending to remain in Adelaide for 5 years and more, one could infer that the majority intend to migrate to another destination after working and living in Adelaide.

Table 7.7: Length of time Chinese and Indian respondents intend on remaining in Adelaide ( $\mathrm{n}=352)$

\begin{tabular}{|cccc|}
$\begin{array}{c}\text { Length of time } \\
\text { intended in Adelaide } \\
\begin{array}{c}\text { Do not intend to } \\
\text { remain in Adelaide }\end{array}\end{array}$ & $\begin{array}{c}\text { \% of Total } \\
(\mathbf{n}=352)\end{array}$ & $\begin{array}{c}\text { \% of Chinese } \\
(\mathbf{n}=256)\end{array}$ & $\begin{array}{c}\% \text { of Indian } \\
(\mathbf{n}=96)\end{array}$ \\
\hline 1 year and less & 5.4 & 4.7 & 7.3 \\
\hline Between 1 and 2 years & 19.3 & 7 & 4.2 \\
\hline Between 2 to 3 years & 13.1 & 20.3 & 15.6 \\
\hline Between 3 to 4 years & 6.5 & 14.5 & 9.4 \\
\hline 5 years and more & 15.6 & 3.9 & 13.5 \\
\hline Unsure & 32.7 & 16 & 34.4 \\
\hline Missing & 1.4 & 32 & 1 \\
\hline
\end{tabular}

Source: CISS 2007; 2008

While this continues to feed into Adelaide's function as a gateway to other destinations due to accorded regional campus points (Section 3.7), a significant proportion was still unsure (32.7\%) of how long they would remain. This uncertainty again raises the factor of cumulative causation and interviews revealed a link with future employment prospects in Adelaide: 
Chapter 7: Life after graduation- Future intentions of Chinese and Indian students

I would like to remain in Adelaide. I love it here, I'm used to the city and I have many friends here. Moving interstate is a hassle but I might move if I get a job there.

-Anuj, Indian student in Bachelor of Commerce-Accounting (UniSA)

If there's a job in Adelaide I would like to stay because I have a lot of friends and I'm familiar with the city. Plus Adelaide is cheaper [to live in].

-John, Chinese student in Bachelor of Media (University of Adelaide)

The intention of Chinese and Indian students to remain in Australia is very clear. On the other hand, the general trend to remain in Adelaide in the short term is apparent, which suggests onwards migration to another place in their transnational migration strategies. It is clear that economic motivations in terms of employment are an important consideration given the reference to lack of job opportunities informing their decision to migrate interstate. The views of the students above however represent a situation which hints at respondents willing to give settlement a try, presenting an opportunity (from a regional perspective) for good government policy to intervene and ensure their stay in Adelaide. The following sections will explore the onward migration patterns of Chinese and Indian students before determining the factors influencing their decision making process.

\subsection{The onward migration of Chinese and Indian students}

According to Hawthorne (2007, pg 19) there is a critical lack of information available on the future employment and study trajectories of international students. Such forms of mobility are reflections of migration flows (Section 4.5.1) which indicate the configuration of places in migrants' transnational migration strategies (Figure 4.2). This section will explore the various forms of onward migration, identify the future or central destinations involved and examine the underlying factors that play a part in the students' decision making process.

\subsubsection{The intention to migrate to a third destination}

Only the proportion of respondents who expressed an intention to apply for a PR or SIR visa and to remain in Australia ( $\mathrm{n}=309$ as listed in Table 7.5) was examined in order to capture their plans to migrate interstate. Similarly, only respondents not returning to their home countries immediately $(n=389)$ were examined with regards to their third country migration intentions. 
Tables 7.8 and 7.9 revealed significant proportion of respondents who were "Unsure' and as discussed earlier (Sections 7.2.1 \& 7.2.2), the element of cumulative causation and uncertainty is not uncommon among other temporary migrants in Australia (Khoo et al. 2005, pg 23-25). Cumulative causation should therefore not be underestimated and perhaps one needs to take into consideration the potential increase of these onward migration intentions.

Table 7.8: Intention to migrate interstate $(n=309)$

\begin{tabular}{|cccc|}
$\begin{array}{c}\text { Intention to } \\
\text { migrate interstate }\end{array}$ & $\begin{array}{c}\text { \% of Total } \\
(\mathrm{n}=\mathbf{3 0 9})\end{array}$ & $\begin{array}{c}\% \text { of Chinese } \\
(\mathrm{n}=224)\end{array}$ & $\begin{array}{c}\% \text { of Indian } \\
(\mathrm{n}=\mathbf{8 5})\end{array}$ \\
\hline Yes & 27.8 & 22.8 & 41.2 \\
\hline No & 16.5 & 16.5 & 16.5 \\
\hline Unsure & 55.3 & 60.3 & 42.4 \\
\hline Missing & 0.3 & 0.4 & 0 \\
\hline
\end{tabular}

Source: CISS 2007; 2008

Table 7.9: Intention to migrate to a $3^{\text {rd }}$ country $(n=389)$

\begin{tabular}{|cccc|}
\hline $\begin{array}{c}\text { Intention to migrate } \\
\text { to a } 3^{\text {rd }} \text { country }\end{array}$ & $\begin{array}{c}\text { \% of Total } \\
(\mathbf{n}=389)\end{array}$ & $\begin{array}{c}\text { \% of Chinese } \\
(\mathrm{n}=\mathbf{2 8 6})\end{array}$ & $\begin{array}{c}\text { \% of Indian } \\
(\mathrm{n}=\mathbf{1 0 3})\end{array}$ \\
\hline Yes & 21.6 & 18.9 & 29.1 \\
\hline No & 32.4 & 32.5 & 32.0 \\
\hline Unsure & 40.6 & 45.1 & 28.2 \\
\hline Missing & 5.4 & 3.5 & 10.7 \\
\hline
\end{tabular}

Source: CISS 2007; 2008

Interstate $(27.8 \%)$ and third country $(21.6 \%)$ migration intentions were quite high, although it was more prevalent for Indian respondents. The deliberate nature of these migration intentions (Table 7.10) further demonstrates how Indian students are more purposeful in their transnational strategies.

Nearly a quarter of respondents who seriously considered studying in other Australian States and other countries planned on subsequently moving to these places after their studies (27.5\% and $24.6 \%$ respectively). Again, it is clear that Indian respondents have a higher tendency to do so, especially with regards to interstate migration. This trait of Indian students will be further examined later, but this finding in general is reminiscent of the configuration of places by migrants in their migration strategies (Guerassimoff 2003; Huang \& Yeoh 2005; Thuno 2003; Yeoh et al. 2005). These onward migrations strengthen 
the suggestion of Adelaide and Australia functioning as gateways and emphasises the calculated nature of such forms of mobility.

Table 7.10: Proportion of respondents who intend to migrate to the places which they seriously considered studying in

\begin{tabular}{|c|c|c|c|}
\hline \multicolumn{4}{|c|}{ Respondents with Interstate migration intentions } \\
\hline & $\begin{array}{c}\text { \% of Total } \\
(n=204)\end{array}$ & $\begin{array}{c}\% \text { of Chinese } \\
(n=158)\end{array}$ & $\begin{array}{c}\% \text { of Indian } \\
(n=46)\end{array}$ \\
\hline $\begin{array}{c}\text { Respondents who considered } \\
\text { studying in other Australian } \\
\text { States }(n=204)\end{array}$ & 27.5 & 22.8 & 43.5 \\
\hline \multicolumn{4}{|c|}{ Respondents with $3^{\text {rd }}$ country migration intentions } \\
\hline & $\begin{array}{c}\% \text { of Total } \\
(\mathbf{n}=256)\end{array}$ & $\begin{array}{c}\text { \% of Chinese } \\
(n=189)\end{array}$ & $\begin{array}{c}\% \text { of Indian } \\
(n=67)\end{array}$ \\
\hline $\begin{array}{l}\text { Respondents who considered } \\
\text { studying in other countries } \\
(n=256)\end{array}$ & 24.6 & 23.8 & 26.9 \\
\hline
\end{tabular}

Source: CISS 2007; 2008

Table 7.11: The seriousness of interstate and $3^{\text {rd }}$ country migration

\begin{tabular}{|c|c|c|c|}
\hline & \multicolumn{3}{|c|}{ Intention to migrate Interstate } \\
\hline & $\begin{array}{c}\% \text { of Total } \\
(n=86)\end{array}$ & $\begin{array}{c}\% \text { of Chinese } \\
(\mathbf{n}=51)\end{array}$ & $\begin{array}{c}\% \text { of Indian } \\
(n=35)\end{array}$ \\
\hline Not Serious & 4.7 & 3.9 & 5.7 \\
\hline Still Considering & 45.3 & 51 & 37.1 \\
\hline Serious & 30.2 & 25.5 & 37.1 \\
\hline Very Serious & 16.3 & 13.7 & 20 \\
\hline Missing & 3.5 & 5.9 & 0 \\
\hline Total & 100 & 100 & 100 \\
\hline & $\begin{array}{c}\% \text { of Total } \\
(n=84)\end{array}$ & $\begin{array}{c}\% \text { of Chinese } \\
(n=54)\end{array}$ & $\begin{array}{c}\% \text { of Indian } \\
(n=30)\end{array}$ \\
\hline Not Serious & 7.1 & 9.3 & 3.3 \\
\hline Still Considering & 50 & 53.7 & 43.3 \\
\hline Serious & 23.8 & 16.7 & 36.7 \\
\hline Very Serious & 14.3 & 14.8 & 13.3 \\
\hline Missing & 4.8 & 5.6 & 3.3 \\
\hline Total & 100 & 100 & 100 \\
\hline
\end{tabular}

Source: CISS 2007; 2008 
Chapter 7: Life after graduation- Future intentions of Chinese and Indian students

The onward migration intention of respondents and their level of seriousness are shown in Table 7.11, and findings reveal a combined 46.5 percent of respondents who were 'Serious' and 'Very serious' in migrating interstate. In comparison to 38.1 percent with third country migration intentions, it is safe to say that interstate migration is a more likely strategy. Further analysis shows a combined 57.1 percent of Indian respondents being 'Serious' and 'Very Serious' in migrating interstate compared to a combined 39.2 percent of Chinese respondents. This trend continued as half of Indian respondents were 'Serious' and 'Very Serious' in migrating to a third country compared to 31.5 percent of Chinese respondents. The combination of this with earlier findings which highlighted their flexibility (Section 6.3.2), their stronger intention to remain in Australia (Section 7.3.1) and for longer periods (Section 7.2.1), is a strong indication of the relative higher mobility in their migration strategies.

In addition, significant proportions who were 'Still considering' their decision to migrate interstate $(45.3 \%)$ and/or to a third country $(50 \%)$ is quite the opposite of findings which have shown how the objective of PR can be formed before coming to Australia. Nevertheless the findings in this section demonstrate how the transnational migration strategies of Chinese and Indian students in general, can be very strategic when it comes to getting PR and staying in Australia (both in Adelaide or interstate). Conversely, the intention to migrate to a third destination is relatively weaker.

\subsubsection{The intended future destinations of Chinese and Indian respondents}

The future interstate destinations of respondents shown in Table $7.12^{41}$ accentuate the extent of the Indian student's mobility. Chinese respondents appeared to be less mobile (with none planning to relocate outside of New South Wales, Victoria and Queensland) than their Indian counterparts who displayed a higher propensity to relocate to more States. It is not surprising that New South Wales (53.5\%), Victoria (48.8\%) and Queensland $(29.1 \%)$ were the top three interstate destinations, with the concentration of international students in these States evidence of their popularity.

Australian residents presented similar interstate migration patterns in the last two decades as they consistently exhibited the same preferences for the abovementioned States (ABS 2004; 2005; 2006; 2007a; 2008a; 2009; 2010b). Moreover, in the context of South Australia, considerable proportions of skilled and economically productive young South

\footnotetext{
${ }^{41}$ Respondents were allowed to select multiple states.
} 
Australians (especially pronounced for ages 20-29) have consistently departed for other capital cities (ABS 2010a; Bell 2000; Hugo 2002b), which is comparable to the average ages of CISS respondents (Figure 5.3).

Table 7.12: Future interstate destinations of Chinese and Indian respondents $(n=86)$

\begin{tabular}{|ccc|c|}
$\begin{array}{c}\text { Future interstate } \\
\text { destinations }\end{array}$ & $\begin{array}{c}\% \text { of Total } \\
(\mathrm{n}=86)\end{array}$ & $\begin{array}{c}\% \text { of Chinese } \\
(\mathrm{n}=51)\end{array}$ & $\begin{array}{c}\% \text { of Indian } \\
(\mathrm{n}=35)\end{array}$ \\
\hline New South Wales & 53.5 & 43.1 & 68.6 \\
\hline Victoria & 48.8 & 47.1 & 51.4 \\
\hline Queensland & 29.1 & 27.5 & 31.4 \\
\hline Western Australia & 16.3 & 0 & 40 \\
\hline $\begin{array}{c}\text { Northern Territory } \\
\text { Tasmania }\end{array}$ & 3.5 & 0 & 8.6 \\
\hline $\begin{array}{c}\text { Australia Capital } \\
\text { Territory }\end{array}$ & 3.5 & 0 & 5.7 \\
\hline
\end{tabular}

Source: CISS 2007; 2008

Table 7.13: Future $3^{\text {rd }}$ country destinations of Chinese and Indian respondents $(n=84)$

\begin{tabular}{|cccc|}
$\begin{array}{c}\text { Future } 3^{\text {rd }} \text { country } \\
\text { destinations }\end{array}$ & $\begin{array}{c}\text { \% of Total } \\
(\mathbf{n = 8 4})\end{array}$ & $\begin{array}{c}\text { \% of Chinese } \\
(\mathbf{n}=54)\end{array}$ & $\begin{array}{c}\text { \% of Indian } \\
(\mathbf{n}=\mathbf{3 0})\end{array}$ \\
\hline US & 50 & 48.1 & 53.3 \\
\hline Canada & 23.8 & 22.2 & 26.7 \\
\hline Europe & 15.5 & 16.7 & 13.3 \\
\hline Singapore & 14.3 & 18.5 & 6.7 \\
\hline New Zealand & 6.0 & 3.7 & 6.7 \\
\hline Not Sure & 3.6 & 1.9 & 10.0 \\
\hline
\end{tabular}

Source: CISS 2007; 2008

In a similar vein, as shown in Table 7.13, the US (50\%), UK (23.8\%) and Canada (15.5\%) were indicated by respondents as their top three third country destinations. As earlier mentioned (Section 4.5.1.1), these countries are also popular among Indian IT workers (Biao 2004) and the Chinese diaspora (DeVoretz \& Ma 2002; Waters 2001; 2005). These preferences correlate with the fact that the US and UK are consistently the top two destination countries for international students (Figure 1.1) while Canada's attractiveness

\footnotetext{
${ }^{42}$ Multiple European countries indicated by a minority of respondents; they include Germany, Switzerland, Holland, France, Italy and Spain.
} 
is associated with their stability, security and the opportunity to acquire human capital (Waters 2001, pg 18; 2005, pg 367).

When it comes to emigration in Australia, Hugo (2008, pg 93) found that "overseas-born dominate among the permanent departures". Statistics show that Australia has experienced a rapid increase in the departure of 'long term temporary residents' or settlers from 8,839 in 1995-1996 to 26,229 in 2003-2004 (Birrell et al. 2005, pg 13). Although most of them return to their home countries, these outflows further the concept of Australia as a gateway to another destination. One could link the popularity of future interstate or third country destinations with earlier findings (Sections 6.3.1 and 6.3.2) which revealed them as the most seriously considered study destinations before coming to Australia. Interviews further reinforced the gateway function of Adelaide and Australia, and how they are not commonly first choice destinations:

RESEARCHER: Do you find students telling you of their plans to migrate to another city after they graduate and get PR?

DANIEL: Yes, definitely they will have that in mind. Once they satisfy the immigration requirements and get PR status...I don't think DIMIA has any restrictions [with regards to] when you get PR you have to remain in the city [Adelaide] right? So they will 'suffer' until they get that and then go off to Sydney or Melbourne.

-Daniel, Education Agent

A lot of my friends want to move interstate. For example, I got a friend who is studied in Sydney...was studied in Sydney, came here to Adelaide to study and to get PR before moving [back] to Sydney.

Dong, Chinese student in Master of Commerce-Accounting (University of Adelaide)

I have come across Indian students with the intention of using Australia to get their PR, stay for 5years, become a citizen and then apply for a green card to go to the US.

-Stephen, IDP Staff

An academic in our nursing programme mentioned how we get something like 150-200 nurses from India each year who come to do a conversion programme at UniSA... And because nursing is a very in demand profession in Australia at the moment, they find it very easy to pick up nursing employment at the end of their conversion programme. As estimated recently, a senior academic from our school recently mentioned that a majority of these 100-200 students who do their conversion in South Australia are going to Melbourne or Sydney or Queensland to work after their conversion programme. So yes, I believe that there are quite a few who use South Australia for the study purpose but still end up going interstate to work. 
The intention to migrate interstate was generally strong for interviewees, however, third country migration intentions were comparatively weaker. Although the majority of student interviewees had no third country migration intentions, they were often able to recount stories of friends with such strategic intentions:

RESEARCHER: Do you have any plans to migrate to another country?

RAVIPRABA: No I don't. I may move back to India if it doesn't work and finances don't work out for me. But three of my close friends plan to work for a few years to get PR, and down the road become citizens of Australia and move to the USA. Migrating as citizens of Australia is easier.

-Ravipraba, Indian student in MBA (UniSA)

It's true [the route to the US via other countries] and it happens. I have two friends from my PEP ${ }^{43}$ course who have chosen Australia as a first stop destination. After getting a PR and an Australian passport they will try to move to the USA.

-Annie, Chinese student in Master of Accounting and Finance (University of Adelaide)

RESEARCHER: If Australia's not the end destination, what have you come across?

NATALIE: Two dots don't normally create a trend. I am talking perhaps, half a dozen conversations where students basically said they want to come to Australia first, get Australian PR and then move on to the US or Canada or Singapore.

-Natalie, Marketing Staff (UniSA)

A young woman [ex international student-Chinese] I know quite well, does IT has an IT job and would like to stay in Adelaide before working somewhere else in Australia. And she would like to go to the States [Unites States]. They want to be international and an Australian passport is a good way to become international.

-Rose, Marketing Staff (University of Adelaide)

Although this addresses the gap in the literature on the "post-completion study and employment trajectories" of international students (Hawthorne 2007, pg 19), uncertainty and cumulative causation continues to emerge in the interviews and supports earlier discussion on such onward migration:

When applying for PR, it is granted that $20-30 \%$ of my clients [Indian] would move Interstate and after getting PR, about $75 \%$ of them would do so.

-Gavin, Migration Agent

\footnotetext{
${ }^{43}$ The Pre-Enrolment English Programme (PEP), specific to the University of Adelaide, provides a direct entry pathway for prospective international students who have been offered a place which is conditional upon English proficiency.
} 
Chapter 7: Life after graduation- Future intentions of Chinese and Indian students

Some students may plan to use Adelaide as a stepping stone to other States but that often changes. But there will be a small number who may stick to the original plan.

They may plan, in the beginning, to use Australia as a stepping stone to the USA or the UK but, not many will follow through with it.

-Shaun, Migration Agent

This uncertainty has been attributed to employment reasons (Section 7.3.1) which is similar to how economic downturn and labour market conditions are often major factors for outflows of residents from South Australia (Debelle \& Vickery 1999, pg 255; Hugo 2002b, pg 31). However, the determinants behind the loss of 'long term temporary residents' in Australia remains unclear (Hawthorne 2007, pg 19). Subsequent sections will investigate the decision to relocate interstate and overseas in order to gain a comprehensive understanding of the drivers behind their transnational strategies.

\subsection{Main factors that influence the decision to migrate interstate and to a third country}

As mentioned in the previous section, economic drivers are significant in the decision to relocate interstate and/or to a third country. These reasons will be established in this section alongside other factors. Due to the structure of the survey, there is a caveat with the findings in Figures 7.5 and 7.6 as there was no distinction made between the multiple Australian States or third countries they might have listed, and the reasons given. Notwithstanding, when combined with the information gathered from interviews, the overwhelming preferences for Victoria, New South Wales; and the US and UK (Tables 7.12 and 7.13) lend weight to the following findings.

As Figure 7.5 shows, the main determinants in interstate migration largely pertained to economic motivations, they include 'Better' career advancement prospects', 'More employment opportunities' and 'Higher salary'. Adelaide's perceived inferior lifestyle, limited social and leisure opportunities and relative lack of range in shopping followed. On the other hand, economic motivations were less important for third country migration. Instead, gaining international experience and personal aspirations were their core reasons for emigration (Figure 7.6). Nevertheless, it is important to ascertain the value placed on each factor by Chinese and Indian respondents. 
Chapter 7: Life after graduation- Future intentions of Chinese and Indian students

Figure 7.5: Factors influencing the decision to migrate interstate $(n=86)$

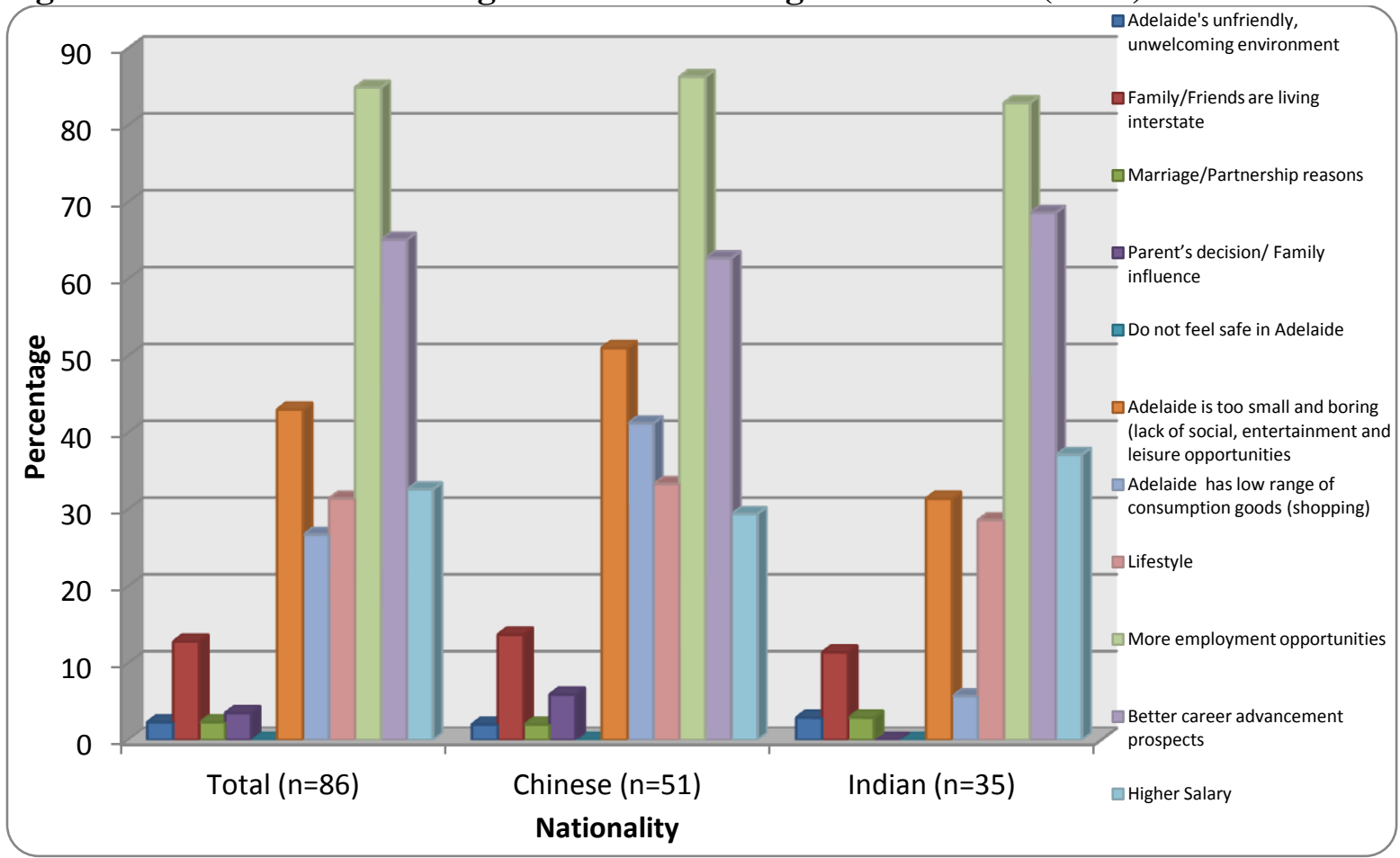

Source: CISS 2007; 2008

Figure 7.6: Factors influencing the decision to migrate to a $3^{\text {rd }}$ country $(n=84)$

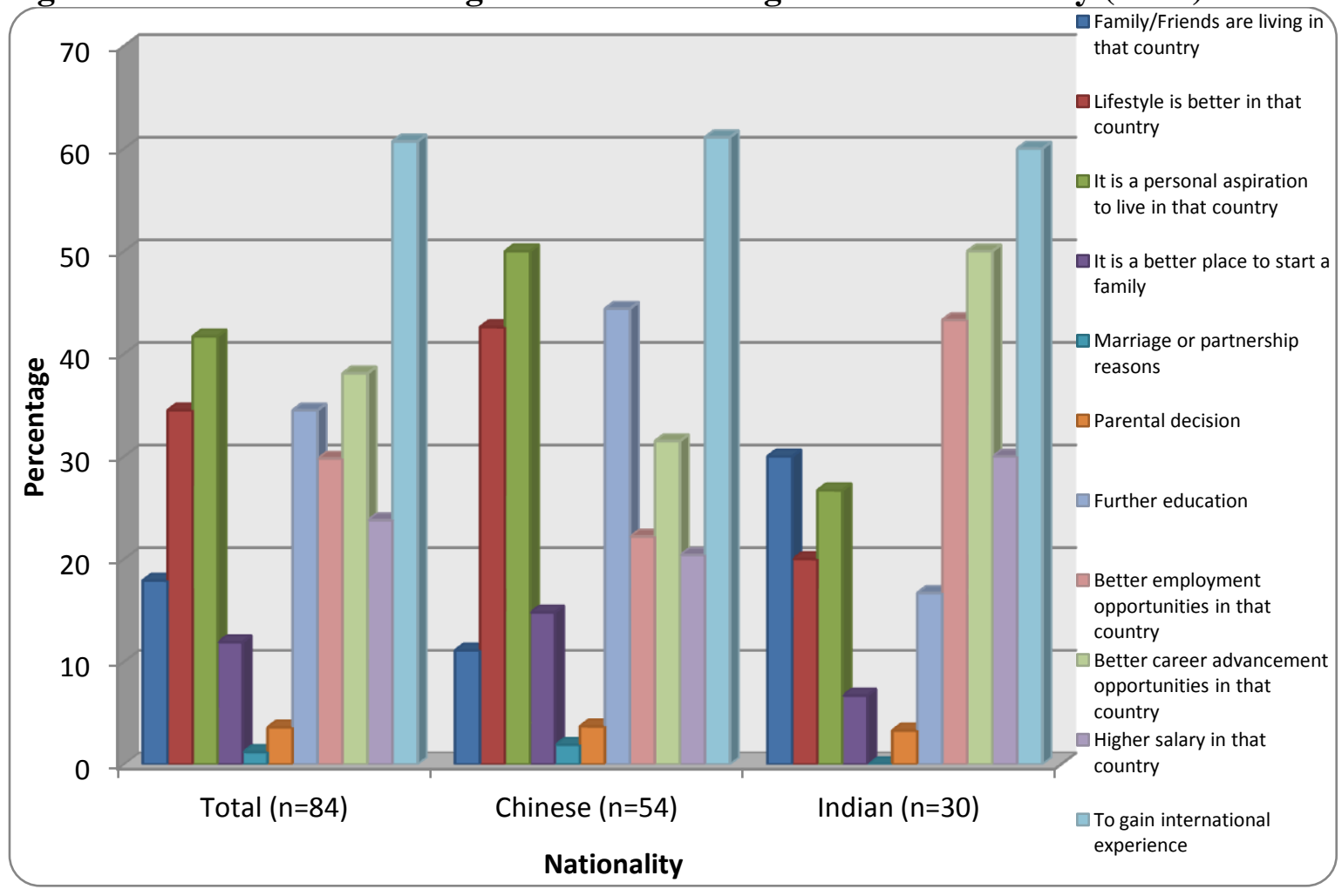

Source: CISS 2007; 2008 
Chapter 7: Life after graduation- Future intentions of Chinese and Indian students

\subsubsection{Professional, employment and economic based factors}

The high importance attached to career advancement, employment and salary based reasons by respondents was particularly significant for interstate migration, drawing parallels with studies that have shown similar factors driving the outmigration of locals from South Australia (Debelle \& Vickery 1999; Hugo 2002b).

Young adults migrating interstate were overwhelmingly motivated by better economic and employment conditions interstate (Hugo et al. 2000, pg 109-110), they include, the lack of suitable employment in Adelaide, higher salaries interstate and the desire for promotion. Similarly, these factors were reflected by temporary skilled migrants. ${ }^{44}$ They were mainly based in major Australian cities due to the location of most employers in these cities "where there is a global perspective to the labour market" (Khoo et al. 2005, pg 11). Such views were common among interviewees:

The opportunities in Adelaide are limited. The career exhibitions here are quite poor because the main concentration of business and firms are in Sydney and Melbourne.

-Jenny, Chinese student in Master of Accounting and Finance (University of Adelaide)

I don't think I will get a job if I stay in Adelaide. There is a higher chance to get a job in Melbourne or Sydney because they have more major corporations there.

-Carol, Chinese student in Master of Commerce-Accounting (University of Adelaide)

There are definitely better job opportunities in Melbourne and salaries are higher as well.

-Kunal, Indian student in MBA (UniSA)

I should be able to find work here but the headquarters of many Accounting firms like Deloitte are in New South Wales and Victoria. There would be more opportunities interstate.

-Abhay, Indian student in Master of Accounting (UniSA)

The above perceptions were more prevalent for Indian than Chinese respondents. With the exception of 'More employment opportunities interstate', there were higher proportions of Indian than Chinese respondents in Figure 7.5 who indicated 'Better career advancement interstate' and 'Higher salary'. And despite the generally lower emphasis placed on these factors in third country migration, they were still prominent factors.

\footnotetext{
${ }^{44}$ The temporary skilled migrants in Khoo's et al.'s (2005) study, held the temporary business entry long stay visa (457).
} 
Chapter 7: Life after graduation- Future intentions of Chinese and Indian students

Respondents' reasons for moving to a third country resonate with studies on Australian emigrants living abroad (Hugo et al. 2003, pg 44) and in the US (Parker 2009, pg 125128). Better employment, professional and income related opportunities were commonly cited as main factors for their overseas migration which correlates with CISS survey findings. One can therefore infer that students hold the same view that Australia has relatively inferior work and economic conditions compared to countries such as the US or UK.

Markedly higher proportions of Indian than Chinese respondents were also motivated by 'Better career advancement in third country' (50\% to 31.5\%) and 'Better employment opportunities in third country' (43.3\% to $22.2 \%$ ), which suggests Indian students are more driven, career wise. These factors are also linked with noticeably higher proportions of Indian than Chinese respondents who were attracted by 'Higher salary interstate' $(37.1 \%$ to $29.4 \%$ ) and 'Higher salary in third country' (30\% to 20.4\%). One can attribute the strong focus on economic and employment opportunities by Indian respondents to the need to repay the substantial loans undertaken for their education in Australia (Figure 5.10). However, as already shown, while Indian interviewees relayed a more flexible and open attitude towards onward migration, they exhibited a preference to remain in Adelaide unless they were offered better pay elsewhere.

\subsubsection{Lifestyle and cultural considerations}

Adelaide's positive study environment was ironically associated with its reputation as a boring city (Section 6.4.3), which in turn, can be a push factor. As illustrated in Figure 7.5, lifestyle considerations were less significant than economic related motivations for respondents. Nevertheless, interstate migration reasons such as "Adelaide was too small and boring (lack of social, entertainment and leisure opportunities)' (43\%), 'Lifestyle was better interstate $(31.4 \%)$ and that 'Adelaide has low range of consumption goods (shopping)' (26.7\%) are important and cannot be disregarded. Similarly, while Hugo et al. (2000, pg 110,218) found lifestyle considerations to be less important in the outmigration of South Australians, the lack of a 'big city' lifestyle in Adelaide, otherwise found in Melbourne and Sydney, is an undeniable disadvantage.

These perceptions of Adelaide by international students were found in other studies (Braham et al. 2007; Lawrence 2004; Tustin \& Nelson-Field 2006, pg 21-22) and were also acknowledged by interviewees: 
Chapter 7: Life after graduation- Future intentions of Chinese and Indian students

I looked at Divali photos from Melbourne and it looked more exciting. Although Adelaide had celebrations, it seemed more colourful and better interstate.

-Ravipraba, Indian student in MBA (UniSA)

I think there is a general attractiveness of Melbourne. One of the reasons a lot of my friends move interstate is because they have better entertainment and shopping.

-Annie, Chinese student in Master of Accounting and Finance (University of Adelaide)

Some migration agents felt that they were more important for Chinese than Indian respondents.

SHAUN: I feel that this [using Adelaide as a gateway] applies more to the Chinese students compared to the Indians who mostly would end up staying in Adelaide.

RESEARCHER: What are their reasons for moving?

SHAUN: Reasons for moving? Employment. Employment opportunities are better interstate and for the Chinese, they prefer the busier fast paced city environment.

-Shaun, Migration Agent

CISS survey findings back up this opinion as significantly higher proportions of Chinese than Indian respondents indicated 'Adelaide is too small and boring (lack of social, entertainment and leisure opportunities' (51\% to 31.4\%) and 'Adelaide has low range of consumption goods (shopping)' $(41.2 \%$ to $5.7 \%$ ) as reasons for moving interstate. In the same way, similar trends emerged with more Chinese than Indian respondents reflecting 'Better lifestyle in third country destination' (42.6\% to $20 \%$ ) as a factor in third country migration. It is clear that there is stronger emphasis placed on lifestyle and cultural considerations by Chinese students, a stark difference when juxtaposed with the driven nature of Indian students - career wise.

\subsubsection{A fascination with the West}

Apart from tangible reasons discussed previously, it was noted that the main reasons for moving to a third country were somewhat less tangible. As shown in Figure 7.6, the top two factors were 'To gain international experience' (60.7\%) and 'It is a personal aspiration to live in that country' $(41.7 \%)$. While the vagueness of the former can be argued, it is akin to the want of an overseas education (Table 6.1) and a basic desire for life experiences which an interviewee raised:

A lot of students don't do this but once you have the skills and push yourself out of the comfort zone, you'd then want to explore the world and see and experience more. 
Chapter 7: Life after graduation- Future intentions of Chinese and Indian students

-Abhay, Indian student in Master of Accounting (UniSA)

Such notions were not common in the interviews and the literature suggests that while Chinese and Indians are influenced and inspired to seek international experiences, the desire appeared to be more aligned with the increased exposure to Western countries and lifestyles (Sections 2.5.1 and 2.5.2), with particular reference to the US and UK.

I think so, the most powerful nation in the world, best unis, best resources, best infrastructure and the most money are all part of the US. If you are a higher achiever, that's where you go.

- Ewan, Marketing Staff (Flinders University)

The US has a good reputation. It's a more developed country. There is a general 'betterness' about it and my friend said to me "if you are ambitious, you would want to go to the USA".

-Annie, Chinese student in Master of Accounting and Finance (University of Adelaide)

While these perspectives highlight the aspect of human capital accumulation when seeking international experience, the interviews provided a further insight into how moving to the US or UK became embedded into their culture and their personal aspirations as well:

Talking about profiling students, it's [US] ingrained into people, it's seen through movies, press releases, newspapers. It's the way that the US is perceived, they project themselves as a country where there's still a lot of opportunity...

-Simon, Marketing Staff (Flinders University)

MARY: In India, the US has traditionally been the destination of choice for education, work and still is...

RESEARCHER: ... so with this fascination, do you think it's become a cultural thing?

MARY: It's been there for a long time. It is. It is.

RESEARCHER: So people have always gone..?

MARY: Westwards.

- Mary, Marketing Staff (University of Adelaide)

This attraction with the West resonates to an extent with historical structuralist and world systems theories (Section 4.3.1) that posit migration as a result of wealthy countries dominating poorer ones. Through these findings, one can see how third country migration has over time 'seeped' into the culture of migration for Chinese and Indian students, often favouring countries such as the US and UK. 
Chapter 7: Life after graduation- Future intentions of Chinese and Indian students

\subsubsection{Influence of networks and family}

Networks are important for Chinese and Indian respondents when deciding on their study destinations (Section 6.4.4). Although these micro structures (Massey et al. 1998, pg 4243; Portes 1995, pg 12) facilitate migration for international students (Section 2.5.4), they are less important for respondents in their onward migration intentions as shown in Figures 7.5 and 7.6. Despite only 12.8 and 17.9 percent of respondents influenced by family/friends living in interstate and third country destinations respectively, the higher proportion motivated by family/friends living in another country demonstrates the significance of network ties due to the greater risks and barriers involved when migrating overseas (Massey et al. 1993, pg 460). Also, nearly 3 times as many Indian (30\%) than Chinese $(11.1 \%)$ respondents indicated the importance of family/friends living in their intended third country destinations, suggesting stronger transnational networks within the Indian student community.

The Indians in history have always been very mobile. Study is just a prelude to their life. It doesn't mean they will stay here [in Australia] forever. Many of the Indians who do come here, if you get to talk to them, they'll tell you of their uncles in the UK, cousins in Canada. Many have got extended family throughout the world. They are very mobile and might end up working in some country in some point in their career.

-Jeremy, Marketing Staff (UniSA)

The stronger transnational networks of Indian students back up earlier findings that emphasised on the greater reliance on networks by Indian respondents. It also backs up the findings in this chapter which have so far suggested this group of students to be more transnational and mobile than their Chinese counterparts.

Another aspect of networks includes the role of family. The factor that the future third country destination was considered a better place to start or raise a family was indicated by more than twice as many Chinese (14.8\%) than Indian respondents (6.7\%). Such views echo the role of the family raised by many commentators particularly in the context of migration (Herman 2006; Huang \& Yeoh 2005; Khoo \& Mak 2003; Salaff 2004; Waters 2001; Yeoh et al. 2005). Members of the Chinese diaspora from Hong Kong or Taiwan often offered a political explanation, namely the handover of Hong Kong to China in 1997 and in general a widespread fear of the political instability of China when justifying their decision to migrate to Canada (Waters 2003, pg 226-227; 2005, pg 361-363; Zhao 1996). 
The familial aspect is also linked to parental influence which appears to be trivial for interstate $(3.5 \%)$ and third country migration (3.6\%) intentions. It is however noted that more Chinese than Indian respondents, as seen in Figures 7.5 and 7.6, were influenced by their parents. This difference is linked to earlier findings which reflected parents as a relatively more important factor for Chinese students due to their financial dependence on their parents (Tables $5.10 \& 5.11$ ). Although CISS findings downplays the influence of parents on their children's' onward migration intentions, the general sense inferred through interviews continues to suggest otherwise.

As far as Chinese students are concerned, parental consent and their approval, following what their parents want is important.

-Daniel, Education Agent

RESEARCHER: How important are your parents in your overseas study?

ABHAY: Parents are very important. Having financial support and parental support in going abroad was a big thing, it was very important.

RESEARCHER: To what extent do they influence your studies?

ABHAY: It's primarily to get their blessings. I pretty much run my plans past them but my decision was pretty much down to myself.

-Abhay, Indian student in Master of Accounting (UniSA)

Moreover, parental influence on the transnational migration strategies of Chinese and Indian students extends beyond simply providing funds. Their influence is also linked to the future migration plans of their family members as illustrated in Figure 7.7.

Figure 7.7: Intentions to bring family to Australia or to $3^{\text {rd }}$ country destination $(\mathbf{n}=393)$

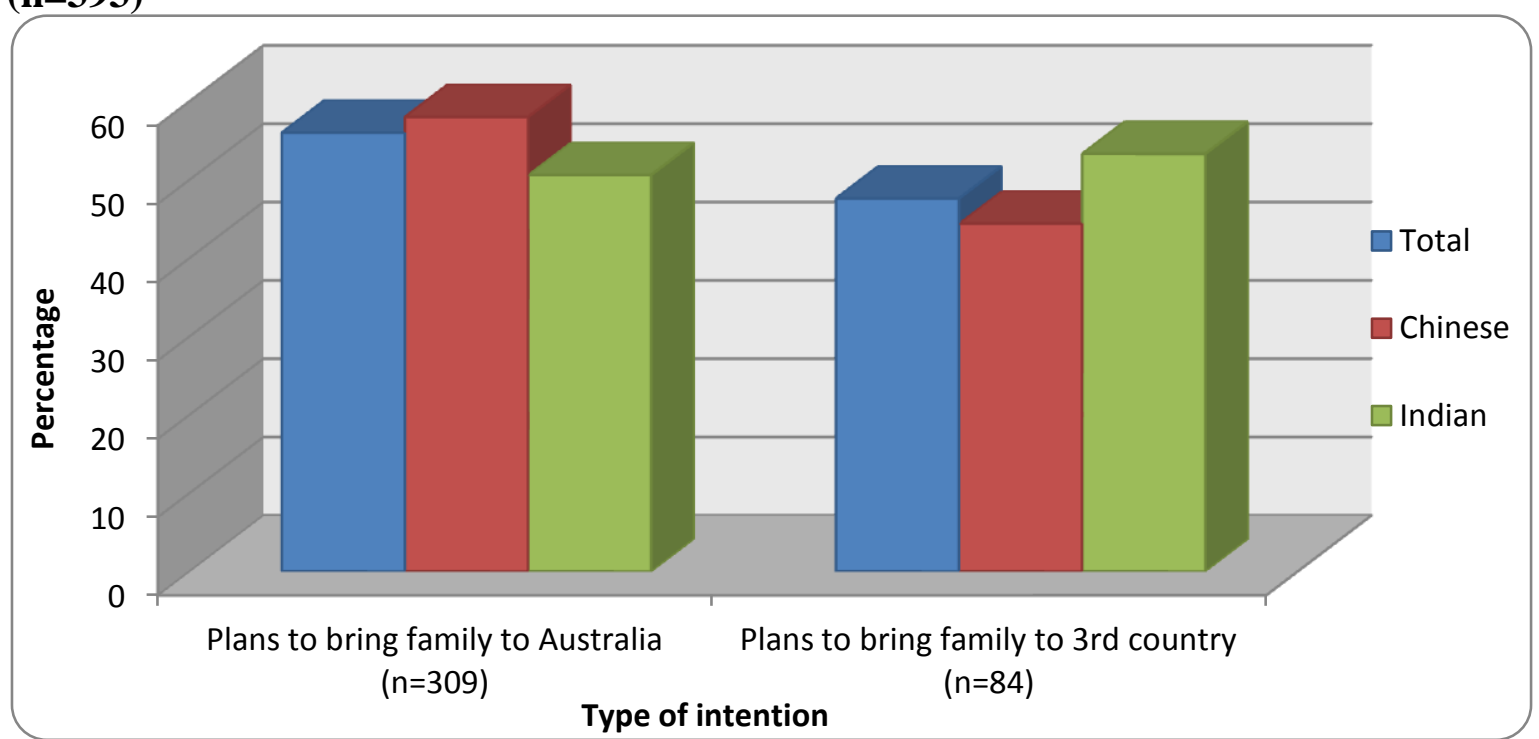

Source: CISS 2007; 2008 
As Figure 7.7 shows, respondents planned on bringing their family over to Australia (56\%) and to the third country destination (47.6\%), with a higher proportion of Chinese respondents indicating so for the former and a higher proportion of Indian respondents for the latter. Although this difference might suggest varying levels in transnational mobility between the two groups of students, it nevertheless exemplifies the theory of new economics of labour migration with the household or family as the denominator in the decision to migrate.

This is particularly well documented among Asian students (Section 4.5.1.1) with Taiwanese or Hong Kong parents using their children's educational sojourn to enhance their own mobility with the long term aims of retirement and citizenship in Canada (Ley \& Kobayashi 2005, pg 120-123; Waters 2003, pg 219). Such intentions were not unusual as some key informants recounted the business objectives of their parents in Australia:

I had a student who was going to Australia but not anymore. I can't remember where in Australia but I recall that the reason for choosing that state was because his parents wanted to start a business there.

-Frank, Education Agent

The intention is to maybe set up a business in Australia [by the parents] while still having their business running in China. Investing in their child's education and PR is seen as a safety net for the parents.

-Joseph, Migration Agent

Although some might bring their parents over, the exorbitant fees associated would put many off and the more common approach rested with their siblings:

I'm beginning to see more Indians sponsoring and bringing family over, and some do plan that from the start. I reckon about half my clients actually will sponsor family or relatives... We don't get too many parents coming over mainly due to the $10-15$ year wait or the $\$ 30,000$ fee required.

-Shaun, Migration Agent

For example, I have a student [Indian] who hasn't even applied for PR yet but he has already enquired for 2 of his brothers who are working overseas with plans to sponsor them to come over.

I don't have many clients who bring their parents over, about 4 or 5 out of 160 clients have done so. About 20 percent have the intention to bring their parents here, the immense cost is a deterring factor.

- Joseph, Migration Agent 
Chapter 7: Life after graduation- Future intentions of Chinese and Indian students

RESEARCHER: Do you have any interaction with parents?

JONATHAN: Not really, their parents are back in China, but they are the main decision maker because they are the ones who have the money. Their parent's intentions? They are too old, but they'll spend their money for their child to study in Australia and get PR and they could then sponsor their siblings

-Jonathan, Education Agent

And, having PR status would also boost the marriage credentials of Indian students (Biao 2004, pg 172). Some interviewees reflected intentions to bring their future brides over to Australia:

A lot of students go through the process where they will get PR and then go home quickly to get married and bring a spouse over. The pressure I get from students are when will they get PR as they need to go to get married in weddings that are often arranged.

-Gavin, Migration Agent

One of the reasons for coming to Australia or going overseas to study is that an overseas degree will help in getting a wife.

-Kunal, Indian student in MBA (UniSA)

I actually will be getting engaged soon and will bring my wife, future wife over in the future.

-Dawal, Indian student in Master of Telecommunication (UniSA)

Even though CISS findings reflected the negligible impact of parents (Table 7.6; Figures 7.5 and 7.6), it is a factor which must not be underestimated, particularly in the context of other family members. This factor, as discussed in the following section, takes on a greater significance with regards to the intention of returning to the home countries of Chinese and Indian students.

\subsection{Intention to return home}

The main objectives of this study are to understand the onward migration of Chinese and Indian students through their interstate and third country intentions, however, it is apposite to also investigate the return migration aspect of their transnational strategies. This section will provide an insight into the reasons that influenced the decision to return home instead of remaining in Australia.

As shown in Table 7.14, 14.5 percent of respondents intend to return home immediately after their studies. It must be noted that while these specific results are not representative 
due to the size of the sample, qualitative evidence strengthens the validity of these findings.

Table 7.14: Proportion of respondents who intend to return home immediately after their studies $(n=455)$

\begin{tabular}{|cccc|}
$\begin{array}{c}\text { Intention to return } \\
\text { home immediately } \\
\text { after studies }\end{array}$ & $\begin{array}{c}\% \text { of Total } \\
(\mathbf{n}=\mathbf{4 5 5})\end{array}$ & $\begin{array}{c}\text { \% of Chinese } \\
(\mathrm{n}=\mathbf{3 3 8})\end{array}$ & $\begin{array}{c}\% \text { of Indian } \\
(\mathrm{n}=\mathbf{1 1 7})\end{array}$ \\
\hline Yes & 14.5 & 15.4 & 12 \\
\hline
\end{tabular}

Source: CISS 2007; 2008

Overall, as Figure 7.8 illustrates, personal reasons were dominant factors in return migration, followed by reasons related to their careers, employment and society. These main factors were also found in Alberts and Hazen's (2005) on the return intentions of international students in the US.

Figure 7.8: Factors influencing respondents who intend to return home immediately after their studies $(n=66)$

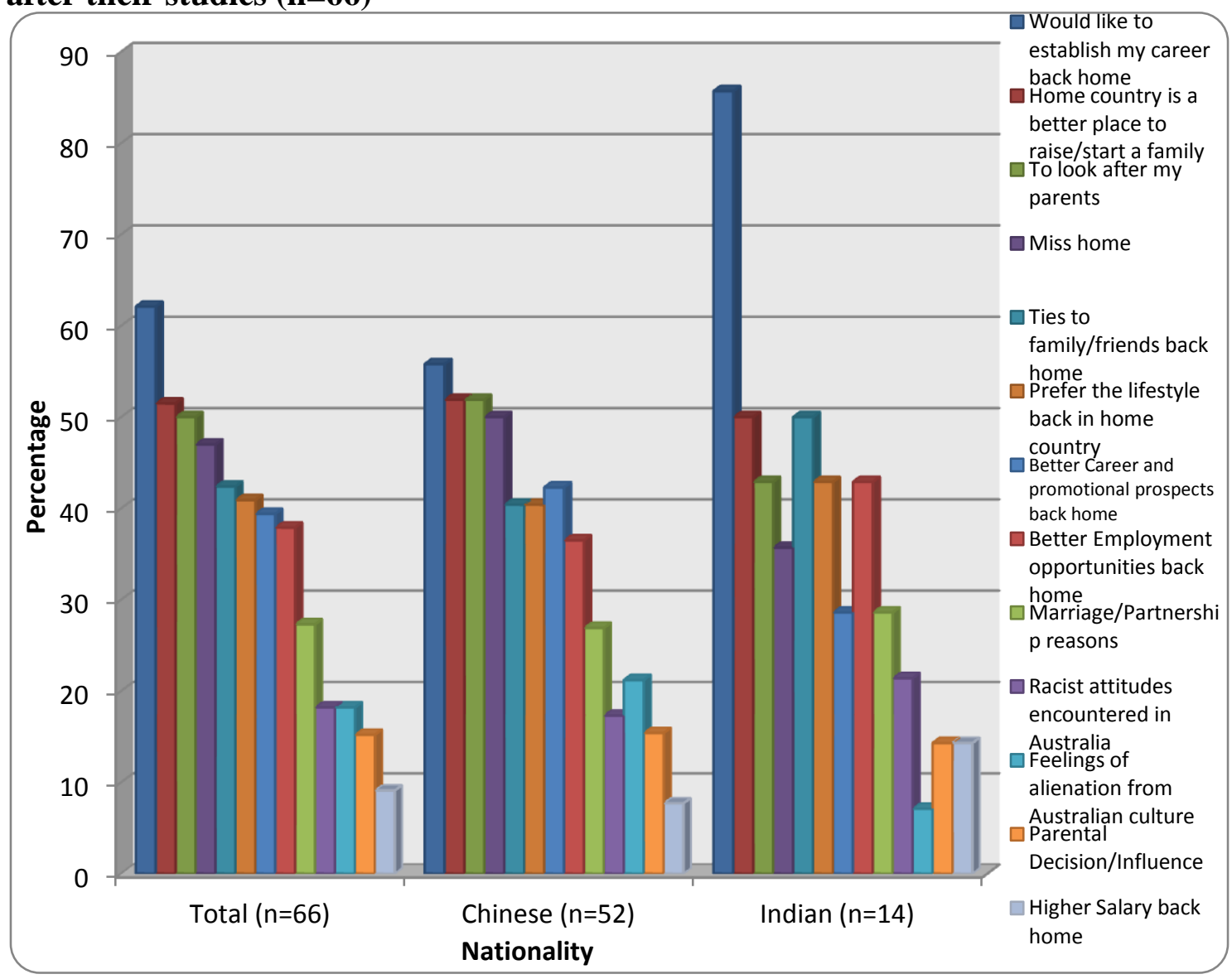

Source: CISS 2007; 2008

Overall, these factors are in line with the main reasons found in migration literature. Dumont \& Spielrogel (2008, pg 177) identified four factors driving return migration, they 
Chapter 7: Life after graduation- Future intentions of Chinese and Indian students

include, a failure to integrate into the host country and changes in economy of the home country, a preference for the home country, achieving a saving objective in the host country and greater employment opportunities at home, which is linked to the human capital acquired abroad.

\subsubsection{Professional, employment and economic factors in their home countries}

The majority of respondents 'Would like to establish my career back home' (62.1\%) while nearly 40 percent were motivated by 'Better career and promotional prospects back home' (39.4\%), followed by 'Better employment opportunities back home' (37.9\%). These factors can be associated with their respective booming economies. For example, the booming IT industry in India, particularly in Bangalore, attracted many professionals back home from the US (Ziguras \& Law 2006, pg 70).

Similarly, growing investment of capital and business in China by multinational corporations was attractive with bright career advancement prospects. There was also strong demand for employees who had a grasp on both local and Western culture were required on the managerial level (Shen 2008, pg 12; Tremblay 2008). Moreover, as discussed (Section 2.4.1.2), the Chinese government established policies and programmes, offering various incentives and higher salaries in order to make "professional opportunities in the home country more attractive" (Alberts \& Hazen 2005, pg 140) and these actions as Zweig $(2006 \mathrm{a}, \mathrm{pg} 65,87)$ points out, have triggered a 'reverse brain drain' and resulted in significant return migration.

It appears that with the exception of those wanting to establish their careers back home, other career, employment and economic related reasons were relatively less important. This is surprising as they are usually the chief drivers influencing post study onward migration. Hence, for Chinese and Indian students, the immediate return to their home countries is not primarily based on professional reasons.

\subsubsection{Societal factors}

Societal influences are broadly understood as to "how comfortable the student feels in a particular social, political and cultural environment” (Alberts \& Hazen 2005, pg 139), and as shown in Figure 7.7, they include 'Racist attitudes encountered in Australia' (18.2\%) and 'Feelings of Alienation from Australian culture' (18.2\%). Although these factors were 
Chapter 7: Life after graduation- Future intentions of Chinese and Indian students

relatively unimportant, nonetheless, they affected Chinese and India respondents at varying levels.

For example, a higher proportion of Indian than Chinese respondents (21.4\% to $17.3 \%$ ) encountered racist attitudes which could be due to the isolated incidents of violence towards Indian students in Adelaide (891 ABC Adelaide 2009; Silicon India 2006). Although, this could be downplayed as international students perceived Adelaide to be safe (Lawrence 2004; Tustin \& Nelson-Field 2006, pg 11). Similarly, these concerns were not raised by any respondents in the CISS survey (Figure 7.5) and interviews. However, it is acknowledged that this thesis was conducted before recent incidents of violence elsewhere in Australia (ABC 2010; D' Costa 2010; Hose 2010; The Times of India 2009). While this societal attitude is not widespread, recent concerns were raised with regards to a resulting potential collapse in the international student market (Hartcher 2010; Healy 2009a; b).

On the other hand, alienation from Australian culture was a factor more so for Chinese than Indian respondents $(21.2 \%$ to $7.1 \%)$. Such sentiments were found in the interviews:

The pub is an important place, I feel that it is hard because if I want to socialise, I need to go to the pub. But Chinese culture is different and I don't drink alcohol so I find it difficult.

-Shu, Chinese student in Master of Commerce- Accounting (University of Adelaide)

These sentiments are also linked to English proficiency. Asian students who were keen on connecting with Australian society often found it a challenge as "exposure to the Australian experience is something that international students find difficult to negotiate with limited Australian English and knowledge of social norms" (Kell \& Vogl 2006, pg 89). The interviews also mentioned this could have implications for employment:

I've actually noticed a lot of Chinese go home and work due to the education and lack of English skills...even after getting PR here in Australia.

-Shaun, Migration Agent

This relationship was also established in Hawthorne's (2007, pg 11-12) study as former Chinese students who obtained PR had difficulties in gaining professional work, particularly if they had low English standards. This relationship indicates a link with professional reasons and demonstrates the interconnectedness between these factors. 
Chapter 7: Life after graduation- Future intentions of Chinese and Indian students

\subsubsection{Personal factors}

Personal factors were found to be key reasons in the decision to return home immediately after their studies. These factors are issues "related to the personal circumstances of an individual, such as family status and friendship networks" (Alberts \& Hazen 2005, pg 139) and they include, "Home country is a better place to raise/start a family" (51.5\%), "Look after my parents" (50\%), "Miss home" (47\%), "Ties to family/friends back home" (42.4\%), "Prefer lifestyle back home" (40.9\%) and "Parental decision/influence" (15.2\%).

In general, Dumont and Spielrogel (2008, pg 171, 203) have noted and stressed the need to further explore the key role of marital and family status in migratory behaviour, i.e., place of family formation and place of residence of family members. Likewise, these were found to be very strong factors in influencing the return migration of Chinese and Indian students (Alberts \& Hazen 2005, pg 146-148; Shen 2008; Tremblay 2008), however, they can be interconnected with other factors as well. For example, the influence of 'Ties to family/friends back home' is linked to professional factors where existing networks and contacts formed before studying abroad "are important for business returnees...where Guangxi, or connections in English, are crucial” (Shen 2008, pg 12).

Although parental influence was a less important factor, a high proportion indicated that looking after their parents was one of the main reasons for returning, especially so for Chinese respondents (51.9\% to 42.9\%). Alberts and Hazen (2005, pg 147) found that being close to one's family was important for Asian students as it was "not only a societal value, but also a moral obligation". Filial obligations are epitomised in China as strong cultural values and the one child policy emphasized the "undeniable duty of the children to be responsible for their elderly parents" (Shen 2008, pg 10-11). The interconnectedness between factors is demonstrated with societal norms shaping personal factors, a sentiment reiterated by interviewees who also stressed China's one child policy:

Because of the one child policy in China, I think this should not be undervalued, the children of parents coming to study have their heart strings so finely stretched that they want to go back home; and often their parents miss them so much they put a lot of pressure on them to remain in China or to remain nearby.

-Natalie, Marketing Staff (UniSA)

My parents won't migrate to Australia, they have no friends, they cannot speak English and the culture is different. This is probably why I will move back eventually, because I am the only child.

-John, Chinese student in Bachelor of Media (University of Adelaide) 
Chapter 7: Life after graduation- Future intentions of Chinese and Indian students

A lot of us will go back because we are the only child, we have to go back to look after our parents. Many families are like this because of the one child policy.

-Linda, Chinese student in Master of Commerce- Accounting (University of Adelaide)

This adds onto earlier discussion which underscored parents as a key factor for Chinese and Indian students despite CISS survey results indicating otherwise. Although parents are not always actively involved in the decision making process, they undoubtedly represent a somewhat passive, yet important factor for Chinese and Indian students. When examining the return migration of these students, the intentions of respondents to remain in Australia and/or relocate interstate or to a third country are not necessarily permanent as they might return to their home countries at some stage in the future.

As Table 7.15 shows, approximately a fifth (21.1\%) of all respondents plan on making a permanent move back home, with a higher proportion of Indian respondents than Chinese respondents (30.1\% to $17.8 \%)$ intending to do so. It is noted that the majority $(53.1 \%)$ of respondents were 'Unsure' which again demonstrates how the decision making process is subject to cumulative causation.

Table 7.15: The return home intentions of respondents who remained in Australia and/or in third country after their studies $(n=389)$

\begin{tabular}{|cccc|}
$\begin{array}{c}\text { Intention of making } \\
\text { permanent move } \\
\text { back home after } \\
\text { some time abroad }\end{array}$ & $\begin{array}{c}\% \text { of Total } \\
(\mathrm{n}=389)\end{array}$ & $\begin{array}{c}\% \text { of Chinese } \\
(\mathrm{n}=286)\end{array}$ & $\begin{array}{c}\% \text { of Indian } \\
(\mathrm{n}=\mathbf{1 0 3})\end{array}$ \\
\hline Yes & 21.1 & 17.8 & 30.1 \\
\hline No & 22.1 & 22.4 & 21.4 \\
\hline Unsure & 48.6 & 53.8 & 34 \\
\hline Missing & 8.2 & 5.9 & 14.6 \\
\hline
\end{tabular}

Source: CISS 2007; 2008

Respondents were asked to indicate the reasons for this return migration in an open ended question. These reasons are organised in broad categories as Figure 7.9 illustrates. Personal factors such as 'Ties to Family/Friends' (36.6\%), 'Preference to lifestyle, culture back home (food, weather etc)' (22\%) and the obligation to 'Look after parents' (14.6\%) were found to be the leading reasons behind respondents' decision to eventually return home. These reasons are in line with the factors that motivated students who chose to return home immediately after their studies (Figure 7.8). 
Chapter 7: Life after graduation- Future intentions of Chinese and Indian students

Figure 7.9: Factors influencing respondents who, after some time abroad, intend to make an eventual permanent move back home $(n=82)$

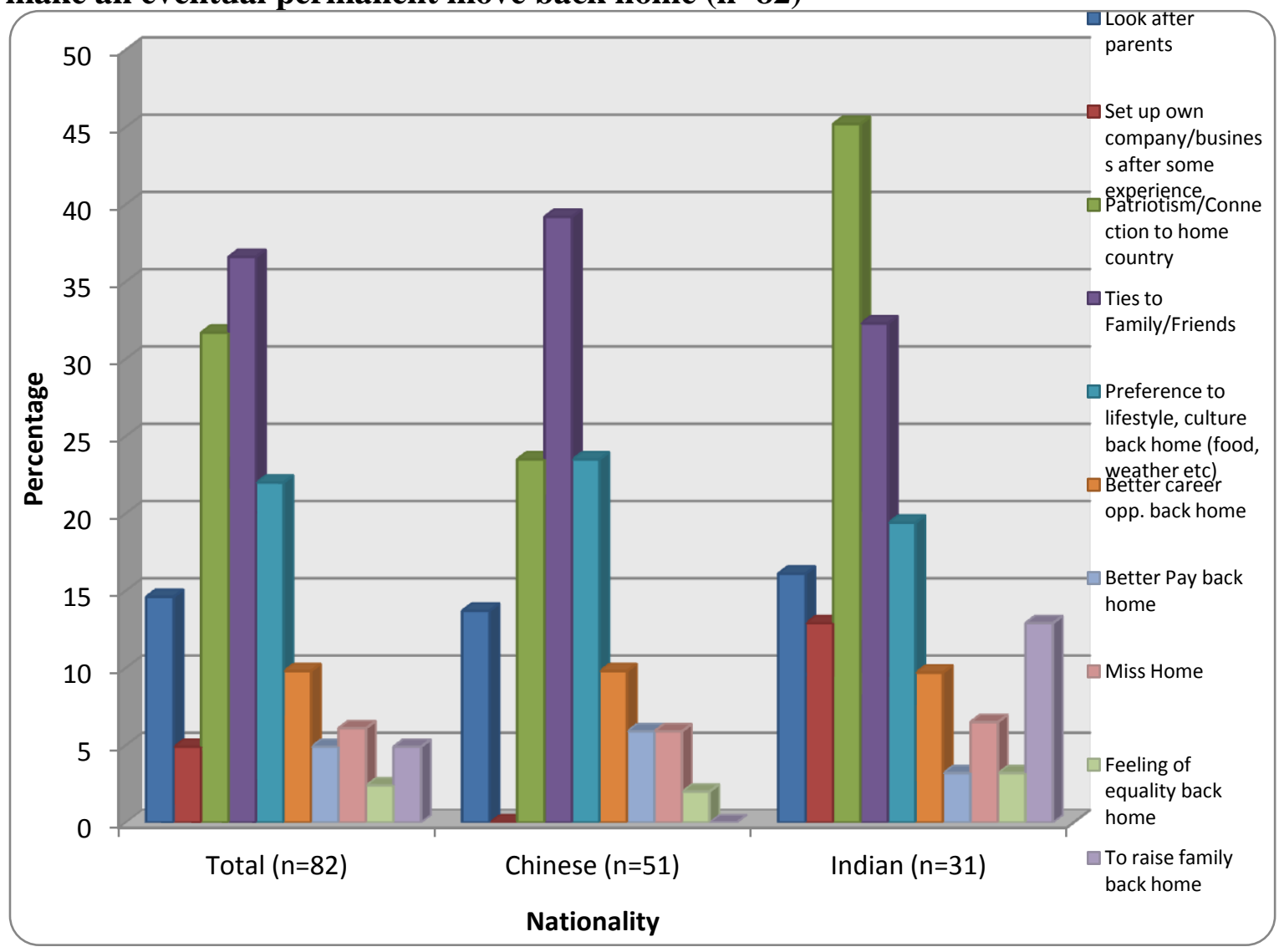

Source: CISS 2007; 2008

Feelings of 'Patriotism/Connection to home country' (31.7\%) are another aspect of personal factors reflected by respondents, particularly Indians. These feelings ranged broadly from a sense of duty, to an emotional attachment and sense of belonging to their country, as commented on by some of the open ended answers provided by respondents in the survey:

My country should have an advantage of my knowledge and experience for development. It's my duty to serve my country.

\section{- Indian respondent}

I'm willing to serve my home country.

$$
\text { - Chinese respondent }
$$

I love my home country!

$$
\text { - Chinese respondent }
$$

Since every fallen leaf must return to its roots.

-Chinese respondent

It's really hard to say in words but one thing I can say is whenever I am sleeping in Australia, I am at my home in my country! 
Chapter 7: Life after graduation- Future intentions of Chinese and Indian students

To conclude this section, it is evident that personal reasons are the strongest in the return migration decision of respondents and it is important to note the interconnected relationship between some factors. Additionally, one should consider that different the social, cultural contexts, and language skills causes Chinese and Indian students to be influenced differently. However, it must be stressed that due to the size of the sample, these findings are not representative. Nonetheless, it is a useful base for future research in understanding the return migration decisions of Chinese and Indian students.

\subsection{Conclusion}

The conceptual model in Figure 4.2 has been strengthened as findings in this chapter have established the PR intentions of Chinese and Indian students and their subsequent post study migrations to other destinations. It was found that the original intentions of the students were mainly to remain in Australia for extended periods of time after their studies. In addition gaining PR was a key objective for many and there was a strong indication that PR intentions were formed right at the beginning of their educational sojourn, outlining the strategic nature of their plans. The role of policy shaping their strategies is clear and the evidence shows that education is increasingly used as a migration instrument to enhance the mobility of international students. However, having PR was crucial for successful poststudy employment in Australia and at times, PR was seen as a by-product of studying in Australia.

Questions of permanency were therefore raised as PR did not necessarily equate to permanent settlement due to the onward migration intentions exhibited by some respondents. This findings sheds light on the transnational migration strategies of Chinese and Indian students by identifying how Adelaide and Australia are fallback destinations and configured as gateways to more popular interstate and third countries. Victoria, New South Wales, the US and the UK were identified as popular interstate and third country destinations. Similarly, these future destinations were the most seriously considered study destinations of Chinese and Indian students which further demonstrate the gateway function of Adelaide and Australia.

Migrating interstate was a more likely strategy as they were stronger than third country migration intentions. On the whole, Australia's quality of life, standard of living, and factors relating to future employment, higher salaries and career prospects motivated students to remain after their studies. In a similar vein, they were prominent in driving 
Chapter 7: Life after graduation- Future intentions of Chinese and Indian students

onward migration. Interstate migration was largely driven by career, employment and economic opportunities followed by lifestyle and cultural consideration. Conversely, career, employment and economic reasons were relatively less important factors for third country migration compared to personal aspirations and the desire for an international experience.

It also emerged that there were different characteristics between Chinese and Indian students. While career, employment and economic related reasons primarily influenced their migration, it was more prevalent for Indian respondents as Chinese respondents were mainly attracted by lifestyle and cultural considerations. This is a clear indication that Indian students are more driven career wise, partly linked to their need to repay bank loans undertaken to finance their studies. Indian students were also stronger and more transnational in their mobility. They not only displayed stronger PR intentions, but also were more likely to onward migrate. Moreover, they were found to consider more potential future destinations than Chinese students.

The plan to bring family over to join them in future interstate and third country destinations further highlights the complexity of the students' transnational strategies. The role of the family is underlined in their decision making process. Despite CISS survey findings suggesting otherwise, parental influence were an important factor, particularly when it came to return migration. Overall, parental influence alongside personal factors, were main motivations for those who intended to return to their home countries. A contrast against career, employment and economic reasons are often the main drivers in their transnational strategies. Some respondents (particularly Indians) also indicated an eventual intention to return to their home countries after spending some time in Australia or in a third country. This shows that while the international education sojourn might involve additional post study destinations, their transnational migration strategies could also result in a permanent move back home. However, the element of cumulative causation must not be underestimated as it emerged very strongly in various aspects of their decision making process.

The onward migration intentions of the students have established highlighted the suitability of the concept of transnationalism in describing the mobility of international students. The configuration of Australia and Adelaide as gateways also served to demonstrate the coproductive relationship between geographical and social space. The next chapter will 
Chapter 7: Life after graduation- Future intentions of Chinese and Indian students conclude this thesis and examine the implications of the findings on migration theory, Australia's policy on skilled migration and set the platform for future research. 


\section{CHAPTER 8: Implications and Summation}

\subsection{Introduction}

International student mobility is often analysed within the confines of the student's home and host countries. As a result, understandings of their migration have been inadequate. This study has established the nexus between international education and permanent migration, and argued that international student migration should be viewed beyond the paradigm of permanent and temporary settlement. Particular focus on the motivations and future intentions of Chinese and Indian students has identified the underlying factors driving the migration of these two groups. Findings from the CISS survey and in-depth interviews with key informants and students have provided insights into the transnational migration strategies of Chinese and Indian students, and furthered the theoretical knowledge on transnationalism.

This final chapter reviews the major findings of this study and the implications for migration theory and policy in Australia. The final part of the chapter will briefly discuss the limitations of this study and also set the platform for future research.

\subsection{Summary and discussion of major findings}

The overarching aim of this thesis was to explore the link between international education and permanent migration in Australia by examining the mobility of Chinese and Indian students studying in Adelaide. The following research objectives underpinned the research.

\subsubsection{International student mobility in migration theory}

The first objective was to examine international students in the context of migration theory.

This study attempted to conceptualise the migration of international students and explore the nexus between international education and permanent settlement. A review of traditional migration theories in Chapter 4 found they assisted in explaining fundamental drivers behind student migration. Through economic migration theories, the basic desire to study abroad was explained by the desire to acquire or accumulate human capital via the investment into one's overseas education. 
In addition, other economic theories also linked parental influence and the economic structures of developed countries as factors behind the study abroad decision. Facets of historical structuralist and world systems theories were able to link student migration as part of a response to forces of supply from mainly developed first world countries in the form of aggressive recruitment campaigns; and the concentration of international students in particular countries such as the US and the UK. Migration systems theory was a contemporary approach used to analyse the various structures which perpetuate the migration of international students. Micro structures in the form of migration networks and social capital and meso structures in the form of education and migration agents are important components of student migration. However, macro structures in the form of government policy in both home and desired countries, were crucial in the decision making process of international students.

Although there was evidence in the literature to suggest international education was a precursor for permanent immigration, international student migration needs to be viewed beyond the rigidity of temporary and permanent settlement. By virtue of the links maintained between the home and host countries of international students, transnationalism was found to be a more suitable approach. Social fields, made up of economic, familial, political relationships and others, are created by students and embedded in transnational networks that connect them with their home countries; resonating with facets of migration systems theory. The literature review identified how micro, meso and macro structures in migration systems exist in the transnational networks of international students and how they contribute to "the abatement of national boundaries" (Glick Schiller \& Basch 1995, pg 48). This thesis builds on this view through the transnational lens which further expands the emergence of transnational social spaces in student migration.

Transnational social spaces arise when ties connect people across national borders. However, a different way of seeing the relationship between the spatial and social in transnational social spaces changes the way migration is viewed. The container notion of nation-states is made less relevant as social processes co-produced alongside national boundaries. This co-productive relationship between the social and spatial posit that as much as social processes influence the spatial aspect of transnational social spaces, the spatial component can also rebound and influence the social processes. From this 
perspective, it is clear that theorising contemporary international student migration is a complicated process.

Following from this, a conceptual model (Figure 4.2) which explored the link between international education and permanent migration and illustrated the transnational migration strategies of Chinese and Indian students was constructed. In the context of international student migration, the spatial component of transnational social spaces essentially consists of nodes (in other words, countries or study destinations) that make up the student's transnational migration network. The social side pertains to processes or factors linked to micro, meso and macro structures in migration systems theory which help explain drivers that influence the decision making process of the student.

The transnational strategies of Chinese and Indian students include gateways and central destinations which highlighted the co-productive relationship of transnational social spaces and elucidated the mechanisms behind the circumvention of destinations in their transnational migration strategies. Restrictive post 9/11 immigration policies in the US which led to many international students studying in alternative countries such as Australia exemplified the influence of the spatial element on social processes. Conversely, international students in Australia who take advantage of policies leading to post study employment and/or PR, accumulate human capital which eases their previously unsuccessful entry to the US, thus demonstrating how social processes can influence the spatial element through the configuration of Australia as a gateway to the US, their central destination.

Traditional approaches that theorise movement along a linear plane between the home and host countries of students are inadequate as they only capture an aspect of contemporary international student migration. Examining the mobility of Chinese and Indian students provided further clarity and a different perspective, as it demonstrated that "migration is not a single act leading to a permanence of settlement divorced from sites of origin" (Walton-Roberts 2003, pg 247). This emphasised a need for an updated approach, hence, transnationalism is the most appropriate concept when conceptualising the transnational migration of international students. 


\subsubsection{Transnational migration strategies of Chinese and Indian students}

The second objective was to investigate the various migration strategies adopted by students including the transition to permanent settlement; the mechanisms behind the decision to remain in Australia after their studies and future strategies that may go beyond settling permanently in Australia.

Investigating the motivations and future intentions of Chinese and Indian students revealed PR as a key objective in their transnational strategies which supports claims that international education is a precursor to permanent migration. On the whole, respondents indicated that Australia's attractive immigration policies were one of the main reasons for studying in Australia. A third of respondents intended to permanently settle in Australia even before leaving their home countries. The key role of immigration policy in the prearrival decision making process of Chinese and Indian students is clear, as much as provisions facilitating the retention of international students are fundamentally, post study factors.

Undeniably PR is an important objective for Chinese and Indian students, even in the early stages of their decision making process, reflecting the complexities of their transnational migration strategies. The intention to seek PR even before coming to Australia is strengthened by the fact that nearly 30 percent of respondents studied in Adelaide due to the regional bonus points available for PR applications. In addition, 37.1 percent of respondents enrolled in courses which were linked to occupations on the MODL, even though they might have no interest in the course, nor any intention to work in a job related to it. The deliberate selection of Adelaide and courses continues to demonstrate the extent of PR as a key objective for Chinese and Indian students, and underlines the influence of immigration policy on their decision making process.

Australia and Adelaide are not necessarily the respondents' preferred study destinations as significant proportions of respondents seriously considered other countries or Australian States. Popular preferences for alternative countries include the US, UK and Canada and alternative States were New South Wales, Victoria and Queensland. These choices were unsurprising as they are traditionally, the most popular study destinations for international students. While higher costs (alongside other factors) associated with studying in other countries or States deterred a significant proportion of respondents, immigration policy 
emerged as an important factor. Some 23 percent of respondents were discouraged from studying in alternative countries as they were unable to obtain a student visa. Limited opportunities for permanent migration presented in those countries were also a factor for 36 percent of respondents. In a similar vein, this was also the case within Australia as bonus points were not made available to those graduating from universities in destinations such as Melbourne or Sydney. Hence, as much as students were motivated by the attractive immigration policies and regional bonus points in Australia and Adelaide respectively, they were similarly influenced by restrictive immigration policies which either restricted their entry or limited their chances of becoming permanent migrants.

The deliberate selection of study destinations underlines the role of Australia and Adelaide in the students' transnational migration strategies. Strong evidence points towards the above places as fall back or secondary destinations and their function as gateways to other places. Although a high proportion of respondents planned to remain in Australia permanently, the majority however intend to either go home or migrate to a third country after working in Australia for a period of time. Likewise, this applied to respondents' intentions on remaining in Adelaide after their studies. The desire for PR is linked to it being a by-product of international education and the underlying issue shows that PR does not equate to permanent settlement as findings suggested migration strategies which involved onward migration patterns.

A reasonably high proportion of respondents have interstate $(27.8 \%)$ and third country migration intentions (21.6\%), which is a strong indication of Australia and Adelaide's gateway function. This finding backs up the conceptual model in Figure 4.2 which demonstrates how barriers to entry (eg, cost and/or restrictive immigration policy) in preferred or central destinations, such as the US or UK, resulted in the configuration of Australia as a gateway or intermediate destination. This was based on the idea Australia would provide an opportunity to acquire human capital in the form of PR, work experience and English language proficiency. More importantly, citizenship in the form of an Australian passport is also desirable as it would facilitate entry to their central destinations. In a similar sense, the transnational migration strategies of students also involved the use of Adelaide as a gateway to preferred interstate destinations such as Victoria or New South Wales. The advantage of studying in Adelaide rested in the availability of bonus points for 
PR applications. Upon graduating and after obtaining PR, students would then migrate to their central interstate destinations.

Moreover, configuring Australia and Adelaide as gateways is a deliberate strategy formed even before students leave their home country, demonstrated by high proportions of respondents intending to onward migrate to destinations which were seriously considered as study destinations. The recursive relationship within transnational social spaces emerges with the common denominator of immigration policy as a key factor. As much as the spatial element (study destinations) pushed and pulled students into choosing alternative study destinations, the configuration of Australia and Adelaide as gateways and the circumvention of policy in order to migrate to their central destinations clearly shows the co-production of space in their transnational migration strategies.

Respondents stated that interstate migration rather than third country migration was more likely in their transnational migration strategies. On the whole, Indian respondents had a stronger intention to apply for PR, moreover, they indicated a higher level of familiarity and seriousness with regards to Australia's PR laws and intention to remain in Australia. However, a slightly higher proportion of Chinese students intend to remain in Australia permanently and Indian students on the other hand displayed a higher propensity for onward migration; a trend similarly found in Hugo's (2007) study. Not only were interstate and third country migration intentions higher for Indian respondents, but also, they considered a greater range of settlement destinations, particularly interstate. The higher mobility and flexibility underlining their transnational migration strategies therefore demonstrates a strong element of flexible transnationalism.

The factors influencing the onward migration of Chinese and Indian students varied as well. Indian students were largely driven by economic and employment reasons which were perceived to be better at their future destinations. These motivations were partly linked to a pressing need to repay substantial bank loans used to bankroll their overseas education. Conversely, Chinese students were motivated by lifestyle and cultural factors as they were pushed by Adelaide's boring lifestyle and limited entertainment and shopping opportunities. Through the contrasting nature of Chinese and Indian students, it is clear that their respective transnational strategies will be different. 
Despite attempts to determine the future trajectories of Chinese and Indian students in Australia, the extent of their permanency in Australia and the actual realisation of their transnational strategies are inconclusive. However, it is clear that while PR is a key objective for both groups of students, they each have differing approaches in their transnational migration strategies. Understanding their return migration intentions assists in clarifying the complex nature of their migration patterns as well.

The minority of respondents who had immediate return migration intentions underlines the fact that international education represented an opportunity for students to remain in Australia and/or to migrate to a third country. The intention to return home was more prevalent for respondents who intend to do so after spending some time abroad, particularly for Indians. Main motivating factors revolved around economic and employment based reasons, societal factors and personal reasons. Booming economies in the respective countries of respondents provided a positive economic atmosphere for them to return to. This factor was particularly enhanced by policies and programmes in China which resulted in significant return migration (Zweig 2005a; 2006a; Zweig et al. 2005). However, economic and employment related factors were less important in the decision to return home. This is different compared to how they are often the chief reasons driving the migration of Chinese and Indian students.

Societal factors were on the whole less significant, although a slightly higher proportion of Indian respondents encountered racist attitudes, Adelaide was largely perceived as a safe place. Recent incidents of violence against Indian students in Melbourne have partly triggered $^{45}$ the collapse of the Indian student market in Australia with nearly 50 percent less commencements in 2010 than 2009 (D' Costa 2010; Hodge 2010). At the time of writing, the long term effects of these events is unclear, nevertheless, it is a factor which has already influenced the decision making process of Indian students and may well continue to affect Australia's reputation as a safe study destination. Alienation from Australian culture was also a factor for return migration, although this was more applicable for Chinese respondents due to their poor English proficiency.

Personal factors were key reasons which influenced the return migration decision. Among the reasons which included a sense of duty, belonging and attachment to their home

\footnotetext{
45 This decline should also be considered alongside recent policy changes in 2009 and 2010 which greatly diminished PR opportunities for international students. See Section 8.2.4.2 for more detail.
} 
country, ties to family and friends and a preference for the lifestyle back home- looking after their parents emerged as a very significant factor. Although respondents indicated that their parents had minimal influence in their overall decision making process, it is evident through examining return migration intentions that parents had a passive yet significant contributing role in their decision making process.

The above findings revealed the intricate nature of the transnational migration strategies of Chinese and Indian students, demonstrating the recursive relationship within transnational social spaces. As much as a place could influence students through immigration policy, students were conversely able to use international education to enhance their mobility by configuring places and circumventing policy to meet their objective. Australia and Adelaide were regarded not only as fallback study destinations, but also as gateways to central destinations either interstate and/or to a third country. Furthermore, it was noted that the onward migration patterns in their transnational strategies also included an eventual return to their respective home countries, driven by personal reasons. Respondents also reflected how the decision to seek PR in Australia or to onward migrate could also be formulated even before they left their home countries and Indian students were found to be more driven, flexible and mobile in their migration strategies. However, the element of cumulative causation also emerged in the decision making process.

\subsubsection{Factors influencing the decision making process and mobility of Chinese and Indian students}

\section{The third objective was to uncover the determinants that factored in the decision making process of Chinese and Indian students which have a bearing on their mobility.}

This study found that Chinese and Indian students were primarily driven by the desire to accumulate human capital. Students were driven to study abroad as the returns of a foreign degree were more advantageous, improving their career prospects. In comparison a degree from a university in their home country was often associated with a lack of quality and reputation. This factor was present in various stages of the students' decision making process as well. For example, study destinations, and in this instance Australia and Adelaide were selected (among other reasons) for their academic reputations, an acknowledgement of the benefits of studying in reputable countries on their future careers. This factor was further emphasised as respondents reflected superior economic and 
employment conditions in the US or in Victoria for example, as motivating factors for onward migration. Experiences associated with living and working in another country also furthered their human capital. The aim of improving one's English language while studying abroad was also important as it opened doors to career opportunities abroad or even in Western multinational corporations established in their home countries.

English proficiency is an anticipated outcome of their educational sojourn which is linked to the popularity of Western universities. This objective resonated with historicalstructuralist and world systems theories in relation to the dominance of first world or core countries over developing countries. Such predominant views influenced their migration as findings revealed the US and UK as popular and preferred study destinations ahead of Australia. The attraction to Western lifestyles, culture and preferences for the US in particular are seen to have 'seeped' into the cultural consciousness of Chinese and Indian students, a result of Western countries 'dominating' less developed ones, so to speak. However, the decision to study in Australia was influenced by macro structures such as immigration policies established by the governments of study destinations.

Some respondents were deterred from studying in the US as the fallout from 9-11 resulted in restrictive immigration policies. The rejection of many student visa applications created an unreceptive climate for visa applications as they were viewed as a waste of time and money. This correlated with respondents who chose to study in Australia due to the relative ease of obtaining a student visa. Additionally, respondents chose Australia because its attractive immigration policies provided the best opportunity for permanent migration, in comparison to the slimmer chances presented in alternative study destinations. Similarly, nearly a third of respondents chose Adelaide over other Australian States as they were influenced by the availability of bonus points in their PR applications. Moreover, respondents indicated that course selection was based on the MODL for PR purposes, giving them the highest possible chance of success in their PR applications. These findings therefore highlight the highly important role of immigration policy in the decision making process of Chinese and Indian students.

Chinese and Indian students were also motivated to study abroad by macro structures in the form of their respective home governments failing to meet basic demand for higher education and establish universities of high quality. Moreover, the surge in demand for an international education was also explained by economic reforms and policies which 
allowed more Chinese and Indians than ever before, the opportunity to study abroad; further underlining the role of macro structures.

While micro structures and meso structures were less substantial factors, they were nevertheless important in the decision making process of Chinese and Indian students. Meso structures in the form of education agents representing institutions were consulted by nearly half of all respondents, a valuable source for information and assistance in facilitating the applications and enrolments of students. Micro structures on the other hand were in the form of networks of friends and/or family with study experience in Australia and Adelaide. The selection of study destinations revealed a heavier reliance on education agents for Chinese respondents while recommendations from family/friends were more influential for Indian respondents. Social networks were significant in helping Chinese and Indian students make informed decisions when selecting a study destination. In general, findings suggested that students had a larger network of friends than family/relatives to rely on as sources of information. Moreover, the same trend emerged with respondents having more friends than family/relatives who were either PRs or citizens of Australia. This is an indication of the significant role informal networks have on the PR intentions of Chinese and Indian students, particularly with friends exerting a stronger influence than family/relatives. Aside from providing valuable information for PR purposes, these networks served as successful examples able to remain in Australia after their studies. Additional findings which showed a correlation between respondents motivated by favourable immigration policies in Australia and Adelaide and the network of family/relatives and friends who were PRs or citizens further emphasised the role of social networks. The findings also hinted that the stronger social networks available to Indian students influenced their propensity to seek PR, consider a wider range of study destinations and future interstate and third country destinations to move to.

Although these micro structures were less influential in the onward migration intentions of respondents, the role of the family emerged. Significant proportions of respondents planning on remaining in Australia and/or migrating to a third country, intended to have their family members join them in Australia and/or in the third country destination. Notwithstanding whether these intentions are realised, the finding here illustrates influence of the family in the students' transnational migration strategies. Moreover, it emerged through interviews that some Indian students would bring their future brides to join them, 
introducing the aspect of marriage migration into the transnational strategies of Indian students.

The importance of the family was further highlighted by respondents who placed parental influence alongside other personal factors as the main reason influencing their return migration, rather than economic reasons which have been dominant in the decision making process of Chinese and Indian students. Although this contradicted earlier findings which largely downplayed the influence of parents in the students' decision making process which narrowed their involvement as a source of funds, the fact that looking after their parents was a significant factor in the return migration decision highlights their passive, yet important role. Other personal factors as raised by respondents essentially revolved around sentiments which essentially demonstrated emotional attachments and a sense of belonging which included a preference for the lifestyle and culture at home, ties with family/friends, and the view that their respective home country was a good place to start a family.

It is important to note that while the factors discussed above generally applied to both Chinese and Indian students, findings indicated how each group was motivated differently, suggesting varying approaches in their transnational migration strategies. Firstly, accumulating human capital was important for both Chinese and Indian students, however Indian students were more driven with regards to their career. Findings revealed higher proportions of Indian respondents consistently motivated by economic and employment related factors in the decisions to study abroad, stay in Australia and onward migrate. This was partly linked to the pressing need to repay bank loans taken out to finance their overseas education. Moreover, the value of part-time work for Indian students was clear as more Indians than Chinese respondents worked part-time and did so more frequently and for longer hours as well. This finding highlights the disparity in wealth between these two groups of students and explains the stronger economic and employment motivations of Indian students. Chinese students generally did not need to work as much as they were dependant on their parents or family for financial assistance. To some extent, this is linked to Australia's quality of life influencing the decision of Chinese students to remain. As mentioned, their decision to onward migrate was largely associated with lifestyle and cultural considerations which includes a range of entertainment and leisure opportunities available at their interstate and third country destinations, quite different from the motivations of Indian students. 
This study demonstrates the factors which influence the mobility of Chinese and Indian students and has established the different ways in which the two groups of students are motivated. It is clear there are uncertainties in their decision making process. The element of cumulative causation was significant with regards to their future intentions as significant proportions of respondents were unsure of how long they would remain in Adelaide after their studies. There was also greater uncertainty surrounding their onward migration intentions interstate and to a third country. This also applied to the eventual return migration of respondents. Therefore, as much as this study has shed light on their transnational migration strategies, one has to take into consideration that their intentions and future plans are subject to change. However, findings show a lower proportion of Indian respondents who were unsure of their future plans, thus underlining the driven and highly strategic nature of their mobility. Together, these findings have important implications for policy, research and migration theory.

\subsubsection{Theoretical and policy implications and recommendations for future research}

\section{The final objective is to focus on the implications of this study's findings on migration} theory and policy; and put forward recommendations for future research.

\subsubsection{Theoretical implications}

The findings in this study have confirmed how international education can be a precursor to permanent migration. Examining traditional and contemporary migration theories against the findings identified the basic drivers of international student migration and how they shape the students' migration strategies. However, the different extent of influence on the motivations and future intentions between Chinese and Indian students revealed nuances in their respective migrations. This thesis has highlighted the weaknesses of approaches that homogenise international students. Research needs to consider the heterogeneity of international students and the value of examining international students in the context of their respective nationalities and associated characteristics.

Studying in Australia as a pathway to permanent migration is undeniable for Chinese and Indian students. The relative lack of attention given to macro structures, mainly in the form of immigration policy in internationals student research is clear. As this study found, the role of immigration policy is a significant variable in the transnational strategies of 
Chinese and Indian students. The realisation of future intentions and migration strategies rests largely upon immigration policies established by governments. Hence, from a theoretical perspective, there should be greater emphasis on immigration policy as a motivating factor and its key role in influencing student migration.

Another theoretical implication relates to micro and meso structures which although less significant, still played an important role in influencing the migration of the students. Formal and informal networks had significant influence on Chinese and Indian students' selection of study destinations, and their PR and onward migration intentions. The influence of friends was an especially prominent factor, however the influence of family, in particular parents, cannot be underestimated with regards to return migration. This demonstrates the importance of considering the role of social networks in the different stages of the students' migration. Also, there are implications with deconstructing networks to determine the influence respective forms of networks have in strengthening the migration flows of Chinese and Indian students.

Macro, micro and meso structures (Migration systems theory) are useful for theorising international student migration, however, this thesis has emphasised the need for a multidimensional approach. The limitations faced by using migration theories in isolation can be overcome by combining contemporary and traditional migration concepts. This thesis also found transnationalism as a more suitable approach. One of the central elements of transnationalism is a new form of “ hyperconnectivity' between migrants and their home communities" (Dade 2004, pg 1), enabled by technological advancements connecting migrants instantaneously, continuously and intimately with their home countries thus allowing for higher levels of international student mobility.

To recapitulate, the similarities found between the transnational migration patterns of students and other groups of migrants reinforces the calls of some commentators (Li et al. 1996; Tremblay 2005, pg 204) to categorise them as highly skilled migrants. Research needs to include international students as part of international labour flows and this thesis furthers the call to acknowledge international students as an important component of highly skilled migration. This will contribute to the literature and the dynamics of future migration research. In addition, the emergence of the transnational nature of international students emphasised the advantage of the transnational lens which extends flexibility when defining and ascertaining the type and duration of their migration. 
The extent of permanency in student migration is associated with the permanent migration and onward migration of Chinese and Indian students. The strategic configuration of places as gateways and central destinations is a clear indication that their educational sojourn involves more than just their home and host countries, as interstate and third country destinations are included in future migrations. These implications of these findings demonstrate that the extent to which other destinations are involved in their migration needs to be considered. The notion of international education as a migration instrument to enhance one's mobility is apparent and the importance of including post study trajectories when conceptualising student migration is underlined.

The higher mobility and flexibility underlining the transnational migration strategies of Indian students also demonstrates a strong element of flexible transnationalism. Overall, the migration of Chinese and Indian students resonates with Oishi's (2007) concept of "multiple migration and hyper transnationalism". This advanced stage of transnationalism refers to a growing trend of people no longer bound by the traditional idea of settlement, remaining mobile and never settling in any one country in their lifetime. Elements of flexible and hyper transnationalism characterising the migration of Chinese and Indian students are indicative of the need for a fundamental change in the conceptualisation of international student migration. Following from this, the concept of a central destination in students' transnational strategy needs to be reviewed due to the gradual dimunition of its 'centrality'.

The element of cumulative causation is largely neglected in the theorisation of student migration. This implication raises questions on studies that depict their international student migration in a rigorous and inflexible framework as there was great uncertainty in the future intentions of Chinese and Indian students. While this factor represents a snapshot of their migration strategies in time, the potential to change their minds is undeniable. This contributes to the advancement of migration theory as it underpins the importance of including cumulative causation when conceptualising the contemporary migration of international students. There are further implications as "factors tend to shift as migrants go through each segment of multiple migration" (Oishi 2007). Hence, it is necessary to link shifting future intentions accordingly to the stage which students are at in their transnational migration strategies. Future research should also consider ways of measuring the factors that influence uncertainty to determine the extent to which shifting intentions 
direct or redirect the eventual decision of the students. Investigating these implications will increase understanding on how cumulative causation shapes the transnational migration strategies of Chinese and Indian students.

It is rare for conceptualisations of international student migration to incorporate the recursive relationship between the social and spatial elements of the students' transnational migration strategies. This limited the understanding on the construction of transnational migration strategies and the configuration of places into gateways and central destinations. The theoretical implication of this relationship demonstrated the way in which the social element makes the spatial and allowed us to view the spatial beyond a physical place on a map. The circumvention of policies by Chinese and Indian students highlights the importance of the agency of the student in an increasingly transnational world. This adds value and contributes to the advancement of the transnationalism literature.

As much as the discussion in this section emanates from and relates to Chinese and Indian students, the theoretical implications raised are very much applicable to international students as a whole. This thesis has shown that the current migration framework is inadequate when conceptualising international student migration. In order to gain a comprehensive understanding of their migrations, research on student mobility needs to move away from the traditional framework of migration. This study has shown how dynamics of international student migration has changed, with the transnational nature of their mobility coming to the fore. The value of a transnational lens is crucial for future research as it:

enhances our understanding of the specific nature of various immigration flows...it demands that we contextualise our investigations across multiple spaces as well as across various scales, from national systems of governance to local processes of settlement (Walton-Roberts 2003).

In order to achieve a greater understanding on the mechanisms and complexities driving student migration, future research should endeavour to collect and find out as much detail as possible with regards to their motivations and future intentions of international students.

\subsubsection{Policy implications}

The increasing knowledge on the migration of international students provides scope for the development of policies to further engage with complex patterns of their mobility. The 
policy implications which arose from this study's findings essentially revolves around the effectiveness of immigration policy in attracting and retaining international students. This is exemplified through the strategies employed by Chinese and Indian students to circumvent immigration policy in order to achieve their migration objectives. Australia's attractive immigration policy has clearly, influenced the PR intentions of Chinese and Indian students. The configuration of Australia as a fallback or secondary destination due to restrictive immigration policies in the US and UK raises doubt on the efficacy of Australia's immigration policies facilitating the retention of international students.

The onward migration intentions of Chinese and Indian students are indicative of how policy can be circumvented; undermining policy objectives that seek to retain international students to supplement labour and skill shortages. This is a limitation of Australia's skilled migration policy which clearly needs to be addressed. In a similar sense, with strong interstate migration intentions, the advantage posited by bonus points for PR in Adelaide (and other regional areas) is overshadowed by strong interstate migration intentions. Moreover, PR does not necessarily translate into permanent settlement as some students view $\mathrm{PR}$ as a form of compensation for the amount of money spent on their education in Australia, or to enhance their employability in Australia. Policy at state level should therefore consider ways to reduce or curb the outflow of international students upon their successful transition to PR to other Australian States or countries.

Despite better economic and employment opportunities driving the outmigration of Chinese and Indian students, some respondents indicated their preference to remain in Adelaide if they were able to find suitable employment. This is a strong indication that some students are willing to give settlement in Adelaide a try, leaving room for policy makers to develop ways to facilitate and encourage a positive climate in the economic and employment sense.

Additionally, MODL driven course selection for PR purposes might mean that while student PR intentions are met, Australia's skill shortages are not. The efficacy of immigration policy is reduced as student graduates are not bound to work in jobs directly related to their occupations, or in MODL nominated occupations. The challenge for policy would be to ensure that the GSM programme meets the skill shortages in respective areas by reducing the amount of student graduates working in occupations unrelated to the ones they nominated in their PR applications. 
There is a caveat as this thesis worked within the time frame of 2005-2007, since then, modifications to immigration policy have truncated the PR component for international students and addressed some of the above mentioned policy implications. They include, in 2007, the restriction in the accessibility of MODL points only to applicants with a year's work experience in the nominated occupation, in 2009, the introduction of the CSL (Critical Skills List) which had fewer occupations listed and was given priority over those applying with MODL points, in 2010, the abolition of the MODL and the CSL as a new SOL was introduced, with a further reduction in the number of occupations listed (Birrell \& Healy 2010).

As a whole, these changes were introduced largely as responses to better meet the demands of Australia's labour market. The importance of MODL points in PR applications was gradually reduced. There was increasing emphasis on meeting specific skill shortages as priority was given to applicants with employer and State Government sponsorship and to those with CSL nominated occupations. This was partly due to the propensity of international students graduating as cooks or hairdressers ${ }^{46}$ intending not to work in these jobs (Birrell \& Perry 2009, pg 69-70). As it currently stands, the new SOL is designed to target high calibre skilled migrants and to successfully deliver them to places where "the cost to the economy and local communities of the skill being in short supply is great" (Evans 2010).

Suffice to say, PR pathways for international students are now less direct and much more difficult than ever. While the recent changes are seen to mainly impact the VET (Vocational Education and Training) sector (Birrell \& Healy 2010; Birrell \& Perry 2009), a few outcomes with regards to international students in higher education are predicted. Firstly, with Accountants still on the SOL, enrolments in these courses might remain steady or experience further increase. However, the 2010 changes will require students desiring PR to enrol in more difficult and expensive course such as engineering. This is aimed at evening out the imbalance of international students enrolling in IT and Management and Commerce, triggering "a wider mix of professions and trades coming through as independent skilled migrants to supplement the national skills base" (Evans 2010). Secondly, even though the 485 visa provides student graduates a pathway to PR, it

\footnotetext{
${ }^{46}$ Cookery and hairdressing remained on the MODL, however, they were excluded from the CSL.
} 
will be a more onerous process as applicants are required to nominate an occupation listed on the new SOL. The implications of these policy changes will be significant factors for potential international students and this may impact on the future enrolment levels of international students in Australia.

The alternative for student applicants as Birrell and Healy (2010, pg 78) have noted, will be via State Government Skilled sponsored visas and the ENS (Employer Nomination Scheme). State Government sponsorship, depending on the individual State, usually does not require a firm job offer for the applicant. Moreover, they are given liberty to decide on the occupations needed. With South Australia and Victoria having indicated their intention to boost their migrant intake (Birrell \& Perry 2009, pg 76), one can surmise that future transnational migration strategies of international students could still involve the configuration of destinations as gateways for PR and work experience reasons before onward migrating to their preferred destination. To an extent, this potential strategy resonates with the policy implication faced by the offer of bonus points raised in this study. It is too early to determine if the above scenario will take place, however, it must be acknowledged that this pathway has less to do with students studying in higher education institutions as it largely concerns those in the VET sector. Nevertheless, the bottom line is that challenge of minimising the potential loss of skills from student graduates remains a prospective issue for policy makers.

The ENS requires the applicants to have the sponsorship of an employer along with at least three years of relevant work experience in the sponsored occupation. Additionally, applicants can seek out temporary entry sponsorship (visa subclass 457) whereby the requirement for work experience is substantially lower before applying for the ENS visa (Birrell \& Healy 2010, pg 78). As this study discussed, having PR increased employment opportunities as employers were otherwise unwilling to hire student graduates on temporary visas. Hence, the issue of being able to find the required occupation still prevails. Regardless of whether the long term intention of the student graduate is to permanently remain in Australia, onward migrate or even return migrate, the underlying challenge would be to ensure their successful employment in occupations relevant to their qualifications. From this point of view, anything less would neither benefit the Australian economy nor the individual student. Thus, meso structures in the form of agents will have a much bigger role to play as they will be "out and about looking, on behalf of their clients, 
for such employers" (Birrell \& Healy 2010, pg 78). In order to reduce employer bias, policy should seek to improve linkages between employers, agents and student graduates.

Attempting to resolve the conundrum of using international education to deliver skilled migration objectives remains a challenging issue. Despite the changes made to immigration policy post-2007, some of the predicted challenges remain relevant to the policy implications raised in this study. Although the underlying objective in the 2010 changes have made steps towards delivering optimum results for the GSM programme, it is too soon to fully understand the full scale impacts of these modifications. However, when combined with other issues, (i.e., incidents relating to shonky education providers, violence, racism, discrimination and exploitation against Indian students ${ }^{47}$ ), enrolments are projected to experience a significant decrease which could lead to a loss of 30,000 jobs in Australia (Jakubowicz \& Monani 2010, pg 11) and, unavoidably, a decrease in valuable export earnings generated by the international student market. Hence, the volatile nature of the international student market when combined with the regular modifications made to immigration policy, highlights the dynamic nature of the nexus between international education and permanent migration. Therefore, the biggest challenge for Australia in the long run would be to develop policy with the aim of creating a sustainable international education industry while delivering optimum results for skilled migration.

The onward migration intentions of Chinese and Indian students as found in this study, demonstrate that "while permanent settlement is one element in the migration system...it is only one part of a much larger and more complex set of flows" (Hugo 2007, pg 25). One can surmise that those who intend to emigrate to a third country or return home might entertain the idea of returning to Australia in the future due to the flexibility offered by PR. Including PRs or citizens (former students) who have emigrated to a third country or returned home, as part of the Australian diaspora should therefore be explored. For example, policy should consider targeting former students. Their experiences of living and working in other countries will benefit Australia as they will be 'more skilled' than when they first left Australia. Additionally, it will be relatively easier to attract the return of these former students on the proviso that they had positive experiences in Australia. This would

\footnotetext{
${ }^{47}$ See Jakubowicz and Monani (2010) for a detailed discussion on the wider issues underpinning the current crisis faced by Australia's international student industry.
} 
be further enhanced by social networks forged during their time previously spent in Australia.

The onward migration of former students should be placed higher on policy agenda in Australia. Policy should reflect a better grasp on the transnational nature of international students as the emigration of former students to other countries should not be viewed as the end of their relationship with Australia. Instead, Australia should look into developing policy to facilitate and maintain transnational linkages with former students. The value of these linkages needs to be better understood in order to be able to harness and channel their potential benefits into areas that will positively impact Australia.

For example, former students should be targeted as ambassadors for Australia. A recent strategic approach is the International Student Ambassador Program established by the ACT government in 2010 (Business and Industry Development 2010). This initiative recognises international students as "a unique and valuable resource in terms of business and intellectual capital, skills, access to international networks, marketing opportunities for education and tourism". It aims are to achieve trade, migration and investment objectives by building "networks and relationships with international students already in Canberra, and through them, back in their home countries". The success of this programme is yet to be determined, however, it would be unwise for policy makers at the Federal and State level to ignore the potential benefits of adopting a similar strategy.

The return migration intention of the students is also not to be ignored as it indicates a need to consider the impacts of international student migration on sending countries. Hence, the transnational migration strategies of Chinese and Indian students raised in this study clearly shows a complex set of movements which strongly suggests a need to explore a more holistic approach in migration policy. The final policy implication here therefore concurs with Hugo's (2007, pg 25-27) suggestion that governments should aim to construct 'co-development' migration policies, where adopting a more developmentally sensitive stance could lead to "win-win-win outcomes not only for the destination but also the migrants themselves and the origin communities". Furthermore, introducing development sensitivity into Australia's immigration policy might secure Australia's interests by beginning repairs to the damage to its reputation as a safe study destination offering high quality education. 


\subsubsection{Recommendations for future research}

This thesis has contributed to a deeper understanding of the transnational migration strategies of Chinese and Indian students in Australia and a number of recommendations flow from the findings.

The first recommendation would be to increase the scale of future research, beyond the scope of Chinese and Indian students studying in Adelaide. Being able to survey students from Flinders University would have assisted in fully capturing the motivations and futures intentions of all Chinese and Indian students studying in Adelaide based universities. Researching these students in other Australian States would also provide further clarity on their respective motivations and future intentions. As mentioned before, study destinations such as Victoria and New South Wales attract a substantial proportion of all international students in Australia. Hence, examining Chinese and Indian students studying in these areas would help to determine why Adelaide is losing out to other States in attracting international students. Moreover, the potential of a nationwide study will assist in determining the extent of influence State specific factors have on their decision making processes, further contributing towards understanding the drivers that influence the migration of the students to and within Australia.

Further study into Chinese and Indian culture is essential in order to develop a well rounded understanding of the dynamics behind the motivations and future intentions of students from these countries. Combining an anthropological approach similar to Baas' (2006) research on Indian students studying in Australia would offer an additional dimension which will provide valuable insights into the psyche of Chinese and Indian students. This will allow for the development of a comprehensive framework which includes culturally specific factors.

Future research needs to navigate through the 'turbulent' nature of international student migration. This 'turbulence' is linked to the dynamic mobility of international students and the constant evolution of immigration policy. Researchers can address this challenge by shedding light on the element of cumulative causation and the element of flexible- or hyper-transnationalism characterising international student mobility. This sets the platform for future research to adopt a longitudinal approach. Surveying and interviewing students over a period of time, at varying stages of their migration will paint a clearer picture of their international education sojourn. By investigating the motivations and future intentions 
of students before they arrive in Australia, during the course of their studies and after the completion of their studies, a well rounded and comprehensive understanding of their transnational migration strategies will be formed.

Oishi's (2007) and Hugo's (2007) recommendations lead the way as the key analytical dimension of their approach is to understand the options available to students at the various stages of their life and career cycle. Researching these options at the macro, micro and meso levels will further clarify the nature of cumulative causation in their decision making and illuminate the factors influencing the crystallisation of their shifting intentions.

Another recommendation links recent developments which include the 2010 changes to immigration policy and the combined incidents of violence, racism, discrimination and corrupt education providers to the future of the international student market in Australia. Although the full impact of the above issues are still to fully unfold, the recent collapse of the Indian student market in Australia (D' Costa 2010) have led to some commentators dubbing this a crisis (Jakubowicz \& Monani 2010). Hence, future research will have to take into consideration the fallout of these incidents in order to be able to fully appreciate the ramifications on international student migration in Australia.

Lastly, the introduction of marriage migration to the transnational migration strategies is another avenue for future research, albeit this mainly concerned Indian students. Interviews with key informants and students revealed that having an overseas degree and PR status boosted the marriage credentials of Indian students, subsequently leading to the future migration of their brides to Australia. With significant proportions of Indian students planning to seek PR, the potential of marriage migration further highlights the complex nature of their transnational strategies, thus warranting further investigation. However, this might prove to be inconsequential due to the collapse of the Indian student market in Australia.

\subsubsection{Conclusion}

This chapter has discussed and summarised the major findings and implications of this thesis. This study has shown how international education can be used as an instrument to enhance the mobility of international students. This thesis has provided strong evidence which illuminated the nexus between international education and permanent settlement, as PR was found to be a key objective for Chinese and Indian students. Additionally, it has 
also argued and substantiated claims to classify international students as highly skilled migrants. The findings in this study revealed nuances between the transnational migration strategies of Chinese and Indian students, emphasising the importance of not homogenising international students.

The patterns of onward migration characterising their mobility substantiated the need to reconceptualise their movements beyond the temporary and permanent paradigms of migration. The transnational migration strategies of Chinese and Indian students are best viewed through a transnational lens as they displayed an element of flexible and hyper transnationalism in their plans. The strategic configuration of Adelaide and Australia as gateways to central destinations contributed to a deeper understanding on the recursive relationship within the social spaces of the students' transnational migration strategies. The evident circumvention of immigration policy was discussed and it is clear that despite Australia's "long history of flexibility in its migration policy, readily adapting it to shifts in the international context and internal conditions" (Hugo 2007, pg 24), the highly evolving and dynamic nature of Chinese and Indian students posed a challenge. The transnational migration strategies of Chinese and Indian students have underlined their adaptability to shifts in immigration policies in both Australia and other countries.

In order to be able to develop a comprehensive understanding on the complex migration systems of these students, future research should continue to research their motivations and future intentions. The transnational nature of Chinese and Indian students should be embraced. The recommendations for future research put forth in this chapter should be explored as there is potential for Australia, and both China and India to benefit from the transnational migration of these students. 
Appendix 1: Comparison of retention policies towards international students in industrialised countries in 2006

NOTE:

This appendix is included on pages 220-223 of the print copy of the thesis held in the University of Adelaide Library. 
Appendix 2: Chronology of Australia's international education policy shifting from aid to trade

\begin{tabular}{|c|c|c|c|}
\hline Year & Policy Initiatives & Quota & Description \\
\hline 1950 & Colombo Plan & $\begin{array}{l}1,000 \text { international students, } \\
\text { gradually increased to } 5,000 \text { by } \\
1965\end{array}$ & $\begin{array}{l}\text { - Established to promote educational assistance to } \\
\text { Commonwealth developing countries }\end{array}$ \\
\hline 1973 & $\begin{array}{l}\text { Higher Education Funding and } \\
\text { Upper ceiling established }\end{array}$ & $\begin{array}{l}\text { Upper ceiling of } 10,000 \text { of } \\
\text { international students established }\end{array}$ & $\begin{array}{l}\text { Whitlam government took responsibility of higher } \\
\text { education funding and abolished tuition fees. } \\
\text { - The development assistance agenda was dropped } \\
\text { from the private overseas student policy. }\end{array}$ \\
\hline 1979 & Fraser Government initiatives & $\begin{array}{l}\text { Upper limit of } 10,000 \text { was removed } \\
\text { and replaced by a flexible approach } \\
\text { dependent on the capacity of } \\
\text { institutions }\end{array}$ & $\begin{array}{l}\text { - Overseas Student Charge (OSC) was introduced } \\
\text { where students paid a percentage of the total cost of } \\
\text { their education. } \\
\text { - Allocation of student visas for different countries } \\
\text { was set each year. } \\
\text { - Mandatory for students to return to their home } \\
\text { countries for two years before being eligible for } \\
\text { permanent residence }\end{array}$ \\
\hline 1983 & $\begin{array}{l}\text { Appointment of Goldring and } \\
\text { Jackson Committees }\end{array}$ & $\begin{array}{l}\text { Policy recommendations by the two } \\
\text { committees varied. }\end{array}$ & $\begin{array}{l}\text { Jackson Committee recommended that the OSC be } \\
\text { progressively increased so that full cost of fees will } \\
\text { be borne by students that by mid 1990s. } \\
\text { - Goldring Committee recommended the OSC be } \\
\text { regulated at } 30-40 \text { percent as a full cost system } \\
\text { would disadvantage poor students. }\end{array}$ \\
\hline 1985 & $\begin{array}{l}\text { New policy based on the } \\
\text { recommendations of the } \\
\text { Goldring and Jackson } \\
\text { Committees was announced }\end{array}$ & $\begin{array}{l}\text { Annual ceiling in all categories } \\
\text { determined by government. } \\
\text { Institutions were allowed to enrol } \\
\text { international students up to } 10 \\
\text { percent of their total number or } 20 \\
\text { percent in any course within the } \\
\text { overall ceiling }\end{array}$ & $\begin{array}{l}\text { Plans for the OSC to be increased to } 35 \text { percent in } \\
1986 . \\
\text { Plans to increase progressively increase it to } 45 \\
\text { percent in } 1987 \text {. } \\
\text { - Allocation of visas for different countries to remain } \\
\text { in place. }\end{array}$ \\
\hline
\end{tabular}




\begin{tabular}{|c|c|c|c|}
\hline 1986-1990 & $\begin{array}{c}\text { Full fee marketing of education } \\
\text { established }\end{array}$ & $\begin{array}{l}\text { Quotas for international students } \\
\text { were removed in } 1988\end{array}$ & $\begin{array}{l}\text { - From 1986, government adopted a trade oriented } \\
\text { approach. Fee paying international students were } \\
\text { allowed in publicly funded institutions. } \\
\text { - } 1990 \text { Subsidised programme was phased out. } \\
\text { - Educational assistance to developing countries } \\
\text { remained but was selective. } \\
\text { - From 1990, fee based market was established as } \\
\text { institutions were encouraged to be entrepreneurial } \\
\text { and set fees at or above cost. } \\
\text { - Introduction of } \mathrm{HECS}^{48} \text { in } 1989 \text {. }\end{array}$ \\
\hline
\end{tabular}

Source: adapted from (Baker et al. 1996a; Bayley et al. 2002; Cameron 2002; Department of Employment 1992; Goldring 1984; Harris \& Jarrett 1990; Jones 1986; Williams 1989).

${ }^{48}$ HECS otherwise known as Higher Education Contribution Scheme was introduced by the Hawke government in 1989 as a means to fund the large scale expansion of higher education. This is in contrast to the "utopian" fee-free era of the Whitlam government as local students now had to pay tuition fees through an income-contingent loans scheme with repayments made through the taxation system. 


\section{Appendix 3: Summary of points test application from July 2005 to September 2007}

\begin{tabular}{|c|c|c|}
\hline Conditions & Poin & \\
\hline Skill & 2005 & 2007 \\
\hline $\begin{array}{l}\text { Specialised professional or trade occupations } \\
\text { - qualification (degree or trade certificate) } \\
\text { - meet any Australian registration requirements }\end{array}$ & 60 & unchanged \\
\hline $\begin{array}{l}\text { General professional occupations } \\
\text { - qualification equivalent to Australian bachelor degree or higher (not necessarily related to } \\
\text { nominated occupation) }\end{array}$ & 50 & unchanged \\
\hline $\begin{array}{l}\text { Other general skilled occupations } \\
\text { - qualification equivalent to Australian diploma or advanced diploma higher (not necessarily } \\
\text { related to nominated occupation) }\end{array}$ & 40 & unchanged \\
\hline Age (at time of application) & 2005 & 2007 \\
\hline $18-29$ years & 30 & unchanged \\
\hline $30-34$ years & 25 & unchanged \\
\hline $35-39$ years & 20 & unchanged \\
\hline $40-44$ years & 15 & unchanged \\
\hline English Language Ability & 2005 & 2007 \\
\hline $\begin{array}{l}\text { Proficient English } \\
\text { - was formerly categorised as competent English in } 2005 \text { which awarded } 20 \text { points if }\end{array}$ & 20 & 25 \\
\hline
\end{tabular}


applicant was a native speaker or IELTS band was 6.0 in each of four components of

reading, writing, speaking and listening

- changes in 2007 introduced the proficient English category and increased the IELTS

band score to 7.0 in each of the four components, awarding 25 points

Vocational English (for tradespersons only)

- IELTS band score of 5 in each of four components of reading, writing, speaking and listening

Competent English

- IELTS band score of 6 in each of four components of reading, writing, speaking and listening

\begin{tabular}{|c|c|c|}
\hline Specific Employment & 2005 & 2007 \\
\hline $\begin{array}{l}\text { Employed in } 60 \text { point nominated skilled occupation or closely related } 60 \text { point occupation for at } \\
\text { least } 36 \text { out of } 48 \text { months immediately preceding application }\end{array}$ & 10 & unchanged \\
\hline $\begin{array}{l}\text { Employed in any skilled occupation on the SOL for at least } 36 \text { out of } 48 \text { months immediately } \\
\text { preceding application }\end{array}$ & 5 & unchanged \\
\hline Australian Employment & 2005 & 2007 \\
\hline $\begin{array}{l}\text { Employed in nominated occupation or closely related skilled occupation in Australia for at least } 12 \\
\text { out in the last } 48 \text { months }\end{array}$ & n.a & 10 \\
\hline Completed a professional year specified by the minister for a total of 12 out in the last 48 months & n.a & 10 \\
\hline Australian Qualifications & 2005 & 2007 \\
\hline Completed a doctorate onshore at an Australian educational institution in a minimum of 2 years & 15 & 25 \\
\hline
\end{tabular}


- a Bachelor and a Masters degree or

- a Bachelor degree with Honours (at least second class)

In $\underline{\mathbf{2 0 0 7}}$, the minimum amount of time was increased to a total of $\mathbf{3}$ years with the abovementioned qualifications

Completed full time study in Australia towards a degree, diploma or trade qualification over 2 years

\begin{tabular}{|c|c|c|}
\hline MODL & 2005 & 2007 \\
\hline 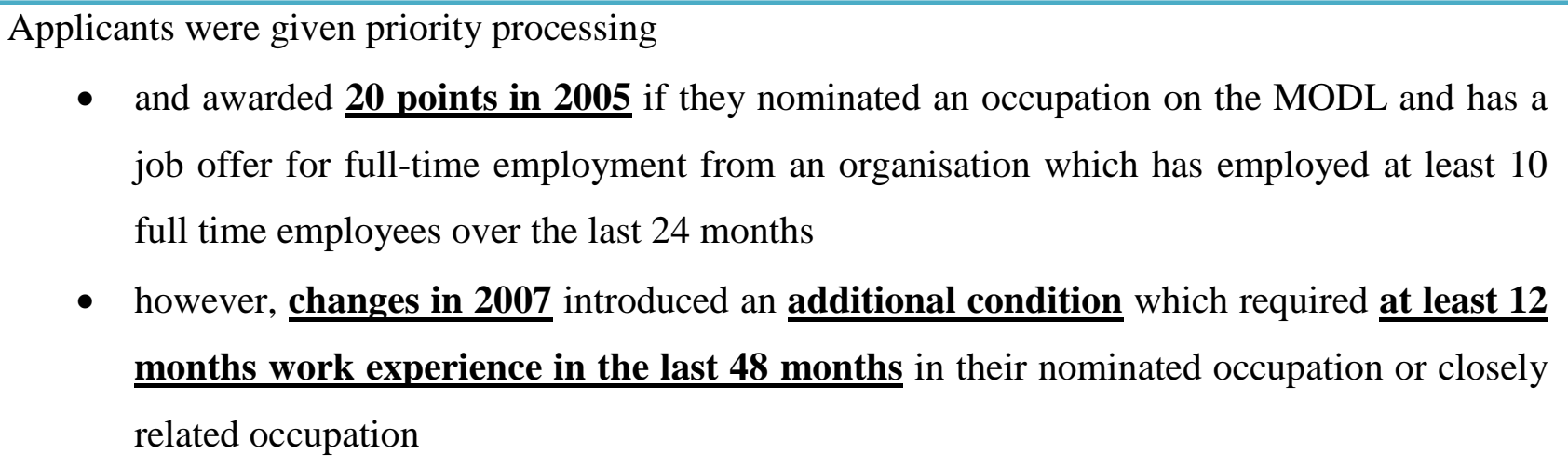 & 20 & 20 \\
\hline $\begin{array}{l}\text { Applicants were given priority processing } \\
\text { - if they nominated an occupation on the MODL with no need for a job offer } \\
\text { - however changes in } \mathbf{2 0 0 7} \text { introduced an additional condition which required the applicant } \\
\text { to also have } 1 \mathbf{1 2} \text { months work experience (in the last } 48 \text { months) in their nominated or } \\
\text { closely related occupation }\end{array}$ & 15 & 15 \\
\hline
\end{tabular}




\begin{tabular}{|c|c|c|}
\hline Bonus Points (for one of the following only) & 2005 & 2007 \\
\hline $\begin{array}{l}\text { Capital investment of } \$ 100,000 \text { in Australia in an approved government investment for at least } 12 \\
\text { months } \\
\text { - changes in } \mathbf{2 0 0 7} \text { however removed this component in the points test for all application } \\
\text { lodged after the changes }\end{array}$ & 5 & n.a \\
\hline Professional level language skills in a designated language & 5 & unchanged \\
\hline 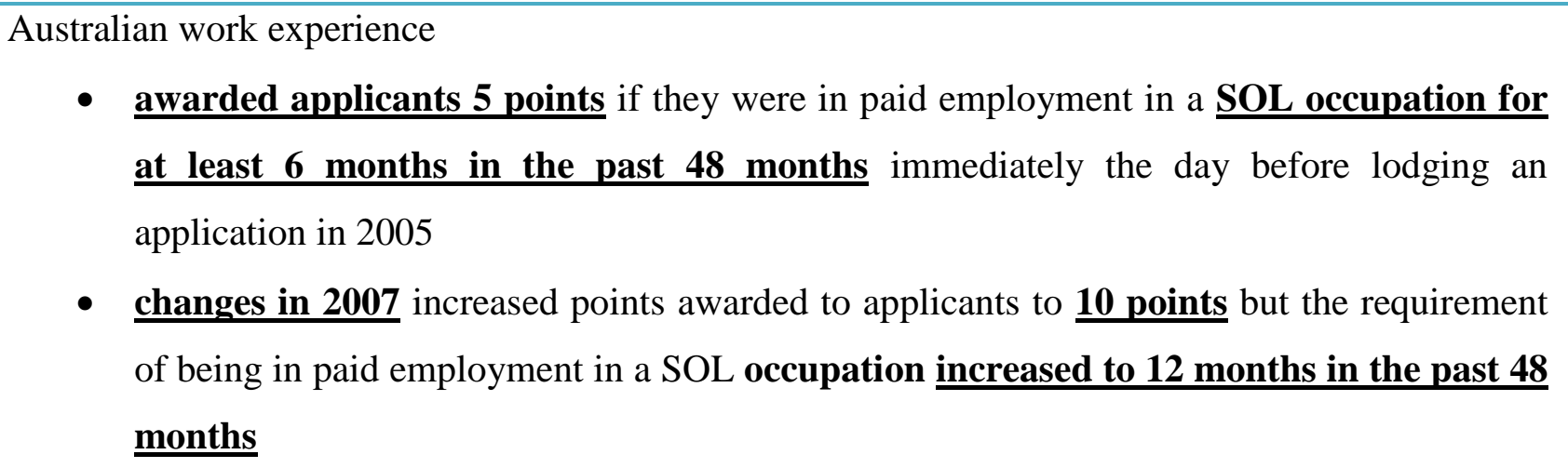 & 5 & 10 \\
\hline Studying and Living in Regional Australia & 2005 & 2007 \\
\hline $\begin{array}{l}\text { Applicant has to have lived and studied in a regional or low population growth metropolitan area } \\
\text { for at least } 2 \text { years }\end{array}$ & 5 & unchanged \\
\hline Spouse Skills & 2005 & 2007 \\
\hline $\begin{array}{l}\text { Applicant's spouse meets threshold GSM criteria } \\
\text { - under the age of } 45 \\
\text { - has vocational English } \\
\text { - has nominated an occupation }\end{array}$ & 5 & unchanged \\
\hline
\end{tabular}


- been assessed by relevant authorities to have suitable skills

- either has an Australian qualification or has work experience

\begin{tabular}{|c|c|c|}
\hline Sponsorship & 2005 & 2007 \\
\hline $\begin{array}{l}\text { Sponsorship by a relative who is either a citizen or PR of Australia } \\
\text { - applicant needs to be a non-dependent, and a parent, brother or sister, niece or nephew, } \\
\text { aunt or uncle of the relative who is willing to sponsor them }\end{array}$ & 15 & unchanged \\
\hline $\begin{array}{l}\text { Sponsorship by State/Territory government } \\
\text { - State and Territory governments may nominate applicants who have an occupation that is } \\
\text { in shortage in their particular State or Territory }\end{array}$ & 10 & unchanged \\
\hline
\end{tabular}

Source: Adapted from (ISCAH Migration n.d; Argel n.d; Birrell et al. 2006, pg 12-16) 


\section{Appendix 4: Chinese and Indian Student Survey}

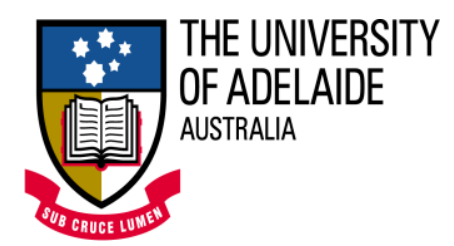

\section{Survey of International Students at the University of South Australia}

Should you have any queries with regards to this survey, please do not hesitate to contact myself, George Tan, or my supervisor, Professor Graeme Hugo, Discipline of Geographical and Environmental Studies. Our contact details and more information about this study are provided in the Information Sheet.

\section{Your Decision to Study in Australia}

A1. Why did you decide to study in Australia? (please tick all that apply)

Academic Reputation

Cheaper to study in Australia

Ease of admission to the country (was granted a student visa)

Parent's decision

Attractive immigration policies

Recommended by family/friends

Recommended by Education Agent

Was offered a scholarship to study in Australia

Safe country to study and live in 
Other (please specify)

A2. Why did you choose to study in Adelaide? (please tick all that apply)

Academic Reputation

Cheaper to study in Adelaide compared to other states

Ease of admission to the University

Was offered a scholarship to study in Adelaide

Parent's decision

Courses available here in Adelaide

Bonus Permanent Residency points on offer after graduation

Able to obtain credit transfer from previous course or qualification

Recommended by family/friends

Recommended by Education Agent

Other (please specify)

A3. Which institution are you enrolled in?

Select one university 
A4. Why didn't you study in your home country? (please tick all that apply)

Wanted the experience of studying abroad

Wanted to improve my command of English by studying abroad

Not admitted to home university

Course not available in home country

Lower Quality of courses

Poor Reputation of Universities

Limited or No Academic freedom at home country

Parental Decision

Obtaining an overseas degree will enhance career prospects back in home country

Other (please specify)

A5. Did you seriously consider other countries to study in? Please exclude home country.

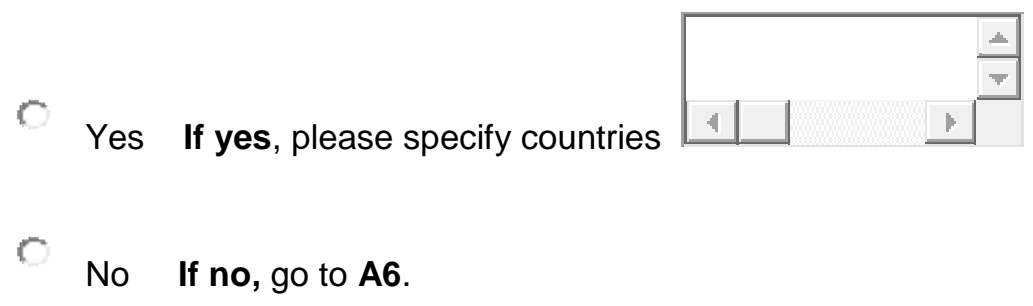

A5.b Why did you decide not to study in these countries? (please tick all that apply) 
Was unable to obtain a Scholarship to study in these countries

Poor reputation of Education System in those countries

Did not have any friends/family in those countries

Lifestyle and weather in those countries did not attract me

Student Visa was not granted in countries considered

Unable to obtain credit transfer from previous course or qualification

My home institution did not have links with institutions in those countries

Course was not available in those countries

Security and safety was an issue in countries considered

The possibility of permanently migrating to those countries after my studies was low

More expensive to study in those countries

Parental Decision

Other (please specify)

\section{A6. Did you seriously consider studying in other states?}

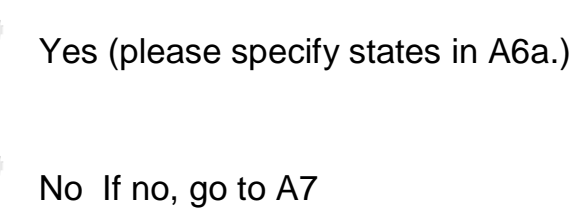


A6.a Which states did you seriously consider studying in? (please specify)

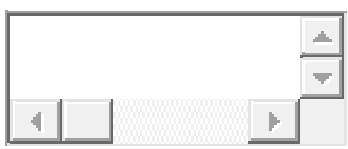

A7. Did you study in another country just before coming to Australia? Do not include your home country.

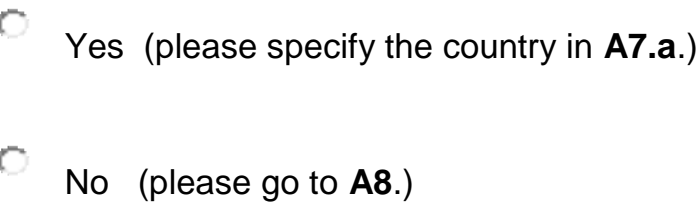

A7.a Please state the last country you were studying in before you commenced your studies

in Australia.

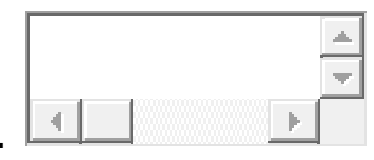

A7.b What course did you study in that country? Select Course

A7.c Did this course help you in gaining admission or credit exemption the course you are currently enrolled in?

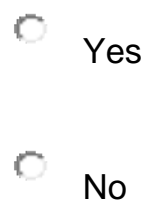

A7.d How long was the duration of the course?

Select Duration 
A8. How many times have you visited Australia before studying here? Select number of times

A8.b How many times have you visited Adelaide before studying here? Select number of times

A9. How many of your family/relatives have studied in Australia prior to your arrival? Select number

A9.b How many of your family/relatives have studied in Adelaide prior to your arrival? Select number

A10. How many of your friends have studied in Australia prior to your arrival? Select number

A10.b How many of your friends have studied in Adelaide prior to your arrival? Select number

A11. How many of your family/relatives are Permanent Residents or Australian citizens?

Select number

A11.b How many of your friends are Permanent Residents or Australian citizens? Select number

A12.What were the MAIN sources of information used before coming to study in Adelaide? (please tick all that apply) 
Education fair/exhibition in home country

IDP

\section{Education Agent}

Migration Agent

Scholarship provider

Study in Australia website

South Australia Government website

Education Adelaide Website

Website of Australian Government

University Website

Direct contact with representative of the University

Information about Adelaide in books, brochures and newspapers

Information about living and studying in Adelaide from other internet sources

Other (please specify)

A13. How do you MAINLY fund your study (tuition fees)?

Please Select 
How

do

you

MAINLY

fund

your

living

expenses?

Please Select

A13.c How much financial assistance do you receive from overseas per year? (include tuition fees, living expenses and please estimate in Australian Dollars)

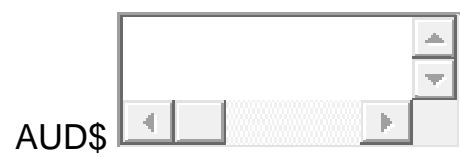

\section{Your Experience in Adelaide}

B1. Have you worked for pay in the last year?

Yes

No (If no go to B5.)

B2. Is this job related to your studies?

Yes No

B3. What is the nature of your work? (please specify)

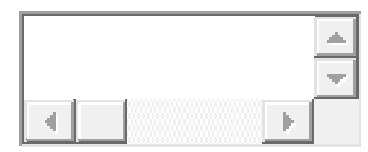

B3.b How many weeks per year do you work? \begin{tabular}{ll} 
Please Select \\
\hline
\end{tabular}

B3.c How many hours per week do you work? Please Select 
B4. Did you organise this job before or after you arrived in Adelaide?

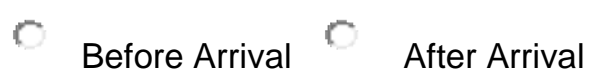

B4.b How did you manage to find this job?

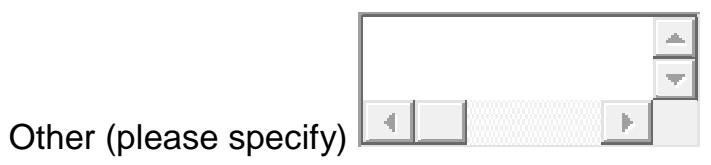

B5. How often do you intend to return to your home country while studying? Please Select

B5.b How often do you keep in touch with family and friends back home? Please Select $\quad$ -

B5.c What is your main form of communication with family and friends back home? Please Select

\section{Your Future Intentions}

C1. When you began your current degree was your initial intention to:

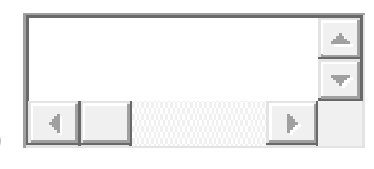


C1.b Has your initial intention changed during the course of your study in Australia?

$$
\text { Yes } \quad \text { No If No, GO TO C2 }
$$

C1.c What is your current intention? Please specify

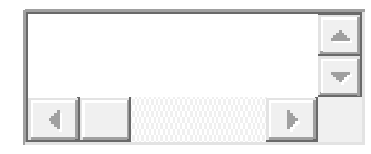

C2. Which Visa do you intend to seek after your studies?

(c) Permanent Residency Visa

SIR Visa

No plans to apply for any visa (please GO TO c3)

Other Visas (please specify)

C2.b How long do you plan to remain in Adelaide after your studies? Please Select

C3. Do you plan to remain in Australia?

Yes If Yes, go to $\mathbf{C 4}$.

No If No, go to $\mathbf{C 7}$. 
C4. What are the reasons for planning to remain in Australia? (please tick all that apply)

Employment opportunities are better in Australia

Better job/career advancement prospects here in Australia

Higher Salary here in Australia

Higher standard of living in Australia

Higher "quality of life" in Australia (non-economic factors, eg, weather, lifestyle)

Ties to friends or family in Australia

Unstable Political Situation in home country

Restrictive Cultural practices (eg, strong gender roles) in home country

Marriage/Partnership reasons

Parental Decision

To gain work experience

Other (please specify)

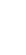


C5. Do your plans include bringing your family over to join you in Australia?

Y Yes

No If NO, GO TO $\mathbf{C 6}$

C5.b When did you decide for your family members to join you here in Australia?

Before coming to Australia to study

During the course of my stay in Australia

C6. Do you plan to move interstate in the future?
C. Yes
No If No or Unsure, please GO TO to question C8.
Unsure If No or Unsure, please GO TO to question C8.

C6.b When did you decide you wanted to move interstate?
B. Before coming to Australia
D. During the course of my stay in Adelaide

C6.c Which state or states do you intend to move to? (please specify) 


\section{C6.d When do you intend to make this move?}

Please Select

Other (please specify)

C6.e Why do you wish to relocate to the state you chose in C6c? (please tick all that apply)

Adelaide has an unfriendly, unwelcoming environment

Family/Friends are living interstate

Marriage/Partnership reasons

Parent's decision/ Family influence

Do not feel safe in Adelaide

Adelaide is too small and boring (lack of social, entertainment and leisure opportunities)

Adelaide compared to Interstate destination has low range of consumption goods (shopping)

Lifestyle is better at Interstate destination

More employment opportunities at Interstate destination

Better career advancement prospects at Interstate destination

Higher Salary at Interstate destination

Other (please specify) 
C6.f Please rate how serious your plans are towards moving Interstate.

Please Select

Skip C7 and go to C8.

C7. If you do not wish to remain in Australia, where do you intend to go to after your studies?

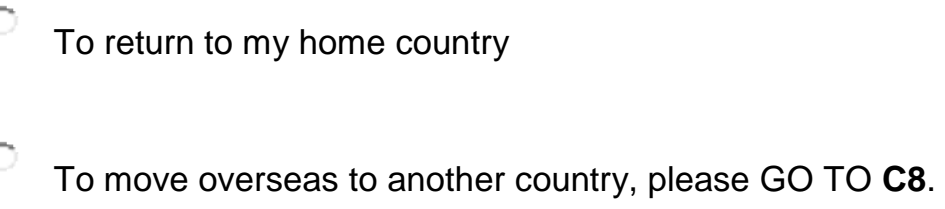

C7.b What are your reasons for returning to your home country after your studies? (please tick all that apply)

Miss home

Ties to family/friends back home

To look after my parents

Home country is a better place to raise/start a family

Marriage/Partnership reasons

Parental Decision/Influence

Prefer the lifestyle back in home country 
Feelings of alienation from Australian culture

Racist attitudes encountered in Australia

Would like to establish my career back home

Have to return due to my scholarship stipulations

Better Employment opportunities back home

Better Career and promotional prospects back home

Higher Salary back home

Other (please specify)

\section{Please GO TO C11.}

C8. Do you have plans to move to another overseas country? Please DO NOT include plans of moving back to your home country.
Yes
No If No or Unsure, GO TO C10
Unsure If No or Unsure, GO TO C10 
C8.b If yes, which country? (please specify) Please DO NOT include plans of moving back to your home country.

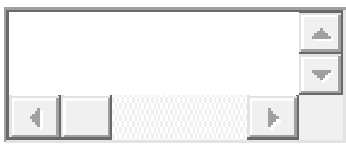

C8.c What are the reasons for moving to that country? (please tick all that apply)

Family/Friends are living there

Attracted to the Lifestyle in that country

It is a personal aspiration to live in that country

It is a better place to start/raise a family

Marriage/partnership reasons

Parental Decision

Further education/study

Better employment opportunities in that country

Better career advancement opportunities in that country

Higher Salary in that country

To gain international experience

Other (please specify) 
C8.d How long do you intend to remain in that country?

C8.e When do you intend to move to that country? Please Select

C8.h When did you decide that you wanted to move overseas to another country after your studies?

Before coming to Australia
During the course of my studies in Australia

C8.i Please rate how serious your plans are towards moving overseas to another country. Please select

C9. Do your plans include bringing your family over to join you in the country which you may decide to move to?
(C) Yes
No If No, GO TO C10

C9.b When did you decide for your family members to join you overseas?

\footnotetext{
Before coming to Australia to study

During the course of my stay in Australia
} 
C10. Do your future intentions include plans of eventually making a permanent move back to your home country?
Yes
No (If No or Unsure, please GO TO C11.)
Unsure (If No or Unsure, please GO TO C11.)

C10.b What are the reasons for moving permanently to your home country in the future?

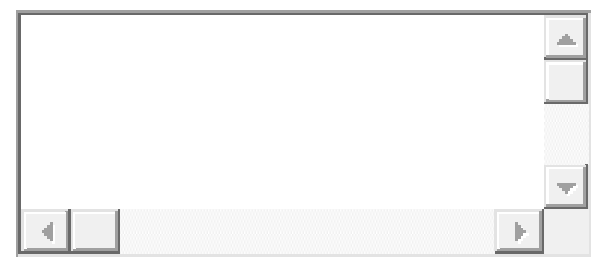

C11. Do you believe that your studies will prepare you to work in an International setting?
Y Yes
No

\section{Your Demographic Characteristics}

D1. What is your gender?
(C) Male
Female

D2. What is the year of your birth? (eg 1980) 
D3. What is your marital status?

D4. What is the current occupation of your Father? (please refer to the Guide to Occupations for a brief description of the job categories).

Please Select

Other (please specify)

D4.b What is the current occupation of your Mother? (please refer to the Guide to Occupations for a brief description of the job categories).

Please Select

Other (please specify)

\section{Guide to Occupations}

Managers/Administrators- include specialist and production managers, farmers, shopkeepers, restaurant managers, branch managers, nursing directors.

Professional- include chemists, architects, doctors, dentists, teachers and lecturers, chemists, social workers, accountants, actors, psychologists, librarians.

Associate professional- include medical and scientific technical officers, engineering and building technicians, pilots, deck officers, nurses, police officers, inspectors, ambulance and prison officers.

Trades- include fitters and toolmakers, metal trades, electrical and electronic trades, carpenters, bricklayers, painters, printers, mechanics, panel beaters, cooks, bakers, cabinet makers, hairdressers. 
Clerical- include clerks, typists, accounting clerks, library and filing clerks, teachers' aides, receptionists, production, recording and despatch clerks.

Sales and Services- include insurance brokers, real estate agents, sales assistants, tellers, travel agents, bar staff and waiters, dental nurses, childcare workers, personal service workers.

Plant and machine operators and drivers- include power generation, engine and boiler room, petroleum and gas plant, crane, kiln operators, all machine operators, bus/truck drivers.

Labourers and related workers- include trade assistants, packers, agricultural labourers, nursery and garden workers, cleaners, concrete workers, porters, guards and security officers, housekeepers, fishers.

D5. What is your Nationality?

Chinese

Indian

D6. What is your highest completed qualification? (NOT current degree enrolled in) Please Select

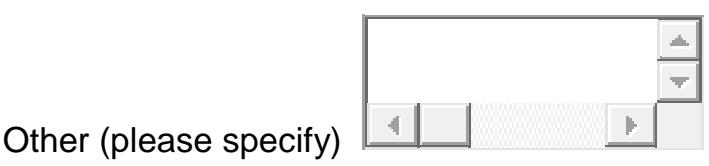

Other (please specify)

\begin{tabular}{|l} 
D6.b What is the field of your \\
\hline Please Select
\end{tabular}


Other (please specify)

D7 In which country did you obtain this qualification? (please specify)

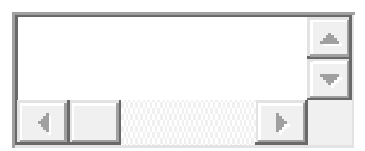

D8. What is the name of the course you are currently enrolled in? (please specify)

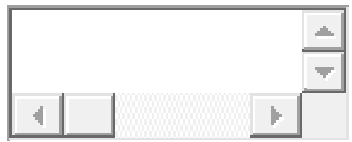

D8.b Did the Migration Occupations in Demand List (MODL) influence your decision on which course to enrol in?
Y Yes
No

D9. At what level are you in your current studies?

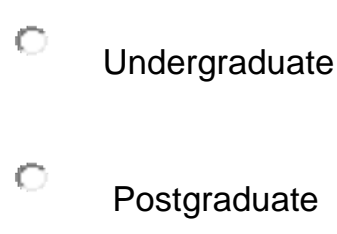

D10. How long (duration) is your current course?

Please Select

D11. Which year did you first arrive in Australia?

Please Select 
D11.b Did you start your current course in the same year you arrived in Australia?

Yes (If answer is Yes, please go to D12 and skip D11.c.)

No (If answer is No, please proceed to D11.c.)

D11.c If you did not study in your current course when you first arrived in Australia, what did you do? (If you studied, please specify the course you enrolled in)

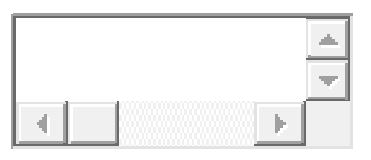

D12. Are you part of a programme that links your home institution to the University of South Australia?

\begin{tabular}{l|l} 
Yes \\
No (If no, skip D12.b and GO TO to D13.)
\end{tabular}

D12.b What is the name of this programme called? (please specify)

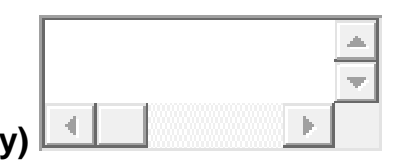

D13. Are there any additional comments you would like to make?

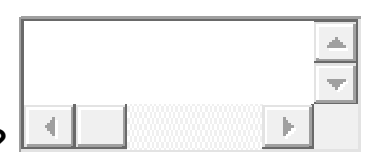

D14. End of Survey. Thank you. 
Would you like to participate in a Focus Group Discussion about living and studying in Australia with other International Students?
C Yes
No

If you ticked Yes, please leave your name, email details or phone number for us to get in touch with you.

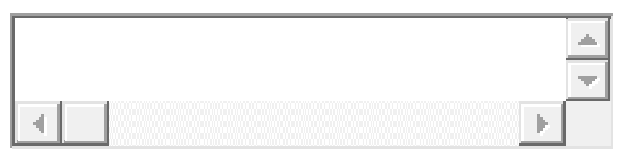

Submit Reset

Appendix 5: Sample letter sent to senior University staff requesting for permission to survey students 
Appendices

Dear

I hope you are well. I am writing to you with regards to an undergoing PhD project by one of my students, George Tan. George is working on the study of Indian and Chinese student migration to Australia, particularly to Adelaide. His research examines on what are the motivations and future intentions of these two groups of international students who are currently the main drivers of the international student market on both a global and local scale. He has been working closely with Education Adelaide in designing the study.

This research aims to have all three South Australian Universities and possibly a Victorian University (at this stage of planning) involved. The Human Research Ethics Committee has also given clearance for this project to embark on its fieldwork stage. We have developed a methodology which puts absolutely minimal demand on the university's international office which fully protects the confidentiality of the participants in this study.

We are hoping to survey the Chinese and Indian international students enrolled in university which is why we are writing to you for assistance in this matter. The findings of this study have the potential to be extremely useful not only to international students and universities, but also to the government on both state and federal levels. I would like to stress on how all ethical codes will be strictly adhered to in this project and that all policies pertaining to the privacy of international students will be respected.

We will make the full results of the total survey available to you and if there are some particular questions that you would like to be asked we could include them. I would greatly appreciate it if you could give this project some consideration and I look forward to hearing from you soon.

Best Regards,

Graeme Hugo

Federation Fellow

University of Adelaide 


\section{Appendix 6: Sample email with participant information sheet sent to Chinese and Indian students}

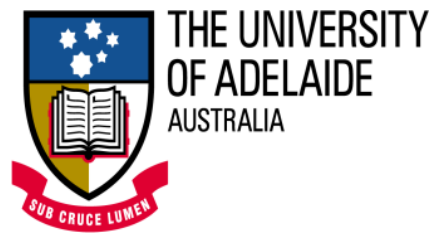

Dear Student,

I am delighted to invite you to take part in a research project on international migration. This research is being undertaken as part of my Federation Fellowship and involves students from both the University of South Australia and the University of Adelaide. Mr George Tan will be assisting me as a part of his $\mathrm{PhD}$ in Geography at the University of Adelaide.

In order to participate in this research you will need to complete the online survey which can be found at:

http://www.aisr.com.au/InternationalStudents.asp

The online survey will take 30 minutes or less to complete and mostly requires a tick or a few words. The survey asks questions relating to:

- The movement of Chinese and Indian students coming to Australia to study (Adelaide in particular).

- The factors that play a role in the decision making process of Chinese and Indian students of selecting a place and institution to study and live in.

Further information about this study and contact details for the researchers can be found by following the Participant Information link on the online survey site.

Please kindly complete the survey by $\mathbf{1}^{\text {st }}$ of May 2007.

The study is completely confidential and responses will not be able to be traced to any individual student.

Thank you for taking time to participate in this important research, your assistance is greatly appreciated and the data gained will contribute to the body of knowledge available to inform future policy and service provision arrangements for International Students like yourself.

I thank you in anticipation of your response.

Yours sincerely,

Professor Graeme Hugo

Federation Fellow

University of Adelaide 


\section{Sample of Participant Information Sheet:}

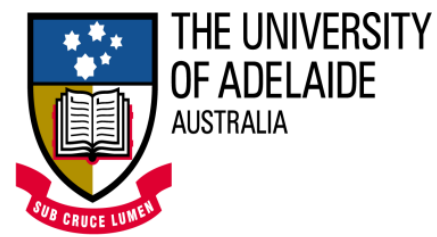

Participant Information Sheet

\section{International Student Movement to Adelaide, South Australia}

My name is George Tan. I am undertaking research as part of my $\mathrm{PhD}$ in Geography at The University of Adelaide. My study is looking at the movement of International Students who come to Australia to study and particularly to Adelaide. I am hoping to survey around 500 students in The University of Adelaide to find out what motivates a student to pursue an education overseas as well as to determine what their future intentions are upon the completion of their study.

The reason for this study is due to the fact that Australia has seen a massive growth in International Students for the last decade and especially in the last 5 years. Likewise, South Australia has also seen an increase in figures as well. Furthermore, being a former International Student myself which initially sparked my interest in this topic, I hope that the results of this study will help in understanding what are the motivations behind the rising numbers of international students in Adelaide as well as find out what their plans are after graduation.

This questionnaire would take less than 30 minutes to complete which mostly requires either a tick or a few words. The study is completely confidential; therefore, whatever is reported in the study will not identify you in anyway. All responses will not be able to be traced to any individual student and all steps will be taken to protect your privacy.

By completing this survey, you would not only have helped me in completing my University Degree, but you would also have contributed to the body of knowledge that the University uses to make decisions to help International Students like you and myself in the future. Please complete the online by the $\mathbf{1}^{\text {st }}$ of May 2007.

Please do not hesitate to contact me if you wish to obtain more information about the study. If you have concerns that you do not wish to discuss with me directly, please contact my supervisor, Professor Graeme Hugo at the Department of Geography and Environmental Studies, or Patricia Anderson, Manager of the International Student Centre.

Thanks for your time and I anticipate your reply.

Once again many thanks.

Yours Sincerely,

George Tan

\section{Contact Details}

\begin{tabular}{|l|l|l|}
\hline George Tan & Professor Graeme Hugo & Patricia Anderson \\
PhD Candidate & PhD Supervisor & Manager of International Student \\
Dept of Geography and & Dept of Geography and & Centre \\
Environmental Studies, & Environmental Studies, & University of Adelaide \\
University of Adelaide & University of Adelaide & Ph 8303 4828 \\
Ph: 83618974 & Ph: 8303 3996 or 8303 3900 & E-mail: \\
ghim.tan@adelaide.edu.au & graeme.hugo@adelaide.edu.au & patricia.anderson@ adelaide.edu.au \\
\hline
\end{tabular}




\section{Appendix 7: Student feedback and the responses to feedback}

\section{SAMPLE A:}

Dear Sir or Madam,

$\mathrm{Hi}$, I am just wondering could you please be kind enough to tell me what is the purpose of this study and in what way would the results of this study be used? Why would you focus only on Chinese and Indian students?

My intention is that, if the result of this survey could be used in anyway way that maybe unfavourable for current or prospective Chinese or Indian students, then I would definitely deny to participate.

I have been honest in answering your questions, please be honest to me as well. I request you to get back to me on this matter. My email and phone number are provided below. Thank you very much for your understanding.

Yours faithfully,

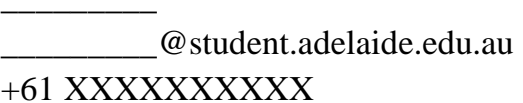

\section{SAMPLE B:}

What is the purpose of the survey? Who will be able to access the result of the survey? Why do you specifically target Chinese and Indian students?

Based on the nature of the questions asked, I cannot infer who would be more interested in the survey than DIMIA, so I need to know, will the results of the survey be surrendered to Australian authorities like the DIMIA or immigrations office? Will the results be used in any way that might be harmful to any current or prospective Chinese or Indian students? And I reserve the right to refuse to participate in the survey if the survey might cause harm to any Chinese or Indian students.

I was expecting a reply from you fairly soon after I complete the survey, but for some reason I did not get any replies till date. You should find my original questions in the box near the end of the survey named "D13. Are there any additional comments you would like to make?". However, if you could Not find it, please reply this email.

Thank you very much for answering my questions. 


\section{Sample of responses to student feedback:}

Dear

Thank you for your email and your questions. Firstly, let me apologise for the delay in answering your questions. The reason why there was a delay is due to the fact that the analysis of the data is still ongoing and I have yet to come across your questions, however, Patricia has brought to my attention the questions which you have to the survey.

Hi, I am just wondering could you please be kind enough to tell me what is the purpose of this study and in what way would the results of this study be used? Why would you focus only on Chinese and Indian students?

Based on the nature of the questions asked, I cannot infer who would be more interested in the survey than DIMIA, so I need to know, will the results of the survey be surrendered to Australian authorities like the DIMIA or immigrations office? Will the results be used in any way that might be harmful to any current or prospective Chinese or Indian students?

This study is to analyse International Student Mobility in Australia which is part of my PhD degree in the Department of Geographical and Environmental Studies. Basically, the aim of this study is to understand the mobility of International Students and what are the factors that influence their decision making when going overseas to an education. The reason why I have selected Chinese and Indian students is due to the rapid increases of students from these countries not only in Australia but also in many other countries in the world. Currently, Chinese student and Indian students are among the top few countries of origin which is why it would be useful to know and understand Chinese and Indian students.

By understanding how Chinese and Indian students choose a place to study and live would help to contribute to the body of knowledge on International Students and hopefully this will help to improve policy and service provision to help International Students.

The selection of China and India are purely due to the increasing statistics of students from these two countries. I have previously done research on International Students from Singapore and Malaysia before which was also based on high enrolment figures from these students as well.

I would also like to reassure you that this project is solely for research purposes and that your privacy is protected. There is no way of tracing the surveys to any student at all and the results will not in identify any student at all.

The results of this study will be in the form of a PhD thesis which will be available in the Barr Smith Library, if you'd like, I would be happy to provide you a copy of it when it is finished. The findings of this study will not be submitted to DIMIA or any Australian authorities as they are not involved in this project at all. However, they will be able to obtain the thesis from the Barr Smith Library if they wish, just like everyone else. I expect the findings of the study to be beneficial to Chinese and Indian students as the results would contribute to understanding International Student Mobility and not at all be harmful to them.

Being a former International Student myself, I understand your concerns and I would like to thank you for completing the survey. Let me reassure you again that this study will not identify any student at all and that all steps have been taken to protect the privacy of all the students.

Thank you for your feedback. Please do not hesitate to contact me if you have any more questions.

Good Luck for the upcoming exams!

Best Regards

George Tan 


\section{Appendix 8: Second email with correct link to the CISS survey sent to students at the University of Adelaide}

Dear Student,

I hope you are well and enjoying your mid-semester break. You would have received an email last week asking you to complete a survey online. As you might have already known, we have been facing some technical difficulties with the survey which have caused some of the responses to the survey to be invalid.

If you have already done the survey, we would greatly appreciate it if you could complete the survey once again by clicking on the link below. If you have not done the survey, we would like to encourage you to do it as soon as possible.

This is the link to the survey: http://www.aisr.com.au/InternationalStudents.asp

We would like to remind you that this study is completely confidential and all responses will not be able to be traced to any individual student and all steps will be taken to protect your privacy.

We apologise for the inconvenience and thank you for your time in completing this survey.

I thank you in anticipation of your response.

Yours Sincerely,

Professor Graeme Hugo

Federation Fellow 
Appendix 9: Question guides used in interviews

Question guide for key informants:

What is your role and how are you involved with regards to international students?

Can you describe the process of prospective students enquiring about studying in Australia up to them entering Australia as International Students?

Can you describe these students? What can you tell me about these students?

What are the factors considered when students decide on overseas study?

Which subjects or courses receives the most interest from these students and why?

What are their views and perception of Australia and Adelaide as study destinations?

What do you think of the kinds of perceptions students have on other Australian States?

...what about other countries?

...how has 9/11 impacted the international student scene?

How do Chinese and Indian student compare Adelaide with other Australian States?

How much do you know about the lifestyle Chinese and Indian students have in Australia while studying? 
....are there any differences between these two groups of students?

Are you aware of the kinds of plans the students have after their studies?

...how about future migration to another destination?

Is getting PR an objective formed before or after studying in Australia?

What do you think is the extent of permanency associated with having PR?

Participant information:

Occupation:

Company/University:

Additional Comments: 
Question guide for students:

What do you think of Australia as a place to study before coming here?

What are your views of Australia compared to other countries as a study destination?

Do you have friends from China/India who go overseas to study?

Why do you go overseas and not remain in China/India for your studies?

... what were the main factors?

Did you consider another country to study?

... which ones and why?

Do your parents influence your study plans?

What is important to you when choosing a country to study in?

What sources of information did you use and how important were they?

What are your preferred Australian States for your studies?

... why did you consider those places? 
What made you decide to study in Adelaide?

...were the 5 bonus points a factor?

Do you intend to apply for PR when you finish your studies?

Was this something you decided before coming here or after?

What are your plans after finishing your studies?

... do you plan to work interstate?

... any plans to go to a $3^{\text {rd }}$ country?

...any plans to return to your home country?

Do you work while studying?

...what are your reasons for working?

After having lived here for awhile, are your expectations met?

What do you think Adelaide can do to improve life for international students?

Participant information:

Age:

Sex:

Nationality:

Course enrolled in: 
Appendices

University:

Additional comments: 


\section{Appendix 10: Sample email and information sheet sent to key informants}

Dear

I hope you are well. My name is George Tan and I am a PhD candidate at the University of Adelaide. The reason why I am writing to you is with regards to having a possible interview as part of my research.

My PhD examines the mobility of International Students coming to Australia and in particular students who are from China and India. My study will examine how education can be used as an instrument towards permanent immigration. In addition, through anecdotal evidence, I have come to understand that Adelaide also functions as a gateway for some of these students who study in Adelaide for a period of time. The extent of Adelaide as a "gateway" is relatively unknown and I hope to be able to establish this possibility. Attached is an information sheet, which gives further explanation about my study.

Please be assured that all interviews are confidential and that in no way will you be identified in the study. I would really appreciate it if you would be able to take some time out of your busy schedule to grant me an interview. The interview will last about 30 minutes to an hour. I will be in contact with you in the near future to discuss further details should you be interested to help me in my research.

Best Regards

George Tan 


\section{Information sheet sent to key informants:}

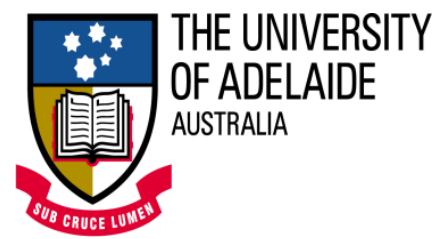

Participant Information Sheet

\section{International Student Movement to Adelaide, South Australia}

My name is George Tan. I am undertaking research as part of my $\mathrm{PhD}$ in Geography at The University of Adelaide. My study is looking at the movement of International Students who come to Australia to study and particularly to Adelaide in order to find out what motivates a student to pursue an education overseas as well as to determine what their future intentions are upon the completion of their study.

The reason for this study is due to the fact that Australia has seen a massive growth in International Students for the last decade and especially in the last 5 years. Likewise, South Australia has also seen an increase in figures as well. I hope that the results of this study will help in understanding what are the motivations behind the rising numbers of international students in Adelaide as well as find out what their plans are after graduation.

The key informants whom I have identified in this study are those linked closely to International Students such as migration agents, education agents, academics, marketing and international student staff members of universities. The knowledge and anecdotal information gained from these interviews will prove to be extremely valuable to this study.

By agreeing to this interview, you would not only have helped me in completing my University Degree, but you would also have contributed to the body of knowledge that the University uses to make decisions to help International Students in the future.

If you have concerns that you do not wish to discuss with me directly, please contact my supervisor, Professor Graeme Hugo at the Department of Geography and Environmental Studies.

Thanks for your time and I anticipate your reply.

Once again many thanks.

Your Sincerely,

George Tan

Contact Details

George Tan
PhD Candidate
Dept of Geography and Environmental
Studies, University of Adelaide
Ph: 83035806
Mob: 0405348115
E-mail: ghim.tan@adelaide.edu.au

Professor Graeme Hugo

$\mathrm{PhD}$ Supervisor

Dept of Geography and Environmental Studies, University of Adelaide

$\mathrm{Ph}: 83033996$ or 83033900

E-mail: graeme.hugo@adelaide.edu.au 


\section{Appendix 11: Sample email sent to student interviewees for their participation in focus groups/interviews}

Dear

I hope this email finds you well and that you are enjoying your semester break.

As you might recall, in March-May of this year you participated in a survey of International Students at http://www.aisr.com.au/InternationalStudents.asp. In that study, you indicated that you would be interested in participating in a focus group discussion about studying in Australia with other International Students. As such, I would like to invite you to participate in a focus group discussion which will be held at UniSA. There will be focus groups held from the 29th of September to the 3rd of October 2008, however, you will only need to attend 1 focus group on any of these days.

These focus group discussions will consist of 6-8 international students and will last approximately one hour. These sessions will be similar to the survey and also focus on your study experience in Adelaide. In addition, refreshments will be provided and, you will be reimbursed for your time as well.

I would like to assure you that your involvement in any of these focus group discussions will be completely confidential and that you will not be identified in any way in the study. I have attached a participant information sheet with further information about the study for your reference.

If you are interested in participating in a focus group discussion, please reply to this email.

Thank you for your time and consideration, and I look forward to hearing from you soon.

Yours Sincerely

George Tan 
Appendix 12: Select information on interviewees; Chinese and Indian students; education agents; migration agents and university staff

\begin{tabular}{|cccccccc|}
\hline Name & Nationality & Sex & Participant Role & Location of interview & Institution/Company & Course enrolled \\
\hline Annie & Chinese & $\mathrm{F}$ & International Student & Adelaide, Australia & University of Adelaide & Master of Accounting and Finance \\
\hline John & Chinese & $\mathrm{M}$ & International Student & Adelaide, Australia & University of Adelaide & Bachelor of Media \\
\hline Carol & Chinese & $\mathrm{F}$ & International Student & Adelaide, Australia & University of Adelaide & Master of Commerce-Accounting \\
\hline Xing & Chinese & $\mathrm{M}$ & International Student & Adelaide, Australia & University of Adelaide & Bachelor of Engineering \\
\hline Jenny & Chinese & $\mathrm{F}$ & International Student & Adelaide, Australia & University of Adelaide & Master of Accounting and Finance \\
\hline Wendy & Chinese & $\mathrm{F}$ & International Student & Adelaide, Australia & University of Adelaide & Master of Commerce-Accounting \\
\hline Yang & Chinese & $\mathrm{M}$ & International Student & Adelaide, Australia & University of Adelaide & Bachelor of Commerce- Marketing \\
\hline Linda & Chinese & $\mathrm{F}$ & International Student & Adelaide, Australia & University of Adelaide & Master of Commerce- Accounting \\
\hline Shu & Chinese & $\mathrm{F}$ & International Student & Adelaide, Australia & University of Adelaide & Bachelor of Media \\
\hline Dong & Chinese & $\mathrm{F}$ & International Student & Adelaide, Australia & University of Adelaide & Master of Commerce-Accounting \\
\hline Ravipraba & Indian & $\mathrm{F}$ & International Student & Adelaide, Australia & UniSA & Master of Business Administration \\
\hline Ranjiv & Indian & $\mathrm{M}$ & International Student & Adelaide, Australia & UniSA & Master of Occupational Therapy \\
\hline Dawal & Indian & $\mathrm{M}$ & International Student & Adelaide, Australia & UniSA & Master of Telecommunication \\
\hline
\end{tabular}

${ }^{49}$ Pseudonyms were given to all interviewees to maintain confidentiality. 


\begin{tabular}{|c|c|c|c|c|c|c|}
\hline Kunal & Indian & M & International Student & Adelaide, Australia & UniSA & Master of Business Administration \\
\hline Anuj & Indian & M & International Student & Adelaide, Australia & UniSA & Bachelor of Commerce-Accounting \\
\hline Abhay & Indian & M & International Student & Adelaide, Australia & UniSA & Master of Accounting \\
\hline Frank & - & $\mathrm{M}$ & Education Agent & Singapore & Private Education Agency & - \\
\hline Daniel & - & $\mathrm{M}$ & Education Agent & Singapore & Private Education Agency & - \\
\hline Stephen & - & $\mathrm{M}$ & Education Agent & Singapore & IDP & - \\
\hline Jonathan & - & M & Education Agent & Singapore & Private Education Agency & - \\
\hline Shaun & - & $\mathrm{M}$ & Migration Agent & Adelaide, Australia & Private Migration Agency & - \\
\hline Joseph & - & $\mathrm{M}$ & Migration Agent & Adelaide, Australia & Private Migration Agency & - \\
\hline Gavin & - & $\mathrm{M}$ & Migration Agent & Adelaide, Australia & Private Migration Agency & - \\
\hline Ewan & - & $\mathrm{M}$ & University Marketing Staff & Adelaide, Australia & Flinders University & - \\
\hline Simon & - & $\mathrm{M}$ & University Marketing Staff & Adelaide, Australia & Flinders University & - \\
\hline Peter & - & M & University Marketing Staff & Adelaide, Australia & UniSA & - \\
\hline Natalie & - & $\mathrm{F}$ & University Marketing Staff & Adelaide, Australia & UniSA & - \\
\hline Jeremy & - & $\mathrm{M}$ & University Marketing Staff & Adelaide, Australia & UniSA & - \\
\hline Nick & - & $\mathrm{M}$ & University Marketing Staff & Adelaide, Australia & UniSA & - \\
\hline Mary & - & $\mathrm{F}$ & University Marketing Staff & Adelaide, Australia & University of Adelaide & - \\
\hline Rose & - & $\mathrm{F}$ & University Marketing Staff & Adelaide, Australia & University of Adelaide & - \\
\hline
\end{tabular}




\section{References}

891 ABC Adelaide. 2009, Rann Gives Reassurance on Racial Fears, Retrieved 22 October 2009 from www.abc.net.au/news/stories/2009/06/12/2596234.htm?site=adelaide.

ABC. 2010, Police Knew About Racist Indian Attacks, Jan 20, Retrieved 22 May 2010, from www.abc.net.au/news/stories/2010/01/20/2797173.htm.

Adler, P. S. \& Kwon, S.-W. 2002, 'Social Capital: Prospects for a New Concept', The Academy of Management Review, 27(1): 17-40.

Agarwal, P. 2006, Higher Education in India: The Need for Change, Indian Council for Research on International Economic Relations, Working Paper no. 180.

Agarwal, V. \& Winkler, D. 1985, 'Foreign Demand for United States Higher Education: A Study of Developing Countries in the Eastern Hemisphere', Economic Development and Cultural Change, 33(3): 623-644.

Alberts, H. \& Hazen, H. 2005, ' 'There Are Always Two Voices'... International Students' Intentions to Stay in the United States or Return to Their Home Countries', International Migration, 43(3): 131-153.

Alberts, H. \& Hazen, H. 2006, 'Visitors or Immigrants? International Students in the United States', Population, Space and Place, 12: 201-216.

Altbach, P. 1991, 'Impact and Adjustment: Foreign Students in Comparative Perspective'. Higher Education, 21: 305-323.

Altbach, P. 1997, 'Let the Buyer Pay: International Trends in Funding for Higher Education', International Higher Education, November(9).

Altbach, P. 1998, Comparative Higher Education: Knowledge, the University and Development, Comparative Education Research Centre, The University of Hong Kong.

Altbach, P. 2004, 'Higher Education Crosses Borders', Change, March-April.

Altbach, P. \& Jayaram, N. 2009, 'India: Effort to Join 21st Century Higher Education', International Higher Education, 54 (Winter).

American Council on Education. 2006, Students on the Move: The Future of International Students in the United States, American Council on Education. 
Amin, M. \& Mattoo, A. 2005, Does Temporary Migration Have to Be Permanent?, Policy, Research working paper no. WPS 3582, World Bank.

Amin, S. 1974, Accumulation on a World Scale: A Critique of the Theory of Underdevelopment, 2 Vols. Monthly Review Press, New York.

Ammassari, S. \& Black, R. 2001, Harnessing the Potential of Migration and Return to Promote Development, IOM Migration Research Series, Geneva, Switzerland, International Organization for Migration, vol 5.

Anbasaran, E. 1998, India's Loss, West's Gain, Retrieved 18 June 2006 from http://www.unesco.org/courier/1998_09/uk/dossier/txt33.htm.

Andersson, F. \& Konrad, K. 2001, Globalization and Human Capital Formation, CEPR Discussion Papers.

Andressen, C. 1990, Can I Afford It? The Sot of Education and the Choice of Australia as a Study Destination: The Case of Private Malaysian Students, Policy Organisation and Society, Summer.

Andressen, C. 1991, West Malaysian Students Overseas: A Study with Special Reference to Australia. Adelaide, $\mathrm{PhD}$ Thesis, Flinders University of South Australia.

Andressen, C. 1993, 'Educational Refugees: Malaysian Students in Australia', Monash Papers on Southeast Asia, Victoria, Centre of Southeast Asian Studies, Monash University.

Andressen, C. 2001, The Educational Mobility of Korean Overseas Students. Occasional Papers, Centre of East Asian Studies, Monash Univeristy.

Anonymus. 2004, International Student Mobility, Sussex Centre for Migration Research, University of Sussex and the Centre for Applied Population Research, University of Dundee.

Arango, J. 2004. 'Theories of International Migration' in Joly, D. (ed,), International Migration in the New Millenium, Ashgate Publishing Limited: 15-35.

Argel, I. n.d, Changes to General Skilled Migration from 1 September, 2007, Retrieved 10 July 2009 from http://www.iargel.com.au/Portals/Iargel/articles/Microsoft\%20Word\%20\%20Changes\%20to\%20GSM\%2001.09.07.pdf.

Arunachalam, S. 2008, India: Students Drawn to Study Overseas, Retrieved 29 August 2009 , from http://www.universityworldnews.com/article.php?story=20080613092000955. 
Asian Pacific Post. 2005, Foreigners Flock to Canada, Retrieved 19 November 2006 from http://www.asianpacificpost.com/portal2/40288182079edd010107c38d551102ab.d o.html.

Australian Broadcasting Corporation. 2005, The Degree Factories, Four Corners.

Australian Bureau of Statistics. 1995, Australian Social Trends- Education-Participation in Education: Overseas Students in Higher Education, Retrieved 11 April 2003, from www.abs.gov.au.

Australian Bureau of Statistics. 2004, Migration, Australia, Retrieved 18 Nov 2009 from http://ausstats.abs.gov.au/austats/subscriber.nsf/0/179567A9B64A5DB0CA256E84 00017CE2/\$File/34120_2002-03.pdf.

Australian Bureau of Statistics. 2005, Migration, Australia, Retrieved 18 Nov 2009 from http://ausstats.abs.gov.au/austats/subscriber.nsf/0/179567A9B64A5DB0CA256E84 00017CE2/\$File/34120_2003-04.pdf.

Australian Bureau of Statistics. 2006, Migration, Australia, Retrieved 18 Nov 2009 from http://ausstats.abs.gov.au/austats/subscriber.nsf/0/179567A9B64A5DB0CA256E84 00017CE2/\$File/34120_2004-05.pdf.

Australian Bureau of Statistics. 2007a, Migration, Australia, Retrieved 18 Nov 2009 from http://ausstats.abs.gov.au/austats/subscriber.nsf/0/179567A9B64A5DB0CA256E84 00017CE2/\$File/34120_2005-06.pdf.

Australian Bureau of Statistics. 2007b, 'Quickstats by Location', 2006 Census, Retrieved 18 August 2008 from

http://www.censusdata.abs.gov.au/ABSNavigation/prenav/PopularAreas?\&collecti on=Census\&period=2006\&\&navmapdisplayed $=$ true $\&$ javascript=true $\&$ textversion $=$ false.

Australian Bureau of Statistics. 2008a, Migration, Australia, Retrieved 19 Nov 2009 from http://ausstats.abs.gov.au/austats/subscriber.nsf/0/179567A9B64A5DB0CA256E84 00017CE2/\$File/34120_2006-07.pdf

Australian Bureau of Statistics. 2008b, Perspectives on Migrants 2007, Retrieved 26 Feb 2008, from

http://www.abs.gov.au/ausstats/abs@.nsf/Previousproducts/3416.0Main\%20Featur es42007? opendocument \&tabname $=$ Summary \&prodno $=3416.0 \&$ issue $=2007 \&$ num $=\&$ view $=$.

Australian Bureau of Statistics. 2009, Migration, Australia, Retrieved 19 Nov 2009 from http://ausstats.abs.gov.au/austats/subscriber.nsf/0/179567A9B64A5DB0CA256E84 00017CE2/\$File/34120_2007-08.pdf. 
Australian Bureau of Statistics. 2010a, Intertstate Departures from South Australia, Retrieved 17 Nov 2010 from http://www.abs.gov.au/AUSSTATS/abs@.nsf/Lookup/1345.4Feature\%20Article1 May\%202010.

Australian Bureau of Statistics. 2010b, Migration, Australia, Retrieved 17 Nov 2010 http://ausstats.abs.gov.au/austats/subscriber.nsf/0/179567A9B64A5DB0CA256E84 00017CE2/\$File/34120_2008-09.pdf.

Australian Education International. 2000, Overseas Student Statistics 2000, AEI, Canberra.

Australian Education International. 2002, Comparative Costs of Higher Education Courses for International Students in Australia, New Zealand, the United Kingdom, Canada and the United States, AEI and IDP Education Australia.

Australian Education International. 2005a, 'International Students in Higher Education Comparison of Major English Speaking Destinations for the Top Five Source Markets', Research Snapshot, October 2005, Retrieved 3 July 2006 from http://aei.gov.au/AEI/CmsTemplates/DocumentTemplates/Document.aspx?NRMO $\mathrm{DE}=$ Published\&NRNODEGUID $=\{$ 4D99ED1E-B551-4FFD-90AF8FA4B88633F3 \} \&NRORIGINALURL=\%2FAEI\%2FPublications AndResearch\% 2FSnapshots\%2F03SS05_pdf.pdf\&NRCACHEHINT=ModifyGuest.

Australian Education International. 2005b, Why Choose Australia? Insights from a Survey of International Students Who Commenced Study in 2000, AEI, Canberra.

Australian Education International. 2008a, 'Annual International Student Statistics- 2007 Detailed Annual Pivot Table', Market Information Package AEI, Retrieved 16 July 2008 from www.aei.gov.au/AEI/MIP/Statistics/StudentEnrolmentAndVisaStatistics/2007/Def ault.

Australian Education International. 2008b, AEI International Student Data 2007, Retrieved 15 March 2009 from

http://aei.gov.au/AEI/MIP/Statistics/StudentEnrolmentAndVisaStatistics/2007/Tim e_Series_pdf.pdf.

Australian Education International. 2008c, 'International Higher Education Students by Level of Course', Research Snapshot, Retrieved 16 May 2008 from http://www.aei.gov.au/AEI/PublicationsAndResearch/Snapshots/38SS08_pdf.pdf.

Australian Education International. 2008d, International Student Data for 2008, 2009, Retrieved 22 April 2010 from http://www.aei.gov.au/AEI/MIP/Statistics/StudentEnrolmentAndVisaStatistics/200 $\underline{\text { 8/Default.htm. }}$ 
Australian Education International. 2009a, 'Annual International Student Statistics- 2008 Detailed Annual Pivot Table', Market Information Package AEI, Retrieved 22 Dec 2009 from

www.aei.gov.au/AEI/MIP/Statistics/StudentEnrolmentAndVisaStatistics/2008/Def ault.

Australian Education International. 2009b, 'Export Income to Australia from Education Services from 2008-2009', Research Snapshot, Retrieved 13 January 2010 from http://aei.gov.au/AEI/PublicationsAndResearch/Snapshots/20091110_pdf.pdf.

Australian Education International. 2009c, 'Export Income to Australia from Education Services in 2008', Research Snapshot, Retrieved 15 Dec 2009 from http://aei.gov.au/AEI/PublicationsAndResearch/Snapshots/50SS09_pdf.pdf.

Australian Education International. 2009d, 'International Student Numbers 2008', Research Snapshot, Retrieved 25 June 2009 from http://www.aei.gov.au/AEI/PublicationsAndResearch/Snapshots/44SS09_pdf.pdf.

Australian International Education Foundation. 1997, 1997 Survey of International Students Studying in Australia, Australian Government Publising Services, Canberra.

Avveduto, S. \& Brandi, M. 2002, International Mobility: Students Vaganates, Consortium of Higher Education Researchers, Vienna, Austria.

Baas, M. 2006, 'Students of Migration: Indian Overseas Students and the Question of Permanent Residency', People and Place,14(1).

Baas, M. 2007a, 'The Language of Migration: The Education Industry Versus the Migration Industry', People and Place ,15(2): 49-60.

Baas, M. 2007b. Learning How to Work in the Grey Zone: The Case of Indian Overseas Students in Melbourne, Australia, paper presented to connference International migration, multi-local livelihoods and human security: Perspectives from Europe, Asia and Africa, The Netherlands, Institute of Social Studies \& Chucbu University 30-31 August.

Baas, M. 2010, Imagined Mobility: Migration and Transnationalism among Indian Students in Australia, London, Anthem Press.

Baker, J. \& Finn. M. 2003, Stay Rates of Foreign National Doctoral Students in U.S. Economics Programs, Retrieved 17 August 2005 from http://ssrn.com/abstract=398640.

Baker, M., Creedy, J. \& Johnson, D. 1996a, Financing and Effects of Internationalisation in Higher Education: An Australian Country Study, Australian Government Publising Services, Canberra. 
Baker, M., Robertson, F., Taylor, A. \& Doube, L. 1996b, The Labour Market Effects of Overseas Students, Bureau of Immigration Multicultural and Population Research, Canberra.

Balaz, V. \& Williams, A. 2004, ' 'Been There, Done That': International Student Migration and Human Capital Transfers from the UK to Slovakia', Population, Space and Place, 10: 217-237.

Balaz, V. \& Williams, A. 2005, 'What Human Capital, Which Migrants? Return Skilled Migration to Slovakia from the UK', International Migration Review, 39(2): 439468.

Balaz, V., Williams, A. \& Kollar, D. 2004a, 'Temporary Versus Permanent Youth Brain Drain: Economic Implication', International Migration, 42(4): 4-34.

Balaz, V., Williams, A. \& Wallace, C. 2004b,' International Labour Mobility and Uneven Regional Development in Europe: Human Capital, Knowledge and Entrepreneurship', European Urban and Regional Studies, 11(1): 27-46.

Ballard, B. \& Clancy, J. 1984, Study Abroad: A Manual for Asian Students, Longman, Kuala Lumpur.

Ballard, B. \& Clancy, J. 1988, Studying in Australia, Longman, Melbourne.

Ballard, B. \& Clancy, J. 1997, Teaching International Students: A Brief Guide for Lecturers and Supervisors, Deakin, A.C.T.

Banks, M., Olsen, A. \& Pearce, D. 2007, Global Student Mobility: An Australian Perspective 5 Years On, IDP, Sydney.

Bardak, U. 2005, Migration Trends in Meda and a Discussion on the Links between Migration and Educational Systems, European Training Foundation, Retrieved 4 March 2006 from http://www.etf.europa.eu/pubmgmt.nsf/\%28getAttachment\%29/3AC74F8271814A $\underline{71 \mathrm{C} 125704 \mathrm{C} 00645 \mathrm{~A} 0 \mathrm{C} / \$ F \text { File/Med_migration_05_EN.pdf. }}$

Basch, L., Glick-Schiller, N. \& Blanc, C. 1994, Nations Unbound: Transnational Projects, Postcolonial Predicaments, and Deterritorialized Nation-States, Gordon and Breach Science Publishers, Langhorne, PA.

Batalova, J. 2007, 'The 'Brain Gain' Race Begins with Foreign Students', Migration Information Source, Retrieved 3 January 2007 from http://www.migrationinformation.org/Feature/display.cfm?ID=571.

Bayley, S., Fearnside, R., Arnol, J., Misiano, J. \& Rottura, R. 2002. International Students in Victorian Universities, People and Place, 10(2): 45-54. 
Beal, T. \& Sos, F. 2001, Asian Nationalism in the Diaspora: The Case of Taiwanese Astronauts, Asian Nationalism in an Age of Globalisation, Starrs, R. (ed)., Japan Library, Curzon Press, Surrey: 124-143.

Bell, M. 2000, Interstate Migration: The South Australian Experience 1991-1996. Adelaide, Geodemographic Research Group, South Australia, Department for Transport, Urban Planning and the Arts and Adelaide University.

Bhandari, N. 2006, Indians Yearn for Points to Migrate. Daily News \& Analysis, Retrieved 25 March 2007 from http://www.dnaindia.com/dnaPrint.asp?NewsID=1035576\&CatID=9/report.asp?Ne $\underline{\text { wsID }=1035576}$.

Bhat, C. \& Sahoo, A. 2003,' Diaspora to Transnational Networks: The Case of Indians in Canada', Fractured Identity: The Indian Diaspora in Canada, (eds) Varma, S. \& Seshan, R., New Delhi, Rawat Publication: 141-167.

Biao, X. 2001, 'Structuration of Indian Information Technology Professionals' Migration to Australia: An Ethnographic Study’, International Migration, 39(5): 73-90.

Biao, X. 2002, Ethnic Transnational Middle Classes in Formation- a Case Study of Indian Information Techonology Professionals, The 52nd Annual Conference of Political Studies Association- Making Politics Count, University of Aberdeen, Scotland, 5-7 April.

Biao, X. 2003,' Emigration from China: A Sending Country Perspective', International Migration, 41(3): 21-48.

Biao, X. 2004, 'Indian Information Technology Professionals' World System: The Nation and the Transnation in Individuals' Migration Strategies', State/Nation/Transnation: Perspectives on Transnationalism in the Asia-Pacific, Yeoh, B. \& Willis, K. (eds)., Routledge, London,.

Biao, X. 2005, Promoting Knowledge Exchange through Diaspora Networks: The Case of People's Republic of China, ESRC Centre on Migration, Policy and Society (Compass), University of Oxford, Oxford.

Birrell, B. 2001,'Immigration on the Rise: The 2001-2002 Immigration Program', People and Place, 9(2): 21-28.

Birrell, B. 2005, Immigration Rules and the Overseas Student Market in Australia, Centre for Population and Urban Research, Retrieved 22 Feb 2006 from http://www.idp.com/research/researchpublications/disp_researchform.asp?ID=33.

Birrell, B. 2006, 'Implications of Low English Standards among Overseas Students at Australian Universities', People and Place, 14(4): 53-64. 
Birrell, B., Hawthorne, L. \& Richardson, S. 2006, Evaluation of the General Skilled Migration Categories, DIMA, Retrieved 8 Feb 2007 from http://www.immi.gov.au/media/publications/research/gsm-report/index.htm.

Birrell, B. \& Healy, E. 2010, 'The February 2010 Reforms and the International Student Industry', People and Place, 18(1): 65-80.

Birrell, B. \& Perry, B. 2009, 'Immigration Policy Change and the International Student Industry', People and Place, 17(2): 64-80.

Birrell, B. \& Rapson, V. 2005, 'Migration and the Accounting Profession in Australia', Centre for Population and Urban Research, Monash University, Melbourne.

Birrell, B., Rapson, V. \& F., S. 2005, Immigration in a Time of Domestic Skill Shortages: Skilled Movement in 2003-2004, Centre for Population and Urban Research, Monash University, Melbourne.

Blaikie, N. 1991, 'A Critique of the Use of Triangulation in Social Research', Quality and Quantity, 25(2): 115-136.

Blight, D. \& Archer, W. 2005, A New Vision of International Student Recruitment, AIEC, Gold Coast, Australia.

Bochner, S. \& Wicks, P. (eds). 1972, Overseas Students in Australia, University of New South Wales Press, Sydney.

Bodycott, P. 2009, 'Choosing a Higher Education Study Abroad Destination', Journal of Research in International Education, 8(3): 349-373.

Bohm, A., Davis, D., Meares, D. \& Pearce, D. 2002, Global Student Mobility 2025, IDP Education Australia, Sydney, Australia,

Bollag, B. 2004, 'Wanted: Foreign Students', Chronicle of Higher Education Chronicle of Higher Education J1 - Chronicle of Higher Education, 51(7): A37A38.

Borjas, G. 2002, 'Rethinking Foreign Students', National Review, June 17: 38-41.

Bourdieu, P. 1986, 'The Forms of Capital', Handbook of Theory and Research for the Sociology of Education, Richardson, J. (ed)., Greenwood Press: 241-258, New York.

Bourdieu, P. \& Wacquant, L. 1992, An Invitation to Reflexive Sociology, University of Chicago Press, Chicago. 
Boyd, M. 1989, 'Family and Personal Networks in International Migration: Recent Developments and New Agendas', International Migration Review, 23(3): 638670 .

Boyle, P., Halfacree, K. \& Robinson, V. 1998, Exploring Contemporary Migration, Addison Wesley Longman, New York.

Braham, K., Woodlands, J. \& Makaev, L. 2007, Students in Transition: Making the Move to Studying and Living in Adelaide, The University of Adelaide \& Adelaide City Council, Adelaide, South Australia: 1-47.

Brettell, B., Caroline. 2000, 'Theorizing Migration in Anthropology', Migration Theory, Brettell, B. (ed)., Routledge, London: 97-135.

Brown, D. \& Martin, B. 2005, Measuring Temporary Mobility: Dimensions and Issues, paper presented to International Union for the Scientific Study of Population-25th Conference, Tours, France: 18-23 July.

Browne, R. \& Dale, E. (eds). 1989, Overseas Students: Educational Opportunity and Challenge, The Australian College of Education, Australian Capital Territory.

Brumfiel, G. 2003a, 'Researchers Rage at Tightened Restrictions on Us Immigration', Nature, 422(6931): 457-458.

Brumfiel, G. 2003b, 'US Loses Allure in Foreign Student's Eyes', Nature, 6 Nov, 426: 5.

Burke, B. 1989, 'The New Face of Australia's Overseas Student Program in the 1990s', ANZAAS News, (32).

Business and Industry Development. 2010, ACT International Student Ambassador Program, Retrieved 18 December 2010, from http://www.business.act.gov.au/doing_business_in_canberra/business_initiatives/ac t_international_student_ambassador_program.

Butcher, A. \& McGrath, T. 2004, 'International Students in New Zealand: Needs and Responses', International Education Journal, 5(4): 540-551.

Bystydzienski, J. M. \& Resnik, E. P. (Eds). 1994, Women in Cross-Cultural Transitions, Phi Delta Kappa Educational Foundation, Bloomington, Indiana.

Cameron, J. 2002, International Students in Victorian Universities, Government Printer for the State of Victoria, Victoria, Australia.

Campbell, D. \& Fiske, D. 1959, 'Convergent and Discriminant Validation by the Multitrait-Multimethod Matrix', Psychological Bulletin, 56(2): 81-105. 
Canadian Bureau for International Education. n.d., International Expectations for Higher Education, Retrieved 10 January 2010 from http://www.cbie.ca/data/media/policy/20050501_RaeSubmission_e.pdf.

Cao, C. 2005, China's Brain Drain and Brain Gain: Why First-Rate Overseas Chinese Academics Still Hesitate to Return or Be Deeply Involved in China's Education and Scientific Enterprises, paper presented to People on the Move: The Transnational Flow of Chinese Human Capital Conference, Hong Kong University of Science and Technology, Hong Kong, 20-22 Oct.

Cao, C. 2008, 'China's Brain Drain at the Higher End. Why Governmnt Policies Have Failed to Atract First-Rate Academics to Return', Asian Population Studies, 4(3): 331-345.

Carrington, W. \& Detragiache, E. 1999, 'How Extensive Is the Brain Drain?', Finance \& Development, 36 (2).

Castells, M. 1989, The Informational City: Information Technology, Economic Restructuring, and the Urban-Regional Process, Basil Blackwell, Oxford.

Castells, M. 1996, 'The Net and the Self', Critique of Anthropology, 16: 9-38.

Castles, S. 2000, Ethnicity and Globalization: From Migrant Worker to Transnational Citize, Sage, London.

Castles, S. \& Miller, M. 1993, The Age of Migration: International Population Movements in the Modern World, Macmillan, Basingstoke, England.

Castles, S. \& Miller, M. 2003, The Age of Migration, Palgrave Macmillan, New York.

Castles, S. \& Miller, M. 2009, The Age of Migration- International Population Movements in the Modern World, Palgrave Macmillan, New York.

Castles, S., Miller, M. 1998, The Age of Migration, Guilford Press, New York.

Central Advisory Board of Education. 2005, Report of the Cabe Committee on Financing Higher and Technical Education, Government of India.

Cervantes, M. \& Guellec, D. 2002, The Brain Drain: Old Myths, New Realities, Retrieved 19 March 2006 from http://www.oecdobserver.org/news/fullstory.php/aid/673/The brain_drain:_Old_m yths, new realities.html.

Chadee, D. Naidoo, V. 2009, 'Higher Educational Services Exports: Sources of Growth of Asian Students in US and US', Service Business, 3(2): 173-187. 
Chalamwong, Y. 2004, The Migration of Highly Skilled Asian Workers in OECD Member Countries and Its Effects on Economic Development in East Asia, paper presented to Expert's Seminar, OECD Headquarters, 15 May.

Chanda, R. 2005a, 'The Competition for Global Talent', The Financial Express, Feb 8, Retrived 18 June 2006 from http://www.financialexpress.com/old/columnists/full_column.php?content_id=8195 $\underline{9}$

Chanda, R. 2005b, India's Experience with Skilled Migration, paper presented to Conference on Competing for Global Talent, Singapore, 13-14 Jan.

Chang, P. \& Deng, Z. 1992, 'The Chinese Brain Drain and Policy Options', Studies in Comparative International Development, 27(1): 44-60.

Chaudhry, H. 2004, Trade in Higher Education, paper presented to Asia Pacific Economic: Multilateral \& Bilateral Relationships Conference, City University of Hong Kong, 19-21 May.

China Daily. 2006, Students Again Make Beeline to US Colleges, 5 April, Retrieved 19 August from http://www1.china.org.cn/english/China/164529.htm.

Chiswick, P., \& Miller, B. 2006, ' Immigration to Australia During the 1990s: Institutional and Labour Market Influences', Public Policy and Immigrant Settlement, CobbClark, A. \& Khoo, S-E. (eds)., Edward Elgar: 3-24.

Clark, G. 2005,' Secondary Data', Methods in Human Geography, Flowerdew, R. \& Martin, D. (eds)., Essex, Pearson Education Ltd: 57-74.

Commander, S., Kangasniemi, M., Winters, A. 2003, The Brain Drain: Curse or Boon, IZA Discussion Paper Series no. 809, Institute for the Study of Labor.

Crush, J., Pendleton, W. \& Tevera, D. 2005, 'Degrees of Uncertainty: Students and the Brain Drain in Southern Africa', South African Migration Project. Crush, J. (ed)., Migration Policy Series no. 35, Retrieved 19 June 2009 from http://www.queensu.ca/samp/sampresources/samppublications/policyseries/policy3 5.htm.

D' Costa, B. 2010. 'Curry Bashing? A Racist Australian Underbelly and the Education Industry', South Asia Masala, Retrieved 9 May 2010, from http://asiapacific.anu.edu.au/blogs/southasiamasala/2010/02/06/feature-articlecurry-bashing-a-racist-australian-underbelly-and-the-education-industry/.

Dade, C. 2004,'Transnationalism Foreign Assistance, Domestic Communities: New Opportunities and New Challenges for Canada and the United States', Focal Point: Canadian Foundation for the Americas, Special Edition March 2004:1-3, Retrieved 19 July 2007 from http://www.focal.ca/pdf/focalpoint_se_march2004.pdf. 
Das, M. 1972, Brain Drain Controversy and International Students, Lucknow, Lucknow Publishing House.

Davie, S. 2004, 'Students Flocking to US Universities Again' The Straits Times, 24 September, Retrieved 18 May 2007 from http://singapore.usembasy.gov/092404.html.

de Ridder-Symoens, H. 1992, 'Mobility', A History of the University in Europe, de Ridder-Symoens, H. (ed). Cambridge, Cambridge University Press, 1: 280-304.

Debelle, G. \& Vickery, J. 1999, 'Labour Market Adjustment: Evidence on Interstate Labour Mobility', The Australian Economic Review, 32(3): 249-263.

Demuth, A. 2000, 'Some Conceptual Thoughts on Migration Research', Theoretical and Methodological Issues in Migration Research: Interdisciplinary, Intergenerational and International Perspectives, Agozino, B. (ed)., Ashgath Publishers, Aldershot: 21-57.

Denzin, N. 1989, The Research Act: A Theoretical Introduction to Sociological Methods, Prentice Hall Inc, New Jersey.

Denzin, N. 2009, The Research Act: A Theoretical Introduction to Sociological Methods, Transaction Publisher New Jersey.

Denzin, N. \& Lincoln, Y. 2000, 'The Discipline and Practice of of Qualitative Research', Handbook of Qualitative Research, Denzin, N. \& Lincoln, Y. (eds)., Sage Publications Inc, Thousand Oaks, California.

Denzin, N. \& Lincoln, Y. 2005 'Introduction: The Discipline and Practice of Qualitative Research', The Sage Handbook of Qualitative Research, Denzin, N. \& Lincoln. Y (eds)., Sage Publications Inc, Thousand Oaks, California.

Department of Education Science \& Training. 2002a, Students 2001: Selected Higher Education Statistics, Australian Government Publishing Service, Canberra.

Department of Education Science \& Training. 2002b, Students 2002: Selected Higher Education Statistics, Australian Government Publishing Service, Canberra.

Department of Education Science \& Training. 2003, Students 2003: Selected Higher Education Statistics, Retrieved 22 June 2006 from www.dest.gov.au/sectors/higher_education/publications_resources/profiles/students _2003_selected_higher_education_statistics.htm\#versionAvailable.

Department of Education Science \& Training. 2005, Students 2004: Selected Higher Education Statistics, Retrieved 22 June 2006 from 
www.dest.gov.au/sectors/higher_education/publications_resources/profiles/students _2004_selected_higher_education_statistics.htm\#versionAvailable.

Department of Education Science \& Training. 2006, Students 2005: Selected Higher Education Statistics, Retrieved 29 Dec 2007 from

www.dest.gov.au/sectors/higher_education/publications_resources/profiles/students _2005_selected_higher_education_statistics.htm\#authors.

Department of Education Science \& Training. 2007, Students 2006: Selected Higher Education Statistics, Retrieved 22 Oct 2007 from

www.dest.gov.au/sectors/higher_education/publications_resources/profiles/statistic s/documents/08_overseas_students_2006.xls.htm.

Department of Education Science \& Training. 2008, Students 2007: Selected Higher Education Statistics, Retrieved 2March 2009 from

www.dest.gov.au/sectors/higher_education/publications_resources/profiles/students _2007_full_year_htm .

Department of Employment, Education and Training. 1992, International Students Policy Handbook, Australian Government Publishing Service, Canberra.

Department of Foreign Affairs and Trade. 2005, 'Education without Borders: International Trade in Education', 7 September, Retrieved 27 July 2007 from http://www.dfat.gov.au/publications/eau_education/index.html.

Department of Foreign Affairs and Trade. 2009, Trade at a Glance 2009, Department of Foreign and Trade, Commonwealth of Australia.

Department of Immigration and Citizenship. 2008, Population Flows: Immigration Aspects, Department of Immigration and Citizenship, Commonwealth of Australia.

Department of Immigration and Citizenship. 2009, Population Flows: Immigration Aspects, Department of Immigration and Citizenship, Commonwealth of Australia.

Department of Immigration and Citizenship. n.d-a, Skilled - Graduate (Temporary) Visa (Subclass 485), Retrieved 22 March 2008 from http://www.immi.gov.au/skilled/general-skilled-migration/485/.

Department of Immigration and Citizenship. n.d-b, Skilled Independent (Residence) Visa (Subclass) 885, Retrieved 15 October 2010 from http://www.immi.gov.au/skilled/general-skilled-migration/regional-growth.htm.

Department of Immigration and Citizenship. n.d-c, Visas, Immigration and Refugees: Professionals and Other Skilled Migrants, Retrieved 18 October 2010 from http://www.immi.gov.au/skilled/general-skilled-migration/485/. 
Department of Immigration and Mulitcultural Affairs. 2007, Population Flows: Immigration Aspects, Department of Immigration and Mulitcultural Affairs, Commonwealth of Australia.

Department of Immigration and Multicultural and Indigenous Affairs. 2004, Population Flows: Immigration Aspects, Department of Immigration and Mulitcultural and Indigineous Affairs, Commonwealth of Australia.

Department of Immigration and Multicultural and Indigenous Affairs. 2005, Population Flows: Immigration Aspects, Department of Immigration and Mulitcultural and Indgineous Affairs, Commonwealth of Australia.

Department of Immigration and Multicultural and Indigenous Affairs. 2006, Population Flows: Immigration Aspects, Department of Immigration and Mulitcultural and Indgineous Affairs, Commonwealth of Australia.

Desai, M., Kapur, D. \& McHale, J. 2001, The Fiscal Impact of the Brain Drain to the U.S, paper presented to the Third Annual National Bureau of Economic Research (NBER) and the National Council of Applied Economic Research (NCAER), Conference, India, 17-18 Dec.

DeVoretz, D. \& Ma, J. 2002, 'Triangular Human Capital Flows between Sending, Entrepot and the Rest of the World Regions', Canadian Studies in Population, 29(1): 53-69.

Dillman, D. 2000, Mail and Internet Surveys: The Tailored Design Method, New York, Wiley.

Dillon, S. 2004, 'U.S. Slips in Attracting the World's Best Students', The New York Times. New York.

Dolfsma, W. \& Dannreuther, C. 2003, 'Subjects and Boundaries: Contesting Social Capital--Based Policies', Journal of Economic Issues, 37(2): 405(409).

Dumont, J. \& Spielrogel, G. 2008, 'Return Migration: A New Perspective', International Migration Outlook: Sopemi 2008, OECD Publishing: 162-207.

Dunn, K. 2005, ‘ 'Doing' Qualitative Research in Human Geography', Qualitative Research Methods in Human Geography, Hay, I. (ed)., Oxford University Press, South Melbourne, Victoria: 79-105.

Institute of International Education. 2009, 'Source of Funds', Open Doors 2009, Retrieved 8 February 2010 from www.opendoors.iienetwork.org/? $\mathrm{p}=150813$.

Eriksen, T. H. 2007, Globalization : The Key Concepts, Berg, Oxford, UK. 
Evans, C. 2010, Changes to Australia's Skilled Migration Program, Department of Immigration and Citizenship, Retrieved 18 June 2010 from http://www.minister.immi.gov.au/media/speeches/2010/ce100208.htm.

Faist, T. 1997, 'The Crucial Meso-Level', International Migration, Immobility and Development. Multidisciplinary Perspectives, Hammar, Berg, Oxford: 187-217.

Faist, T. 2000, 'Transnationalization in International Migration: Implications for the Study of Citizenship and Culture', Ethnic and Racial Studies, 23(2): 189-222.

Faist, T. 2004, 'Towards a Political Sociology of Transnationalization. The State of the Art in the Migration Research', Archives Europeennes De Sociologie 42(3): 331-368.

Favell, A., Feldblum, M. \& Smith, M. 2005, 'The Human Face of Global Mobility: A Research Agenda', The Human Face of Global Mobility: International Highly Skilled Migration in Europe, North America and the Asia-Pacfic, Flavell, A. \& Smith, M. (eds)., Transaction Press, New Brunswick.

Fawcett, J. \& Arnold, F. 1987, 'The Role of Surveys in the Study of International Migration: An Appraisal', International Migration Review, 21(4): 1523-1540.

Fielding, N. \& Fielding, J. 1986, Linking Data: Qualitative Research Methods, Sage Publications, Beverly Hills.

Findlay, A. 1994, 'The Economic Impact of Immigration to the United Kingdom', Strangers and Citizens, Spencer, S. (ed)., Rivers Oram, London: 114-138.

Findlay, A. 2001, From Brain Exchange to Brain Gain: Policy Implications for the Uk of Recent Trends in Skilled Migration from Developing Countries, International Labour Office: 1-48.

Finn, M. 2003, Stay Rates of Foreign Doctorate Recipients from U.S. Universities, 2001, Retrieved 16 July 2005, from www.orau.gov/orise/pubs/stayrate03.pdf.

Flick, U. 1998, An Introduction to Qualitative Research, Sage, Thousand Oaks, California.

Foley, M. \& Edwards, B. 1999, 'Is It Time to Disinvest in Social Capital', Journal of Public Policy, 19(2): 141-173.

Forbes-Mewett, F., Marginson, S., Nyland, C., Ramia, G. \& Sawir, E. 2007, 'Australian University International Student Finances', Department of Managment Working Paper Series, Working Paper 23/07, Centre for the Study of Higher Education, University of Melbourne, Monash University.

Frank, A. 1969, Capitalism and Undevelopment in Latin America, Monthly Review Press, New York. 
Gaillard, J. \& Gaillard, A. 1997, 'The International Mobility of Brainds; Exodus or Circulation?', Science Technology \& Society, 2(2): 195-228.

Gao, M. \& Liu, X. a. 1998, 'From Students to Citizen: A Survey of Students from the People's Republic of China (PRC) in Australia', International Migration, 36(1): 2748.

Garnaur, J. 2006, 'Universities Being Used as Immigration Factories', Sydney Morning Herald, Sydney, March 30.

George, B. \& Shyamsundar, A. 2007, 'The Factors That Affect Indian Migrants' Decision to Stay in or Counter Migrate from the United States: A Study with Special Reference to the Role of Tourism Related Imagery as a Determinant', Journal of Identity and Migration Studies, 1(2): 99-123.

Ghosh, S. \& Wang, L. 2003, 'Transnationalism and Identity: A Tale of Two Faces and Multiple Lives', The Canadian Geographer, 47(3): 269-282.

Gillan, M., Damachis, B. \& McGuire, J. 2003, 'Australia in India- Commodification and Internationalisation of Hgher Education', Economic and Political Weekly, April 5.

Glick Schiller, N. \& Basch, L. 1995, 'From Immigrant to Transmigrant: Theorizing Transnational Migration', Anthropological Quarterly, 68(1): 48-63.

Glick Schiller, N., Basch, L. \& Szanton Blanc, C. 1994, Nations Unbound: Transnational Projects, Postcolonial Predicaments, and Deterritorialized Nation-States, Gordon and Breach Science.

Glick Schiller, N. \& Wimmer, A. 2003, 'Methodological Nationalism, the Social Sciences, and the Study of Migration: An Essay in Historical Epistemology', International Migration Review, 37(3): 576-610.

Goldring, J. 1984, Mutual Advantage: Report of the Committee of Review of Private Overseas Student Policy, Australian Government Publishing Service, Canberra.

Goss, J. \& Lindquist, B. 1995, 'Conceptualizing International Labor Migration: A Structuration Perspective', International Migration Review, 29(2): 317-351.

Government of South Australia. 2004, Prosperity through People: A Population Policy for South Australia, Adelaide, Government of South Australia.

Greene, J. 2008, 'Is Mixed Methods Social Inquiry a Distinctive Methodology', Journal of Mixed Research Methods, 2(1): 7-22.

Greenwood, M. 1975, 'Research on Internal Migration in the United States: A Survey', Journal of Economic Literature, 13(2): 397-433. 
Group of Eight. 2007, Australian Higher Education Funding Trends, Retrieved 2nd May 2008 from

http://www.go8.edu.au/storage/go8statements/2007/Go8_Backgrounder_No1_1007 .pdf.

Guerassimoff, C. 2003, 'The New Chinese Migrants in France', International Migration, 41(3): 135-154.

Guha, B. 1977, 'Brain Drain and Indicators on Brain Drain', International Migration, 15(1): 3-20.

Guo, F. \& Iredale, R. 2002, 'The View from Australia', Return Skilled and Business Migration and Social Transformation, Iredale, R., Guo, F. \& Rozario, S. (eds). Wollongong, Centre for Asia Pacific Social Transformation Studies: 21-37.

Gupta, A. 2005, International Trends in Private Higher Education and the Indian Scenario, Research \& Occasional Paper Series: CSHE.11.05, Centre for Studies in Higher Education, University of California, Berkley.

Hägerstrand, T. 1982, 'Diorama, Path and Project', Tijdschrift voor Economische en Sociale Geografie, 73: 323-339.

Hammersley, M. \& Atkinson, P. 2007, Ethnography: Principles in Practice, Taylor \& Francis, New York.

Hardill, I. 2004, 'Transnational Living and Moving Experiences: Intensified Mobility and Dual-Career Households', Population, Space and Place, 10(5): 375-389.

Harris, G. \& Jarrett, F. 1990, Educating Overseas Students in Australia: Who Benefits?, Allen \& Unwin, Sydney.

Hartcher, P. 2010, 'When Indian Students Suffer, Australia Risks Being Scarred for Life', The Sydney Morning Herald, 13 April, Sydney.

Hawthorne, L. 2005, ' 'Picking Winners': The Recent Transformation of Australia's Skill Migration Policy', International Migration Review, 39(2).

Hawthorne, L. 2007, Outcomes, Language, Employment and Further Study: A Discussion Paper for a National Symposium: English Language Competence of International Students, paper presented to 2007 National Symposium on English Language Competence of International Students, Sydney, Australia, August.

Healy, G. 2009a, 'Dollar's Rise, Attacks Hit Demand', The Australian, Oct 21, Retrieved 20 Jan 2010 from http://www.theaustralian.com.au/higher-education/dollars-riseattacks-hit-demand/story-e6frgcjx-1225789064686. 
Healy, G. 2009b, 'Violence Risks Foreign Student Market', The Australian, 3 June, Retrieved from 5 Aug 2010 from www.theaustralian.com.au/highereducation/violence-risks-foreign-student-market/story-e6frgcjx-1225720496070.

Held, D., McGrew, A., Golbatt, D. \& Perraton, J. 1999, Global Transformations : Politics, Economics and Culture, Polity, Oxford.

Herman, E. 2006, 'Migration as a Family Business: The Role of Personal Networks in the Mobility Phase of Migration', International Migration, 44(4): 191-230.

Ho, E., Bedford, R. \& Goodwin, J. (eds). 1997a, ‘Astronaut' Families: A Contemporary Migration Phenomenon', East Asian New Zealanders: Research on New Migrants. Asia-Pacific Migration Research Network Research Papers, Friesen, W., Ip, M., Ho, E., Bedford, R. \& Goodwin, J. (eds). Department of Geography, Massey University, Albany.

Ho, E., Bedford, R. \& Goodwin, J. 1997b, Linking Migrants into Their Family Contexts: Methodological Considerations, Population Studies Centre Discussion Paper no. 23. University of Waikato, Hamilton.

Hodge, A. 2010, 'Indian Students Ditching Australian Education Plans', The Australian, 29 November, Retrieved 2 Dec 2010 from http://www.theaustralian.com.au/national-affairs/indian-students-ditchingaustralian-education-plans/story-fn59niix-1225962389527.

Hollifield, J. 2007. 'The Emerging Migration State', Rethinking Migration, Portes, A. \& DeWind, J. (eds)., Berghahn Books, New York: 62-89.

Hose, A. 2010, 'Attacks on Indian Students the Product of a Racist Society', 29 Jan, Socialist Alternative, Retrieved 16 May 2010 from http://www.sa.org.au/index.php?option=com_k2\&view=item\&id=4593:attacks-onindian-students-the-product-of-a-racist-society \&Itemid=453

Huang, S. \& Yeoh, B. 2005, 'Transnational Families and Their Children's Education: China's 'Study Mothers' in Singapore', Global Networks, 5(4): 379-400.

Hugo, G. 1994, Migration and the Family, Occasional Papaers Series for the International Year of the Family, (12), United Nations, Vienna.

Hugo, G. 1999, 'A New Paradigm of International Migration in Australia', New Zealand Population Review, 23: 1-39.

Hugo, G. 2002a, Emigration of Skilled Australians Patterns, Trends \& Issues, paper presented to DIMIA Immigration and Population Issues Conference, Migration: Benefiting Australia, Australian Technology Park, Sydney.

Hugo, G. 2002b, 'A Population Policy for South Australia', People and Place, 10(3): 1-10. 
Hugo, G. 2003, Circular Migration: Keeping Development Rolling?, Retrieved 29th May 2005 from http://migrationinformation.org/feature/print.cfm?ID=129.

Hugo, G. 2004, 'Temporary Migration: A New Paradigm of International Migration', Research Note, (55).

Hugo, G. 2005, Chinese Academic Migration to Australia, paper presented to People on the Move: The Transnational Flow of Chinese Human Capital Conference, Hong Kong University of Science and Technology, Oct 20-22.

Hugo, G. 2006, 'Immigration Responses to Global Change in Asia: A Review', Geographical Research, 44(2): 155-172.

Hugo, G. 2007, In and out of Australia: Rethinking Chinese and Indian Skilled Migration to Australia, paper presented to In and out of Asia: Migrating talent, Globlalising cities Conference, National University of Singapore, FASS Migration Research Cluster \& the Asia Research Institute, 19-21 Nov.

Hugo, G. 2008, 'A Changing Diaspora: Recent Trends in Migration between China and Australia', Chinese Southern Diaspora Studies, 2: 82-103.

Hugo, G., Harris, K., Bell, M., Spoehr, J. \& Coffee, N. 2000, Bring Them Back Home: Factors Influencing Interstate Migration to and from South Australia, report prepared for the Office of the Premier of South Australia by The National Key Centre for Social Applications of Geographical Information Systems, University of Adelaide.

Hugo, G., Rudd, D. \& Harris, K. 2003, Australia's Diaspora: Its Size, Nature and Policy Implications, CEDA Information Paper no. 80, Committee for Economic Development Australia, Melbourne.

Humfrey, C. 1999, Managing International Students, Open University Press, Philadelphia, USA.

IDP. 2003, International Education Worth $\$ 4.2$ Billion to Australian Economy, Retrieved 22 May 2003 from http://www.idp.com/aboutidp/mediacentre/march2003/article980.asp

IDP. 2005, International Students in Australian Universities: Semester 2, 2004, Retrieved 28 July 2005 from http://www.idp.com/research/fastfacts/Semester\%20Two\%202004\%20\%20Key\%20Outcomes_Web.pdf.

IDP. 2008, Our \$13.7 Billion Education Export Can Beat Global Recession- IDP Chief. Retrieved 18 November 2009 from http://www.idp.com/about_idp/media/2008/october/our_educataion_exports.aspx. 
IDP. 2009, Global Network, Retrieved 18 December 2009 from

http://www.idp.com/about_idp/contact_idp/global_network.aspx.

IDP. 2010, IDP Today, Retrieved 18 November 2010 from http://www.idp.com/idptoday/about-idp.aspx.

Institute of International Education. 2008a, Atlas of International Student Mobility-United States, Retrieved 7 January 2010 from http://www.atlas.iienetwork.org/?p=48048.

Institute of International Education. 2008b, Atlas of Student Mobility- United Kingdom, Retrieved 7 January 2010 from http://www.atlas.iienetwork.org/?p=48047.

International Organisation for Migration. 2000, World Migration Report 2000, International Organisation for Migration \& United Nations.

Ip, M. 2004, PRC Migrants and Returnees: New Trends in Globalisation, paper presented to 5th Conference of the International Society for the Study of Chinese Overseas, Nordic Institute of Asian Studies, University of Copenhagen.

Iredale, R. 1999. 'The Need to Improve Skilled Personnel: Factors Favouring and Hindering Its International Mobility', International Migration, 37(1): 89-123.

Iredale, R. 2001, 'The Migration of Professionals: Theories and Typologies', International Migration, 39(5): 7-26.

ISCAH. n.d., New Points Test, Retrieved 19 March 2009 from http://www.iscah.com/index_files/Page849.htm.

Islam, W. \& Borland, H. 2006, South Asian Students' Adaptation Experiences in an Australian Postgraduate Coursework Environment, paper presented to17th International Conference ISANA. Sydney, Unpublished.

Jackling, B. 2007, 'The Lure of Permanent Residency and the Aspirations and Expectations of International Students Studying Accounting in Australia', People and Place, 15(3): 31-41.

Jakubowicz, A. \& Monani, D. 2010, International Student Futures in Australia: A Human Rights Perspective on Moving Foward to Real Action, Occasional Paper 6/2010, The Academy of Social Sciences in Australia, Canberra.

Jick, D. 1979, 'Mixing Qualitative and Quantitative Methods: Triangulation in Action', Administrative Science Quarterly, 24(4): 602-611.

Johnson, B. \& Turner, L. 2003, 'Data Collection Strategies in Mixed Methods Research', Handbook of Mixed Methods in Social Behavioral Research, Tashakkori. A \& Teddlie, C. (eds)., Sage Publications Inc, Thousand Oaks, California: 297-320. 
Johnson, J. \& Regets, M. 1998, International Mobility of Scientists and Engineers to the United States-Brain Drain or Brain Circulation?, National Science Foundation, Arlington, VA.

Jolley, A. 1997, Exporting Education to Asia, Victoria University Press for the Centre for Strategic Economic Studies, Melbourne.

Jones, N. 2003, 'A Money Spinner', The Hindu Business Line, 28 July 2003, Chennai, Katsuri and Sons, Retrieved 12 March 2009 from http://www.campusabroadlk.com/web/Media.htm

Jones, P. 1986, Australia's International Research in Education, Council for Educational Research, Hawthorn, Australian.

Kaufman, H. \& Goodman , A. 2002, Institute of International Education Annual Report, Institute of International Education, Washington DC.

Kaul, S. 2006, Higher Education in India: Seizing the Opportunity, ICRIER Working Paper no. 179, Indian Council for Research on International Economic Relations.

Kearns, R. 2005, 'Knowing Seeing? Undertaking Observational Research', Qualitative Research Methods in Human Geography, Hay, I. (ed)., Oxford University Press, South Melbourne, Victoria: 192-206.

Kell, P. \& Vogl, G. 2006, International Students: Negotiating Life and Study in Australian through Australian Englishes, paper presented to Everyday Multiculturalism Conference, Macquarie University, Centre for Research on Social Inclusion, 28-29 Sept.

Kemper, E., Stringfield, S. \& Teddlie, C. 2003, 'Mixed Methods Sampling Strategies in Social Science Research', Handbook of Mixed Methods in Social and Behavioral Research, Tashakkori, A. \& Teddlie, C. (eds)., Sage Publications Inc, Thousand Oaks, California: 279-296.

Kendall, T. 2004, 'Exporting Australian Educational Services to China', Journal of Higher Education Policy and Management, 26(1): 23-33.

Khadria, B. 1999, The Migration of Knowledge Workers: Second-Generation Effects of India's Brain Drain, Sage Publications, New Delhi.

Khadria, B. 2001, 'Shifting Paradigms of Globalization: The Twenty-First Century Transition Towards Generics in Skilled Migration from India', International Migration 2 39: 45-71.

Khadria, B. 2002, Skilled Labour Migration from Developing Countries: Study on India, International Labour Office, Geneva. 
Khawaja, N. \& Dempsey, J. 2007, 'Psychological Distress in International University Students: An Australian Study', Australian Jounral of Guidance and Counselling, 17(1): 13-27.

Khoo, S.-E. \& Mak, A. 2003, 'Career and Family Factors in Intention for Permanent Settlement in Australia', Chinese Migrants Abroad: Cultural Educational and Social Dimensions of the Chinese Diaspora. Charney, M., Yeoh, B. \& Tong, C.-K., Singapore University Press \& World Scientific Publishing, Singapore.

Khoo, S.-E., Mcdonald, P. \& Hugo, G. 2005, Temporary Skilled Migrants in Australia: Employment Circumstances and Migration Outcomes, Department of Immigration and Multicultural and Indigeneous Affairs.

Khoo, S.-E. \& Voigt-Graf, C. 2004, 'Indian Student Migration to Australia', Asian and Pacific Migration Journal, 13(4): 426-443.

King, R. 2002, 'Towards a New Map of European Migration', International Journal of Population Geography, 8: 89-106.

King, R. \& Ruiz-Gelices, E. 2003, 'International Student Migration and the European 'Year Abroad': Effects on European Identity and Subsequent Migration Behaviour', International Journal of Population Geography, 9: 229-252.

King, S. 2001, 'The Funding of Higher Education in Australia: Overview and Alternatives', Australian Economic Review, 34(2): 190-194.

Kinnell, M. (ed). 1990, The Learning Experiences of Overseas Students, SRHE \& Open University Press, Bristol, PA, USA.

Kivisto, P. 2001, 'Theorizing Transnational Immigration: A Critical Review of Current Efforts', Ethnic and Racial Studies, 24(4): 549-577.

Kleinschmidt, H. 2006, Migration and the Making of Transnational Social Spaces, paper presented to The Mobility, Culture and Communication Symposium, Australian Centre, University of Melbourne, 11 June.

Koser, K. \& Salt, J. 1997, 'The Geography of Highly Skilled International Migration', International Journal of Population Geography, 3: 285-303.

Kosinski, L. \& Mansell Prothero, R. 1975, People on the Move : Studies on Internal Migration, Methuen, London.

Krause, K., Hartley, R., James, R. \& McInnis, C. 2005, The First Year Experience in Australian Universities: Findings from a Decade of National Studies, Department of Education, Science and Training, Centre for the Study of Higher Education, University of Melbourne, Commonwealth of Australia, Canberra. 
Kritz, M. 1987, 'International Migration Policies: Conceptual Problems', International Migration Review, 21(4): 947-964.

Kritz, M., Lim, L. \& Zlotnik, H. (eds). 1992, International Migration Systems. A Global Approach, Clarendon Press, Oxford.

Kuptsch, C. 2003, Foreign Students in Europe: Between Red Carpet and Red Card, paper presented to IILS/ILO workshop: Temporary migration- Assessment and practical proposlas for overcoming protection gaps, Geneva, 18-19 Sept.

Kuptsch, C. 2005, Students and Talent Flow- the Case of Europe: From Castle to Harbour?, paper presented to Conference on Competing for Global Talent, Singapore, January 13-14.

Kwiek, M. 2001, 'Globalization And Higher Education', Higher Education in Europe, 23(1): 27-38.

Lake, R. 2010, 'Making Space', Journal of Planning History, 9(4): 277-285.

Lawrence, R. 2004, Brand Test: Quantitative Results, Education Adelaide, Adelaide.

Lawrence, R. 2009, International Student Perceptions Today, paper presnted to Australian International Education Conference, Sydney, Australia, 14 Oct.

Levitt, P. 2004, Transnational Migrants: When 'Home' Means More Than One Country, Retrieved 20 July 2005 from http://www.migrationinformation.org/Feature/orint.cfm?ID=261.

Levitt, P., Dewind, J. \& Vertovec, S. 2003, 'International Perspectives on Transnational Migraton: An Introduction', International Migration Review, 37(3): 565-575.

Lewis, P. 1992a, The Demand for Education in Singapore, paper presented to 21st Conference of Economists, Working paper no. 74, University of Melbourne, July.

Lewis, P. 1992b. Singapore Students in Australia- What's a Degree Worth?, Working paper no. 84, Economics Programme and Asia Research Centre, Murdoch University, Nov.

Ley, D. \& Kobayashi, A. 2005, 'Back to Hong Kong; Return Migration or Transnational Sojourn?’, Global Networks, 5(2): 111-127.

Li, F., Findlay, A., Jowett, A. \& Skeldon, R. 1996, 'Migrating to Learn and Learning to Migrate: A Study of the Experiences and Intentions of International Student Migrants', International Journal of Population Geography, 2: 51-67. 
Li, F., Jowett, A., Findlay, A. \& Skeldon, R. 1995, 'Discourse on Migration and Ethnic Identity: Interviews with Professionals in Hong Kong', Transactions of the Institute of British Geographers, 20(3): 342-356.

Li, M. \& Bray, M. 2005, Social Class and Cross-Border Higher Education: Mainland Chinese Students in Hong Kong and Macau, paper presented to People on the Move: The Transnational Flow of Chinese Human Capital, Hong Kong University of Science and Technology, Oct 20-22.

Lien, D. W., Yan. 2005, 'Brain Drain or Brain Gain: A Revisit', Journal of Population Economics 18: 153-163.

Lin, C.-P. 1994, 'China's Students Abroad: Rates of Return', American Enterprise, (5).

Lin, N. 1999, 'Building a Network Theory of Social Capital', Connections, 22(1): 28-51.

Liu-Farrer, G. 2009, 'Educationally Channeled International Labor Mobility: Comtemporary Student Migration from China to Japan', International Migration Review,43(1): 178-204.

Liu, X.-F. \& Norcliffe, G. 1996, 'Closed Windows, Open Doors: Georpolitics and Post 1949 Mainland Chinese Immigration to Canada', The Canadian Geographer, 40(4): 306-319.

Lowell, L. 2003, Skilled Migration Abroad or Human Capital Flight?, Retrieved 20 September 2005 from http://migrationinformation.org/Feature/print.cfm?ID=135.

Luce, E. 2007, 'Strict Visa Policies 'Damage US Reputation and Business' ', Financial Times, 31 Jan, Retrieved 4 February, 2007, from http://www.ft.com/cms/s/0/b23352c8-b0d0-11db-8a62-0000779e2340.html.

Ma, X. \& Abbott, M. 2006, Chinese Students and the Higher Education Market in Australia and New Zealand, Occasional Paper no. 7, Centre for Research in International Education. Auckland, New Zealand,

Mabogunje, A. L. 1970, 'Systems Approach to a Theory of Rural-Urban Migration', Geographical Analysis, 2(1): 1-18.

Macnamara, L. 2006, 'Unis Seen as Entry Factories', The Australian, 30 March.

Mahmood, T. \& Schomann, K. 2003, Assessing the Migration Decison of Indian ItGraduates: An Empirical Analysis, Discussion Paper SP II 2003-23, Wissenschaftszentrum Berlin.

Mahroum, S. 2000, 'Highly Skilled Globetrotters: Mapping the International Migration of Human Capital', $R$ \& D Management, 30(1): 23-31. 
Man, G. C.-f. 2005, Transnational Migration, Gender and Work: Exploring the Experience of Chinese Immigrant Women in Canada, paper presented to People on the Move: The Transnational Flow of Chinese Human Capital, Hong Kong University of Science and Technology, Oct 20-22.

Marginson, S. 1997, Markets in Education, Allen \& Unwin, New South Wales.

Marginson, S. 2001, 'Trends in the Funding of Australian Higher Education', The Australian Economic Review, 34(2): 205-215.

Marginson, S. 2002, 'Education in the Global Market, Lessons from Australia', Academe, May/June, Retrieved 18 July 2005 from http://www.aaup.org/publications/Academe/2002/02mj/02mjmar.htm.

Marginson, S. 2004, 'Competition and Markets in Higher Education: A 'Glonacal' Analysis', Policy Futures in Education, 2(2): 175-244.

Marginson, S. 2006, 'Dynamics of National and Global Competition in Higher Education', Higher Education, 52(1): 1-39.

Marginson, S. 2010, International Student Security: Globalisation, State, University, speech to the World Universities Forum, 9-11 Jan, Davos, Retrieved 17 Aug 2010 from

http://cshe.unimelb.edu.au/people/staff_pages/Marginson/WUF_2010_keynote_Ma rginson_paper.pdf.

Marginson, S., Nyland, C., Sawir, E. \& Forbes-Mewett, H. 2010, International Student Security, Cambridge University Press, Melbourne, Australia.

Miller, M. \& Counihan, C. 2005, Highly Skilled Migration: Forging a New Theoretical Perspective, paper presented to Conference on Competing for Global Talent, Singapore, 13-14 Jan.

Martin, S. 2000, ‘An Era of International Migration', World Migration Report 2000, International Organisation for Migration and United Nations: 3-56.

Maslen, G. 2007, China: Chinese Students to Dominate World Market, Retrieved 15 December 2007 from http://www.universityworldnews.com/article.php?story=20071101150549773.

Massey, D. 1991, ‘A Global Sense of Place', Marxism Today, June: 24-29.

Massey, D., Arango, J., Hugo, G., Koaouci, A., Pellegrino, A. \& Edward Taylor, J. 1998, Worlds in Motion: Understanding International Migration at the End of the Millennium, Oxford Unversity Press, New York. 
Massey, D., Arango, J., Hugo, G., Koaouci, A., Pellegrino, A. \& Edward Taylor, J. 2005, Worlds in Motion: Understanding International Migration at the End of the Millennium, Oxford Unversity Press, New York.

Massey, D., Arango, J., Hugo, G., Koaouci, A., Pellegrino, A. \& Taylor, E. 1993, 'Theories of International Migration: A Review and Appraisal', Population and Development Review, 19(3): 431-466.

Massey, D. \& Taylor, E. 2004, International Migration, Oxford University Press, New York.

Massey, D. 1987, 'Understanding Mexican Migration to the United States', American Journal of Sociology, 92(6): 1372-1403.

Mattes, R. \& Mniki, N. 2005, 'Restless Minds: South African Students and the Brain Drain', South African Migration Project. Crush, J. (ed)., Migration Policy Series no. 36, Retrieved 19 June 2009 from http://www.queensu.ca/samp/sampresources/samppublications/policyseries/policy3 $\underline{6 . h t m}$

Mazzarol, T., Choo, S. \& Nair, V. 2001a, Australia and the Indian Postgraduate Science and Technology Market : Examining Why Indian Students Choose to Study in Countries Other Than Australia Smith, Australian Education International, Dept. of Education, Training and Youth Affairs, Canberra.

Mazzarol, T. \& Soutar, G. 2002, ' 'Push-Pull' Factors Influencing International Student Destination Choice', International Journal of Educational Management, 16(2): 8290 .

Mazzarol, T., Soutar, G., Smart, D. \& Choo, S. 2001b, Perceptions, Information and Choice: Understanding How Chinese Students Select a Country for Overseas Study, Australian Education International. Department of Education, Training and Youth Affairs.

Mazzarol, T., Soutar, G. \& Thein, V. 2001c, 'Critical Success Factors in the Marketing of an Educational Institution: A Comparison of Institutional and Student Perspectives', Journal of Marketing For Higher Education, 10(2): 39 - 57.

McGowan, S. \& Potter, L. 2008, 'The Implications of the Chinese Learner for the Internationalization of the Curriculum: An Australian Perspective', Critical Perspective on Accounting, 19: 181-198.

McMahon, M. 1992, 'Higher Education in a World Market: An Historical Look at the Global Context of International Study', Higher Education, 24: 465-482.

McNamara, D. \& Harris, R. 1997, Overseas Students in Higher Education: Issues in Teaching and Learning, Routledge, London. 
McSwiney, C. 1995, Essential Understandings: International Students Learning Libraries, Auslib Press, Adelaide.

Mehra, B. 2003, 'Lives in Transition: Stories of Three Foreign Elementary Students from India', The Qualitative Report, 8(3): 377-407.

Meijering, L. \& van Hoven, B. 2003, 'Imagining Difference: The Experiences of 'Transnational' Indian It Professionals in Germany', Area, 35(2): 174-182.

Meyer, J.-B. 2003, Policy Implications of the Brain Drain's Changing Face, Science and Development Network, Retrieved 24 October 2005 from http://www.scidev.net/braindrain.

Migration Policy Institute. 2005, Top 10 Migration Issues of 2005 Issue \#8: Growing Competition for Skilled Workers (and Foreign Students), Retrieved December 21 2005 from http://www.migrationinformation.org/Feature/display.cfm?ID=357.

Miller, P. 1999, 'Immigration Policy and Immigrant Quality: The Australian Points System', The American Economic Review, 89(2): 192-197.

Ministry of Education of the People's Republic of China. 2004, Work Related to Students and Scholars Studying Abroad, Retrieved 26 June 2005 from http://www.moe.gov.cn/edoas/website18/en/international_2.htm.

Mooney, P., Neelakantan, S., Birchard, K., Cohen, D. \& Labi, A. 2004, 'No Longer Dreaming of America', Chronicle of Higher Education, 51(7): A41-A43.

Morguerou, P. 2006, The Brain Drain of Ph.D.S from Europe to the United Stages: What We Know and What We Would Like to Know, Working paper 2006/11, European University Institute, Retrieved 11 March 2007 from http://cadmus.iue.it/dspace/bitstream/1814/4286/1/RSCAS\%202006.11.pdf.

Mueller, R. 2005, Restricted Immigration of Foreign Students to the United States in the Post 9/11 Period: Is the U.S. Loss a Gain for Canada, Prairie Centre of Excellence for Research on Immigration and Integration, Working paper 07-05.

National Association of Student Advisers. 2006, What Is Still Wrong with U.S Visa Policy: The Case of the Indian Scientist, Press statement, Retrieved 18 May 2007 from http://www.nafsa.org/press_releases.sec/press_releases.pg/visa_policy_2.

National Association of Student Advisers. 2006, Restoring U.S. Competitiveness- for International Students and Scholars, Retrieved 27 November 2006 from http://www.nafsa.org/uploadedFiles/NAFSA_Home/Resource_Library_Assets/Publ ic_Policy/restoring u.s.pdf? $\mathrm{n}=8823$. 
National Liaison Committee. 2009, Inquiry into the Welfare of International Students, Submission to: The Senate Standing Committee on Education, Employment and Workplace Relations, August, Retrieved 25 Jan 2010, https://senate.aph.gov.au/submissions/comittees/viewdocument.aspx?id=4f7eb929e7f8-4c70-8634-19de1a35d159.

Nesdale, D., Simkin, K., Sand, D. \& Burke, B. 1995, International Students and Immigration, Australian Government Publishing Service, Canberra.

Neuman, L. 2006, Social Research Methods: Quantitative and Qualitative Approaches, Pearson Education Inc, Boston.

O' Neill, D. \& Cullingford, C. 2005, 'Cultural Shock or Cultural Acquisition? The Experiences of Overseas Students', Globalisation, Education and Culture Shock, Cullingford, C. \& Gunn, S. (eds)., Ashgate Publishing Limited, Aldershot, England.

Organisation for Economic Co-operation and Development. 2001, 'Trends in International Migration. Continous Reporting System on Migration', Annual Report, OECD, Paris.

Organisation for Economic Co-operation and Development. 2004, Internationalisation of Higher Education, Retrieved 18 September 2005 from www.oecd.org/publications/Pol_brief.

Organisation for Economic Co-operation and Development. 2009, Education at a Glance 2009: OECD Indicators, OECD, Paris.

Oishi, N. 2007, Multiple Migration and Hyper-Transnationalism: The Conceptual Framework and Future Research Agenda, paper presented to12th International Metropolis Conference, Melbourne, Australia, Oct 9.

Ong, A. 1999, Flexible Citizenship: The Cultural Logics of Transnationality, Duke University Press, Durham.

Oppermann, M. 2000, 'Triangulation- a Methodological Discussion', International Journal of Tourism Research, 2: 141-146.

Pang, B. \& Appleton, N. 2004, 'Higher Education as an Immigration Path for Chinese Students and Scholars', The Qualitative Report, 9(3): 500-527.

Papastergiadis, N. 2000, The Turbulence of Migration, Malden, Massachusetts, Blackwell.

Parfitt, J. 2005, 'Questionnaire Design and Sampling', Methods in Human Geography, Flowerdew, R. \& Martin, D. (eds)., Pearson Education Ltd, Essex: 78-109. 
Parker, K. 2009, Engaging Emigrants: A Study of the Australian Diaspora in the United States of America, PhD Thesis, Department of Geographical and Environmental Studies. Adelaide, The University of Adelaide.

Pe-Pua, R., Mitchell, C., Castles, S. \& Iredale, R. 1998, 'Astronaunt Families and Parachute Children: Hong Kong Immigrants in Australia', In the Last Half Century of Chinese Overseas, Sinn, E. (ed)., Hong Kong University Press, Hong Kong.

Pearson, R. \& Morrell, J. 2002, Knowledge Migrants; the Motivations and Experiences of Professionals in the UK on Work Permits, NOP Business \& Institute for Employment Studies, Home Office/Department of Trade and Industry, Retrieved 29 March 2007 from http://www.homeoffice.gov.uk/rds/pdfs2/knowmigrants.pdf

People Daily. 2007, 'Ninety Pct of Chinese Students Overseas Have to Stump up for Their Education', People Daily, 6 March, Retrieved 19 Sept 2007 from http://english.peopledaily.com.cn/200703/06/eng20070306_354868.html.

Peterson, W. 1968, 'Migration: Social Aspects', International Encyclopedia of the Social Sciences, 10: 286-300.

Piore, M. 1979, Birds of Passage: Migrant Labor in Industrial Societies, Cambridge University Press, Cambridge.

Pope, J. 2008, 'Their Economy Booming, Chinese Students Head to US', International Herald Tribune, 17 Nov, Retrieved 13 March 2009 from http://www.iht.com/articles/ap/2008/11/17/america/Colleges-Foreign$\underline{\text { Students.php?page }=1}$

Portes, A. 1995, 'Economic Sociology and the Sociology of Immigration: A Conceptual Overview', The Economic Sociolocy of Immigration, Portes, A. (ed)., Russell Sage Foundation, New York: 56-87.

Portes, A. 2003, 'Conclusion: Theoretical Convergencies and Empirical Evidence in the Study of Immigrant Transnationalism', International Migration Review, 37(3): 874-892.

Portes, A. \& Borocz, J, 1989. 'Contemporary Immigration: Theoretical Perspectives on Its Determinants and Modes of Incorporation', International Migration Review, 23(3): 606-630.

Portes, A. \& Dewind, J. 2004, 'A Cross-Atlantic Dialogue: The Progress of Research and Theory in the Study of International Migration', International Migration Review, (38): 828-851.

Portes, A., Guarnizo, L. \& Landolt, P. 1999, 'The Study of Transnationalism: Pitfalls and Promise of an Emergent Research Field', Ethnic and Racial Studies, 22: 217-237. 
Portes, A. \& Rumbaut, R. 1996, Immigrant America : A Portrait, University of California Press, Berkeley.

Portes, A. \& Walton, J. 1981, Labor, Class, and the International System, Academic Press, New York.

Poston Jr, D. \& Luo, H. 2007, 'Chinese Student and Labor Migration to the United States: Trends and Policies since the 1980s', Asian and Pacific Migration Journal, 16(3): 323-355.

Pries, L. 2001, 'The Approach of Transnational Social Spaces- Responding to New Configuratons of the Social and the Spatial', New Transnational Social Spaces, Pries, L. (ed)., Routledge, London: 3-33.

Professional International Education Resources. 2009, Qualified Education Agent Counsellors, Retrieved 22 March 2010 from http://www.pieronline.org/qeac/default.aspx?page=charts.

Punch, K. 1998, Introduction to Social Research, Sage Publications Inc, Thousand Oaks, California.

Putnam, R. \& Goss, K. 2002, 'Introduction', Democracies in Flux. The Evolution of Social Capital in the Contemporary Society, Putnam, R. (ed)., Oxford University Press, New York.

Radford, M., Ongkili, D. \& Toyoizumi, M. 1984, Overseas Students in South Australia, The Flinders University International Students Association, Bedford Park, South Australia.

Rani, G. 2004, 'Economic Reforms and Financing Higher Education in India', Indian Journal of Economics and Business, 3(1): 1-30.

Rao, L. 1976, Overseas Students in Australia: Some Major Findings from a Nation-Wide Survey, Education Research Unit, Australian National University, Canberra.

Rao, L. 1979, Brain Drain and Foreign Students: A Study of the Attitudes and Intentions of Foreign Students in Australia, the USA, Canada and France, University of Queensland Press, Brisbane.

Rao, M. 1995, 'Foreign Students and Graduate Economic Education in the United States', Journal of Economic Education, 26(3): 274-281.

Ravenstein, E. 1885, 'The Laws of Migration', Journal of the Statistical Society of London, 48(2): 167-235. 
Richardson, J. (ed). 1986, Handbook of Theory and Research for the Sociology of Education, Greenwood Press, New York.

Rivero-Fuentes, E. 2006, 'Cumulative Causation among Internal and International Mexican Migrants', Crossing the Border: Research from the Mexican Migration Project, Duran, J. \& Massey, D. (eds)., Russel Sage Foundation, New York: 201234.

Robertson, S. 2009, 'Student Switchers and the Regulation of Residency: The Interface of the Individual and Australia's Immigration Regime', Population, Space and Place, 17 (1): 103-115.

Robison, L., Schmid, A. \& Siles, M. 2002, 'Is Social Capital Really Capital?', Review of Social Economy, 60(1): 1(23).

Rossman, G. \& Wilson, B. 1994, 'Numbers and words revisited: Being Shamelessly Eclectic', Quality \& Quantity, 3: 315-327

Salaff, J. \& Greve, A. 2003, The Migration Triangle: Social Capital and Migration Systems: How the Comparison of Two Peoples on the Move Reveals Broader Structures and Relations of Migration of Hong Kong and Mainland Chinese, paper presented to New Paradigms in Hong Kong Studies Conference, University of Hong Kong, Hong Kong, 12 Dec.

Salaff, J., Greve, Arent. \& Chen, Xuan. 2004, Motherhood Shifts When Chinese Families Relocate: Chinese Women's Education Work in Canada, paper presented to Workshop on the lives of Asian Mothers: Negotiating Work Challenges and Family Commitments, National University of Singapore, Centre for Advanced Studies, 29 Jan.

Salt, J. 2005, Current Trends in International Migration in Europe, Council of Europe.

Sassen, S. 1988, The Mobility of Labor and Capital: A Study in International Investment and Labor Flow, Cambridge University Press, Cambridge.

Sauve, P. 2002, 'Trade, Education \& the Gats: What's in, What's out, Whats All the Fuss About?', Higher education management and policy: Journal of the Programme on Institutional Management in Higher Education,14(3).

Saxenian, A. 2002, 'Transnational Communities and the Evolution of Global Production Networks: The Cases of Taiwan, China and India', Industry and Innovation, 9(3): $183-202$.

Schoenberger, E. 1991, 'The Coporate Interview as a Research Method in Economic Geography', The Professional Geographer, 43(2): 180-189. 
Secor, A. 2010, 'Social Surveys, Interviews and Focus Groups', Research Methods in Geography, Gomez, B. \& Jones III, JP. (eds)., Blackwell Publishing Ltd, West Sussex.

Shachar, A. 2006, 'The Race for Talent: Highly Skilled Migrants and Competitive Immigration Regimes', New York University Law Review, 81(1): 143-201.

Shanka, T. \& Musca, J. 1998, An Exploratory Study of International Students' Involvement in Domestic Tourism- a West Australian Case paper presented to Australia and New Zealand Marketing Academy Conference 1998, University of Otago, New Zealand, 29 Nov-3 Dec.

Sharda, H. 2005, Cost Cutting at What Cost? Australian University Scenario, paper presented to Australasian Association for Institutional Research Forum, Melbourne, Sept 2005.

Sharma, V. \& Kumar, M. 2004, 'Students Seek New Shores', The Tribune-Magazine Section, 20 Nov, Retrieved 10 Jan 2005 from http://www.tribuneindia.com/2004/20041120/saturday/main1.htm.

Shen, W. 2008, Made in France? Chinese Student Return Migration from French Business Schools, Robert Schuman Centre for Advances Studies Working Papers, MIREMAR 2008/06, European University Institute, Florence.

Sidhu, R. 2006, Universities and Globalization: To Market, to Market, Lawrence Erlbaum Associates, Mahwah, NJ.

Silicon India. 2006, Gang Attack Cases Rise against Indians in Adelaide, Retrieved 28 May 2007 from

www.siliconindia.com/shownees/Gang_attack_rise_against_Indians_in_Adelaidenid-33837.html.

Simmons, A. 1999, 'International Migration and Designer Immigrants: Canadian Policy in the 1990s', Free Markets, Open Societies, Closed Borders? Trends in International Migration and Immigration Policy in the Americas, Castro, M. (ed)., North-South Center Press, Miami.

Sin, I. L. 2006, 'Malaysian Students in Australia: The Pursuit of Upward Mobility', Asian and Pacific Migration Journal, 15(2): 239-265.

Skeldon, R. 1994, 'Reluctant Exiles or Bold Pioneers: An Introduction to Migration from Hong Kong', Reluctant Exiles? Migration from HongKong and the New Overseas Chinese, Skeldon, R. (ed)., Hong Kong University Press, Hong Kong.

Skeldon, R. 1997, Migration and Development: A Global Perspective, Addison Wesley Longman Limited, Essex, England. 
Skop, E. 2006, 'The Methodological Potential of Focus Groups in Population Geography', Population, Space and Place, 12: 113-124.

Slaughter, S. \& Leslie, L. 2001, 'Expanding and Elaborating the Concept of Academic Capitalism', Organization, 8(2): 154-161.

Smart, D. \& Ang, G. 1992, Medium Term Market Opportunities for Australian Higher Education: A Pilot Survey of Singapore, Asia Research Centre, Murdoch University.

Smith, H. 2002, Global Migration. New Zealand and European Union Experiences and Challenges, New Zealand European Studies, National Centre for Research on Europe, Christchurch.

Smith, R. C. 2003, 'Diasporic Memberships in Historical Perspective: Comparative Insights from the Mexican, Italian and Polish Cases', International Migration Review, 37(3): 724-759.

Snape, D. \& Spencer, L. 2003, 'The Foundations of Qualitative Research', Qualitative Research Practice: A Guide for Social Science Students and Researchers, Ritchie, J. \& Lewis, J. (eds)., Sage Publications, Inc, London.

Soja, E. 1980, 'The Socio-Spatial Dialectic', Annals of the Association of American Geographers, 70(2): 207-225.

Soja, E. 1989, Postmodern Geographies: The Reassertation of Space in Social Theory, Verso, London.

Solimano, A. \& Pollack, M. 2004, International Mobility of the Highly Skilled: The Case between Europe and Latin America, Working Paper Series 1, Special Office in Europe, Inter-American Development Bank.

Sriskandarajah, D. 2005, Reassessing the Impacts of Brain Drain on Developing Countries, Migration Information Source, Retrieved 21 December 2005 from http://www.migrationinformation.org/Feature/display.cfm?ID=324.

Stark, O. \& Bloom, D. 1985, 'The New Economics of Labor Migration', The American Economic Review, 75(2): 173-178.

Stevens, G., Jin, K. \& Song, H. J. 2006, 'Short-Term Migration and the Acquisition of a World Language', International Migration, 44(1): 167-180.

Suter, B. \& Jandl, M. 2006, Comparative Study on Policies Towards Foreign Graduates Study on Admission and Retention Policies Towards Foreign Students in Industrialised Countries, International Centre of Migration Policy Development, Vienna. 
Swar, B. \& Pandey, S. 2008, 'Impacts of Globalisaztion on Higher Education', Gyanodaya, 1(1): 50-59.

Sweeting, A. 1992, 'Hong Kong Education Withink Historical Processes', Education and Society in Hong Kong: Toward One Country and Two Systems, Postiglione, G. (ed)., Hong Kong University Press, Hong Kong: 39-82.

Szelényi, K. 2003, Explaining the Migration and Settlement of Foreign Graduate Students: Global Intergration Theory and the Theory of Cumulative Causation, Working paper of 2002 for the UCLA Center for Global Comparative Research.

Tan, G. 2003, The Motivations and Future Intentions of Singaporean and Malaysian Students in Adelaide, Hon. Thesis, Department of Geographical and Environmental Studies, Adelaide, The University of Adelaide.

Tashakkori, A. \& Teddlie, C. 2003, 'Major Issues and Controversies in the Use of Mixed Methods in the Social and Behavioral Sciences', Handbook of Mixed Methods in Social and Behavioral Research, Tashakkori, A. \& Teddlie, C. (eds)., Thousand Oaks, California, Sage Publications, Inc.: 3-50.

Teichler, U. 2004, 'Temporary Study Abroad: The Life of Erasmus Students', European Journal of Education, 39(4): 395-408.

Tevera, D. 2005, 'Early Departures: The Emigration Potential of Zimbabwean Students', South African Migration Project, Crush, J. (ed)., Migration Policy Series no. 39, Retrieved 19 June 2009 from http://www.queensu.ca/samp/sampresources/samppublications/policyseries/policy3 9.htm.

The Times of India. 2009, Editorial Comment: Check It, Mate, Retrieved July 292009 from www.timesofindia,indiatimes.com/EDITORIAL-COMMENT--Check-ItMate/articleshow/4600724.cms.

Thomas, W. \& Znaniecki, F. 1918-1920, The Polish Peasant in Europe and America: Monograph of an Immigrant Group, William Badger, Boston.

Thrift, N. 2009, 'Space: The Fundamental Stuff of Geography', Key Concepts in Geography, Clifford, N., Holloway, S., Rice, S. \& Valentine, G. (eds)., Sage Publications Ltd, Trowbridge: 85-96.

Thuno, M. 2003, 'Channels of Entry and Prefered Destinations: The Circumvention of Denmark by Chinese Immigrants', International Migration, 41(3): 99-133.

Tilak, J. 2004, ‘Absence of Policy and Perspective in Higher Education', Economic and Political Weekly, 39(21): 2159-2164. 
Tilak, J. \& Rani, G. 2002, 'Changing Pattern of Univesity Finances in India', Journal of Services Research, 2(2): 5-46.

Tremblay, J.-F. 2008, 'Eyeing the Move Back to China', Chemical and Engineering news, 86 (12), Retrieved 26 June 2008 from http://pubs.acs.org/cen/email/html.8612bus1.html.

Tremblay, K. 2002, 'Student Mobility between and Towards Oecd Countries: A Comparative Analysis', International Mobility of the Highly Skilled-OECD, OECD, Paris: 39-67.

Tremblay, K. 2004, Links between Academic Mobility and Immigration, paper presented to Symposium on International Labour and Academic Mobility: Emerging Trends and Implications for Public Policy, Toronto, 21-22 Oct.

Tremblay, K. 2005, 'Academic Mobility and Immigration', Journal of Studies in International Education, 9(3): 196-228.

Tustin, M. \& Nelson-Field, K. 2006, Report on Chinese International Students for Education Adelaide, Education Adelaide: 1-27.

UNESCO Institute of Statistics. 2006, UIS Data Centre, UNESCO, Retrieved 18 Nov 2007 from www.uis.unesco.org.

UNESCO Institute of Statistics. 2009, UIS Data Centre, UNESCO, Retrieved 22 Oct 2009 from www.uis.unesco.org.

United Nations. 1998, Recommendations on Statistics of International Migration, Revision 1, Statistical Papers Series M, no. 58, Rev 1, New York, Retrieved 5 Dec 2008 from http://unstats.un.org/unsd/publication/SeriesM/SeriesM_58rev1E.pdf.

United Nations. 2010, International Migrant Stock: The 2008 Revision Population Database, United Nations Population Division, Retrieved 15 Jan 2010 from http://esa.un.org/migration/index.asp?panel=1.

Valentine, G. 2005, 'Tell Me About...: Using Interviews as a Research Methodology', Methods in Human Geography, Flowerdew. R, \& Martin, D. (eds)., Pearson Education Ltd, Essex: 110-127.

Varghese, N. 2008, Globalization of Higher Education and Cross-Border Student Mobility, IIEP Research Paper series, International Institute for Educational Planning, Paris.

Verbik, L. \& Lasanowski, V. 2007, International Student Mobility: Patterns and Trends, The Observatory on Borderless Higher Education, Retrieved 9 Dec 2009 from http://nefia.net/dokumente/International_Student_Mobility__Patterns_and_Trends.pdf. 
Vertovec, S. 1999, 'Conceiving and Researching Transnationalism', Ethnic and Racial Studies, 22: 447-462.

Vertovec, S. 2004, Trends and Impacts of Migrant Transnationalism, Centre on Migration, Policy and Society Working Paper no. 3, University of Oxford, Oxford.

Vincent-Lancrin, S. 2004, 'Cross-Border Education: An Overview', Internationalisation and Trade in Higher Education: Opportunities and Challenges, Vincent-Lancrin, S. \& Larsen, K. (eds)., OECD, Paris: 17-38.

Vincent-Lancrin, S. 2008, 'Student Mobility, Internationalization of Higher Education and Skilled Migration', World Migration Report 2008, International Organization for Migrations, Genève.

Voigt-Graf, C. 2004, 'Towards a Geography of Transnational Spaces: Indian Transnational Communities in Australia', Global Networks, 4(1): 25-49.

Wallerstein, I. 1974, The Modern World System I: Capitalist Agriculture and the Origins of the European World Economy in the Sixteenth Century, Academic Press, New York.

Wallerstein, I. 1980, The Modern World-System, Vol. Ii: Mercantilism and the Consolidation of the European World-Economy, 1600-1750, Academic Press, New York.

Wallerstein, I. 1989, The Modern World-System, Vol. Iii: The Second Great Expansion of the Capitalist World-Economy, 1730-1840's, Academic Press, San Diego.

Walton-Roberts, M. 2003, 'Transnational Geographies: Indian Immigration to Canada', The Canadian Geographer, 47(3): 235-250.

Walton-Roberts, M. 2004, 'Transnational Migration Theory in Population Geography: Gendered Practices in Networks Linking Canada and India', Population, Space and Place, 10: 361-373.

Ward, C. \& Masgoret, M. 2004, The Experiences of International Students in New Zealand: Report on the Results of the National Survey, Ministry of Education, Wellington, New Zealand.

Waters, J. 2001, Migration Strategies and Transnational Families: Vancouver's Satellite Kids, Vancouver Centre of Excellence, Research on Immigration and Integration in the Metropolis Working Paper Series no. 01-10, Retrieved 25 October 2005 from http://riim.metropolis.net.

Waters, J. 2003, 'Flexible Citizens? Transnationalism and Citizenship Amongst Economic Immigrants in Vancouver', The Canadian Geographer, 47(3): 219-234. 
Waters, J. 2005, 'Transnational Family Strategies and Education in the Contemporary Chinese Diaspora', Global Networks, 5(4): 359-377.

Webb, E., Campbell, D., Schwartz, R. \& Sechcrest, L. 1966, Unobtrusive Measures: Nonreactive Research in the Social Sciences, Rand McNally, Chicago.

Williams, B. 1989, Overseas Students in Australia: Policy and Practice, Williams, B. (ed)., IDP, Canberra.

Winchester, H. 2005, 'Qualitative Research and Its Place in Human Geography', Qualitative Methods in Human Geography, Hay, I. (ed)., Oxford University Press, South Mebourne, Victoria.

Wright, K. 2005, 'Researching Internet-Based Populations: Advantages and Disadvanatges of Online Survey Researcg, Online Questionnaire Authoring Software Packages, and Web Survey Services', Journal of Computer Mediated Communication, 10(3), Retrieved 6 Jan 2010 from http://jcmc.indiana.edu/vol10/issue3/wright.html.

Wu, C.-T. 2003, 'New Middle-Class Chinese Settlers in Australia and the Spatial Transformation of Settlement in Sydney', The Chinese Diaspora; Space, Place, Mobility and Identity, Ma, L. \& Cartier, C. (ed)., Lanham, Maryland, Rowman \& Littlefield Publishers: 359-377.

Yang, F. 2002, 'Education in China', Educational Philosophy and Theory, 34(2): 135-144.

Yang, M. 2007, 'What Attracts Mainland Chinese Students to Australian Higher Education', SLEID 4(2).

Yang, R. 2003, 'Progresses and Paradoxes: New Developments in Chinas Higher Education', Centralisation Versus Decentralisation: Educational Reforms and Changing Governance in Chinese Societies, Mok, K-H. (ed)., Comparative Education Research Centre, University of Hong Kong, Hong Kong: 173-200.

Yang, R. 2004, 'Toward Massification: Higher Education Development in the People's Replublic of China since 1949', Higher Education: Handbook of Theory and Research, Smart, J. (ed)., Kluwer Academic Publishers, Netherlands: 311-374.

Yao, L. 2004, The Chinese Overseas Students: An Overview of the Flows Change, paper presented to 12th Biennial Conference of the Australian Population Association: Population and society: issues, research, policy, Canberra, Australia, 15-17 Sept.

Yeoh, B., Huang, S. \& Lam, T. 2005, 'Transnationalizing the 'Asian' Family: Imaginaries, Intimacies and Strategic Intents', Global Networks, 5(4): 307-315.

Zelinsky, W. 1971, 'The Hypothesis of the Mobility Transition', Geographical Review, 61(2): 219-249. 
Zhao, D. 1996, 'Foreign Study as a Safety-Valve: The Experience of China's University Students Going Abroad in the Eighties', Higher Education, 31: 145-163.

Zhao, J. \& Guo, J. 2002, 'The Restructuring of China's Higher Education: An Experience for Market Economy and Knowledge Economy', Educational Philosophy and Theory, 34(2): 207-221.

Ziguras, C. \& Law, S.-F. 2006, 'Recruiting International Students as Skilled Migrants: The Global 'Skills Race' as Viewed from Australia and Malaysia', Globalisation, Societies and Education, 4(1): 59-76.

Zweig, D. 2005a, Triggering a Return Tide: China's Efforts to Encourgae a Reverse Brain Drain, paper presented to Conference on Competing for Global Talent, Singapore, 13-14 Jan.

Zweig, D. 2006a, 'Competing for Talent: China's Strategies to Reverse the Brain Drain', International Labour Review, 145(1-2): 65-90.

Zweig, D. 2006b, Is China a Magnet for Global Talent?, paper presented to 8th National Metropolis Conference, Vancouver, Canada, 24 March.

Zweig, D. \& Chung, S. F. 2005, Redefining the Brain Drain: China's 'Diaspora Option', Working paper no. 1, Center on China's Transnational Relations, Hong Kong.

Zweig, D., Vanhonacker, W. \& Chung, S. F. 2005, Reverse Migration and Technology: The Case of China, paper presented to People on the Move: The Transnational Flow of Chinese Human Capital conference, Hong Kong University of Science and Technology, Hong Kong, Oct 20-22.

Zweig, D. H., Donglin. 2005b, Serving the Nation from Abroad: Comparing Mainland Professors in the United States and Hong Kong, paper presented to People on the Move: The Transnational Flow of Chinese Human Capital conference, Hong Kong University of Science and Technology, Hong Kong, Oct 20-22. 